Perspectivas das Engenharias na Sociedade 5.0: Educaçäa, Ciência, Tecnologia e Amor

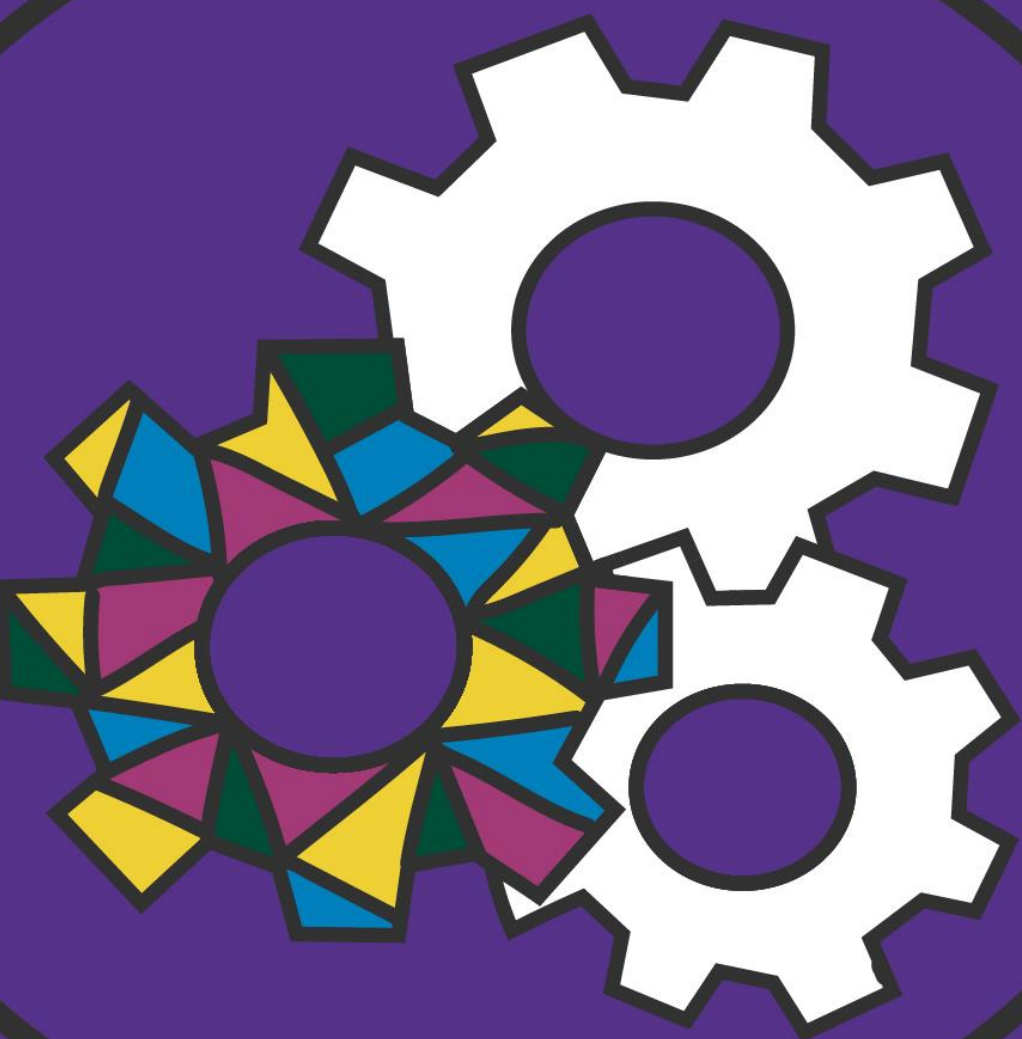


Dados Internacionais de Catalogação na Publicação (CIP) (Câmara Brasileira do Livro, SP, Brasil)

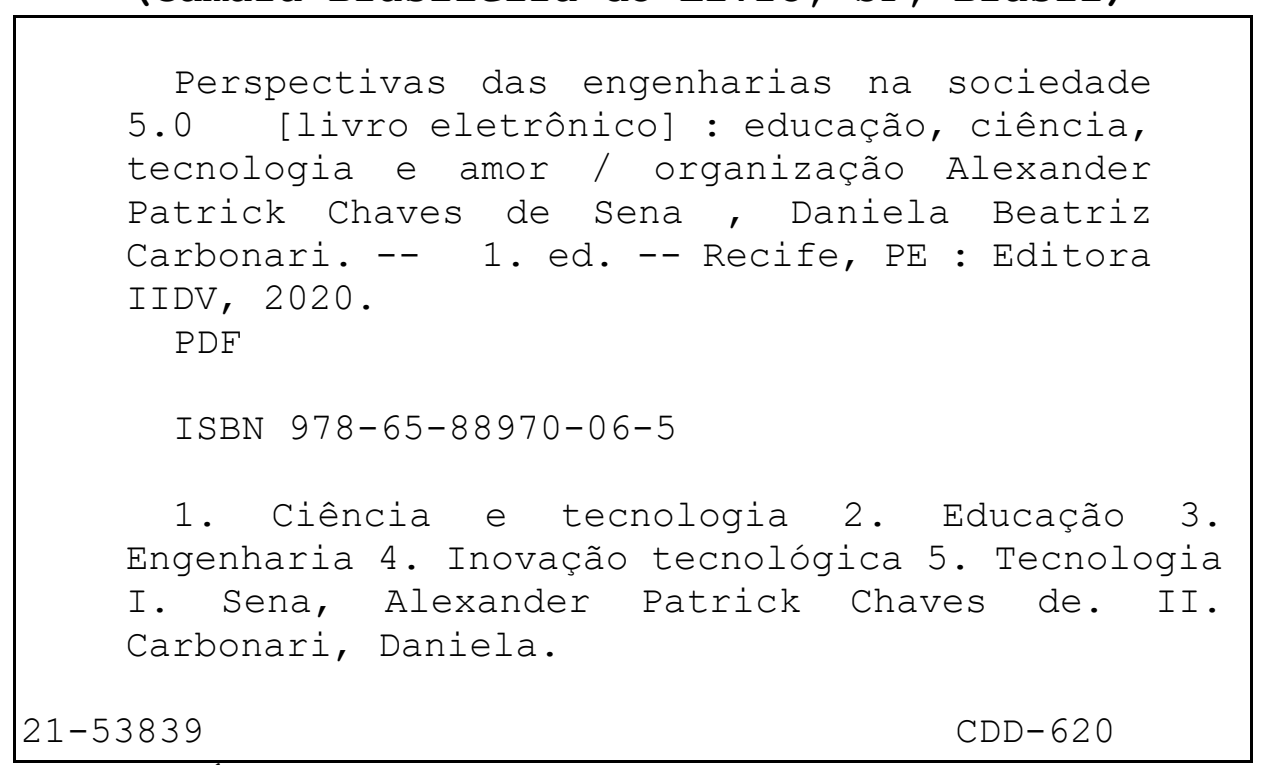

Índices para catálogo sistemático:

1. Engenharia 620

Aline Graziele Benitez - Bibliotecária - CRB-1/3129 


\section{Perspectivas das Engenharias na Sociedade 5.0: Educação, Ciência, Tecnologia e Amor}




\section{LIVRO DOS TRABALHOS PREMIADOS NO IV CONGRESSO INTERNACIONAL DA GESTÃO E TECNOLOGIAS - IV COINTER PDVGT 2020}

ORGANIZADORES: Alexander Patrick Chaves de Sena Daniela Beatriz Carbonari

EDITOR: Ayrton Matheus da Silva Nascimento

DIAGRAMAÇÃO: Ana Beatriz Rocha de Barros David

Luana Negromonte Marinho Capiberibe

Mariana Almeida Ferreira de Lima

ISBN: 978-65-88970-06-5

DOI: $\underline{\text { https://doi.org/10.31692/978-65-88970-06-5 }}$

EDITORA: Instituto Internacional Despertando Vocações (IIDV)

Edição Digital 2020. Direitos exclusivos reservados para todos os países. Proibida sua reprodução total ou parcial, para uso privado ou coletivo, em qualquer meio impresso ou eletrônico de acordo com as leis de Propriedade Intelectual.

Digitalizado no Brasil / Digitalizado en Brasil/ Digitized in Brazil. 


\section{PREFÁCIO}

O livro PERSPECTIVAS DAS ENGENHARIAS NA SOCIEDADE 5.0: EDUCAÇÃO, CIÊNCIA, TECNOLOGIA E AMOR é resultado do concurso de melhores trabalhos publicados no IV Congresso Internacional de Gestão e Tecnologias - IV COINTER PDVGT, realizado entre os dias 02 e 05 de dezembro de 2020, de forma online. O evento é promovido pelo Instituto Internacional Despertando Vocações com o objetivo de promover e divulgar os trabalhos científicos desde 2017.

No ano de 2020, tivemos o processo de seleção, realizado por avaliadores ad hoc, coordenados pela Comissão Científica e com a participação de membros do Conselho Editorial da Editora IIDV. A dinâmica de avaliação presencial dos trabalhos foi substituída pelas salas virtuais e a presencialidade, o compartilhamento de experiências, mesmo em um ano de dificuldades como 2020, foram preservados, na medida do possível.

Os trabalhos premiados em 2020 representam, para além do mérito acadêmico, o esforço coletivo de pesquisadores, profissionais e estudantes, do Brasil e do exterior, que superaram, a duras custas, muitas vezes, dificuldades pessoais e limitações para execução de suas pesquisas.

Em um período da história no qual sombras de dúvidas tentam se colocar, no Brasil e no mundo, sobre a importância da Ciência no progresso da humanidade, mais do que nunca, o tema do COINTER PDVGT. Sociedade 5.0: Educação, Ciência, Tecnologia e Amor se tornam, além de contemporâneo, indispensável na formação de pessoas que possam se desenvolver sob a luz da Ciência e da ética humanista.

O Instituto IDV, através do COINTER PDVGT e da Editora IIDV dedica o esforço da elaboração desse livro a todas as pessoas que perderam seus entes queridos, aos profissionais da saúde, aos pesquisadores e a todas as pessoas que se encontram trabalhando, arduamente, para encontrar soluções que minimizem o sofrimento que assolou a humanidade em 2020. 


\section{CONSELHO EDITORIAL}

\section{PRESIDÊNCIA}

Dr. ${ }^{a}$ Kilma da Silva Lima Viana - Instituto Federal de Pernambuco (IFPE) | Instituto Internacional Despertando Vocações (IIDV)

\section{CONSELHEIROS}

Dr. Airton José Vinholi Júnior - Instituto Federal de Mato Grosso do Sul (IFMS)

Dr. Alexander Patrick Chaves de Sena - Instituto Federal de Pernambuco (IFPE)

Dr. ${ }^{a}$ Ana Patrícia Siqueira Tavares Falcão - Instituto Federal de Pernambuco (IFPE)

Dr. Arquimedes José de Araújo Paschoal - Instituto Federal de Pernambuco (IFPE)

Dr. Dewson Rocha Pereira - Universidade Federal de Pernambuco (UFPE)

Dr. Edísio Raimundo Silva - Instituto Federal de Pernambuco (IFPE)

Dr. ${ }^{a}$ Francisca da Rocha Barros Batista - Instituto Federal do Piauí (IFPI)

Dr. ${ }^{a}$ Iraneide Pereira da Silva - Instituto Federal de Pernambuco (IFPE)

Dr. Jaime Patrício Leiva Nuñez - Universidad de Playa Ancha (UPLA)

Dr. Jeymesson Raphael Cardoso Vieira - Universidade Federal de Pernambuco (UFPE)

Dr. José Ângelo Peixoto da Costa - Instituto Federal de Pernambuco (IFPE)

Dr. José Ayron Lira dos Anjos - Universidade Federal de Pernambuco (UFPE)

Dr. Jose Cuauhtemoc Ibarra Gamez - Instituto Tecnológico de Sonora, Ciudad Obregón (ITSON)

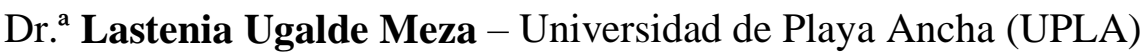

Dr. ${ }^{a}$ Renata Cristine de Sá Pedrosa Dantas - Instituto Federal de Pernambuco (IFPE)

Dr. Roberto Gómez Fernández - Ministério da Educação de Luxemburgo

Dr. ${ }^{a}$ Suzana Pedroza da Silva - Universidade Federal Rural de Pernambuco (UFRPE)

Dr. ${ }^{a}$ Maria Trinidad Pacherrez Velasco - Instituto Federal do Rio Grande do Norte (IFRN)

Dr. Thales Ramon de Queiroz Bezerra - Instituto Federal de Pernambuco (IFPE)

Dr. ${ }^{a}$ Viviane da Silva Medeiros - Universidade Federal do Rio Grande do Norte (UFRN) Coordenação Executiva

MSc. Erick Viana da Silva- Instituto Federal de Pernambuco (IFPE) | Instituto Internacional Despertando Vocações (IIDV)

\section{COORDENAÇÃO ADMINISTRATIVA}

Esp. Ayrton Matheus da Silva Nascimento - Instituto Internacional Despertando Vocações (IIDV)

Esp. Douglas Salgado da Silva - Instituto Internacional Despertando Vocações (IIDV) 


\section{SETOR COMERCIAL/MARKETING}

Cynthia Alice Canuto de Oliveira - Instituto Federal de Pernambuco (IFPE)

Heloisa de Barros Dantas - Universidade Federal de Pernambuco (UFPE)

Kaline Soares da Silva - Instituto Federal de Pernambuco (IFPE)

Larissa Amanda Pereira da Silva - Instituto Internacional Despertando Vocações (IIDV)

Mariana Almeida Ferreira Lima - Instituto Federal de Pernambuco (IFPE)

Misael Tomaz de Araújo - Universidade Federal Rural de Pernambuco (UFRPE)

\section{COORDENAÇÃO TÉCNICA EDITORIAL}

Vinícius de Barros Monteiro - Instituto Federal de Pernambuco (IFPE)

\section{ASSISTENTES EDITORIAIS}

Anderson Soares da Silva - Instituto Federal de Pernambuco (IFPE)

Carlos Augusto Brandão - Universidade Federal de Pernambuco (UFPE)

Cecília Lima Siqueira - Instituto Federal de Pernambuco (IFPE)

Danielly Francielly dos Santos Silva - Instituto Federal de Pernambuco (IFPE)

Jussara Ricardo da Silva Rodrigues - Instituto Federal de Pernambuco (IFPE)

Karoliny Paula da Silva - Centro Universitário Guararapes (UNIFG)

Palloma Joyce de Aguiar Silva - Instituto Federal de Pernambuco (IFPE) 


\section{SUMÁRIO}

CAPÍTULO 01: PERSPECTIVA DO PROTAGONISMO ESTUDANTIL POR ESTUDANTES DO CURSO DE QUÍMICA INDUSTRIAL

OSEIAS FERREIRA DA SILVA SOBRINHO, LENILTON SOUZA FERREIRA DE LIMA

DOI: https://doi.org/10.31692/978-65-88970-06-5.1-14

CAPÍTULO 02: UTILIZAÇÃO DE FÓRUM VIRTUAL COMO FERRAMENTA DE ESTUDO PARA AUXíLIO AO ENSINO REMOTO

STEFANE DE ASSIS ORICHUELA, PEDRO LUCCA PADILHA SIQUEIRA RIBEIRO, VICTOR LUCAS DA COSTA LOPES, LEIDIVÂNIA MENDES DE ARAÚJO MELCHUNA, JOEL DE OLIVEIRA SANTOS.

DOI: https://doi.org/10.31692/978-65-88970-06-5.15-29

CAPÍTULO 03: FATORES CLIMÁTICOS E A INCIDÊNCIA DA DENGUE NO MUNICÍPIO DE PICOS-PI

ITALO GIULLIAN CARVALHO DE ALBUQUERQUE, JOSÉ ANATIEL GONÇALVES SANTOS LANDIM

DOI: https://doi.org/10.31692/978-65-88970-06-5.30-47

CAPÍTULO 04: TECHNO PODCAST: FERRAMENTA PARA O ENSINOAPRENDIZAGEM SIGNIFICATIVO

GEÓRGIA CARIN MARTINS DA SILVA, JOSÉ AILSON DANTAS QUEIROZ JÚNIOR, LEIDIVÂNIA MENDES DE ARAÚJO MELCHUNA, JOEL DE OLIVEIRA SANTOS

DOI: https://doi.org/10.31692/978-65-88970-06-5.48-61

CAPÍTULO 05: GESTÃO INFORMATIZADA DE UM SETOR DE ASSISTÊNCIA ESTUDANTIL: UM ESTUDO DE CASO NO IFMG - CAMPUS BAMBUí

EDUARDO CARDOSO MELO, GABRIEL DA SILVA, MATEUS ARAÚJO CRUZ

DOI: https://doi.org/10.31692/978-65-88970-06-5.62-81

CAPÍTULO 06: SISTEMA EMBARCADO PARA O CONTROLE DE POSIÇÃO DE UM ROBÔ PARALELO TIPO DELTA LINEAR DE BAIXO CUSTO

ALEXANDER PATRICK CHAVES DE SENA, JOSÉ LUCAS MOREIRA CAVALCANTI DE ABREU, ASAFE DOS SANTOS SILVA, JOÃO MANOEL FREITAS SOUZA

DOI: https://doi.org/10.31692/978-65-88970-06-5.82-98

CAPÍTULO 07: ANÁLISE DE DEFEITOS NO ROLAMENTO EM UM MOTOR DE INDUÇÃO TRIFÁSICO UTILIZANDO A EMISSÃO ACÚSTICA

GUSTAVO PEREIRA BRUNO, ANDRÉ FELLIPE CAVALCANTE SILVA, JOSÉ ANSELMO DE LUCENA JÚNIOR, SILVANA LUCIENE DO NASCIMENTO CUNHA COSTA

DOI: $\underline{\text { https://doi.org/10.31692/978-65-88970-06-5.99-115 }}$

CAPÍTULO 08: DESAFIOS ENFRENTADOS COM O USO DE NOVAS TECNOLOGIAS ENSINO E APRENDIZAGEM EM PERÍODO DE PANDEMIA GUILHERME DE SIQUEIRA FREITAS PONTES, DAYANE CAMILE BEZERRA DE LIMA, SIMONE DE PAULA SILVA, DEREK LUIZ ALVES DOS SANTOS, ERICK VIANA DA SILVA DOI: https://doi.org/10.31692/978-65-88970-06-5.116-132 
CAPÍTULO 09: O USO DAS REDES SOCIAIS EM ÉPOCA DE PANDEMIA - UM ESTUDO DE CASO APLICADO EM QUATRO ESCOLAS TÉCNICAS ESTADUAIS DE PERNAMBUCO

ANA ELISABETH DE BRITO ALVES, GUILHERME DA SILVA ANDRADE, JOSÉ ALISSON DE OLIVEIRA, JULIANA DE BRITO ALVES, NADIENE DE PAIVA BRANDÃO

DOI: https://doi.org/10.31692/978-65-88970-06-5.133-149

CAPÍTULO 10: QUARENTENA DAS "LIVES": APRENDENDO COM QUARENTEMAS DURANTE A PANDEMIA

VITOR CARVALHO SILVA, ANDERSON DIAS VIANA, VIVIANE DA SILVA MEDEIROS

DOI: https://doi.org/10.31692/978-65-88970-06-5.150-154 


\title{
CAPÍTULO 01: PERSPECTIVA DO PROTAGONISMO ESTUDANTIL POR ESTUDANTES DO CURSO DE QUÍMICA INDUSTRIAL
}

\author{
CAPÍTULO 01: PERSPECTIVA DEL PROTAGONISMO ESTUDIANTIL POR \\ ESTUDIANTES DE QUÍMICA INDUSTRIAL
}

\section{CHAPTER 01: PERSPECTIVE OF STUDENT PROTAGONISM BY INDUSTRIAL CHEMISTRY STUDENTS}

\author{
Oseias Ferreira da Silva Sobrinho ${ }^{1}$; Lenilton Souza Ferreira de Lima ${ }^{2}$
}

DOI: https://doi.org/10.31692/978-65-88970-06-5.1-14

\begin{abstract}
RESUMO
$\mathrm{Na}$ etimologia da palavra Protagonismo encontra-se a junção das palavras de origem grega protos e agonistes, respectivamente principal e lutador. Quando é referido o termo protagonismo estudantil especificamente, significa, na perspectiva dessa pesquisa, a condição construída junto ao aprendente de tomar decisões na condução de sua história formativa, cidadã, social, cultural e tecnológica à medida em que desenvolve, estrutura sua identidade e toma ciência de sua capacidade, concreta, de interferir na realidade. O presente artigo tem como objetivo geral identificar e avaliar a perspectiva do protagonismo estudantil por estudantes do curso de Química Industrial do Instituto Federal de Educação, Ciência e Tecnologia de Pernambuco (IFPE) - Campus Recife. A área de estudos será o próprio IFPE Campus Recife, através de uma pesquisa qualitativa-quantitativa e análise documental. Dentre as documentações analisadas destacam-se a Lei de Diretrizes e Bases da Educação, o plano de desenvolvimento institucional e organização acadêmica do IFPE. Para coleta de dados foi aplicado um formulário semiestruturado aos estudantes do curso Técnico de Química Industrial do Campus Recife, onde foi realizado uma análise estatística dos dados coletados. Após a análise das documentações, foi verificado que a instituição, a qual foi realizada a pesquisa, já desenvolve atividades que estimulam os estudantes a serem protagonistas, tais como participação em programas e projetos tais como o Programa Despertando Vocações- PDV, a possibilidade de serem monitores na Semana Nacional de Ciências e Tecnologia- SNCT, possibilidade de participação em empresa júnior e incubação de empresas . Percebe-se que o IFPE também estimula a ter desenvolvimento pessoal e projetarem sua própria carreira, assim como também realizam atividades que desenvolve o lado empreendedor dos discentes. Ao confrontar os documentos analisados com os dados coletados, foi possível observar que o IFPE vem atuando de modo o proporcionar o debate e incentivo ao protagonismo estudantil.

Palavras-Chave: protagonismo, perspectiva, identificar, avaliar, empreendedorismo.
\end{abstract}

\section{RESUMEN}

En la etimología de la palabra Protagonismo encontramos la combinación de palabras de origen griego, protos y agonistas, respectivamente principal y combatiente. Cuando el término protagonismo estudiantil se refiere específicamente, significa, en la perspectiva de esta investigación, la condición construida con el aprendiz para tomar decisiones en la conducción de su historia formativa, ciudadana, social, cultural y tecnológica a medida que se desarrolla, estructura su identidad y toma consciente de su capacidad concreta para interferir en la realidad. Este artículo tiene como objetivo identificar y evaluar la perspectiva del liderazgo estudiantil de los estudiantes del curso de Química Industrial en el Instituto Federal de Educación, Ciencia y Tecnología de Pernambuco (IFPE) - Campus Recife. El área de estudio será el propio IFPE Campus Recife, a través de la investigación cualitativo-cuantitativa y el análisis documental. Entre las documentaciones analizadas se destacan la Ley de Directivas y Bases de la Educación, el plan de desarrollo institucional y organización académica de IFPE. Para la recolección de datos, se aplicó un formulario semiestructurado a los estudiantes del curso de Técnico en Química Industrial en el Campus Recife, donde se realizó un análisis estadístico de los datos

${ }^{1}$ Técnico em eletrotécnica, IFPE Campus Recife, oseiasf25@gmail.com;

Especialista em metodologia no ensino de Química e Biologia leniltonlima@recife.ifpe.edu.br 
recolectados. Luego de analizar la documentación, se encontró que la institución, donde se realizó la investigación, ya desarrolla actividades que incentivan a los estudiantes a ser protagonistas, como la participación en programas y proyectos como el Programa Despertando Vocações - POS, la posibilidad de ser monitores en la Semana Nacional de Ciencia y Tecnología - SNCT, posibilidad de participación en una empresa junior e incubación de empresas. Se puede observar que IFPE también fomenta el desarrollo personal y proyecta su propia carrera, además de realizar actividades que desarrollen la vertiente emprendedora de los estudiantes. Al comparar los documentos analizados con los datos recolectados, se pudo observar que IFPE ha venido actuando de tal manera que brinda el debate e incentivo al liderazgo estudiantil.

Palabras Clave: Protagonismo, perspectiva, identificar, para evaluar, emprendimiento.

\begin{abstract}
In the etymology of the word Protagonism we find the combination of words of Greek origin, protos and agonists, respectively principal and fighter. When the term student protagonism is referred to specifically, it means, in the perspective of this research, the condition built with the learner to make decisions in the conduct of their formative, citizen, social, cultural and technological history as it develops, structures its identity and takes aware of its concrete ability to interfere in reality. This article aims to identify and evaluate the perspective of student leadership by students of the Industrial Chemistry course at the Federal Institute of Education, Science and Technology of Pernambuco (IFPE) - Campus Recife. The study area will be the IFPE Campus Recife itself, through qualitativequantitative research and document analysis. Among the documentations analyzed, the Law of Directives and Bases of Education, the institutional development plan and academic organization of IFPE stand out. For data collection, a semi-structured form was applied to students of the Industrial Chemistry Technician course at Campus Recife, where a statistical analysis of the collected data was performed. After analyzing the documentation, it was found that the institution, which the research was carried out, already develops activities that encourage students to be protagonists, such as participation in programs and projects such as the Despertando Vocações Program - POS, the possibility of being monitors at the National Week of Science and Technology - SNCT, possibility of participation in a junior company and business incubation. It can be seen that IFPE also encourages personal development and projects their own career, as well as carrying out activities that develop the students' entrepreneurial side. When comparing the analyzed documents with the collected data, it was possible to observe that IFPE has been acting in such a way as to provide the debate and incentive to student leadership.
\end{abstract}

Keywords: Protagonism, perspective, identify, to evaluate, entrepreneurship.

\title{
INTRODUÇÃO
}

De acordo com a LDB - Lei de Diretrizes e Bases da Educação, artigo 12, inciso I: “Os estabelecimentos de ensino, respeitadas as normas comuns e as do seu sistema de ensino, terão a incumbência de: 'I - elaborar e executar sua proposta pedagógica”" (BRASIL, 1996). Em contrapartida é no PPP - Projeto Político Pedagógico, que cada instituição de ensino deve construir, coletivamente, onde todos assumem sua responsabilidade no processo de gestão democrática.

Sendo assim o IFPE tem um desafio a cumprir: consolidar os objetivos e a gestão das diferentes autarquias representantes da educação técnico-profissionalizante da esfera federal que compõem o estado de Pernambuco, garantindo assim a continuidade dos propósitos de 
cada um tendo como primazia o alinhamento do Governo Federal em função da eficácia dos serviços públicos oferecidos ao cidadão.

Neste cenário, é perceptível que o protagonismo mostra-se viável para as instituições de ensino uma vez que os jovens protagonistas são coadjuvantes em comunidades, grupos e classes, são líderes, seres criativos e pensantes. Jovens que dão a sua contribuição para o social com projetos que viabilizem a inclusão de indivíduos em meios que ainda não pertenciam. Além disso o protagonismo discente nas escolas, enquanto prática pedagógica, favorece a aquisição de valores, cria condições e espaços para um convívio estimulante e necessário para a formação de crianças e jovens autônomos, solidários e participativos.

Partindo dessa concepção, estudos estão sendo realizados em diversos âmbitos educacionais. Russo et al (2015), em um projeto de aplicação do protagonismo nas aulas de educação física em uma escola do interior de São Paulo, analisou que os olhares dos alunos diante do discente protagonista, desmistificou o medo do desconhecido entre eles, detectaramse comportamentos que podem ser modificados se trabalhados no ambiente escolar, criou-se responsabilidade e comunicação, valorizou-se o trabalho em grupo e a criatividade para soluções imediatas.

Semicheche et al (2012) realizou uma entrevista com jovens e profissionais da equipe técnica do Pro-Jovem Adolescente de Cascavel- PR visto que é um espaço que potencializa o protagonismo juvenil. Os resultados da pesquisa mostraram que tanto os jovens como a equipe técnica compreende o protagonismo como possibilidade de transformação social, visto que todas as reflexões e vivências oriundas do espaço do Pro-Jovem, transcendem as barreiras físicas e são materializadas em ações nos locais onde estes jovens vivem cotidianamente.

Sendo assim, o presente relatório tem como objetivo geral identificar e avaliar a perspectiva do protagonismo estudantil por estudantes do curso de Química Industrial do IFPE - Campus Recife. Este trabalho vincula-se ao projeto de pesquisa intitulado Formação empreendedora, protagonismo estudantil e mudanças organizacionais em instituições de ensino brasileiras, tem origem nas atividades de pesquisa e extensão desenvolvidas no âmbito do grupo de Estudos e Pesquisa em Administração e Rede de Cooperação (GEPARC) nos últimos 5 anos.

\section{FUNDAMENTAÇÃO TEÓRICA}

Na etimologia da palavra Protagonismo encontra-se a junção das palavras de origem grega protos e agonistes, respectivamente principal e lutador. Quando é referido o termo 
protagonismo estudantil especificamente, significa, na perspectiva desse projeto, a condição construída junto ao aprendente de tomar decisões na condução de sua história formativa, cidadã, social, cultural e tecnológica à medida em que desenvolve, estrutura sua identidade e toma ciência de sua capacidade, concreta, de interferir na realidade.

Dessa maneira, cria-se a possibilidade real de ter no estudante, ao invés do receptor de informações, um ser que se dispõe a se descobrir com capacidades de através de suas iniciativas, esforço e trabalho coletivo poder contribuir com a sociedade de uma forma que outrora se encontrava privado.(COSTA,2001)

Segundo Escamez,(2003) protagonismo estudantil deve ser para o jovem uma leitura de ação do reflexo de sua ansiedade em conquistar objetivos, porém de realizações concretas, ações que o façam concluir temas, conceitos e, o mais importante, que o leve a estabelecer uma relação de segurança com seu próprio crescimento. Na visão de Ferreti, (2003) o jovem estudante protagonista atua de forma autêntica e participativa, propondo iniciativas e assumindo lideranças. Deixa o papel de coadjuvante, para tornar-se dinamizador de atitudes e ações não só individuais, mas, também na sua comunidade.

Para Silva, et. al.(2013), o protagonismo estudantil é influenciado conforme a metodologia aplicada durante as aulas de cursos formais, levando em consideração para uma efetiva aprendizagem e ideia do quanto maior o número de aulas maior será aprendizagem do estudante, não corresponde atualmente as expectativas do estudante.

Uma participação diferente na sociedade, segundo Foracchi (1972) a participação do jovem estudante se dava pela "contestação permanente" ou do protesto contra as contradições sociais e a insatisfação expressa. Nos dias de hoje, a expressão protagonista social baseia-se em um indivíduo que dialoga que negocia que estabelece parcerias e luta pelos seus interesses perante outros indivíduos, assim como Touraine (1998) definiu em seu artigo a importância do protagonismo para ele, este protagonista é o homem ou mulher que intenta realizar objetivos pessoais em entorno constituído por outros autores, entorno que constitui uma coletividade à qual ela sente que pertence e cuja cultura e regras de funcionamento institucional faz suas, ainda que apenas em parte.

\section{METODOLOGIA}

\section{Área de estudo}

O estudo está sendo desenvolvido no Instituto Federal de Pernambuco campus Recife(Figura 01), instituição que oferece educação básica, profissional e superior, de forma 
"pluricurricular". O campus está localizado na cidade do universitária do Recife. O instituto possui 21,000 (vinte e um mil) estudantes distribuídos entre os 30 (trinta) cursos existentes, em diferentes modalidades tais como integrado, subsequente, especialização, mestrado, licenciatura, bacharelado, tecnólogo e PROEJA (Ministério da Educação, 2020). Desses 30 (trinta) cursos, o plano de trabalho será aplicado apenas no curso de Química Industrial, na modalidade subsequente e integrado.

Figura 01: IFPE - CAMPUS Recife.

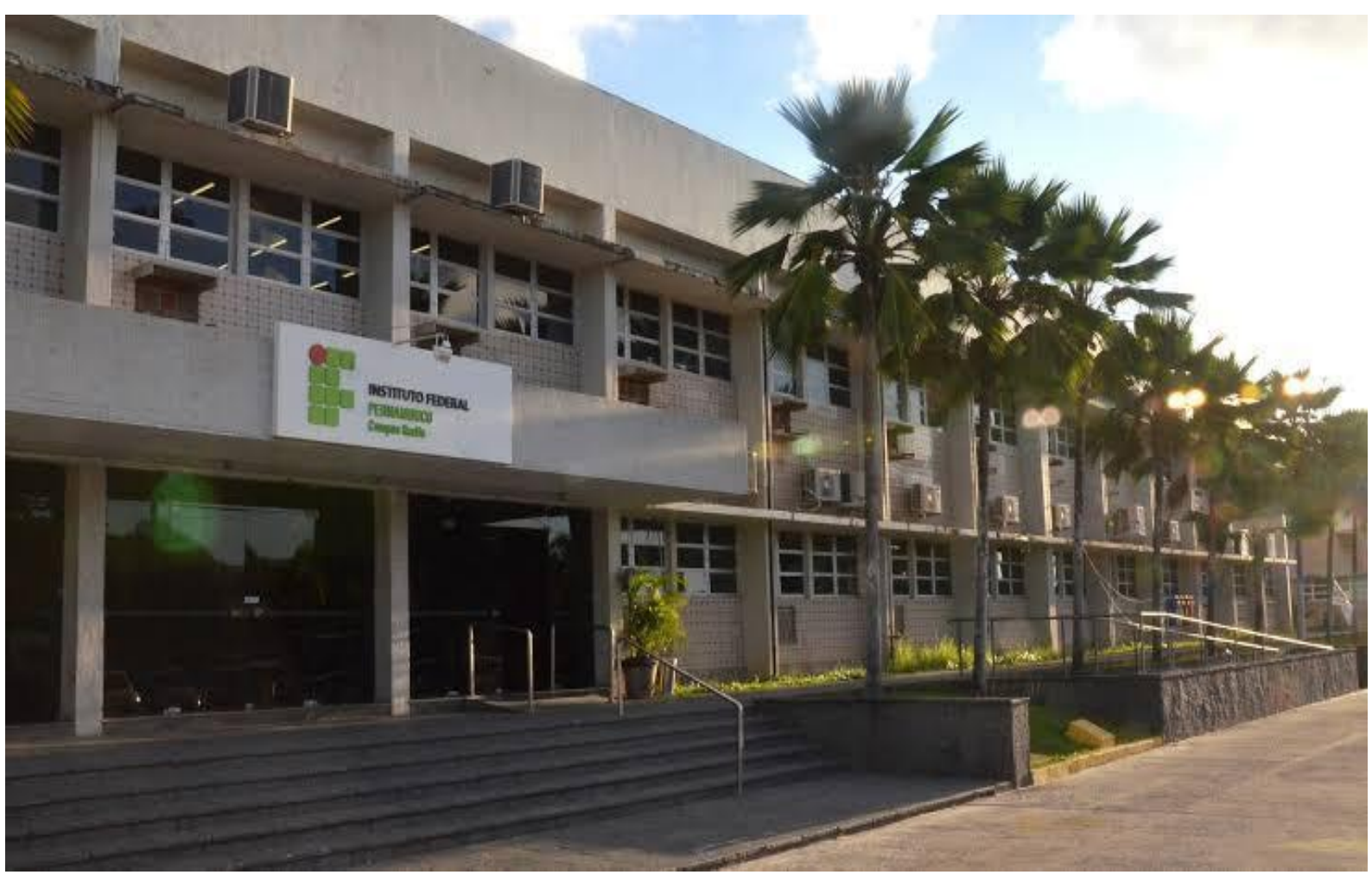

Fonte: Página do IFPE

\section{Análise documental}

Foi realizado uma análise dos documentos oficiais do IFPE, PDI IFPE(Plano de Desenvolvimento Institucional do Instituto Federal de Pernambuco) 2014-2018, além do LDB (Lei de Diretrizes e Bases da Educação). Esses documentos são relativos ao protagonismo estudantil, empreendedorismo estudantil e organização acadêmica. De modo a utilizá-los como base para o seguimento da pesquisa.

\section{Aplicação do formulário}

Realizamos uma aplicação de um formulário semiestruturado aos estudantes do curso Técnico de Química Industrial do Campus Recife, para a coleta de dados e fizemos uma análise estatísticas dos dados coletados. 


\section{RESULTADOS E DISCUSSÃO}

O PDI IFPE (Plano de Desenvolvimento Institucional do Instituto Federal de Pernambuco), trata-se de um caminho para consolidar a missão institucional, aberto ao acolhimento de propostas com participação da família IFPE, permitindo uma ajuda nas decisões das gestoras e dos gestores. Nele, está apresentada a importância do nosso trabalho a favor das causas da sociedade, da humanidade e da Educação.

De acordo com o PDI IFPE, na prática extensionista, a propagação do conhecimento se dá por meio das dimensões da Extensão, nas quais as ações são organizadas e classificadas em vários tipos, um deles o empreendedorismo que compreende a inserção da disciplina de empreendedorismo no currículo e eventos de formação empreendedora (workshops, seminários, desafios), a criação de habitats de inovação (pré-incubadoras, incubadoras, apoio à implantação de parques tecnológicos), assim como a institucionalização das empresas juniores (PDI IFPE, 2014-2018).

Em contrapartida a LDB (Lei de Diretrizes e Bases da Educação) é considerada a lei mais importante no que se refere a educação. Conhecida também por Lei Darcy Ribeiro, é composta por 92 artigos que abordam temas variados sobre a educação do nosso País. Tem como função organizar a estrutura da educação brasileira, o que reflete inteiramente na formação escolar. A educação, dever da família e do Estado, inspirada nos princípios de liberdade e nos ideais de solidariedade humana, tem por finalidade o pleno desenvolvimento do educando, seu preparo para o exercício da cidadania e sua qualificação para o trabalho. (LDB: Lei 9.394/96).

Nas discussões realizadas nas reuniões semanais, percebemos que o Instituto Federal de Pernambuco campus Recife já apresenta atividades que despertam os estudantes a serem protagonistas e promovem atividades que estimulam o discente a ser um empreendedor, como por exemplo o PDV (Programa Despertando Vocações) que tem como um de seus pilares protagonismo estudantil.

\section{Resultado da Coleta de dados}

O questionário é um instrumento desenvolvido cientificamente, composto de um conjunto de perguntas ordenadas de acordo com um critério predeterminado, que deve ser respondido sem a presença do entrevistador (MARCONI; LAKATOS, 1999, P.100) e que tem por objetivo coletar dados de um grupo de respondentes. Na pesquisa em administração de 
empresas, esse instrumento é utilizado para obter informações sobre empresas, indivíduos, eventos, etc. (HAIR et al., 2004, p. 159).

Oliveira (1997, p. 165) afirma que o questionário apresenta as seguintes características: (1) deve ser a espinha dorsal de qualquer levantamento, (2) deve reunir todas as informações necessárias (nem mais nem menos), (3) deve possuir linguagem adequada. Os questionários geralmente são utilizados para a obtenção de grandes quantidades de dados, geralmente para análises qualitativas. Nesse caso, o informante escreve ou responde por escrito a um elenco de questões que devem ser cuidadosamente elaboradas (RUIZ, 1996, p. $51)$.

Segundo Neto (2004), o uso da Internet para a coleta de dados ainda é pouco difundido no Brasil. Deste modo, a maioria dos questionários são enviados em cópia física para o respondente que, após respondê-lo, encaminha a resposta de volta ao pesquisador. Além da possibilidade da utilização da versão física, existe também a versão eletrônica. $\mathrm{O}$ questionário eletrônico pode ser aplicado de duas maneiras: (1) por meio de envio de disquete: o respondente recebe a mídia pelo correio; (2) por meio do envio do arquivo pelo email: deste modo o respondente recebe o questionário em seu endereço eletrônico, ou (3) por meio da construção de uma home-page: neste caso o respondente acessa o questionário acessando um endereço eletrônico (HAIR et al., 2004, p. 230).

Dentre as principais vantagens do uso da Internet na aplicação de questionários, é possível citar: (1) a conveniência: o respondente pode acessar o questionário de qualquer lugar, desde que tenha um microcomputador conectado à Internet; (2) o custo: o acesso virtual torna-se mais barato; (3) a escala: é possível de trabalhar com grandes amostras; (4) a velocidade: é possível obter as respostas mais rapidamente; e (4) a estética e a atratividade: é possível utilizar imagens, sons e hipertexto na construção dos questionários (NETO, 2004). Além disso, Scornavacca Jr., Becker e Andraschko (2001) chamam a atenção para o fato de da possibilidade do controle de entrega das respostas e da redução de consumo de papel.

Além das vantagens, há também desvantagens na aplicação de surveys via Web. Uma das principais é a definição da amostra, já que as listas de endereços eletrônicos geralmente sofrem alterações, e, apesar do aumento do uso da Internet, boa parte da população ainda não possui endereço eletrônico (SCORNAVACCA JR.; BECKER; ANDRASCHKO, 2001).

Observando o cenário de pandemia em que vivenciamos, optamos em realizar o formulário online para identificar e avaliar a perspectiva do protagonismo estudantil pelos estudantes do curso de Química Industrial. O curso é composto por 625 estudantes sendo 323 
na modalidade subsequente e 302 na modalidade integrado. Participaram da pesquisa 60(sessenta) estudantes.

Gráfico 01: Idade dos(as) estudantes do curso de Química Industrial do Campus Recife que responderam o questionário

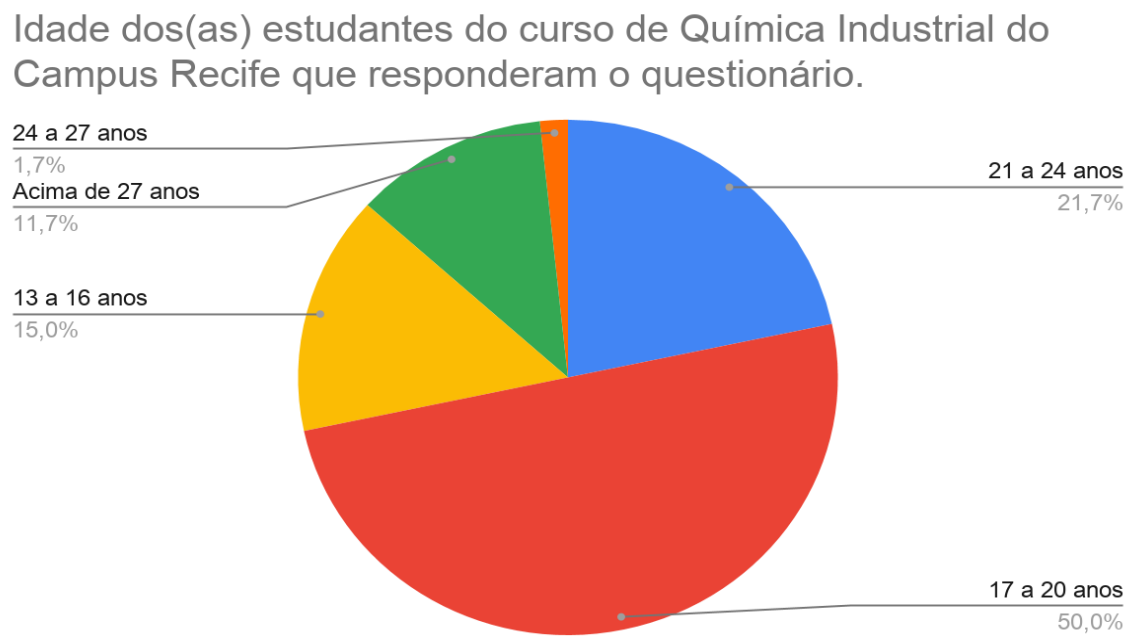

Fonte: Própria (2020).

O gráfico 01 representante a idade dos estudantes do curso de química industrial do campus Recife que responderam o questionário online. Podemos observar que $50 \%$ dos estudantes têm entre 17 a 20 anos, 21,7\% têm entre 21 a 24 anos, $15 \%$ têm entre 13 a 16 anos, $11 \%$ representa os estudantes que têm acima de 27 anos e entre 24 a 27 anos são 1,7\%.

Gráfico 02: Sexo dos(as) estudantes do curso de Química Industrial do Campus Recife que responderam o questionário.

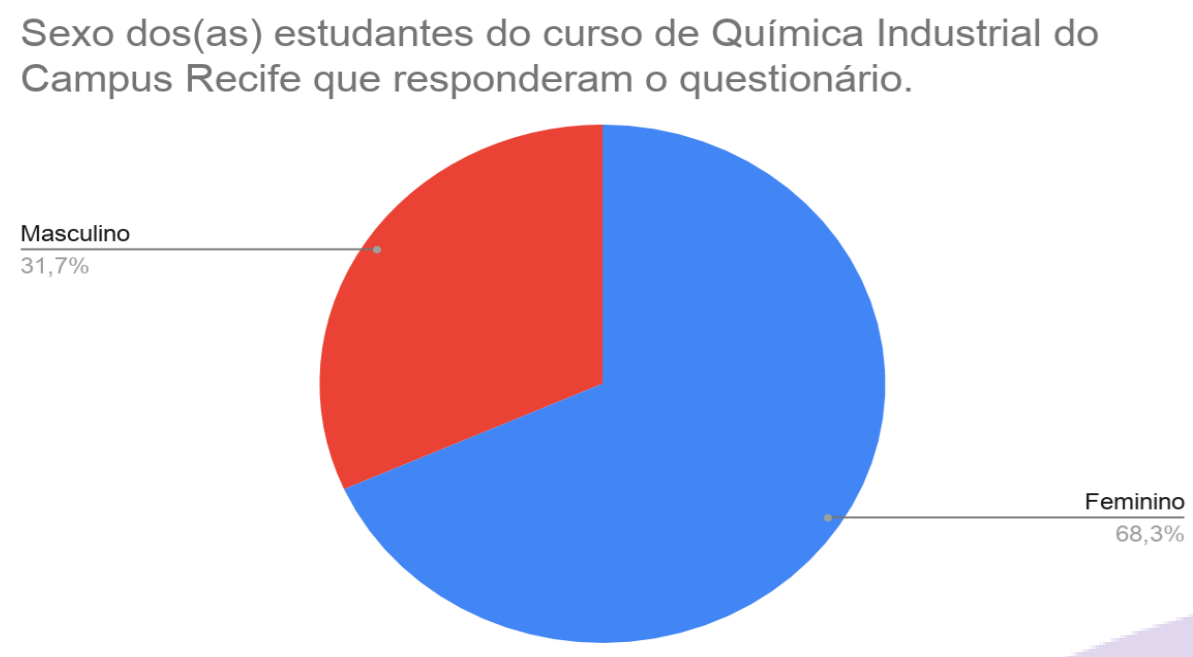

Fonte: Própria (2020).

O gráfico 02 representa o sexo dos estudantes do curso de Química Industrial. Mais que a metade corresponde ao sexo feminino, que é representado por $68,3 \%$, e, apenas $31,7 \%$, corresponde ao sexo masculino. 
Observando as grandes organizações é inegável que as mulheres ainda ocupam timidamente os cargos mais altos. Isto talvez se deva ao fato de a mulher ainda estar dentre uma parcela da população que tem dificuldades em ocupar efetivamente lugares hierarquicamente elevados nas carreiras das instituições de destaque (Kanan, 2010). Por outro lado, se a mulher está dentre uma parcela da população que tem dificuldades em ocupar lugares elevados em grandes organizações, no âmbito acadêmico a situação é totalmente oposta.

Dados do Instituto Brasileiro de Geografia e Estatística (IBGE), relativos ao ano de 2012, revelam que as mulheres são em maior número dentre os com maior escolaridade, em relação aos homens. Em contrapartida, têm remuneração inferior às recebidas pelo universo masculino (IBGE, 2014).

Tabela 01: Porcentagem dos anos de estudos por sexo.

\begin{tabular}{|c|c|c|}
\hline Anos de estudos - por sexo -2012 & \multicolumn{2}{|c|}{} \\
\hline & Homens & Mulheres \\
\hline Total & $48 \%$ & $49 \%$ \\
\hline Até um ano & $49 \%$ & $51 \%$ \\
\hline 1 a 3 anos & $52 \%$ & $48 \%$ \\
\hline 4 a 7 anos & $50 \%$ & $50 \%$ \\
\hline 8 a 10 anos & $49 \%$ & $51 \%$ \\
\hline 11 a 14 anos & $46 \%$ & $54 \%$ \\
\hline 15 anos ou + & $42 \%$ & $58 \%$ \\
\hline
\end{tabular}

Fonte: : IBGE, 2014.

Neste levantamento realizado pelo IBGE no ano de 2012, ao se avaliar o parâmetro anos de estudos, do total de pessoas que estudaram por 15 anos ou mais, $58 \%$ delas eram mulheres, enquanto que $42 \%$ eram do sexo masculino. O que confirma o resultado de 68,3\%(Gráfico 02) serem representados pelo sexo feminino. 
Gráfico 03: Modalidade do curso dos(as) estudantes do curso de Química Industrial do Campus Recife que responderam o questionário.

\section{Modalidade dos(as) estudantes do curso de Química Industrial do Campus Recife que responderam o questionário.}

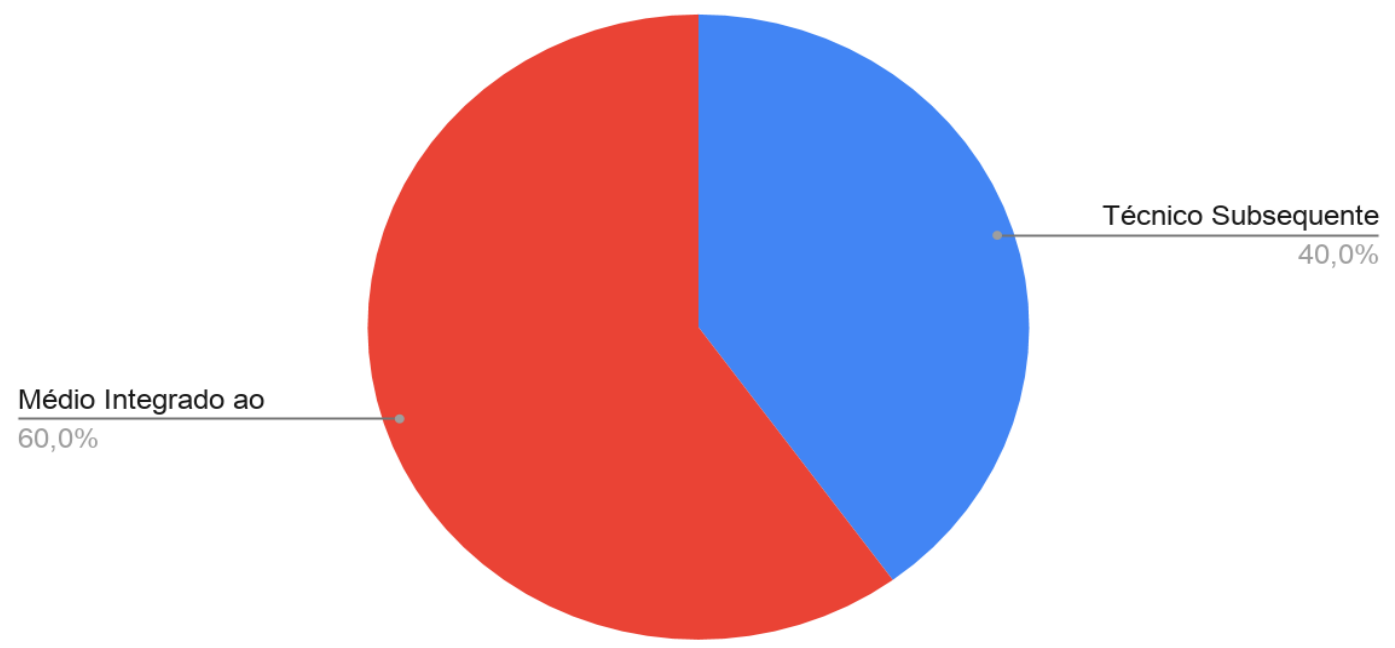

Fonte: Própria (2020).

O gráfico representa a modalidade do curso dos estudantes de química industrial do campus Recife sendo 60\% médio integrado, que é a modalidade onde o estudante cursa um técnico paralelo ao ensino médio. Isso explica os $15 \%$ de estudantes com idade entre 13 a 16 anos mostrado no gráfico 01 .

Gráfico 04: Respostas dos(as) estudante do curso de Química Industrial do Campus Recife em relação a pergunta: "Você sabe o que é protagonismo estudantil?"

Resposta dos(as) estudantes do curso de Química Industrial do Campus Recife em relação a pergunta: "Você sabe o que é

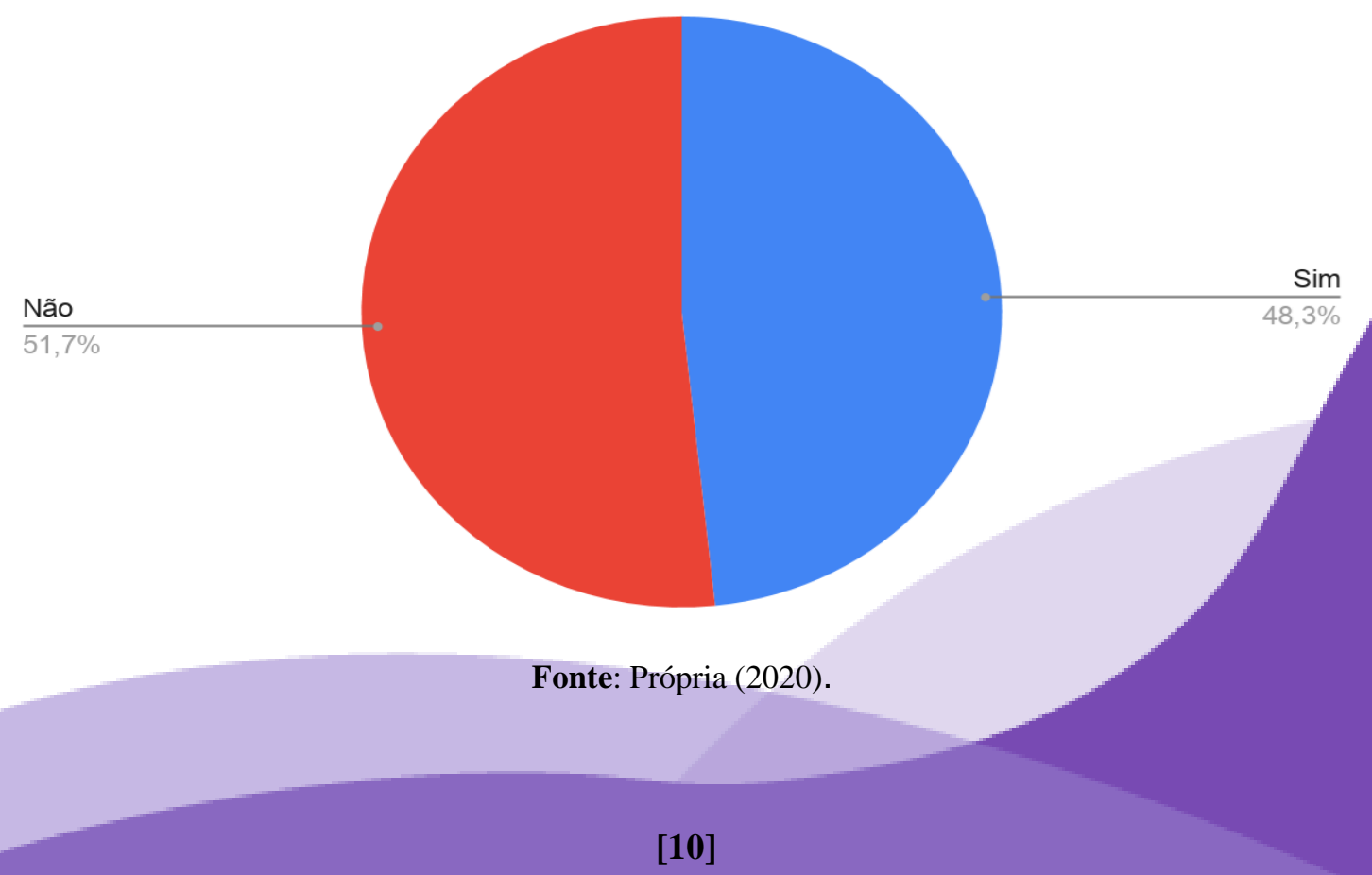


O gráfico representa o resultado que obtivemos no questionamento ao estudante em relação ao conhecimento sobre protagonismo estudantil. 48,3\% responderam que sabia o que era protagonismo estudantil, e 51,7\% responderam que não sabe o que é. Podemos observar que Emanuel Matias, em sua pesquisa, observou que (46,15\%) tem ciência do que é protagonismo estudantil e 21(53,84\%) não sabem o significado(Oliveira, 2020). O IFPE estimula esses estudantes a terem conhecimento sobre protagonismo estudantil?

Ainda em seu trabalho, Emanuel Matias observa que 29(74,36\%) concordam com a afirmação de que o IFPE estimula o protagonismo estudantil, $5(12,82 \%)$ discordam quanto a afirmação e 5(12,82\%) não concordam e nem discordam.(Oliveira, 2020).

Em outro questionamento, foi perguntado aos estudantes que atividades/experiências mais podem beneficiar (direta ou indiretamente) seu desenvolvimento acadêmico e pessoal, tendo em vista que o protagonismo estudantil também tem haver com desenvolvimento pessoal e acadêmico que conta com uma participação democrática e autêntica que leva o estudante ao ganho e construção da sua autonomia, autoconfiança e autodeterminação o que coopera para a construção de sua identidade e projeto de vida (Costa 2016).

E, como mostra no gráfico 05 , podemos observar que "Conceitos e teoria bem explicados em sala de aula, monitoria em ensino, trabalhos de casa propostos em sala de aula, discussões em grupo em sala de aula, jogos pedagógicos em sala de aula, visitas técnicas." tem 40\%, enquanto "Empresas Juniores, hackatons, grêmio estudantil, cursos/estudos extracurriculares, participação voluntária em ONG's e projetos de caridade, ações religiosas" tem 15\%, "Projetos de extensão, olimpíadas do conhecimento (OBMEP, OBA etc.), olimpíadas esportivas, campeonatos, expressões artísticas (participar em bandas, orquestras, etc)" tem 16,7\% e "Congressos Científicos PIBIC -Iniciação Científica, monitorias em eventos escolares (Mais Campus, SNCT, etc)” tem 26,7\%. 
Gráfico 05: Resposta dos(as) estudantes do curso de Química Industrial do Campus Recife para a pergunta: "Na sua opinião, que atividades/experiências mais podem beneficiar (direta ou indiretamente) seu desenvolvimento acadêmico e pessoal?"

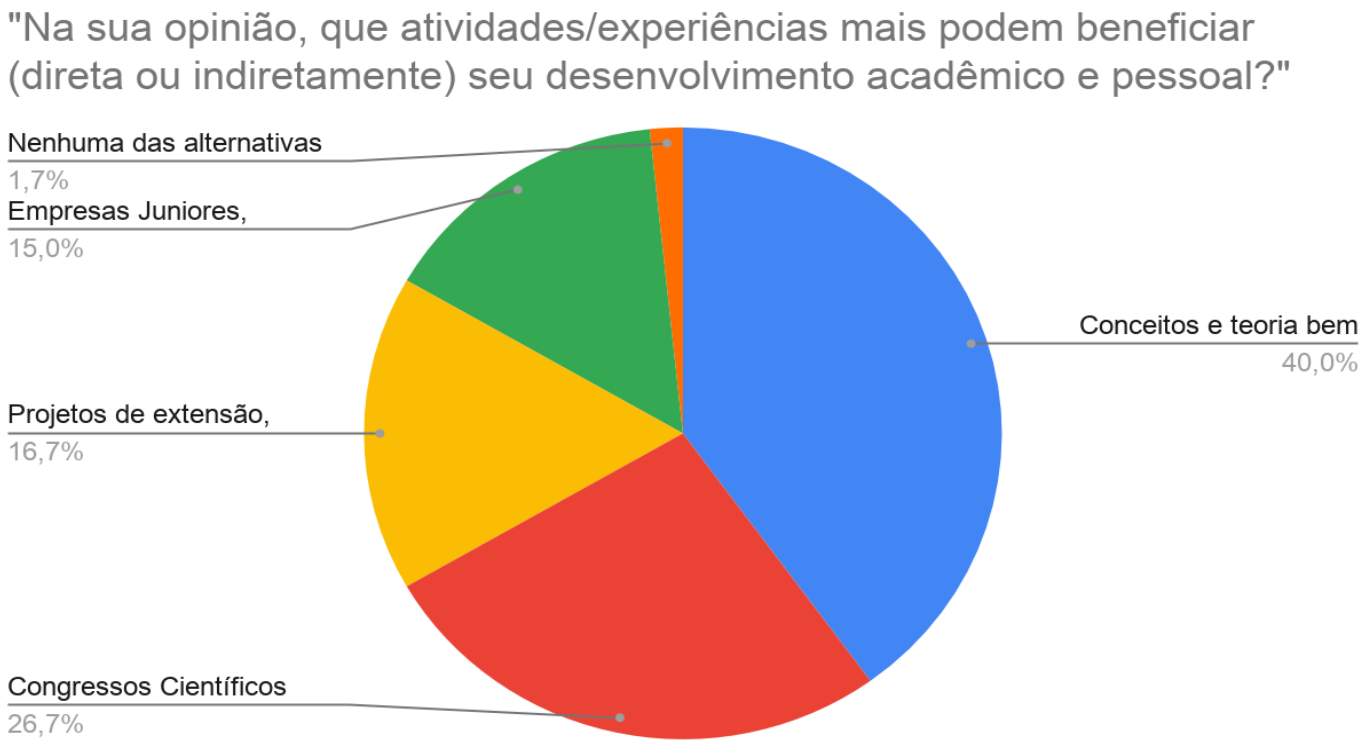

Fonte: Própria (2020).

Logo, podemos concluir que a desinformação acerca do que significa protagonismo estudantil pode ocorrer por conta do desinteresse de parte dos estudantes, tendo em vista que a maioria dos alunos conhecem o significado do mesmo e o IFPE proporcionam atividades que estimula o protagonismo estudantil.

Gráfico 06: Resposta dos(as) estudantes do curso de Química Industrial do Campus Recife que responderam a pergunta: "O IFPE estimula o protagonismo estudantil?

\section{Resposta dos(as) estudantes do curso de Química Industrial do Campus Recife a pergunta: "O IFPE estimula o protagonismo}

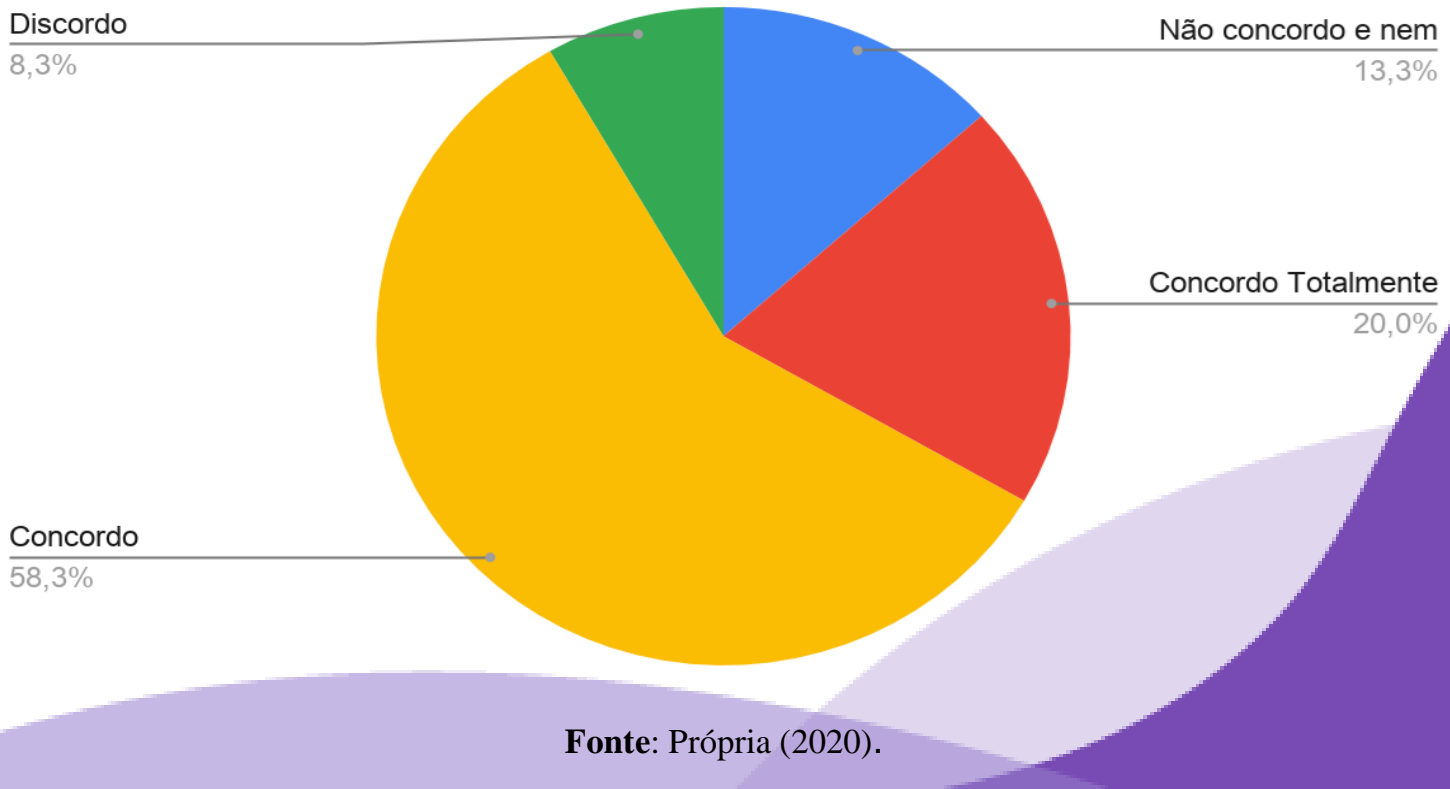


O gráfico representa a resposta dos alunos em relação a pergunta "O IFPE estimula o protagonismo estudantil?". 8,3\% discordaram que o IFPE possa agir estimulando os alunos a serem protagonista, 13,3\% não concordam e nem discordam. Já 58,3\% concordam que o IFPE estimula o protagonismo e $20 \%$ concordam totalmente. O IFPE vem estimulando os estudantes a serem protagonistas através de projetos, participação do estudante como monitor em eventos do próprio Campus, além do PDV( Programa Despertando Vocações), que tem como uma de suas diretrizes o protagonismo estudantil.

\section{CONCLUSÕES}

Neste estudo foi identificado e avaliado a perspectiva do protagonismo estudantil por estudantes do curso de Química Industrial do Instituto Federal Rural de Pernambuco Campus Recife.

Através das reuniões semanais, percebemos que a instituição já apresenta atividades que despertam os estudantes a serem protagonistas e também promovem atividades que estimulam o discente a ser um empreendedor.

Quanto a coleta de dados realizado com 60 discentes do curso de Química Industrial, de forma online devido a pandemia, foi observado que metade dos estudante têm entre 17 a 20 anos e 68,3\% são mulheres. Com relação a pergunta "você sabe o que é protagonismo estudantil?, o gráfico demonstra que 48,3\% responderam que "sim". Já a pergunta "o IFPE estimula o protagonismo? ", o gráfico demonstrou que mais que a metade dos alunos concordam, demonstrando que o IFPE vem estimulando os estudantes a serem protagonistas através de projetos, participação do estudante como monitor em eventos do próprio Campus, além do PDV que tem como objetivo incentivar o protagonismo estudantil.

Ao analisar a viabilidade deste projeto, a expectativa é trazer melhoria a imagem do instituto frente à sociedade e ser referência para outros campi.

\section{REFERÊNCIAS}

CHAER, G. DINIZ, R. R. P; RIBEIRO, E. A. A técnica do Questionário na Pesquisa Educacional. Revista Evidências. v. 7, n. 7, p. 251-266, 2011.

INSTITUTO FEDERAL DE PERNAMBUCO. Histórico IFPE. Disponível em: https://portal.ifpe.edu.br/acesso-a-informacao/institucional. Acesso em 25 de fev. 2020.

INSTITUTO FEDERAL DE PERNAMBUCO. Plano de Desenvolvimento Institucional. Disponível em: http://pdi.ifpe.edu.br. Acesso em: 25 de fev. 2020. 
LDB, Lei de Diretrizes e Bases da Educação. Presidência da República, Casa Civil, Lei nº 9.394, Brasília, 20 de dezembro de 1996.

MOYSÉS, G. L. R; MOORI, R. G; Coleta de Dados para a Pesquisa Acadêmica: Um Estudo Sobre a Elaboração, a Validação e a Aplicação Eletrônica de Questionário. XXII Encontro Nacional de Engenharia de Produção, Paraná, 2007. Anais... Foz do Iguaçu, 2007.

OLIVEIRA, E. M; LIMA, L, S, F. Percepção dos Estudante do Curso Técnico de Segurança do Trabalho Sobre Protagonismo Estudantil. IV Congresso Internacional de Gestão e Tecnologias, Recife, 2020. Anais... Recife, 2020.

RUSSO, A.C.R; FERREIRA, L.A; HENRIQUE.B. O Protagonismo Discente: Olhares das Crianças na Construção de um Festival de Jogos e Brincadeiras nas Aulas de Educação Física. p. 1-11. 2015.

SEMICHECHE, A.; HIGA, K. M.; CABREIRA, L. Protagonismo juvenil: a participação dos jovens para a transformação social. Akrópolis Umuarama, v. 20, n. 1, p. 21-38, jan./mar. 2012.

SOUZA, A. B; SALGADO, T. D. M. Diferenças Entre Gênero na Carreira do Técnico em Química: dos Bancos Escolares à Atuação. Revista Thema, v.14, n³, p. 37/49. 2017. 


\title{
CAPÍTULO 02: UTILIZAÇÃO DE FÓRUM VIRTUAL COMO FERRAMENTA DE ESTUDO PARA AUXÍLIO AO ENSINO REMOTO
}

\author{
CAPÍTULO 02: USO DEL FORO VIRTUAL COMO HERRAMIENTA DE ESTUDIO \\ DE AYUDA A LA EDUCACIÓN REMOTA
}

\section{CHAPTER 02: USE OF VIRTUAL FORUM AS A STUDY TOOL FOR AID TO REMOTE EDUCATION}

\author{
Stefane de Assis Orichuela ${ }^{1}$; Pedro Lucca Padilha Siqueira Ribeiro ${ }^{2}$; Victor Lucas da Costa \\ Lopes $^{3}$; Leidivânia Mendes de Araújo Melchuna ${ }^{4}$; Joel de Oliveira Santos ${ }^{5}$
}

DOI: https://doi.org/10.31692/978-65-88970-06-5.15-29

\begin{abstract}
RESUMO
Desde o início do século XXI, os cientistas vem desenvolvendo novos métodos tecnológicos que facilitam o dia a dia das pessoas, como, por exemplo, a evolução dos Smartphone, ou até o surgimento da Internet, que está cada vez mais aproximando as pessoas em longas distâncias. Diante disso, com os problemas recentes de uma nova pandemia que limitou o convívio social, ocorreu uma busca das tecnologias de informação e comunicação, em especial, na Educação. Assim, com aulas remotas e conteúdos online, o aluno tem infinidade de assuntos para explorar. No entanto, há algumas dificuldades de adaptação por parte tanto dos professores quanto dos estudantes, no último caso, uma delas é ministrar os conteúdos virtualmente, por ser algo novo, e sem a presença de um professor podem surgir dificuldades e dúvidas. Como resultado dessa situação, este artigo científico tem o objetivo de apresentar um sistema de fóruns que foi desenvolvido para que alunos possam tirar dúvidas e discutir com professores e outros alunos conteúdos abordados nas aulas online e presenciais, sendo um ambiente organizado para que os envolvidos interajam a qualquer hora. O referencial teórico que respalda este trabalho encontra-se pautado em estudos realizados sobre Tecnologias da informação e comunicação, e na utilização de fóruns virtuais. Para finalizar, vale ressaltar que o fórum pode ser utilizado por todas as instituições de ensino, facilitando também a monitoria presente nessas instituições, já que além de poder tirar dúvidas e questionar o conteúdo presente, estes registros serão salvos para que futuros estudantes que apresentem as mesmas dificuldades possam encontrar a resolução registrada por um professor ou por um aluno no fórum.
\end{abstract}

Palavras-Chave: Fórum, interatividade, Tecnologia da informação e comunicação.

\section{RESUMEN}

Desde principios del siglo XXI, los científicos han estado desarrollando nuevos métodos tecnológicos que facilitan la vida cotidiana de las personas, como la evolución de los teléfonos inteligentes, o incluso la aparición de Internet, que está uniendo cada vez más a las personas en mucho tiempo. distancias. Ante esto, con los recientes problemas de una nueva pandemia que limitaba la vida social, se buscó las tecnologías de la información y la comunicación, especialmente en Educación. Así, con clases remotas y contenido en línea, el alumno tiene multitud de materias por explorar. Sin embargo, existen algunas dificultades de adaptación tanto por parte de profesores como de alumnos, en este

\footnotetext{
${ }^{1}$ Técnico em Informática, Centro Estadual de Educação Profissional Professora Lourdinha Guerra/RN, stefaneassisori@gmail.com

${ }^{2}$ Técnico em Informática, Centro Estadual de Educação Profissional Professora Lourdinha Guerra/RN ribeiro.lucca2002@gmail.com

${ }^{3}$ Técnico em Informática, Centro Estadual de Educação Profissional Professora Lourdinha Guerra/RN, victolucs21@gmail.com

${ }^{4}$ Mestra em Letras, Centro Estadual de Educação Profissional Professora Lourdinha Guerra/RN, leidivaniamel@gmail.com

${ }^{5}$ Pós-graduando em Tecnologias Aplicadas à Educação, Centro Estadual de Educação Profissional Professora

Lourdinha Guerra/RN, joeloliveira56@gmail.com
} 
último caso una de ellas es la de impartir los contenidos de forma virtual, ya que es algo nuevo, y sin la presencia de un profesor pueden surgir dificultades y dudas. Fruto de esta situación, este artículo científico tiene como objetivo presentar un sistema de foros que se desarrolló para que los estudiantes puedan responder preguntas y discutir con los profesores y otros estudiantes los contenidos cubiertos en las clases online y presenciales, siendo un entorno organizado para que los involucrados interactúen a cualquier hora. El marco teórico que sustenta este trabajo se basa en estudios realizados en Tecnologías de la Información y las Comunicaciones, y en el uso de foros virtuales. Finalmente, cabe mencionar que el foro puede ser utilizado por todas las instituciones educativas, facilitando también el seguimiento presente en estas instituciones, ya que además de poder hacer preguntas y cuestionar el contenido actual, estos registros se guardarán para que los futuros estudiantes que presenten su información Las dificultades pueden encontrar la resolución registrada por un profesor o alumno en el foro.

Palabras Clave: Foro, interactividad, tecnologías de la información y la comunicación.

\section{ABSTRACT}

Since the beginning of the 21st century, scientists have been developing new technological methods that facilitate people's daily lives, such as the evolution of smartphones, or even the emergence of the Internet, which is increasingly bringing people together in long distances. In view of this, with the recent problems of a new pandemic that limited social life, there was a search for information and communication technologies, especially in Education. Thus, with remote classes and online content, the student has a multitude of subjects to explore. However, there are some adaptation difficulties on the part of both teachers and students, in the latter case, one of them is to teach the contents virtually, as it is something new, and without the presence of a teacher difficulties and doubts may arise. As a result of this situation, this scientific article aims to present a system of forums that was developed so that students can answer questions and discuss with teachers and other students content covered in online and face-to-face classes, being an organized environment for those involved to interact at any time. The theoretical framework that supports this work is based on studies carried out on Information and Communication Technologies, and on the use of virtual forums. Finally, it is worth mentioning that the forum can be used by all educational institutions, also facilitating the monitoring present in these institutions, since in addition to being able to ask questions and question the present content, these records will be saved so that future students who present their information difficulties can find the resolution registered by a teacher or student in the forum.

Keywords: Forum, interactivity, Information and communication technology.

\section{INTRODUÇÃO}

O fórum digital ou também conhecido como fórum de discussão, criado por John Smith em 1987, surgiu com o intuito de realizar melhores interações entre as pessoas por meio de mensagens publicadas, promovendo questões em páginas na internet que abordam um mesmo assunto. Ao passar dos anos, o fórum passou a ser mais utilizado nos meíos acadêmicos, possuindo quatro características, quais sejam: (1) livres: o professor desenvolve um fórum no ambiente virtual, a partir de um tema ou um texto de referência; (2) dirigindo: com base no fórum que o professor criou os alunos devem postar um número determinado de mensagens; (3) Permanente: o fórum estará aberto, enquanto a disciplina do curso estiver ocorrendo; (4) Tempo determinado: é determinado pelo professor a fase de funcionamento do fórum. Porquanto, conforme De Oliveira (2002, p. 5), "em termos de avanço na reflexão 
coletiva e na criação de aproximações e afinidades teóricas, o fórum é o espaço central da ação na disciplina on-line."

Destarte, com o fórum, podemos facilitar o auxílio de disciplinas virtualmente que se encontram no contexto acadêmico, oferecendo aos estudantes uma forma de receberem conhecimento e orientações tanto de um professor quanto de outros alunos, criando assim, um vínculo de interação entre a comunidade escolar. Outros benefícios que o espaço virtual oferece são o incentivo da troca de conhecimento entre alunos como também a cooperação dos professores.

Com tudo isso, graças ao espaço de fórum, a educação à distância (EAD) acaba sendo uma forma de ensino e aprendizagem mais aproveitada, visto que se utiliza da tecnologia para que professores possam virtualmente realizar aulas, atividades, fazer monitorias e ministrar conteúdos aos alunos sem haver a preocupação do desentendimento da matéria, já que o estudante poderá utilizar o fórum para tirar dúvidas. Neste contexto de pandemia, causado pela Covid-19, não é viável que ocorram aulas presenciais na escola, por conseguinte, houve um aumento expressivo na utilização de aulas remotas, a fim de buscar novas formas para realização das atividades escolares. Sendo assim, as pessoas começaram a necessitar mais ainda das tecnologias de comunicação, fazendo-as de recursos de extrema importância para o dia a dia, principalmente sendo utilizadas em instituições escolares, proporcionando aos jovens continuarem com seus estudos.

Com os problemas ocasionados pela Covid-19, as aulas presenciais se tornaram inviáveis tanto para os profissionais da educação quanto para os alunos, por esse motivo, houve a necessidade de se utilizar os ambientes virtuais de aprendizagem (AVA), facilitando assim, o compartilhamento de diversos conteúdos e disciplinas, dando um maior alcance aos estudantes, melhorando a mobilidade das aulas, atividades e trabalhos escolares realizados à distância .

Diante dos problemas citados, este artigo científico tem o propósito de apresentar um fórum digital de monitoria para que os alunos e professores possam compartilhar experiências obtidas nas aulas, podendo tirar dúvidas e resolver questões de alguns assuntos, sendo um ambiente para que alunos e professores possam interagir a qualquer momento sem se preocupar com a barreira da distância.

Portanto, o fórum poderá ser utilizado por todas as instituições de ensino, proporcionando também a monitoria escolar, já que além de tirar dúvidas e questionar conteúdos ministrados em aula, eses registros serão salvos para que futuros alunos que possivelmente tenham as mesmas dificuldades possam procurar a discussão de aprendizado 
postada anteriormente por professor ou aluno.

\section{FUNDAMENTAÇÃO TEÓRICA}

\section{UTILIZAÇÃO DO FÓRUM COMO FERRAMENTA DE ESTUDO}

Antes de tudo, é importante analisar que a ferramenta de fórum virtual pode ser utilizada no meio acadêmico, sendo um sistema remoto distribuído em hierarquias, atravessando as barreiras do tempo entre a comunidade estudantil e os professores, chegando até uma comunicação sincronizada entre ambos à distância. Exemplos que demonstram isto estão disponíveis em trabalhos de: Oliveira (2017) e Aurélio (2017), onde foi analisado o comportamento dos alunos diante de um fórum digital criado em um curso EAD de Letras; Martins (2016) e Alves (2016), onde se desenvolveu uma pesquisa exploratória para analisar a opinião dos participantes de cursos a distância, em relação a utilização do fórum como instrumento avaliativo; Gimenes et al. (2012), observaram a interação sociocultural e sua forma de aprendizagem por meio dos ambientes virtuais, e através do fórum conseguiram observar o nível de conhecimento dos alunos sobre as matérias.

Segundo Paste de Oliveira (2002 p.4), “o fórum pode ser visto como um elemento assíncrono de envio de mensagens em rede, destinadas, na maioria das vezes, a um grupo de pessoas habilitadas ao acesso das mesmas". Sendo assim, o ambiente assíncrono permite que alunos e professores aproveitem do mesmo espaço sem que ambos tenham que cumprir um horário específico de uso, proporcionando aos estudantes um maior conforto em poder se pronunciar a qualquer momento.

Além disso, a hierarquia que há dentro da plataforma, serve como um meio mais organizado de distribuir dos usuários que a utilizam, já que os fóruns digitais são organizados em Classes e Tópicos, sendo a classe um conceito geral de um tópico específico, em que cada tópico é dividido por dois tipos: Discussão e Pergunta. Nesse caso, o estudante pode escolher por criar espaços de perguntas a serem respondidas, ou abrir discussões para serem debatidas. Um exemplo que podemos citar são os fóruns presentes no Moodle (2011), que utiliza de quatro tipos diferentes de fórum atendendo aos estudantes de acordo com suas necessidades, sendo estes:

1. Fórum geral: Muito útil para grandes discussões onde há o monitoramento por parte do professor e o debate voltado a todos os alunos que se interessarem pelo assunto e querem discutir sem um prazo limite para terminar.

2. Fórum de uma única discussão simples: Utilizado para discussões curtas e com 
prazo limite.

3. Fórum em que cada usuário inicia um novo tópico: Nesse fórum, o estudante pode criar novos tópicos que incrementam debates oferecidos em discussões maiores. Esse já é um fórum mais restrito onde há um assunto que é colocado em pauta e os outros usuários só poderão criar novos tópicos relacionados ao assunto principal.

4. Fórum P e R (Pergunta e Resposta): sendo uma boa opção para os estudantes que tem alguma pergunta para ser respondida.

Com isso, o ambiente virtual proporciona de forma organizada todo um espaço dedicado para atender a dificuldade específica do aluno.

\section{AS RELAÇÕES INTERPESSOAIS NO MEIO VIRTUAL}

A interação entre alunos pode servir de grande ajuda para desenvolver o autoconhecimento, pois eles compartilham de experiências acadêmicas que já vivenciaram, tanto para ajudar um ao outro em questões como a dificuldade de entender um conteúdo, como também a capacidade de revisar e abrir a mente para o que já tenha aprendido.

\footnotetext{
"Interagir com o conhecimento e com as pessoas para aprender é fundamental. Para a transformação de um determinado grupo de informações em conhecimentos é preciso que estes sejam trabalhados, discutidos, comunicados. As trocas entre colegas, os múltiplos posicionamentos diante das informações disponíveis, os debates e as análises críticas auxiliam a sua compreensão e elaboração cognitiva. As múltiplas interações e trocas comunicativas entre parceiros do ato de aprender possibilitam que estes conhecimentos sejam permanentemente reconstruídos e reelaborados." (KENSKI, 2002:258 apud OLIVEIRA, 2002b, p. 5).
}

Pode-se concluir que, as tecnologias estão facilitando cada vez mais na aprendizagem, fazendo com que a interação remota entre os alunos sejam mais acessíveis, podendo ser dada de diversas maneiras, uma delas citada neste artigo é no fórum, visto que, essa ferramenta possui todo o ambiente adequado para atender a esse requisito.

\section{TICS NA EDUCAÇÃ̃O}

As Tecnologias da informação e comunicação (TICs) são uma excelente alternativa para se buscar uma aprendizagem em que há a comunicação entre os alunos dentro de um ambiente integrado que pode ser através de redes sociais, sites, fóruns etc..

De acordo com Thais Pacievitch (s.d) no site "InfoEscola", "tecnologia da informação e comunicação (TICs) pode ser definida como um conjunto de recursos tecnológicos, utilizados de forma integrada, com um objetivo comum". Logo, adentrar na educação pode 
servir de aliada uma vez que os alunos já têm uma intimidade e conhecimento com as tecnologias que usam.

Ademais, com o desenvolvimento da tecnologia a comunicação entre indivíduos distantes e a troca de informações deixou cada vez mais fácil a interação entre os mesmos, sem a presença física de ambos. Dentro do ambiente escolar, isso pode ser aplicado com o intuito de incentivar a comunicação entre professor e aluno, sem excluir o papel do professor, e até entre os próprios alunos a trocar informações relevantes aos assuntos passados presencialmente. Assim, como Garcia et al. (2012, p. 18) no artigo "Tecnologias de Informação e Comunicação: TICs Aplicadas à Lé” descrevem que:

\begin{abstract}
"As inovações tecnológicas acentuaram a necessidade de novas posturas no processo de ensino e aprendizagem. O professor não deveria ser, simplesmente, visto como único detentor e transmissor do conhecimento e nem o aluno como receptor passivo. O ensinar e o aprender começam a ser subsidiados (e não substituídos) pelo aparato tecnológico, que tem como uma de suas funções otimizar a construção de situações de aprendizagem significativas."
\end{abstract}

Sendo assim, é notório que as TICs vieram para mudar a forma de ensino que era praticado dentro das instituições tradicionais, trazendo de forma dinâmica e interativa, um método de ensinar que conecta tanto professor quanto aluno em um ambiente virtual integrado tanto assíncrono quanto síncrono.

\title{
METODOLOGIA
}

Esta parte do artigo é dividida em três etapas, sendo a primeira: as ferramentas e montagem do fórum, enquanto, na segunda etapa, apresentamos as partes construídas do site, e, por fim, na última etapa, compartilhamos uma pesquisa que realizamos.

\section{MONTAGEM DO FÓRUM}

Primeiramente, para a montagem do site, no qual o fórum foi providenciado, for utilizada uma pasta compactada com arquivos pré-programados (plugins) instalados no sistema, quais sejam: Social Articles, Linked Articles, Classic Editor, Two-Factor, Akismet Anti-Spam. Esses programas possuem o objetivo de adicionar funções maiores a uma aplicação, que no caso do fórum, é uma aplicação web. Graças aos plugins desenyolvidos na linguagem de programação PHP, foi possível adicionar pacotes prontos e editáveis para dar funcionamento ao que é proposto em um fórum virtual voltado à aprendizagem.

Além das tecnologias utilizadas para o funcionamento do fórum, foram aproveitados 
também junto à pasta alguns templates prontos para serem editados, feitos através da linguagem de texto HTML e de estilo CSS que foram utilizados para dar o visual e o estilo da plataforma.

Também foi utilizado o banco de dados MySQL para poder fazer o armazenamento dos dados contidos no site, sendo utilizado para armazenar os dados registrados dos alunos e professores que se cadastram no site, além das postagens e os pontos de reputação que serão apresentados ao longo deste artigo.

Por fim, foi preciso hospedar o site na internet para fazer os ajustes de edição do template e de uma breve simulação do sistema. Para isso, utilizou-se um domínio gratuíto, especificamente, o domínio “.ml” que é utilizado no Mali para poder adquirir os caracteres de identificação do site. Após isso, foi utilizada uma hospedagem gratuita no servidor Epizy para hospedar o site na internet.

\section{PROCESSO DO DESENVOLVIMENTO EXTERNO DA PLATAFORMA}

Após a montagem do site onde ficaria armazenado o fórum virtual, ainda era preciso acrescentar todos os espaços necessários dentro da plataforma, para isso, foi disponibilizado uma página específica para o administrador gerenciar todo espaço do site, criando novos fóruns dentro do sistema. Com isso, a página inicial do site foi dividida da seguinte maneira:

- Fórum Principal: Onde estarão as notícias, informações e eventos dentro do ambiente virtual.

- Fóruns das áreas: São fóruns distribuídos em áreas, onde os usuários poderão colocar conteúdos que estão de acordo com a área apresentada, sendo elas: Humanas, Linguagens, Naturezas, Matemática e a Base Técnica.

- Suporte: O fórum de suporte serve para dar suporte a algum usuário que esteja com alguma dificuldade ou dúvida em algo relacionado ao sistema.

Após essa etapa, foram organizados métodos hierárquicos para cada tipo de usuário sendo denominados de alunos e professores. Nesse caso, há objetivos específicos dentro da plataforma, como mostrado no diagrama de caso e uso abaixo: 
Figura 01: Diagrama de Caso e Uso do fórum virtual.

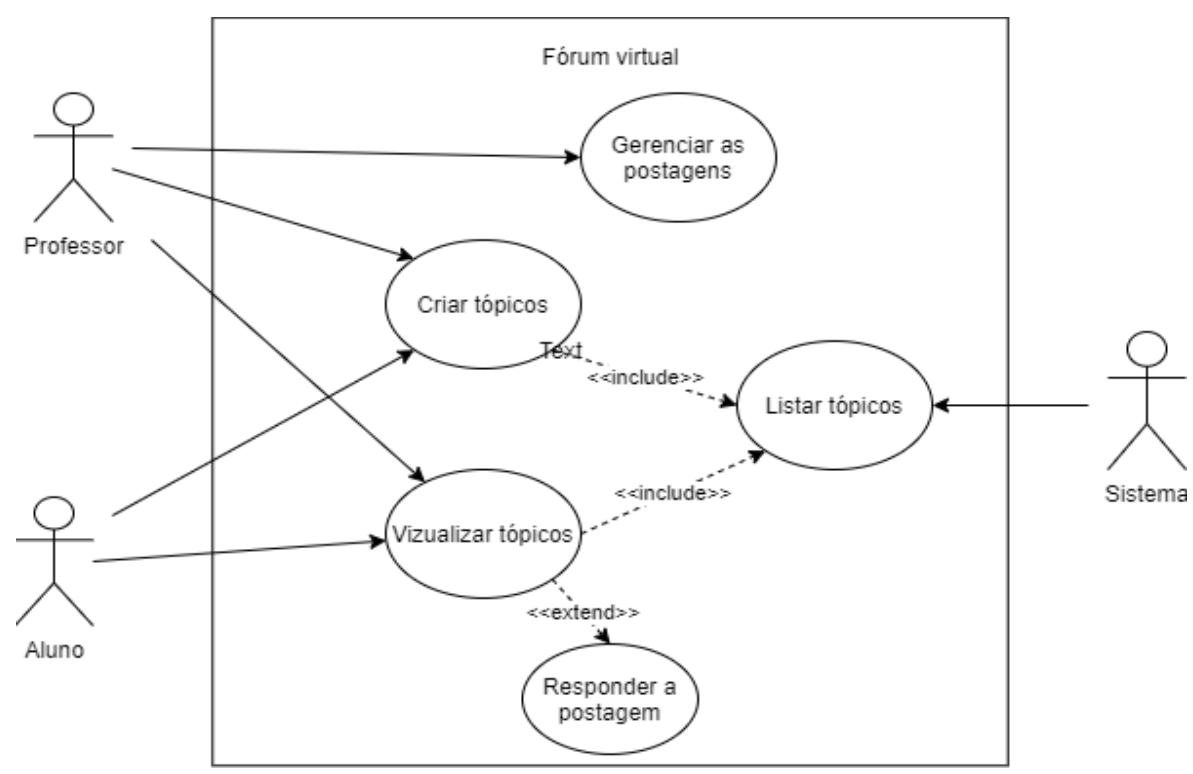

Fonte: Própria (2020).

Como mostrado na figura acima, o aluno é o agente que visualiza, responde e cria novos tópicos de fóruns, com o intuito de fazer alguma pergunta, ou iniciar um debate de um assunto específico de determinada área. Já o professor, além das mesmas opções do aluno, também pode ser o mediador, gerenciando o fluxo de mensagens que os alunos postam na plataforma, podendo assim, analisar se todas as mensagens estão de acordo com a proposta geral do fórum.

\section{PESQUISA REALIZADA}

Além da construção do fórum, fizemos também uma pesquisa quantitativa de estudo de caso com os alunos do Centro Estadual de Educação Profissional Professora Lourdinha Guerra, com o intuito de analisar o quanto os alunos da instituição tem conhecimento acerca de um fórum de discussão, analisando também as dificuldades pendentes nas disciplinas durante a educação remota, com a finalidade de prever como os alunos se comportam diante da plataforma de fórum virtual.

Para tanto, criamos um formulário no Google Forms com algumas perguntas relacionadas com nosso propósito, e compartilhamos para todos os alunos da escola, através dos líderes de sala, que por sua vez, compartilharam nos grupos de WhatsApp. 


\section{RESULTADOS E DISCUSSÃO}

\section{DEMONSTRAÇÃO DO FÓRUM}

Em relação ao desenvolvimento e descrições apresentadas sobre o fórum virtual elaborado para a instituição de ensino, é possível ter uma ideia de como exatamente funciona o fórum virtual. Para tanto, a seguir, apresentamos algumas imagens que mostram como o fórum está situado.

Figura 02: Imagem da seção de áreas na página principal do fórum virtual.

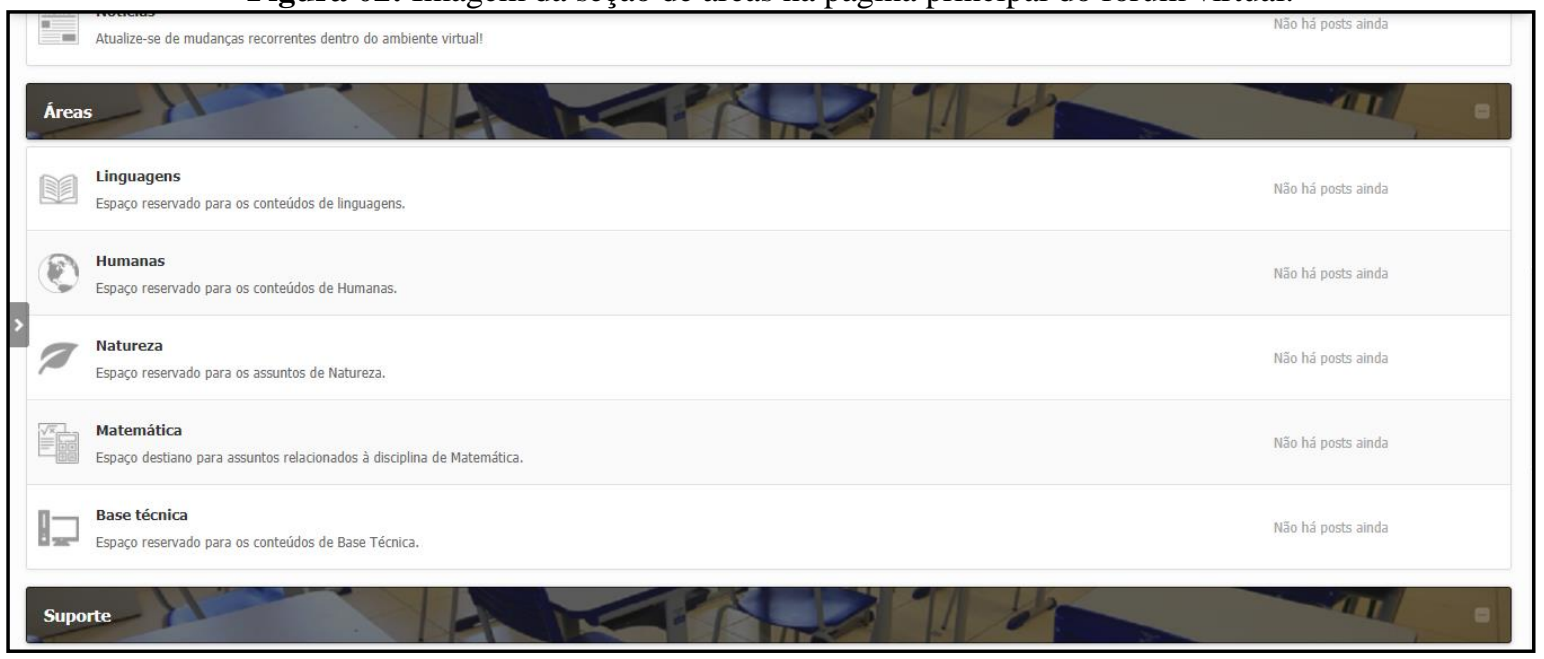

Fonte: Própria (2020)

Nessa primeira imagem, está sendo mostrado o fórum titulado “Áreas" onde está dividida entre suas respectivas camadas: "Linguagens", "Humanas", "Natureza", "Matemática", "Base técnica".

Figura 03: Página de visualização dos tópicos da área de matemática

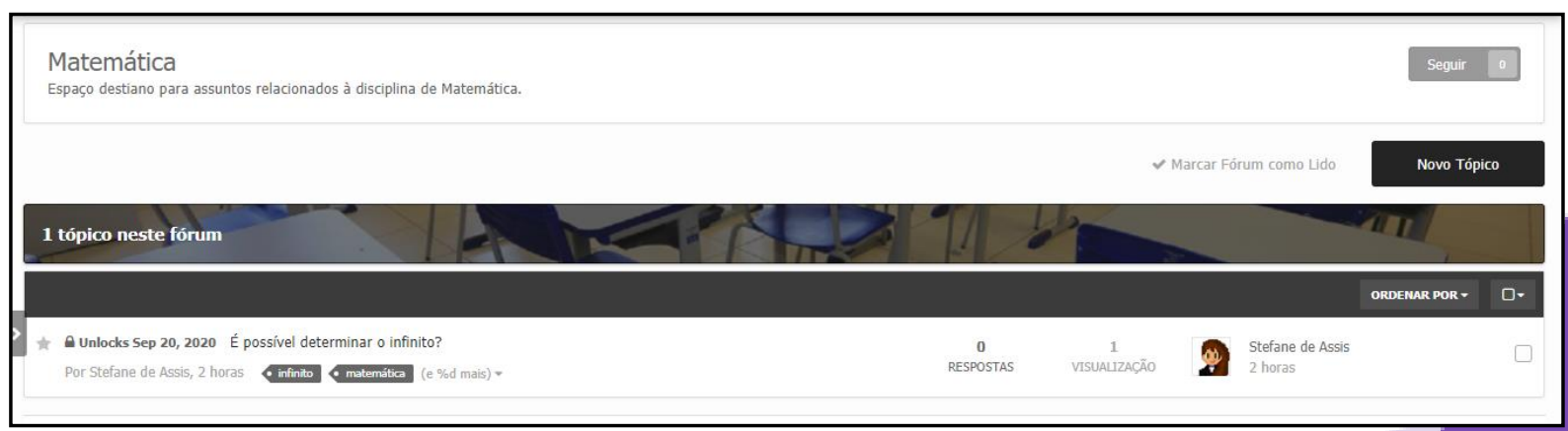

Fonte: Própria (2020).

Nessa segunda imagem, é possível observar um exemplo de postagem realizado dentro da área de "Matemática", e logo dentro da postagem, é possível ver o número de visualizações e respostas adquiridas. já acima e à direita do tópico, há um botão chamado "Novo Tópico" 
onde os alunos podem criar novas postagens dentro da área selecionada.

Figura 04: Página do usuário

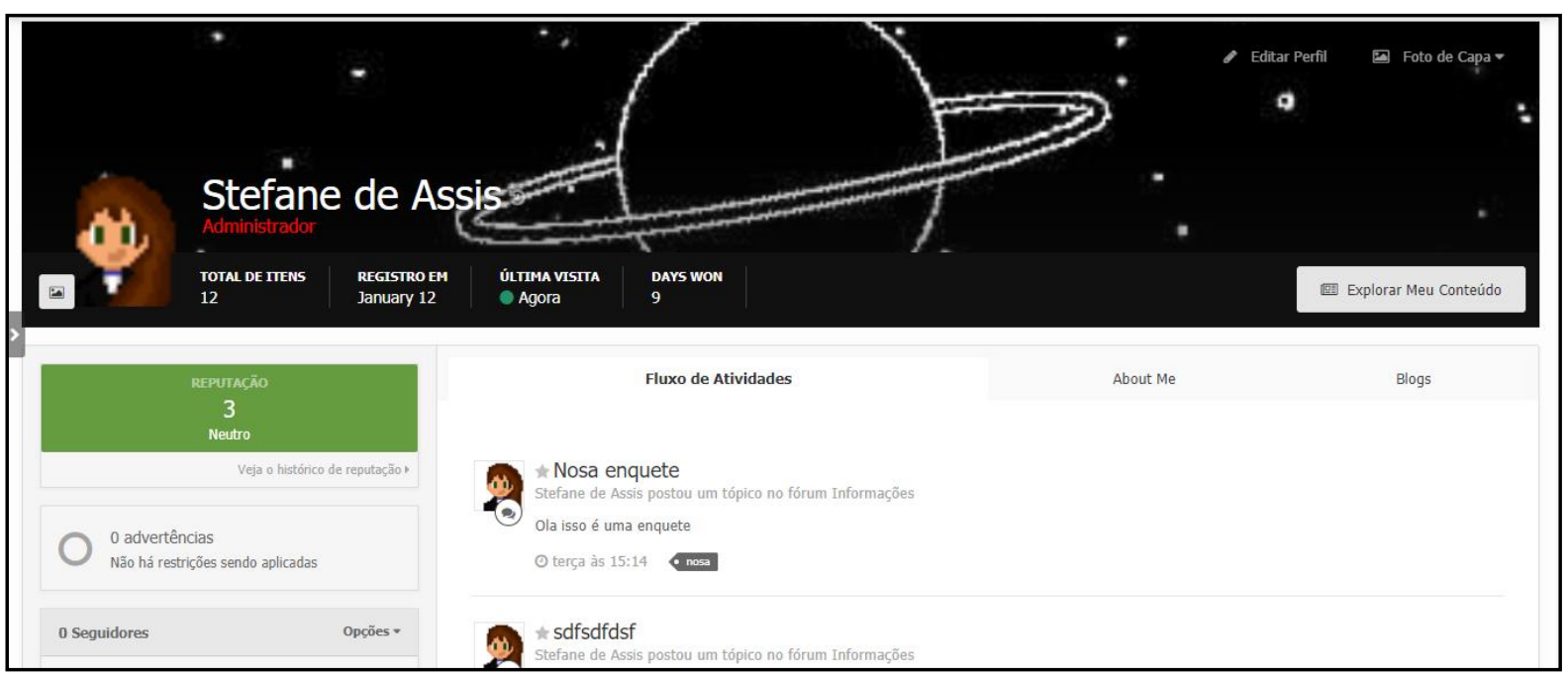

Fonte: Própria (2020).

Nessa terceira imagem, está sendo mostrada a página do perfil do usuário, distribuída pela foto do plano de fundo, que pode ser personalizada pelo usuário, o histórico de postagens, e as informações de atividades.

\section{RESULTADOS DA PESQUISA}

Em relação à pesquisa realizada com os estudantes do Centro Estadual de Educação Profissional Professora Lourdinha Guerra, que foi feita através de levantamentos de dados mediante ao questionário do Google Forms, obtivemos um total de 143 estudantes consultados, que mostrou dados relevantes comprovando a importância de um fórum virtual nas instituições de ensino. 
Figura 05: Analisando a participação dos alunos com algum fórum virtual.

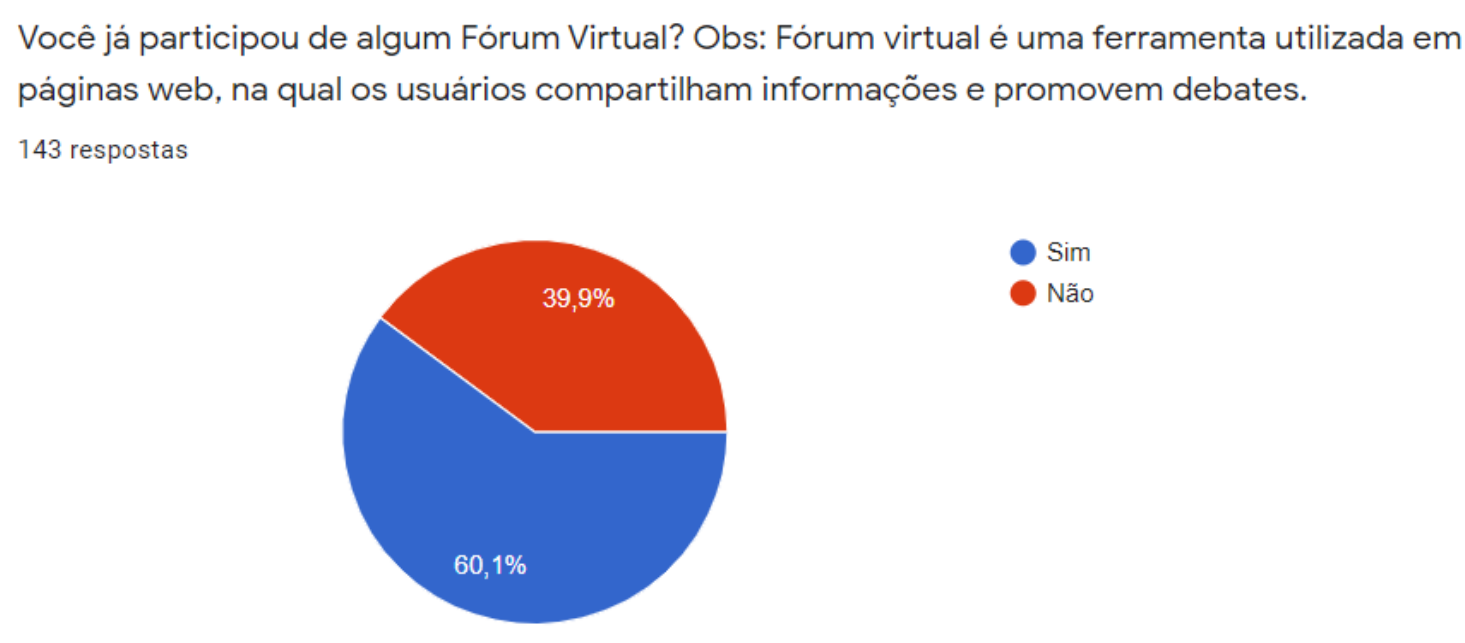

Fonte: Própria (2020).

Na figura 05, a análise de dados feita em relação à primeira pergunta trazida aos estudantes sobre o contato dos alunos com outros ambientes virtuais do tipo "fórum", mostrou-se positiva, uma vez que os resultados da pesquisa comprovaram que $60 \%$ dos 143 estudantes consultados do CEEP Professora Lourdinha Guerra apresentaram algum contato anterior com outros fóruns virtuais.

Figura 06: Analisando a participação dos alunos com seus fóruns específicos.

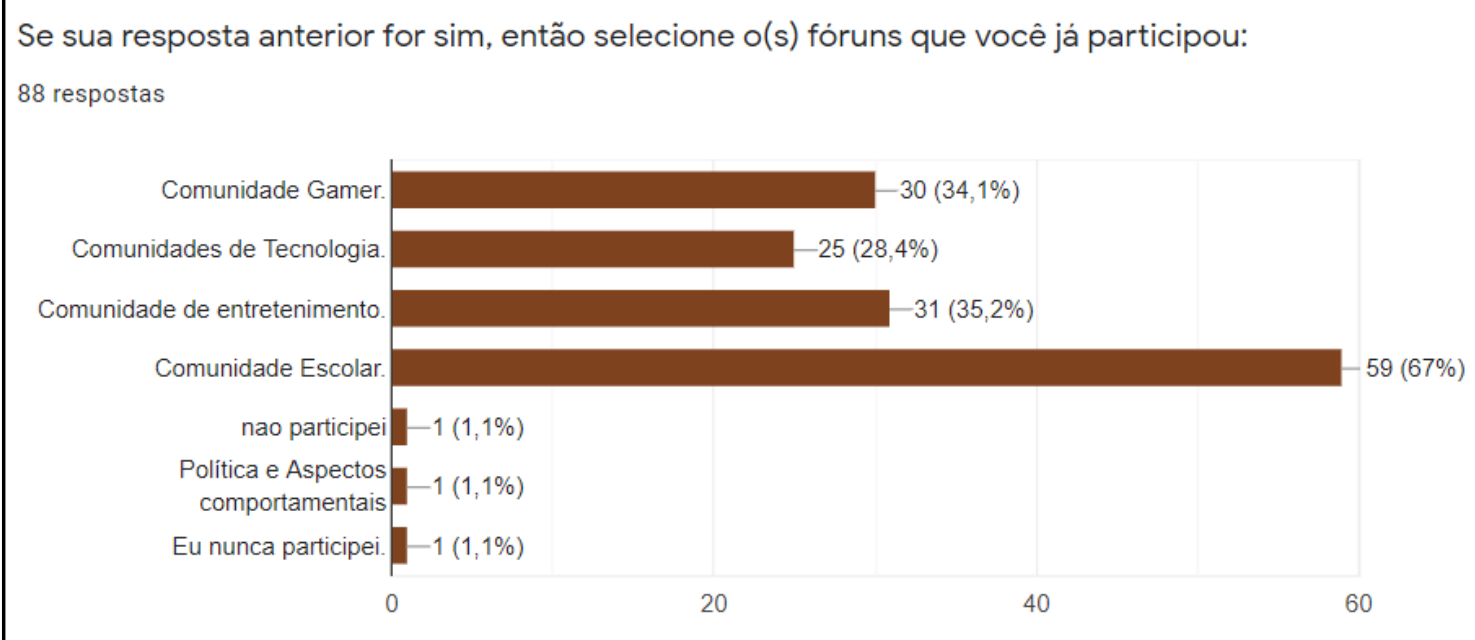

Fonte: Própria (2020).

Considerando os dados presentes na figura 06, verificamos que os alunos apresentados como participantes de fóruns virtuais tiveram que responder a outra pergunta de múltipla escolha, a qual envolvia a análise dos tipos de fórum que eles já haviam participado. Dentre os 88 alunos que responderam o "sim", 67\% já participaram de algum fórum do tipo “Comunidade Escolar". Com isso, foi possível concluir que a maior parte dos alunos já teve contato principalmente com fóruns voltados à educação, portanto não seria uma tecnologia 
desconhecida para esses estudantes.

Figura 07: Analisando o estado de aprendizagem e compreensão por parte dos estudantes em relação aos assuntos administrados remotamente no Moodle.

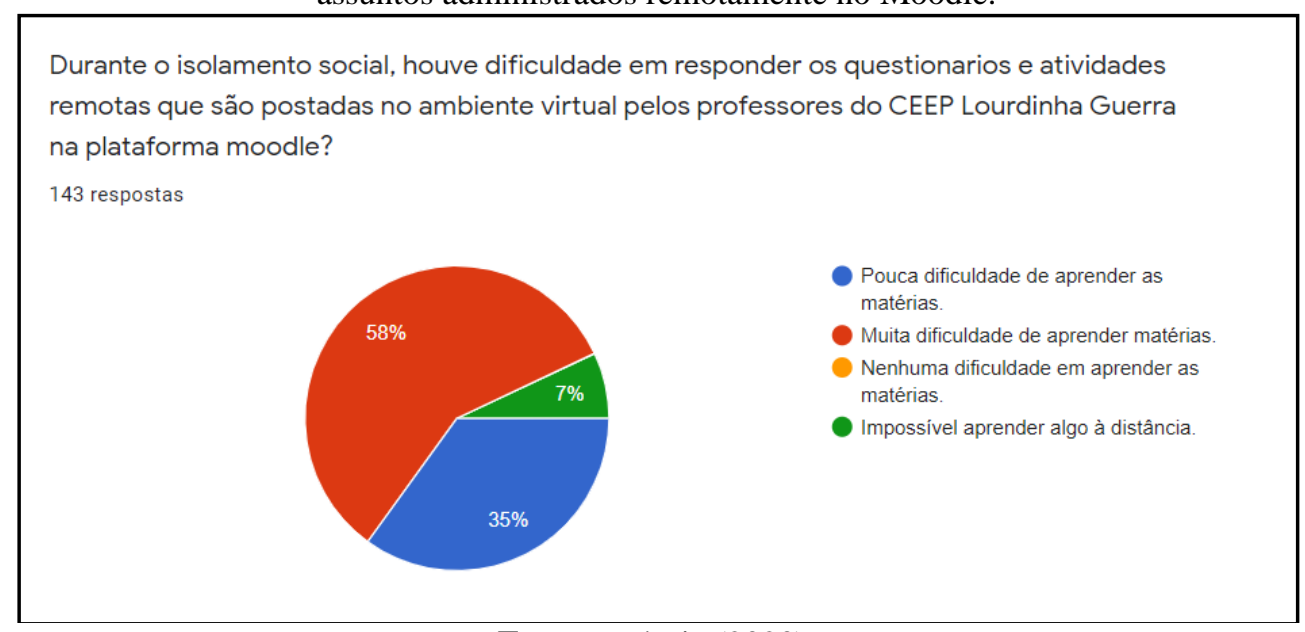

Fonte: Própria (2020).

Já nos dados presentes na figura 07, percebe-se que a maior parte dos alunos possuem problemas em responder aos questionários e aprender as disciplinas administradas remotamente, já que 58\% afirmaram ter dificuldades de aprender as matérias. Isso pode estar sendo causado pela má adaptação dos alunos ao ensino remoto durante a pandemia, uma vez que, por se tratar de uma educação diferente do que era aplicado aos alunos no ensino presencial, há muito mais dificuldade e dúvidas que surgem nas disciplinas passadas virtualmente. Portanto, necessitando de um ambiente virtual que auxilie melhor os alunos durante esse período de dificuldade e até mesmo depois para aprimorar e facilitar o aprendizado.

Figura 08: Analisando o comportamento dos estudantes diante do surgimento de uma dúvida.

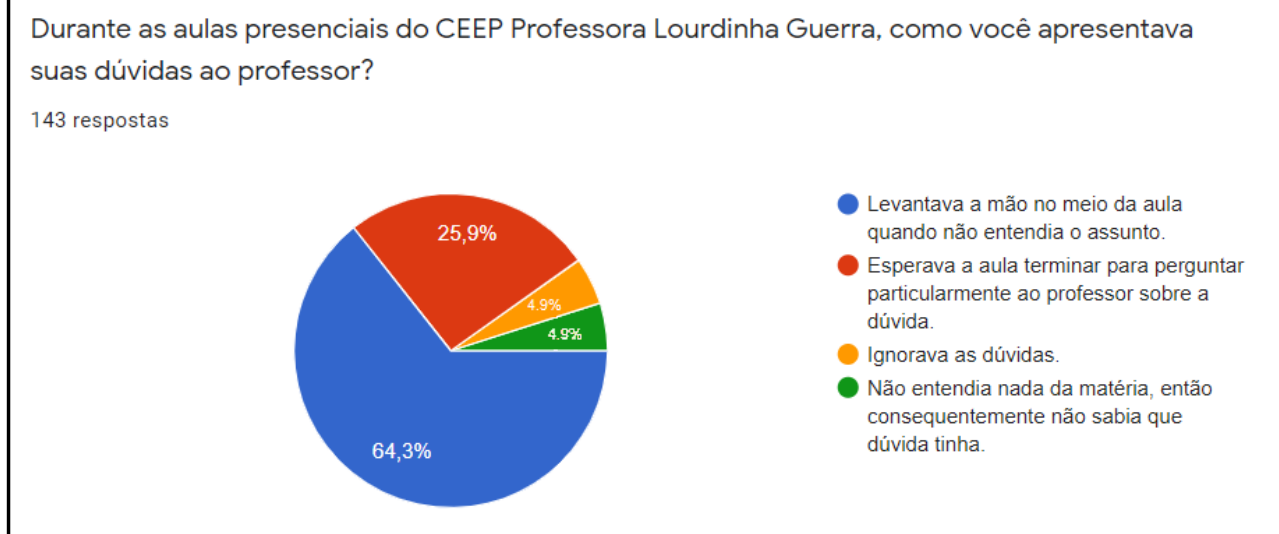

Fonte: Própria (2020).

Com base no gráfico da figura 08 , podemos perceber que a maior parte dos alunos 
levanta a mão para tirar dúvidas no meio de uma aula, o que supostamente poderia causar atrasos no conteúdo, incomodando alguns professores. Não obstante, essa atitude é importante, pois a proatividade de demonstrar dúvidas em determinado assunto torna-se positiva para alunos mais tímidos, os quais geralmente não tiram suas dúvidas em relação aos conteúdos ministrados.

Sabendo disso, se essa situação fosse trazida ao mundo virtual, as dúvidas debatidas em sala de aula poderiam estar dispostas numa forma assíncrona de mensagens salvas dentro do sistema, e a qualquer momento os alunos teriam acesso para visualizar e comentar.

Outro ponto importante, o ato da maioria dos alunos apresentarem autonomia em querer expressar suas dúvidas mostra que, não ocorre desinteresse por parte dos estudantes em demonstrar a problemática de seus entendimentos, isso se aplicada a um meio virtual, pode fazer com que alunos atuem em um ambiente único para poder tirar suas dúvidas a qualquer hora do dia, sendo respondidas até por outros alunos, já que a autonomia dentro da instituição de ensino sempre esteve presente.

\section{CONCLUSÕES}

Com base em todos os dados apresentados pela pesquisa, é possível destacar que o Fórum de discussão proporciona uma melhor interação entre os profissionais de educação e alunos nas instituições de ensino, já que além deles terem um conhecimento sobre essa plataforma, há também muitas dificuldades a serem resolvidas em relação à aprendizagem dos estudantes, principalmente diante das aulas remotas que não são tão bem aproveitadas pelos discentes, principalmente, os que estão experimentando um novo método de ensino devido ao período de distanciamento social em 2020.

Diante desse contexto, o fórum permite que, de maneira mais prática, todos possam tirar dúvidas que não foram possíveis durante as aulas, ou até mesmo tirarem dúvidas de outros estudantes, fazendo com que a aprendizagem seja socializada. Dessa forma, criando um espaço de aprendizagem colaborativa entre os acadêmicos, tornando o Fórum de discussão uma ferramenta de extrema importância para a comunidade escolar.

Por fim, vale ressaltar que, apesar de ter sido uma experiência exaustiva, o resultado foi muito gratificante, trazendo muita experiência para nosso desenvolvimento acadêmico e técnico em nosso curso de Informática. Desse modo, acreditamos que a divulgação deste trabalho nos proporcionará muitos caminhos, visto que somos iniciantes na área de desenvolvimento e projetos. 


\section{REFERÊNCIAS}

ALVES, Lucicleide; MARTINS, Alexandra. O Fórum de Discussão como Instrumento Avaliativo de Aprendizagem. SENAC de Brasília; Universidade Católica de Brasília, Porto Alegre, 2016.

AURÉLIO, Renato; OLIVEIRA, Jossiane. Utilização do fórum enquanto ferramenta pedagógica digital em um curso de letras - Português (EAD). Curso de Especialização em Linguísticas Aplicada ao Ensino de Língua Inglesa - UNEB, Bahia, 2017.

DE OLIVEIRA, Gerson Paste. O fórum em um ambiente virtual de aprendizado colaborativo. São Paulo: Associação Brasileira de Educação a Distância. 2011. Acesso em, v. 14, 2018.

GARCIA, Daniela; MESSIAS, Rozana; NORTE, Mariângela. Tecnologias de informação e comunicação: TICs aplicadas à Le. Curso de especialização para o quadro do Magistério da SEESP, São Paulo, p.08-57, 2012.

GIMENES, Solange; SANTOS, Washington; TOCZEK, Jonathan. O fórum como ferramenta mediadora de aprendizagem: Aprendizagem na educação à distância: Desafios, estratégias e dificuldades. Universidade Federal de São Carlos - UFSCar, São Paulo, 2012.

IZARIAS, Nilma; NUNES, Carolina; SANTOS, Simone. O fórum virtual e suas potencialidades para a interação em ambientes educativos virtuais. XV Congresso Brasileiro de Ensino Superior à distância, IV Congresso Internacional de Educação Superior à Distância, esud, Natal, 2018.

MOODLE. Fóruns, 2011. Documentation. Disponível em: <https://docs.moodle.org/all/pt_br/F\%C3\%B3runs >. Acesso em: 28 de Jul. de 2020.

NOBRE, Artur; NUNES, Isabel; OLIVEIRA, Juliana; PAIVA, Maria; RABELO, Danieli; ROCHA, Stênio. Utilização do fórum como ferramenta colaborativa na EAD. Programa de Pós-Graduação em Inovação em Tecnologias Educacionais;

O QUE é AVA?. edools: Tudo que você precisa saber sobre ensino online, [s.d]. Perguntas Frequentes. Disponível em: 〈https://www.edools.com/faq/o-que-e-ava/>. Acesso em: 28 de Jul. de 2020.

O QUE é EAD?. edools: Tudo que você precisa saber sobre ensino online, [s.d]. Perguntas Frequentes. Disponível em: 〈https://www.edools.com/faq/o-que-e-ead/>. Acesso em: 28 de Jul. de 2020.

O QUE é Monitoria?. Proenem: Atendimento para o enem, [s.d.]. Perguntas frequentes. Disponível em: <https://atendimento.proenem.com.br/hc/pt-br/articles/360001438373-O-queé-Monit\%20oria->. Acesso em: 28 de Jul. de 2020.

POR causa do Coronavírus, aulas EAD têm crescimento significativo. Diário de Goiás, Goiânia, 20 de Mar. de 2020. Disponível em: <https://abmes.org.br/noticias/de

Acesso em: 28 de Jul. de 2020. 
TECNOLOGIA e informação da comunicação. InfoEscola: Navegando e aprendendo, [s.d]. Disponível em: <https://www.infoescola.com/informatica/tecnologia-da-informacao-ecomunicacao/>. Acesso em: 04 de Set. de 2020.

VIEIRA, Rosângela Souza. O Papel das tecnologias da informação e comunicação informação e comunicação na educação à distância: um estudo sobre a percepção da educação à distância o professor/tutor. Formoso-Ba: Universidade Federal do Vale do São Francisco (UNIVASF), v. 10, 2011, pp.66-72 


\title{
CAPÍTULO 03: FATORES CLIMÁTICOS E A INCIDÊNCIA DA DENGUE NO MUNICÍPIO DE PICOS-PI
}

\section{CAPÍTULO 03: FACTORES CLIMÁTICOS Y LA INCIDENCIA DEL DENGUE EN EL MUNICIPIO DE PICOS-PI}

\section{CHAPTER 03: CLIMATE FACTORS AND THE INCIDENCE OF DENGUE IN THE MUNICIPALITY OF PICOS-PI}

\author{
Italo Giullian Carvalho de Albuquerque ${ }^{1}$; José Anatiel Gonçalves Santos Landim²
}

DOI: https://doi.org/10.31692/978-65-88970-06-5.30-47

\begin{abstract}
RESUMO
A dengue é um problema de saúde pública e para combatê-la, é necessário conhecer cada vez mais os fatores favoráveis ao seu desenvolvimento, proliferação, modos de transmissão e outras informações inerentes. Estudos realizados demonstram que existe relação entre as variáveis climáticas e o aumento do número de casos de dengue. Diante disso, o presente trabalho buscou analisar as relações entre as variáveis climáticas com os casos notificados de dengue no município de Picos-PI no período entre 2015 e 2019. Foram utilizados dados de casos de dengue e do clima em Picos, disponibilizados pelas bases de dados do DATASUS e INMET. A pesquisa tem caráter descritivo e é qualitativa. Utiliza ainda uma análise exploratória de dados referentes à dengue no município em questão. Foram feitas análises utilizando as bibliotecas da linguagem de programação Python, e as bibliotecas pandas e matplotlib, onde foi possível fazer a manipulação e a visualização da aplicação do algoritmo. Como resultado, verificou-se que os casos de dengue estão relacionados regularmente com as mudanças climáticas na cidade de Picos-PI, tendo maior incidência no período entre março e junho, quando as condições climáticas são favoráveis: aumento de chuva e da umidade relativa do ar, e a diminuição da temperatura. Na referida cidade estudo revela um elevado índice de notificação de dengue nos meses frios e úmidos, sugerindo políticas públicas de prevenção, bem como a conscientização da população nas ações disciplinares para essa época do ano. Como o clima é mais quente na segunda metade do ano, registra-se um baixo número de casos significante da dengue.
\end{abstract}

Palavras-Chave: Dengue, Clima, Dados.

\section{RESUMEN}

El dengue es un problema de salud pública y para combatirlo es necesario conocer cada vez más los factores favorables a su desarrollo, proliferación, modos de transmisión y demás información inherente. Los estudios han demostrado que existe una relación entre las variables climáticas y el aumento del número de casos de dengue. Ante esto, el presente estudio buscó analizar la relación entre las variables climáticas con los casos reportados de dengue en el municipio de Picos-PI en el período entre 2015 y 2019. Se utilizaron datos sobre casos de dengue y clima en Picos, puestos a disposición por las bases de datos. datos de DATASUS e INMET. La investigación es descriptiva y cualitativa. También utiliza un análisis exploratorio de datos relacionados con el dengue en el municipio en cuestión. Los análisis se realizaron utilizando las bibliotecas del lenguaje de programación Python y las bibliotecas pandas y matplotlib, donde fue posible manipular y visualizar la aplicación del algoritmo. Como resultado, se encontró que los casos de dengue se relacionan regularmente con el cambio climático en la ciudad de Picos-PI, con mayor incidencia en el período comprendido entre marzo y junio, cuando las condiciones climáticas son favorables: aumento de las precipitaciones y humedad relativa en la ciudad. aire, y la disminución de la temperatura. En esa ciudad, un estudio revela una alta tasa de notificación de dengue en los meses fríos y húmedos, sugiriendo políticas

1 Bacharelado em Ciência da Computação, Instituto de Educação italoalbuq@hotmail.com

Especialista em Engenharia de Sistemas, Instituto de Educação Superior Raimundo anatielsantos@gmail.com

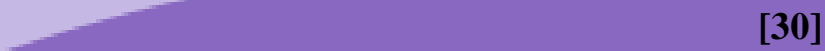


públicas de prevención, así como la concienciación de la población sobre las acciones disciplinarias para esa época del año. Como el clima es más cálido en la segunda mitad del año, hay un número significativamente bajo de casos de dengue.

Palabras Clave: Dengue, Clima, Datos.

\begin{abstract}
Dengue is a public health problem and to combat it, it is necessary to know more and more the factors favorable to its development, proliferation, modes of transmission and other inherent information. Studies have shown that there is a relationship between climatic variables and the increase in the number of dengue cases. In view of this, the present study sought to analyze the relationship between climatic variables and the reported cases of dengue in the municipality of Picos-PI in the period between 2015 and 2019. Data on dengue cases and the climate in Picos, made available by the databases, were used. data from DATASUS and INMET. The research is descriptive and qualitative. It also uses an exploratory analysis of data related to dengue in the municipality in question. Analyzes were made using the Python programming language libraries, and the pandas and matplotlib libraries, where it was possible to manipulate and visualize the application of the algorithm. As a result, it was found that dengue cases are regularly related to climate change in the city of Picos-PI, with a greater incidence in the period between March and June, when climatic conditions are favorable: increased rainfall and relative humidity in the city. air, and the decrease in temperature. In that city, a study reveals a high dengue notification rate in the cold and humid months, suggesting public prevention policies, as well as the population's awareness of disciplinary actions for that time of year. As the climate is warmer in the second half of the year, there is a significant low number of dengue cases.
\end{abstract}

Keywords: Dengue, Climate, Data.

\title{
INTRODUÇÃO
}

Segundo a Organização Mundial de Saúde (OMS), mais da metade da população mundial vive sob riscos de transmissões ou em áreas endêmicas da doença dengue, e isso a torna uma das principais questões da saúde pública no mundo. Os países mais atacados pela doença são os tropicais e subtropicais, nos quais o ambiente climático favorece o ciclo de vida do transmissor (BRASIL, 2015).

A dengue tem como seu principal vetor o mosquito Aedes aegypt, é constituída por quatro sorotipos: DEN-1, DEN-2, DEN-3, DEN-4 e é caracterizada por ser febril aguda.O meio de transmissão é pela difusão da picada do mosquito. A emergência da infecção sob formas de Dengue Clássica, Síndrome de Choque da Dengue e Febre Hemorrágica da Dengue coloca essa virose como um dos casos mais graves de saúde pública das Américas (SECRETARIA DA SAÚDE DO PARANÁ, 2020).

Está presente em 4.318 municípios brasileiros (77\% das cidades brasileiras), tendo seu primeiro caso em 1982, na cidade de Boa Vista, Roraima. Nessa época, o Brasil atingiu uma elevada endemia, em virtude do rápido contato do vetor em um grande alargamento territorial, o que assegurou a circulação do vírus em grandes números de estados e munícios, expondo aos poucos novas populações a infecções (SOUSA; DANTAS; LIMEIRA, 2007).

A contingência da dengue no Brasil e no mundo está relativamente associada à urbanização sem estruturas de saneamento. Este fator contribui com a aglomeração ativa do 
mosquito e também a disseminação dos vários sorotipos da doença. Neste campo de interação entre meio ambiente e saúde, as variáveis climáticas como umidade relativa do ar, temperatura e precipitação pluviométrica podem ser estudadas para verificar sua associação a doença da dengue.

Neste contexto, esta pesquisa tem como objetivo analisar as relações entre as variáveis climáticas com os casos notificados de dengue no município de Picos-PI no período entre 2015 e 2019, visando o aprimoramento da vigilância e controle da doença no município. Para isso, foram identificados a disseminação de casos da dengue no município de Picos-PI, as variáveis meteorológicas no referido período, e a relação que elas tem em comum.

\section{FUNDAMENTAÇÃO TEÓRICA}

A dengue é um vírus de genoma RNA (Ácido ribonucleico) e a doença é transmitida pelo mosquito vetor fêmea Aedes aegypti, da família Flaviviridae. Apresenta quatro sorotipos conhecidos (DEN-1, DEN-2, DEN-3, DEN-4). É uma doença infecciosa que pode causar desde pequenas infecções assintomáticas e febres constitucionais até formas mais graves que pode ocasionar a morte, como manifestações hemorrágicas. É considerada a arbovirose mais importante que afeta ao homem e é um problema de saúde mundial. Sua convivência com o ser humano é favorecida pelo uso de recipientes artificiais no seu desenvolvimento, condição que torna o vírus predominantemente urbano (SECRETARIA DA SAÚDE DO PARANÁ, 2020).

O primeiro caso de dengue no Brasil, aconteceu no ano de 1982, na cidade de Boa Vista, Roraima, mas, somente em 1986 foi conceituada como epidemia explosiva e atingiu todas as regiões brasileiras. Nessa ocasião, o país alcançou um alto índice endêmico, pois, o vetor se dispersou de forma rápida em grande extensão territorial. Isso ocasionou uma circulação do vírus em maior número de estados e municípios, exibindo novas populações às infecções (SOUSA; DANTAS; LIMEIRA, 2007).

Conforme o relato do Ministério da Saúde (2015), através do Plano de Contingência Nacional para Epidemias da Dengue, no Brasil o padrão epidemiológico vai se alterando conforme o passar dos anos. Primordialmente, era comum os casos de dengue acontecer em pessoas adultas e jovens. Entre 2007 e 2009 foi alterado esse resultado, aumentando as formas graves principalmente em crianças.

No Brasil, a dengue se manifesta de modo sazonal, ocorrendo na maioria dos casos entre os meses de outubro e maio, sendo menos frequente entre dezembro e março. Este período é perceptível na maioria dos estados. A incidência sobe significativamente nos 
primeiros meses do ano, alcançando maior destaque de março a maio, seguida de uma redução considerável dos casos a partir de junho.

Pena (2020), retrata que o clima é o resultado de toda espécie de fenômenos meteorológicos específicos, que definem a situação média da atmosfera, em uma determinada região da superfície terrestre. As variações climáticas interferem diretamente no processo saúde-doença, provocando impactos positivos e negativos na qualidade de vida e de saúde das populações.

Os fatores climáticos são estudados, para que possam ser deduzido hipóteses de causalidade quanto a algum fator de risco cuja permutação na natureza dependa da variação de algum fator climático. (MINISTÉRIO DA SAÚDE, 2020). O que mais tem influência nas comunidades biológicas são os aspectos climáticos: umidade relativa do ar, temperatura e precipitação pluviométrica.

As epidemias da dengue estão relacionadas com as flutuações climáticas, pois se tratam de arbovirose (doenças causadas pelo vírus da dengue, zika vírus, febre chinkungunya e febre amarela), e os aspectos climáticos estão associados a sobrevivência e reprodução de vetores. Moore (1985), identificando a grandeza de relações entre Aedes aegypti e a fatos climáticos, apresentou que a temperatura não foi uma boa referência de abundância larval, porém o volume e o número de dias com chuva podem constituir preditores úteis de sua abundância. Segundo Reiter (1988), isso geralmente é válido, todavia, deve-se considerar que as taxas de infecção viral no vetor também variam com as condições climáticas.

A temperatura ambiente tem ligação com o tamanho da população, período de maturação, atividade de alimento com sangue da fêmea Aedes aegypti e a taxa de sobrevivência do vetor da dengue. A temperatura abala o comportamento do vírus no vetor. A maturação e replicação do vírus no inseto são rápidas com o aumento da temperatura, aumentando assim, a analogia de vetores no ambiente e sua aplicação na transmissão do vírus, ampliando a magnitude das epidemias (HALES; WET; MAINDONALD; WOODWARD, 2002).

De maneira contrária, a temperatura ambiente não é proporcional ao tempo de aumento do Aedes aegypti para a fase adulta, porém, acima de $40^{\circ} \mathrm{C}$ a expectativa de vida do mosquito amortece. As taxas máximas de sobrevivência estão presente na faixa de $20^{\circ}$ a $30^{\circ} \mathrm{C}$, no entanto, o vetor sobrevive acima $\operatorname{dos} 30^{\circ} \mathrm{C}$ com um mínimo de impacto (PATZ; MARTENS; FOCKS; JETTEN, 1998).

Segundo Yasuno e Tonn (1990), as temperaturas máximas, mínimas e médias durante o dia foram testadas como preditivos para disseminação sazonal de dengue, e a temperatura 
mínima mostrou ser o melhor pressagiador. As temperaturas mínimas levam a decadência da taxa de repasto sanguíneo, abaixando a taxa de contato entre mosquitos e humanos, o que pode atingir a taxa de transmissão viral. Elas aparentam ser críticas para a continuidade do mosquito e a propagação da população vetorial.

A temperatura mínima limiar para a pertinência do vírus da dengue foi considerada em $11.9^{\circ} \mathrm{C}$, e o vírus não é ampliado no vetor quando a temperatura está inferior a $18^{\circ} \mathrm{C}$. Em temperaturas muito baixas, o crescimento viral é mais lerdo e o mosquito não sobrevive tempo bastante pra se tornar infeccioso e transmitir o vírus (HALES; WET; MAINDONALD; WOODWARD, 2002).

A umidade relativa do ar é a combinação da quantidade de água existente no ar e da quantidade máxima que poderia conter na mesma temperatura. Simplificando, ela é o total de água em forma de vapor existente na atmosfera no momento, em relação ao total máximo que poderia existir na temperatura analisada. Ela é um dos indicadores usados na meteorologia para saber como o tempo se comportará (fazer previsões). A umidade do ar é mais baixa no final do inverno e início da primavera (CENTRO DE GERENCIAMENTO E DE EMERGÊNCIAS CLIMÁTICAS, 2020).

De acordo com o InfoEscola (2006), dependendo da temperatura, ocorre uma variância na umidade relativa do ar. A $0^{\circ} \mathrm{C}$, a umidade relativa do ar é de $4,9 \mathrm{~g} / \mathrm{m}^{3}$, e a $20^{\circ} \mathrm{C}$ é de $17,3 \mathrm{~g} / \mathrm{m}^{3}$. Varia também de acordo com a presença ou não de florestas ou vegetação, rios e represas, e à queda da temperatura.

A umidade relativa atinge a existência do vetor, tanto na fase de ovo como na forma adulta. A concordância de umidade e calor toma força com a junção de hábitos alimentares e atração entre os mosquitos (LIANG; HUALIAN; WEIZHONG; JIMIN; QIYONG, 2009). Na época em que a umidade no ambiente é relativamente baixa, pode beneficiar a fêmea do mosquito na procura de humanos para alimentação, proporcionando a transmissão da doença.

O índice pluviométrico é o resultado do somatório da quantidade da precipitação de água em um determinado local durante um período de tempo. Existem três diferentes causas da formação de chuva, e todas tem a ver com a ascensão de massa de ar quente e úmida na atmosfera.

A primeira causa é a Precipitação Orográfica, que ocorre quando uma massa de ar quente e úmida se move ao longo de uma região.

A segunda é a Precipitação Convectiva, que resulta como uma massa de ar instável e se eleva na atmosfera a partir de uma área que se aqueceu.

A última é a Precipitação Frontal que resulta do confronto entre duas grandes massas 
de ar, uma massa quente e outra massa fria. Se a massa fria é a que avança, o resultado é uma frente fria; se a quente avança, uma frente quente se desenvolve (OLIVEIRA, 2020).

O aumento da precipitação ocasionaria o acréscimo no número de locais para a reprodução das larvas do vetor da dengue, devido ao acúmulo de água. Todavia, chuva em excesso poderia eliminar o habitat por causa das enchentes, o que resultaria a diminuição da população vetorial. (PATZ; MARTENS; FOCKS; JETTEN, 1998). Níveis de chuva muito baixos leva o acúmulo de água em reservatórios que podem também ser geradores. Nesse caso, a precipitação poderá ou não ser relacionada com a doença conforme as características locais.

A Ciência de Dados inclui vários elementos e baseia-se em teorias e técnicas derivadas de vários campos da engenharia e da ciência. A Ciência de Dados surge como ingrediente cada vez mais importante em várias áreas, tais como saúde, financeira, astronomia, bioinformática, segurança digital e entre outros (PORTO; ZIVANI, 2014). Ela permite aplicar técnicas com finalidade de descoberta de padrões como também de descoberta de conhecimento através de bases de dados.

Pode-se enumerar os passos para o processo de descoberta correspondendo às etapas deste processo, que são: seleção, pré-processamento, transformação, mineração, interpretação e avaliação.

Figura 01: Processo de descoberta de conhecimento em base de dados.

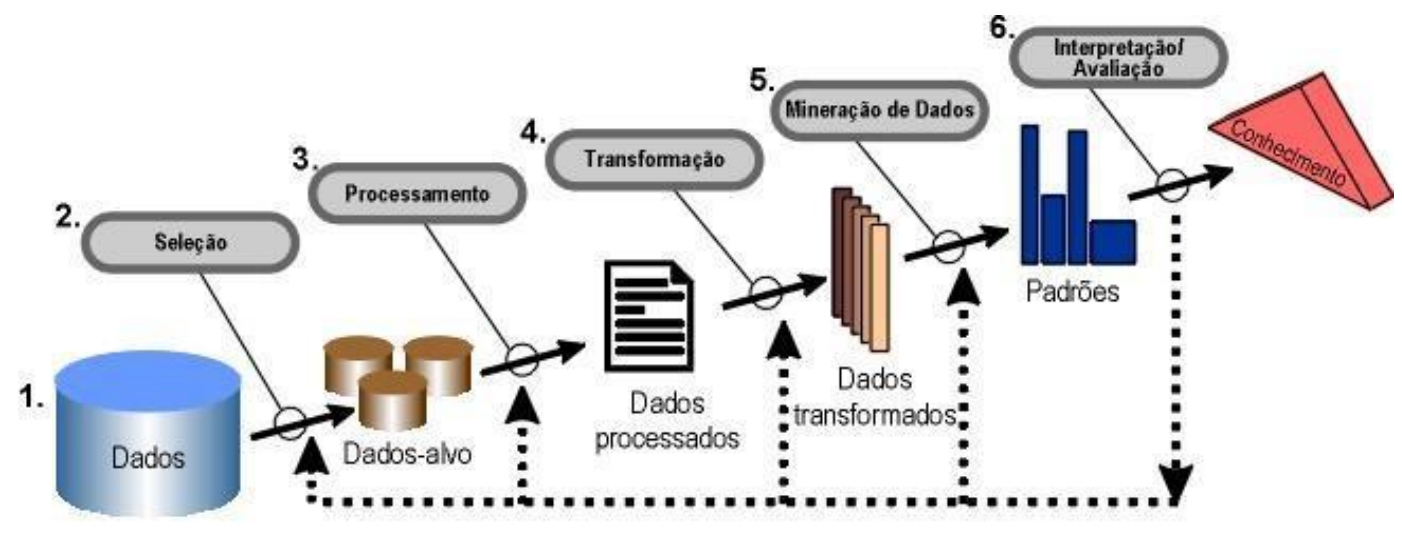

Fonte: Loureiro, et al. (2014).

1 - Compreender o domínio do conhecimento importante e dos objetivos do usuário.

2 - Criar o conjunto de dados para a utilização através da seleção dos dados ou atributos relevantes (seleção).

3 - Pré-processar os dados, limpeza e remoção de ruído e desvios, estratégia de correção de dados desconhecidos ou faltantes, normalização, remoção de atributos 
numéricos de documentos e logs (pré-processamento).

4 - Reduzir e projetar novamente os dados, isto pode ser atuado através da seleção de atributos relevantes para representar melhor os dados sem perda de precisão, constantemente dependendo do objetivo a ser atingido (transformação).

5 - Definir o método de mineração considerando o objetivo do processo (classificação, regressão, agrupamento).

6 - Estabelecer os algoritmos de mineração de dados com base no objetivo geral e na estrutura imposta aos dados. A definição dos algoritmos envolve a escolha de modelos, parâmetros e formas de execução.

7 - Minerar os dados em busca de amostras de interesse usando algoritmos e dados selecionados (mineração).

8 - Interpretar os resultados e avaliar os padrões e regras achados pelo processo de mineração. (interpretação).

9 - Avaliar os conhecimentos adquiridos, documentação e elaboração de relatórios (avaliação) (NETO, 2019).

A análise das características presentes em um dado conjunto de dados, possibilita o descobrimento de padrões e tendências comportamentais que podem apresentar informações sobre os processos que os gerou. Muitas informações podem ser obtidas por simples estatísticas, outras através de técnicas de visualização de dados (HAN; KAMBER, 2011).

O pré-processamento de dados é um conjunto de técnicas de mineração de dados utilizadas para transformar dados brutos em modelos úteis e eficientes. Existem três principais passos que envolvem este processo: limpeza de dados, transformação de dados e redução de dados. A limpeza de dados se enquadra com o manuseio ou preenchimento de dados ausentes, redução de ruídos, identificação e remoção de valores aberrantes e a resolução de inconsistências. A transformação de dados é realizada para transformar os dados originais em modelos mais apropriados e adequados para o processo de mineração. E a redução de dados é usada para enfrentar o grande volume de dados (DATA GEEKS, 2020).

Este conjunto de técnicas se torna um processo semiautomático, pois entende-se que essa fase necessita da capacidade do analista de dados em identificar os problemas que estão presentes nos dados, como também a natureza desses problemas com o objetivo de utilizar os métodos mais apropriados para solucionar cada um dos problemas (BATISTA, 2003).

Batista (2003), ainda destaca que, na fase de normalização dos dados, os valores dos atributos e variáveis são desfigurados de seus intervalos originais para um intervalo específico. Essas transformações são especialmente valiosas para métodos que calculam 
distâncias entre variáveis.

O Python é uma linguagem de programação interpretada, de script, funcional, orientada a objetos, imperativa, de alto nível, de tipagem forte e com semântica dinâmica. É uma das linguagens que mais cresce, devido sua compatibilidade capacidade de auxiliar outras linguagens, e também a linguagem mais utilizada para análise de dados (CAELUM, 2020).

Inicialmente, era comporta por uma comunidade relativamente pequena, de engenheiros e cientistas que usavam o Python para necessidades de computação. Migrou para a utilização do módulo numérico, na qual tratava do desenvolvimento de operações simbólicas que envolviam fatoração de derivadas, integrais e polinômios, como também cálculo de matrizes (MILLMAN; AIVAZIS, 2011). Esta comunidade continuou com o avanço do módulo numérico do Python e começou a desenvolver e compartilhar os pacotes adicionais para a computação científica.

Hoje, códigos científicos requer não somente números, desempenho ou facilidade de uso, mas geralmente precisam de protocolos de rede de suporte, aplicativos baseados na Web, aplicativos baseados em banco de dados, e gráficos sofisticados com interfaces. Esta visão geral argumenta que o Python aumentou com uma pilha de ferramentas desenvolvido especificamente para computação científica e forma um ambiente altamente produtivo para a computação moderna (MILLMAN; AIVAZIS, 2011).

Além dos usuários individuais, o Python é aplicado também em produtos de empresas reais, como o Google e o Yahoo! que o utiliza em serviços de internet, a IBM que o usa para testes de hardware, a Light and Magic que utiliza o Python para produção de animação, entre outras (LUTZ; ASCHER, 2007).

O uso do Python para análise de dados, exploratória e visualização de dados é impreterivelmente comparada com as muitas outras linguagens de programação, como $\mathrm{R}$ e MATLAB. Essa linguagem ganhou destaque tanto em programação de propósito geral quanto como uma linguagem única para criação de aplicações focadas em computação científica e análise de dados (MATOS, 2020).

\section{METODOLOGIA}

Para realização desse trabalho, recorre-se a abordagem quantitativa de pesquisa, na qual é "à linguagem matemática para descrever as causas de um fenômeno, as relações entre variáveis, etc." (FONSECA, 2002, p. 20). Esse tipo de abordagem se concentra na 
objetividade, uma vez que considera que a realidade há de ser compreendida com base na análise de dados. Também aborda a qualitativa, que segundo Pádua (2017), objetivam da densidade às análises dos dados coletados, evidenciando toda a subjetivação do conteúdo para que possa gerar uma discussão crítica e reflexiva sobre o assunto.

O trabalho compreende uma pesquisa descritiva, que segundo Gil (2016, p. 42), "têm como objetivo primordial a descrição das características de determinada população ou fenômeno ou, então, o estabelecimento de relações entre variáveis". Essa abordagem vai além do simples reconhecimento da existência de afinidade entre variáveis, e pretendem ajustar a natureza dessa relação. Também faz parte de um outro tipo, a pesquisa exploratória, que objetiva proporcionar maior coleguismo com o problema, com concepções a torná-lo mais coerente ou a constituir hipóteses (GIL, 2016).

Neste estudo se faz necessário o uso de uma metodologia que consiste em pesquisas utilizando-se referências bibliográficas detalhadas e o levantamento das controversos da dengue. Com esse levantamento, a pesquisa busca detectar relações entre a incidência de casos de dengue e as variáveis climáticas no município de Picos-PI no período entre 2015 e 2019.

O seio desta pesquisa é analisar os dados referente às notificações de casos de dengue, como também dados climatológicos na cidade de Picos-PI.Para a captura dos dados, foi usado como base, os órgãos públicos que são responsáveis por esse armazenamento dos dados e sua divulgação.

Pelo DATASUS (Departamento de Informática do Sistema Único de Saúde do Brasil), através dos boletins epidemiológicos emitidos pela Secretaria de Vigilância em Saúde, a fim de monitorar e investigar doenças específicas sazonais no Brasil, foi possível utilizar os dados de casos notificados de dengue para a tabulação no dataset criado. O DATASUS é alimentado pela investigação de casos de doenças e agravos constantes da lista nacional de doenças de notificação compulsória. A entrada de dados é feita a partir de instrumentos de coleta padronizados, como a Ficha Individual de Notificação (FIN) e a Ficha Individual/de Investigação (FII) (BRASIL, 2008).

Os dados referentes ao clima foram obtidos através do INMET (Instituto Nacional de Meteorologia), por meio do BDMEP (Banco de Dados Meteorológicos para Ensino e Pesquisa). Foi possível selecionar diversas variáveis climáticas no período referido. O INMET provém de informações meteorológicas alcançada por meio de monitoramento, análise e previsão de tempo e de clima, que se fundamentam em pesquisa aplicada, trabalho em parceria e, compartilhamento do conhecimento, com ênfase em resultados práticos e $[38]$ 
confiáveis. O sistema de coleta e distribuição de dados meteorológicos do instituto é dotado de estações de sondagem de ar superior (radiossonda), estações meteorológicas de superfície, e a maior rede de estações automáticas da América do Sul (INMET, 2020).

Os dados foram tratados em conjunto com a etapa de criação da base de dados utilizada, verificando a presença de atributos e valores nulos, como também a formatação dos valores presentes nos dados capturados. Dessa maneira, os dados puderam ser avaliados de maneira inicial, evitando erros de processamento na etapa de análise. As variações climáticas mensais, foram avaliadas por estudo direto e por métodos estatísticos.

Após a seleção das bases de dados utilizadas, os dados foram tabulados e organizados em uma planilha eletrônica contendo 61 linhas referentes aos meses de cada ano e 8 colunas referentes às variáveis analisadas.

Em seguida, os dados foram convertidos para o formato CSV (Valores Separados por Vírgula), pois com esse formato é possível fazer importação e exportação para planilhas e bancos de dados usados em Python, como mostra a Tabela 01 os valores iniciais do arquivo.

Tabela 01: Amostra dos dados utilizados

\begin{tabular}{rrrrrrrr}
\multicolumn{2}{c}{$\begin{array}{c}\text { Evapotranspiracao } \\
\text { Data }\end{array}$} & Insolacao & Precipitacao & TemperaturaMaxima & Temperaturaminima & UmidadeRelativa & CasosDengue \\
\hline $\mathbf{2 0 1 5 - 0 1 - 3 1}$ & 46.600000 & 257.9375 & 46.600000 & 35.98500 & 23.80500 & 50.25000 & 15.0 \\
$\mathbf{2 0 1 5 - 0 2 - 2 8}$ & 91.300000 & 162.6000 & 84.300000 & 34.37800 & 23.59600 & 64.82100 & 13.0 \\
$2015-03-31$ & 54.354052 & 257.9375 & 47.611765 & 35.42586 & 23.07798 & 58.28304 & 64.0 \\
$2015-04-30$ & 74.124000 & 268.1000 & 41.300000 & 33.73600 & 22.35300 & 67.56600 & 205.0 \\
$2015-05-31$ & 32.549000 & 242.7000 & 19.700000 & 34.37700 & 21.95400 & 56.25800 & 97.0
\end{tabular}

Fonte: O autor (2020).

A Tabela 2 descreve os tipos de dados referentes as variáveis utilizadas, a fim de especificar melhor para a análise posteriormente.

Tabela 02: Tipos de variáveis presentes

\begin{tabular}{|c|c|}
\hline VARIÁVEL & UNIDADE DE MEDIDA \\
\hline Data & data (dia/mês/ano) \\
\hline Evapotranspiração & $\mathrm{mm}$ (milímetros) \\
\hline Insolação & hs (horas) \\
\hline Precipitação & $\mathrm{mm}$ (milímetros) \\
\hline TemperaturaMáxima & ${ }^{\circ} \mathrm{C}$ (graus celsius) \\
\hline TemperaturaMínima & ${ }^{\circ} \mathrm{C}$ (graus celsius) \\
\hline UmidadeRelativa & $\%$ (porcentagem) \\
\hline CasosDengue & inteiro \\
\hline \multicolumn{2}{|c}{} \\
\hline
\end{tabular}


Por fim, as análises foram feitas com o auxílio da linguagem de programação Python, junto com algumas bibliotecas, como: pandas e matplotlib.

O município de Picos, está localizado na região centro-sul do Estado do Piauí, situado na Latitude Sul de $7^{\circ} 05^{\prime} 13^{\prime \prime}$ e Longitude Oeste de 41 28' 12", posicionada a 202 metros de altitude, com uma população estimada de 78.222 habitantes, possui área total de $534,7 \mathrm{~km}^{2}$. É a maior produtora de mel do país, ficando em $1^{\circ}$ lugar no ranking nacional (IBGE, 2020). O bioma é a caatinga e apresenta o clima o semiárido, caracterizando uma temperatura média anual de $26.5^{\circ} \mathrm{C}$, com baixa amplitude térmica anual da temperatura média.

Em Picos, a estação com imponderação é quente, abafada e de céu encoberto; a estação seca é muito quente, de ventos fortes e de céu parcialmente encoberto. Ao longo do ano, a temperatura varia de $21^{\circ} \mathrm{C}$ a $39^{\circ} \mathrm{C}$ e raramente é inferior a $20^{\circ} \mathrm{C}$ ou superior a $40^{\circ} \mathrm{C}$. A estação quente é entre setembro e novembro, com temperatura máxima média diária acima de $37^{\circ} \mathrm{C}$. A estação fresca permanece de janeiro a abril, com temperatura máxima diária em média abaixo de $33^{\circ} \mathrm{C}$ (WEATHER SPARK, 2020).

A estação de maior precipitação dura quatro meses, que compreende de dezembro a abril, com probabilidade acima de $27 \%$ de que um determinado dia tenha chuva. Já estação seca dura oito meses, de abril a dezembro. O período chuvoso do ano dura sete meses, de outubro a maio, com precipitação de chuva de 31 dias contínuos, mínima de 13 milímetros. O máximo de chuva ocorre durante os 31 dias ao redor de 16 de março, com acumulação total média de 134 milímetros. O período sem chuva do ano dura cinco, que compreende maio a outubro. O mínimo de chuva ocorre por volta de 17 de agosto, com acumulação total média de 0 milímetro (WEATHER SPARK, 2020).

\section{RESULTADOS E DISCUSSÃO}

Segundo levantamento do período de epidemia da dengue em Picos-PI, foi apurado que, o surto na cidade, geralmente se dá entre os meses de março a junho, e com isso, não segue o mesmo padrão epidemiológico do restante do Brasil, uma vez que o período epidemiológico no Brasil ocorre entre outubro a maio. Essas informações podem ser analisadas a partir das figuras a seguir: 
Figura 02: Comportamento da dengue nos anos de 2015 a 2019 no município de Picos-PI.
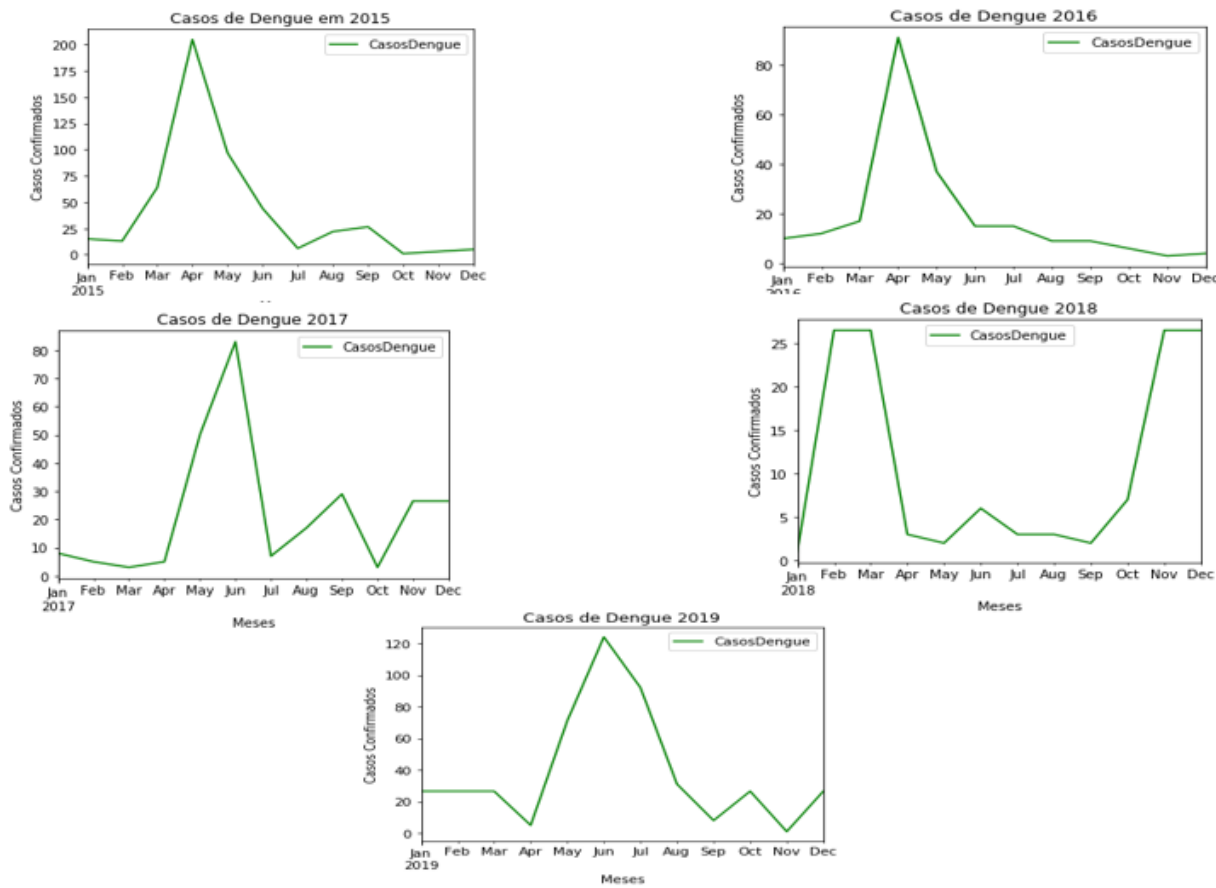

Fonte: O autor (2020).

Em 2018, os níveis apresentados de casos são baixos ou quase nulos, demonstrando que a ocorrência da dengue neste ano não apresentou um comportamento capaz de ser previsto através de uma análise inicial dos dados. Essas características podem estar relacionadas a campanhas governamentais e medidas preventivas adotadas pela população, de modo que não se observou um grande surto neste ano. A imagem anterior, mostra que o período de dengue apresenta um surto frequente entre os anos, destacando-se que os gráficos estão de acordo com a média de cada ano.

A Figura 03, apresenta o comportamento da dengue em um comparativo entre todos os anos analisados, 2015 a 2019.

Figura 03: Comportamento da dengue, em média, nos anos de 2015 a 2019 no município de Picos-PI.

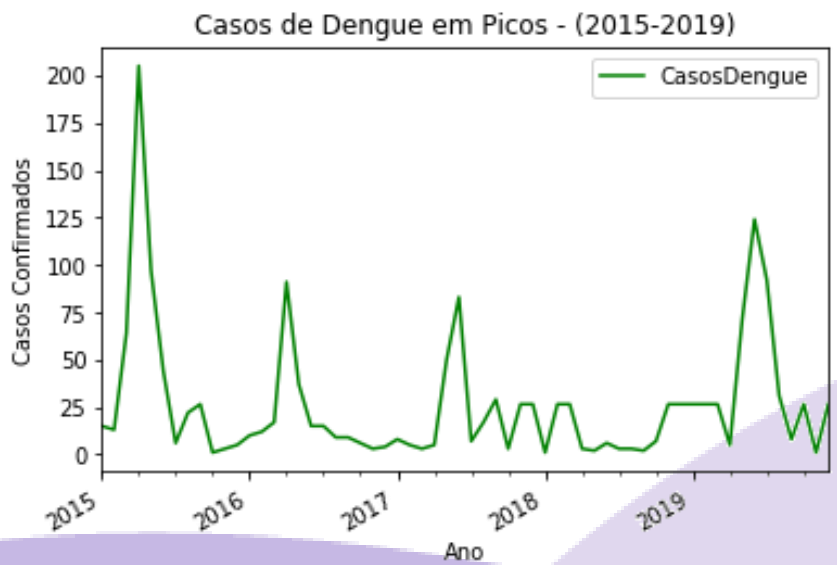

Fonte: O autor (2020). 
Os dados apresentados permitem verificar a curva da incidência da dengue nos anos correspondentes entre 2015 e 2019, onde pode-se concluir que 2015 foi o ano disparado que obteve mais casos e 2019 em sequência.

A Figura 04 abaixo, apresenta a variação dos dados em relação às chuvas durante os meses de cada ano, demonstrando que existe um aumento das chuvas no início do ano e diminuição a partir da segunda metade do ano. No período em 2018, houve uma quantidade considerável na queda das chuvas, isso induz as baixas notificações significativas de casos de dengue no município nesse período.

Figura 04: Comportamento das chuvas (mm), nos anos de 2015 a 2019 no município de Picos-PI.

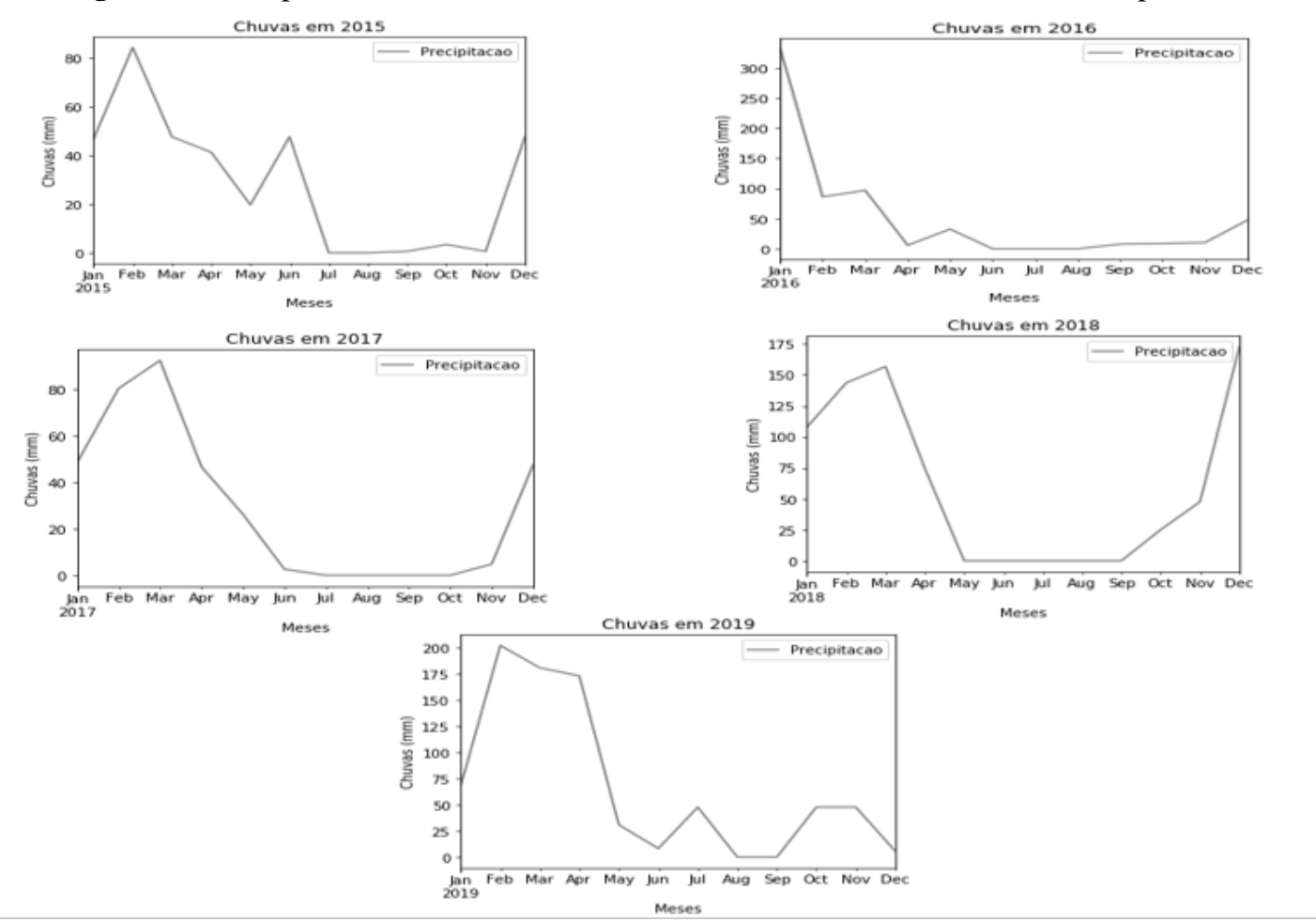

Fonte: O autor (2020).

O período correspondente entre maio e outubro apresenta poucas chuvas, e este período é o de menor incidência da dengue na cidade. Esse agente não é observado em outros estados do Brasil onde a estação de grandes incidências da dengue combina com o período chuvoso, segundo o Ministério da Saúde (FARHAT, 2003).

A umidade relativa do ar tem relação direta com a propagação da dengue, estando diretamente ligada aos padrões da doença. Na Figura 05, é constatado a variação média durante o período de estudo, apresentando de maneira também semelhante ao padrão de distribuição do comportamento da dengue. 
Figura 05: Relação da dengue coma umidade relativa do ar (\%), nos anos de 2015 a 2019 no município de Picos-PI.

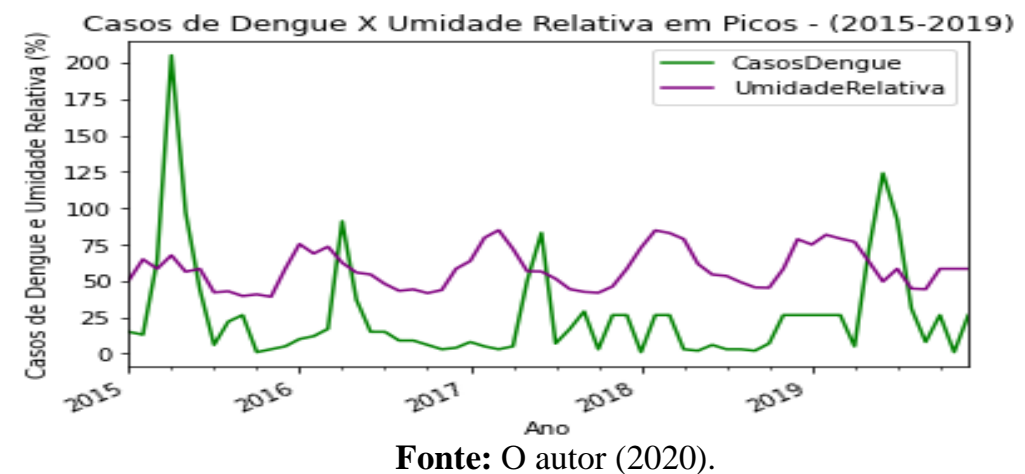

Outro fator que atenua a propagação da dengue é a temperatura. Na Figura 06, vê-se a variação média da temperatura máxima no decorrer de todos os anos analisados e a variação média da temperatura mínima no mesmo período. É possível notar que a medida em que passa os meses, a temperatura mínima e máxima decai no primeiro semestre, e voltam a subir a partir do segundo semestre do ano. Esta relação é inversa à da umidade, que tem seu aumento na primeira parte do ano e decréscimo a partir do segundo semestre. Logo, conforme a temperatura abaixa, a umidade relativa do ar aumenta.

Figura 06: Temperaturas máximas e mínimas $\left({ }^{\circ} \mathrm{C}\right)$, nos anos de 2015 a 2019 no município de Picos-PI.
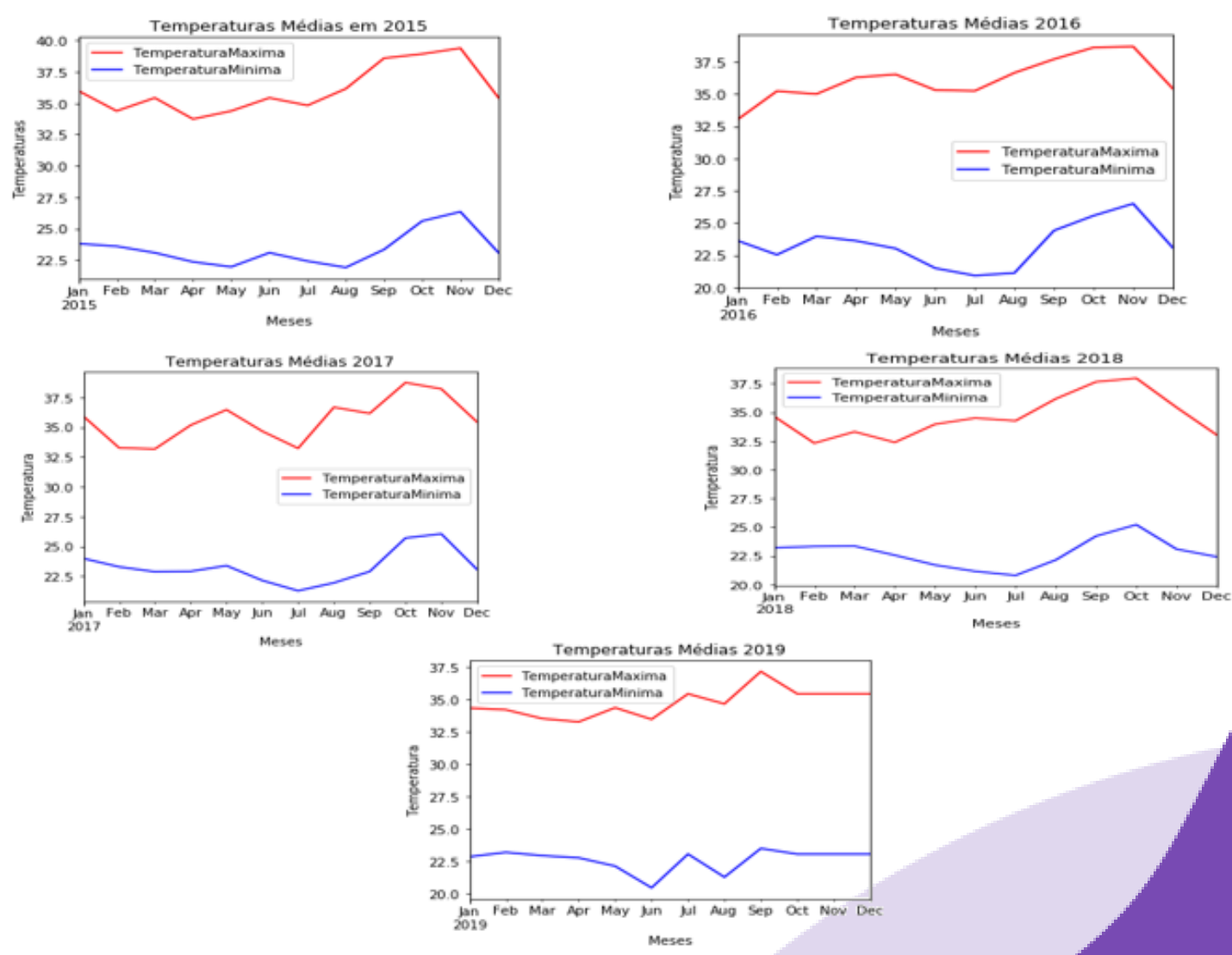

Fonte: O autor (2020). 
É visto, através da imagem anterior, que a dengue possui um comportamento relativo durante o primeiro semestre do ano, em que os casos aumentam na condição da diminuição da temperatura, aumento da chuva e aumento da umidade.

\section{CONCLUSÕES}

Através dessa pesquisa, foi possível perceber que a dengue possui padrões comportamentais complexos no município de Picos-PI, tornando o reconhecimento de relações entre as variáveis climatológicas e os casos de dengue difícil. A análise de dados mostra que a dengue apresenta um comportamento distinto na cidade de Picos, pois os fatores climatológicos demonstraram dados específicos do município, visto que as mudanças climáticas variam de maneira diferente do restante do Brasil.

Verificou-se que, os casos de dengue estão relacionados regularmente com as variações da temperatura, precipitação e umidade relativa do ar, tendo como fatores principais a alta da chuva, a alta da umidade relativa do ar, e, a queda da temperatura durante o ano, permitindo concluir que o período de maior propagação da dengue é entre maio e junho. Aguarda-se uma melhor compreensão que possa ajudar a entender e antecipar processos complexos e indiretos. A mudança global do clima, políticas públicas de combate à dengue e, medidas de prevenção da população se tornam eficientes nesse momento.

De modo geral, as mudanças climáticas de precipitação, umidade relativa do ar e temperatura podem influenciar o comportamento e a distribuição dos vetores transmissor, alterando assim, a incidência de doenças transmitidas por vetores. Ressalta-se também que, não se pode admitir que o clima seja fator único que afete a transmissão da dengue. Todavia, ainda existe grandes diferenças fundamentais entre uma abordagem baseada em dados e uma abordagem baseada em cenário.

Por fim, fica esclarecido que mesmo sendo uma doença que está fortemente relacionada às mudanças climáticas, a dengue pode ser influenciada por diversos outros aspectos, como fatores ambientais, sociais e populacionais. As políticas públicas de saúde para o combate e erradicação da doença podem influenciar na maneira como os padrões epidemiológicos se comportam, tendo como foco os programas e atividades de conscientização da população, modificando o comportamento dos dados dos casos de dengue no município de Picos.

\section{O dataset e os códigos utilizados podem}




\section{REFERÊNCIAS}

BATISTA, Gustavo Enrique de Almeida Prado Alves. Pré-processamento de dados em aprendizado de máquina supervisionado. 2003. 231 f. Tese (Doutorado) - Curso de Instituto de Ciências Matemáticas e de Computação, Instituto de Ciências Matemáticas e de Computação, São Carlos, 2003.

BRASIL. Ministério da Saúde. Secretaria de Vigilância em Saúde. Departamento de Vigilância das Doenças Transmissíveis. Plano de Contingência Nacional para Epidemias de Dengue / Ministério da Saúde, Secretaria de Vigilância em Saúde, Departamento de Vigilância das Doenças Transmissíveis. - Brasília: Ministério da Saúde, 2015. 42 p.

BRASIL. MINISTÉRIO DA SAÚDE. VIGILÂNCIA EM SAÚDE: Dengue, Esquistossomose, Hanseníase, Malária, Tracoma e Tuberculose. 2. ed. Brasília: Ministério da Saúde, 2008. 119 p.

Condições meteorológicas médias de Picos Brasil. Weather Spark, 2020. Disponível em: $<$ https://pt.weatherspark.com/y/30826/Clima-caracter\%C3\%ADstico-em-Picos-Brasildurante-o-ano>. Acesso em 17 de jun. de 2020.

FARHAT, R. Dengue: Brasil prepare-se para a batalha. InformeSaúde, v. 7, n. 196, 2003.

FONSECA, J. J. S. Metodologia da pesquisa científica. Fortaleza: UEC, 2002.

GIL, Antônio Carlos. Como elaborar projeto de pesquisa. São Paulo: Atlas, 2016.

GOMES, Pedro Cesar Tebaldi. Conheça as etapas do pré-processamento de dados. Datageeks, 2019. Disponível em: <https://www.datageeks.com.br/pre-processamento-dedados/>. Acesso dia 23 de maio de 2020.

HAN, Jiawei; KAMBER, Micheline. Data Mining: Concepts and Techniques. 2. ed. São Francisco: Elsevier, 2006.

INSTITUTO BRASILEIRO DE GEOGRAFIA E ESTATÍSTICA (IBGE). Cidades: Picos, Piauí, 2018. Disponível em <https://cidades.ibge.gov.br/brasil/pi/picos/panorama>. Acesso em: 17 mai. 2020.

INSTITUTO NACIONAL DE METEOROLOGIA (INMET). Precipitação Nacional de Meteorologia, 2020. Disponível em < http://www.inmet.gov.br/portal/>. Acesso em: 18 jun. 2020.

J.A. Patz, WJ Martens, D.A. Focks, and T.H. Jetten. Dengue fever epidemic potential as projected by general circulation models of global climate change. Environmental Health Perspectives, 106(3):147, 1998.

L. Liang, L. Hualiang, T. Linwei, Y. Weizhong, S. Jimin, and L. Qiyong. Time series analysis of dengue fever and weather in Guangzhou, China. BMC Public Health, 9, 2009.

LOUREIRO et al. Indução de árvores de decisão na descoberta de conhecimento: caso de 
empresa de organização de eventos. IV Congresso Internacional de Casos Docentes de Marketing Público e Não Lucrativo, 2014. Disponível em: $<$ https://www.researchgate.net/figure/Figura-2-Processo-de-descoberta-de-conhecimento-embases-de-dados_fig1_270449012>. Acesso dia: 10 de jun. de 2020.

LUTZ, Mark; ASCHER, David. Aprendendo Python. 2 ed, Porto Alegre: Bookman, 2007.

MATOS, David. R ou Python para Análise de Dados? Ciência de dados, 2020. Disponível em:< http://www.cienciaedados.com/r-ou-python-para-analise-de-dados/>. Acesso em: 29 de maio de 2020.

MELLOR, P.S.; LEAKE, C.J. Climatic and geographic influences on arboviral infections and vectors. Revue Scientifique Et Technique de L'oie, [s.1.], v. 19, n. 1, p.41-54, 1 abr. 2000. O.I.E (World Organisation for Animal Health). http://dx.doi.org/10.20506/rst.19.1.1211.

MILLMAN, K. Jarrod; AIVAZIS, Michael. Python for Scientists and Engineers. Computing In Science \& Engineering, [s.1.], v. 13, n. 2, p.9-12, mar. 2011. Institute of Electrical and Electronics Engineers (IEEE). http://dx.doi.org/10.1109/mcse.2011.36.

Mudanças Climáticas. Ministério de Saúde, 2020. Disponível em: $<$ https://www.saude.gov.br/vigilancia-em-saude/vigilanciaambiental/vigidesastres/mudancasclimaticas>. Acesso dia 21 de maio de 2020.

NETO, José Trajano Mendes. Utilização da ciências de dados para identificação da relação entre fatores climáticos e a incidência de casos de dengue no município de PatosPB. Trabalho de conclusão de curso (graduação) - Universidade Estadual da Paraíba, Patos PB, 2019.

OLIVEIRA, Aureo S. de. Precipitação Pluviométrica. In: OLIVEIRA, Aureo S. de. Fundamentos de Meteorologia e Climatologia. NEAS/UFRB. Cap. XI. Disponível em: <www.ufrb.edu.br > 8-cca-035-meteorologia-e-climatologia-agricola >. Acesso en $20 \mathrm{de}$ maio de 2020.

O que é Python. CAELUM, 2020. Disponível em: < https://www.caelum.com.br/apostila-pythonorientacao-objetos/o-que-e-python/\#null>. Acesso em: 29 de maio de 2020.

PÁDUA, Elisabete Matallo Marchesini de. Metodologia da pesquisa: abordagem teóricoprática. 20 ed. Campinas, SP: Papirus, 2017. 97 p. (Coleção Magistério: formação e trabalho pedagógico).

PORTO, F. A. M; ZIVIANI, A. Ciência de Dados. In: 3o. Seminário de Grandes Desafios da Computação no Brasil, 2014, Rio de Janeiro, RJ. Anais do 3o. Seminário de Grandes Desafios da Computação, 2014.

S. Hales, N. de Wet, J. Maindonald, and A. Woodward. Potential effect of population and climate changes on global distribution of dengue fever: an empirical model. The Lancet, 360(9336):830-834, 2002.

SOUSA, Nadja Maria Nascimento; DANTAS, Renílson Targino; LIMEIRA, Rodrigo Cézar. Influência de Variáveis Meteorológicas Sobre a Incidência Do Dengue, Meningite e Pneumonia em João Pessoa-Pb. Revista Brasileira de Meteorologia, 2007. São José dos 
Campos - SP, v.22, n.2, p. 183-192, agosto de 2007.

Umidade relativa do ar. Centro de Gerenciamento de Empresas Climáticas da Prefeitura de São Paulo. Disponível em: 〈https://www.cgesp.org/v3/umidade-relativa-do-ar.jsp>. Acesso em: 21 de maio de 2020.

(Vigilância Ambiental - Vetores) Informações Básicas - Dengue. Secretaria da Saúde do Paraná, 2020. Disponível em:

<http://www.saude.pr.gov.br/modules/conteudo/conteudo.php?conteudo=370>. Acesso em: 8 de mar. 2020. 


\title{
CAPÍTULO 04: TECHNO PODCAST: FERRAMENTA PARA O ENSINO- APRENDIZAGEM SIGNIFICATIVO
}

\section{CAPÍTULO 04: TECHNO PODCAST: HERRAMIENTA PARA LA ENSEÑANZA- APRENDIZAJE SIGNIFICATIVA}

\author{
CHAPTER 04: TECHNO PODCAST: MEANINGFUL TEACHING-LEARNING \\ TOOL
}

Geórgia Carin Martins da Silva' José Ailson Dantas Queiroz Junior²; Leidivânia Mendes de Araújo Melchuna; Joel de Oliveira Santos ${ }^{4}$

DOI: https://doi.org/10.31692/978-65-88970-06-5.48-61

\begin{abstract}
RESUMO
Este artigo relata um estudo de caso realizado no Centro Estadual de Educação Profissional Professora Lourdinha Guerra (CEEP PLG), a fim de compreender se a comunidade escolar conhece o funcionamento do computador e principalmente em relação aos Hardwares que o compõem, tendo em vista que, diariamente, alunos e professores que precisam utilizar algum aparelho dentro de sala de aula passam por grandes dificuldades quando é necessário conectar ou manusear esses objetos e não entendem o funcionamento dos mesmos. Desse modo, precisando recorrer a alguém dentro da escola que possua o conhecimento básico da área de informática, para solucionar um simples problema que qualquer pessoa poderia resolver caso tivesse o mínimo de conhecimento sobre Hardwares. Sendo assim, foi criada uma pesquisa, com o objetivo de verificar as dificuldades em relação ao uso do computador, após isso, foi avaliada também a possibilidade da utilização de podcast nas escolas para auxiliar nesse processo de aprendizagem. Os entrevistados assistiram ao podcast e tiveram a oportunidade de avaliá-lo de acordo com o entendimento de cada um em relação ao conteúdo mostrado, a nota média da avaliação foi de 7,6. Para subsidiar o trabalho, os principais embasamentos teóricos foram pautados nos estudos de Bottentuit, et al (2007), Lopes (2002) e Bolzam (1998). Diante do resultado, foi possível notar que a maioria dos alunos e dos funcionários conseguiu responder corretamente às questões, porém, a quantidade de erros relacionados a algumas questões específicas foi preocupante, visto que a maioria dos entrevistados são alunos da $3^{\text {a }}$ série, portanto estão prestes a sair da instituição. Por fim, vale ressaltar que, ao final da avaliação, os participantes constataram que o uso do podcast é viável na instituição, possibilitando, assim, novas formas de aprendizado.
\end{abstract}

Palavras-Chave: Hardware, Podcast, Tecnologia da Informação e Comunicação.

\section{RESUMEN}

Este artículo reporta un caso práctico realizado en el Centro Estatal de Educación Profesional Profesora Lourdinha Guerra (CEEP PLG), con el fin de comprender si la comunidad escolar conoce el funcionamiento de la computadora y especialmente en relación a los Hardwares que la componen, teniendo dado que, diariamente, los alumnos y profesores que necesitan utilizar algún dispositivo en clase experimentan grandes dificultades cuando es necesario conectar o manipular estos objetos y no comprenden el funcionamiento de los mismos. Por lo tanto, necesitan recurrir a alguien en la escuela que tenga los conocimientos básicos del área de informática, para lograr un resoluto simple que cualquiera podría resolver si tuviera los conocimientos mínimos sobre Hardware. Por lo tanto, se creó una investigación, con el objetivo de verificar las dificultades en relación con la computadora, después

\footnotetext{
1 Técnico em Informática, Centro Estadual de Educação Profissional Professora Lourdinha Guerra/RN, georgiacarin@gmail.com

2 Técnico em Informática, Centro Estadual de Educação Profissional Professora Lourdinha Guerra/RN,, jose.ailsun@gmail.com

3 Mestra em Letras, Centro Estadual de Educação Profissional Professora Lourdinha Guerra/RN leidivaniamel@gmail.com

${ }^{4}$ Pós-graduando em Tecnologias Aplicadas à Educação, Centro Estadual de Educação Profissional Professora Lourdinha Guerra/RN, joeloliveira56@gmail.com
}

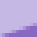


de eso, también se evaluó la posibilidad de utilizar un podcast en las escuelas para ayudar en este proceso de aprendizaje. Los entrevistados vieron el podcast y tuvieron la oportunidad de calificarlo de acuerdo con la comprensión de cada uno sobre el contenido exhibido, la calificación promedio fue de 7.6. Para sustentar el trabajo, los principales fundamentos teóricos se basaron en los estudios de Bottentuit, et al (2007), Lopes (2002) y Bolzam (1998). A la vista del resultado, se pudo notar que la mayoría de los estudiantes y empleados fueron capaces de responder correctamente las preguntas, sin embargo, la cantidad de errores relacionados con algunas preguntas específicas fue preocupante, ya que la mayoría de los entrevistados son estudiantes de tercer grado, por lo que están a punto de salir de la institución. Finalmente, cabe mencionar que, al finalizar la evaluación, los participantes encontraron que el uso del podcast es factible en la institución, posibilitando, así nuevas formas de aprendizaje.

Palabras Clave: Hardware, Podcast, tecnología de la información y comunicación.

\section{ABSTRACT}

This presente article relate a case study accomplished in Centro Estadual de Educação Profissional Professora Lourdinha Guerra (CEEP PLG), in order to understand if the school community knows how the computer works and mainly in relation to hardwares that make it up, given that, daily students and teachers that need to use some device inside the classroom go through difficulties when is necessary connect and handle these objects and don't understand the behavior from them. Thus needing to resort to someone inside the school who has the basic knowledge in the informatic área, to solve a simple problem that anyone could settle in case he had the minimum knowledge about hardwares. Therefore was created a research, with the objetive to check the difficulties in relation to the use of the computer, after that, was also evaluated the possibility of using podcasts in schools to help in the learning process. The interviewess watched to the podcast and had the opportunity to rate it according to the understanding of each one in relation to the content shown, the average grade was 7,6. To subsidize the article the main theorical foundations were guided in studies of Bottentuit, et al (2007), Lopes (2002) e Bolzam (1998). Before the result, it was possible to notice that most students and staff managed to answer correctly to the questions, but, the amount of errors related to some specific questions it's worrying, since most respondents are third grade students, therefore are about to leave the institution. Lastly, it is worth mentioning that at the end of the evaluation, the participants consisted that using the podcast it's viable in the institution, thus enabling new forms of learning.

Keywords: Hardware, Podcast, Information and Communication Technology.

\section{INTRODUÇÃO}

Ao longo dos anos, conseguimos perceber que a tecnologia vem tomando conta de diversas atividades do nosso cotidiano, seja no acesso a internet ou até mesmo no simples manuseio de um smartphone ou computador. Ainda assim, mesmo com o avanço contínuo da tecnologia, muitas pessoas não possuem conhecimento adequado sobre o dispositivo que elas utilizam diariamente.

Essa realidade pode ser constatada pelo fato da tecnologia evoluir de forma contínua e rápida atrapalhando um pouco o processo de imersão das pessoas na tecnologia atual. Outro ponto é em relação à inclusão digital no Brasil. A Pesquisa Nacional por Amostra de Domicílios Contínua - PNAD Contínua - IBGE (2018) constatou que ainda é grande o número de brasileiros sem acesso à internet e meio digitais e os principais motivos em relação

a essa ausência são a falta de conhecimento para saber usar, desinteresse e serviço indisponível. 
No contexto escolar é possível notar que já existe a inserção tecnológica a partir do uso do computador, data show e etc, porém nem sempre esses recursos são utilizados da forma mais adequada, a tecnologia pode estar disponível mas em suma maioria por falta de conhecimento sobre como manusear deixa de ser utilizado. Até mesmo em escolas técnicas, conseguimos perceber nitidamente a deficiência de alunos e funcionários quanto ao funcionamento básico do computador.

Como FRÓES (1998) aborda em seu artigo sobre Educação e Informática, a "Relação Homem/Máquina e a Questão da Cognição", a tecnologia afeta o homem e é vista como extensões de seu corpo, muda seus hábitos, transforma-o de maneira social e cultural e, claro, facilita suas ações cotidianas. Nesse sentido, ela é importante para a formação do indivíduo e é imprescindível que o ser humano tenha, pelo menos, uma base para conseguir viver na sociedade informatizada.

Dessa forma, o grande avanço da tecnologia requer que nós devemos aprender a como manusear os aparelhos tecnológicos para que possamos usufruir das suas capacidades de ajudar os alunos e professores no âmbito escolar.

\footnotetext{
“O ambiente de modernização tecnológica e de novas conquistas científicas no setor produtivo tem provocado, no âmbito das instituições (públicas ou privadas), a necessidade de recursos humanos com maiores conhecimentos e habilidades para atuar dentro dos novos processos organizacionais e para compreender e operar tecnologias com alta agregação de informática". (BOLZAN,1998. p. 1)
}

Como apontado por Bolzan 1998, em seu artigo, é notório que existe uma deficiência sobre informática nos âmbitos escolares, grande parte da comunidade acadêmica não têm conhecimento sobre a informática básica, por isso, temos que nos permanecer informados sobre as mudanças constantes na área, para que não nos tornemos "analfabetos" nessa área tão importante para a nossa vivência.

Diante desse contexto, decidimos aplicar um questionário entre os alunos e os funcionários, com o objetivo de descobrir em que parte da área de informática essas pessoas do CEEP Professora Lourdinha Guerra possuem mais dificuldade de entendimento. Obtendo essas informações, foi organizado um podcast explicando o funcionamento das principais ferramentas tecnológicas utilizadas no cotidiano, sendo uma possível solução para o problema na conclusão do trabalho. Ao fim, podemos notar como a maioria das pessoas não possuem o básico do conhecimento tecnológico mesmo estando cercadas por objetos eletrônicos. 


\section{FUNDAMENTAÇÃO TEÓRICA}

\section{A informática no contexto escolar}

A tecnologia vem adquirindo um papel primordial na formação da sociedade nos dias de hoje e é de extrema importância que ela seja implementada no ambiente escolar. Essa está inserida basicamente através da informática como um instrumento de apoio para as outras matérias da grade comum e com o principal objetivo de preparar o estudante para um âmbito social informatizado (LOPES, 2002). Isso pode ser notado, ao analisar o Censo Escolar (INEP 2018), em que $81,8 \%$ das escolas estaduais possuem acesso a laboratórios de informática e $93,5 \%$ à internet. Entretanto, esses recursos nem sempre são utilizados como deveriam, visto que muitas vezes não há um profissional qualificado para ensinar como se mexe em computadores nessas instituições ou assumem que a informática é apenas uma matéria que serve para os alunos modernizarem suas tarefas da base comum.

Por esse motivo, é necessário que a informática seja incorporada no currículo escolar para servir de ferramenta adicional e auxiliar os professores no âmbito escolar de forma inovadora e intuitiva, como dito por MARÇAL FLORES 1996 apud LOPES, 2002 em sua monografia: A Informática na Educação: Uma Perspectiva Pedagógica:

"A Informática deve habilitar e dar oportunidade ao aluno de adquirir novos conhecimentos, facilitar o processo ensino/aprendizagem, enfim ser um complemento de conteúdos curriculares visando o desenvolvimento integral do indivíduo."

Portanto, é importante que o corpo docente busque novas maneiras de ministrar sua disciplina, de uma forma que haja a incorporação de ferramentas tecnológicas para que os alunos tenham mais interesse pela aula. Além disso, ao introduzir a tecnologia no cotidiano escolar, os estudantes estarão mais habituados à vida em uma sociedade tecnológica. Por fim, precisa-se que componentes curriculares, como Informática Básica e o aprendizado de ferramentas computacionais, sejam inseridas na grade comum, para auxiliar o corpo discente numa formação mais ampla.

\section{Podcast na Educação}

O podcast é uma forma de publicação de áudios na Internet, seja para debates políticos, conversas entre jornalistas e celebridades, leituras etc. Como citado no artigo de “BOTTENTUIT JUNIOR, João Batista, et al, 2007”, “o podcast surge como uma tecnologia alternativa extremamente potente para ser utilizada a serviço do processo de ensino e aprendizagem tanto na modalidade a distância (e-learning) ou como no complemento ao 
ensino presencial (b-learning).” Ele se mostra útil também para o uso nas escolas, tanto para o ensino a distância ou até mesmo presencial para auxiliar os professores.

O artigo "Podcast em educação: um contributo para o estado da arte" mostra como o podcast pode ser utilizado dentro da sala de aula e como é mais acessível para os alunos, pois, os mesmos conseguem escutar os áudios em seus dispositivos móveis em qualquer lugar que

esteja, por conseguinte, incentivando os professores a aproveitarem do avanço da tecnologia para inovar em seus métodos de ensino.

Essa ferramenta possui ainda um tabu muito grande quando se é pensado na sua utilização dentro de salas de aula, contudo, é importante adaptar-se às novas tecnologias e usá-las em prol da educação.

Nesse aspecto, apesar de muitos pensarem que é "arriscado" utilizar essa tecnologia nas salas de aula, diversas instituições utilizam com frequência para justamente auxiliar os alunos no entendimento de diversas matérias, vários alunos que tiveram a oportunidade de usar essa ferramenta, recomendaram que outras escolas passassem a adotar essa prática também.

"Para Kathryn Bowser, uma estudante de biologia, de 19 anos, da Universidade Drexel em Filadélfia, "nada é melhor do que ouvir o professor enquanto se pedala bicicleta no ginásio", como disse num artigo do Financial Times" (MOURA, Adelina; CARVALHO, Ana Amélia Amorim. 2006. p. 1)

Nessa citação, Moura e Carvalho 2006 mostram a opinião de uma estudante universitária em relação aos podcasts e como eles podem ser úteis para a aprendizagem por conseguirem ensinar assuntos acadêmicos de forma totalmente diferente da maneira como eles estão acostumados.

Kathryn Bowser mostra como o podcast é acessível, os alunos conseguem escutar as suas aulas enquanto fazem exercícios físicos, praticam algum esporte, realizam atividades domiciliares, entre outros. Demonstrando como ele pode ser inserido em qualquer atividade do nosso cotidiano e como pode ser uma ferramenta importantíssima para auxiliá-los em matérias consideradas mais complexas. 
Trabalhos relacionados

\begin{tabular}{|l|l|l|}
\hline Autor & Ano & Síntese \\
\hline $\begin{array}{l}\text { BOTTENTUIT, } \\
\text { et al }\end{array}$ & 2007 & $\begin{array}{l}\text { O artigo fala sobre como o Podcast pode ser de extrema } \\
\text { importância para a educação e aprendizado, na mobilidade do } \\
\text { Podcast estar em todo lugar (e-learning) e ou como no } \\
\text { complemento ao ensino presencial (b-learning). }\end{array}$ \\
\hline BOLZAN & 1998 & $\begin{array}{l}\text { A escritora Regina Bolzan aponta, em seu artigo O conhecimento } \\
\text { tecnológico e o paradigma educacional, as dificuldades que } \\
\text { existem na implantação da informática na educação. }\end{array}$ \\
\hline LOPES & 2002 & $\begin{array}{l}\text { No artigo A Introdução da Informática no Ambiente Escolar, Lopes } \\
\text { fala sobre o processo de implantação da informática básica no } \\
\text { ambiente escolar e mostra como ela não só é uma matéria de } \\
\text { suporte para as outras da grade escolar e, sim que pode ser } \\
\text { importante no processo de formação do corpo docente. }\end{array}$ \\
\hline
\end{tabular}

\section{METODOLOGIA}

Esta seção destina-se a detalhar a realização do estudo de caso de cunho quantitativo, a partir da pesquisa aplicada e da avaliação do podcast como um meio de ensino-aprendizagem. Para tanto, o presente trabalho foi dividido em duas partes: Formulação da Pesquisa e Razão da Criação do Podcast.

\section{Formulação da pesquisa}

A pesquisa foi construída, através do Google Forms®, com o intuito de descobrir o quanto a comunidade do CEEP PLG sabe sobre alguns conceitos básicos acerca dos componentes do Hardware. Foi necessário criar perguntas sobre conceitos básicos sobre as peças de um computador.

As duas primeiras questões, que não contaram com a numeração, foram para identificar se o participante era um aluno ou funcionário e, também expôs as seguintes perguntas:

- Sobre o seu conhecimento sobre informática, você o considera: (de 1 a 10)

- Assinale a alternativa que melhor representa a definição de Hardware.

- O que é a Memória RAM? 
Ademais, contou com algumas perguntas para identificar qual parte do computador estava presente nas Figuras, como mostrado no exemplo abaixo. Questões assim, são de grande importância para diagnosticar o que os usuários sabem e o que não conhecem,

Figura 1 - Exemplo de Questão do Formulário.

5) $O$ que é isso? *

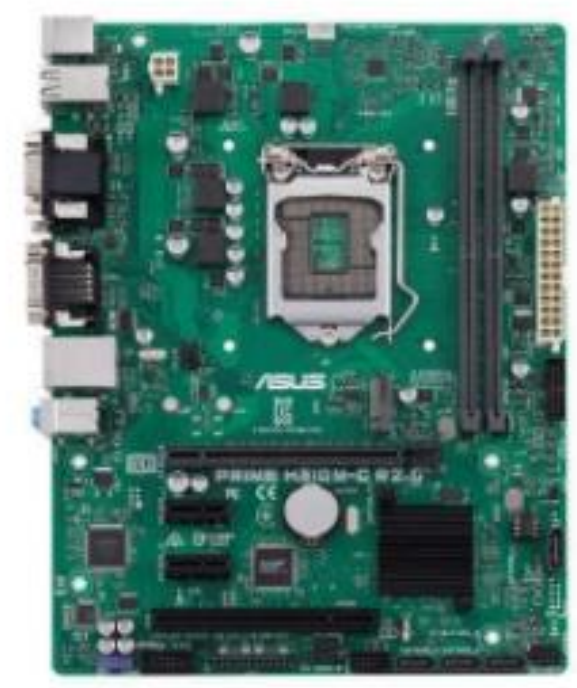

Processador

Placa de Video

Placa Mãe

Não sei

Fonte: Própria (2020);

Por fim, na segunda seção há questionamentos a respeito do Podcast anexado no formulário para saber se o Techno Podcast sanou as dúvidas das questões da primeira seção.

\section{Razão da criação do Podcast}

O Techno Podcast foi criado como uma possível solução e ferramenta de aprendizagem para auxiliar os alunos e funcionários do CEEP Professora Lourdinha Guerra a entender melhor sobre o funcionamento básico dos hardwares presentes nos dispositivos tecnológicos utilizados no cotidiano de toda comunidade escolar.

Nesse contexto, o podcast surge como uma ferramenta moderna que já é utilizada de forma didática em diversas escolas e universidades ao redor do mundo, com o intuito de 
ajudar os professores na apresentação e explicação de matérias complexas, esse método é utilizado tanto em aulas presenciais quanto no EAD.

Em nossa pesquisa, para a criação do logotipo, foi utilizado apenas o Photoshop CC 2012® com base em imagens obtidas na internet; e, para gravação da tela e voz do locutor, foi utilizado o OBS Studio 2020®. No caso, para primeira análise da pesquisa, o vídeo foi hospedado no site do YouTube ${ }^{\circledR}$ e ficou aberto para o público temporariamente.

O Podcast teve como ideia uma apresentação com imagens e trilhas sonoras sendo rápida e direta, para não tomar muito tempo do telespectador e não tornar algo demorado e repetitivo, tornando possível obter uma aprendizagem diferente de forma inovadora.

Neste sentido, a próxima seção apresentará os resultados que averiguam o conhecimento da instituição acerca do assunto supracitado ao longo deste artigo, e em relação ao podcast, será avaliado se o mesmo pode ser utilizado dentro do ambiente escolar como uma ferramenta alternativa de ensino.

\section{RESULTADOS E DISCUSSÃO}

Como dito anteriormente, buscamos avaliar a comunidade do CEEP PLG em relação ao seu conhecimento básico em informática através de uma pesquisa e se os entrevistados consideravam a possibilidade de inserir o podcast como uma ferramenta de ensino auxiliar em algumas matérias ou em todas.

A partir da pesquisa feita na plataforma do Google Forms®, que contava com perguntas objetivas para investigar o conhecimento básico de Hardware do público-alvo, foram obtidos resultados seguidos abaixo.

As questões de identificação, no começo do formulário, contabilizaram uma relação de 47 alunos e 8 funcionários (observe na figura 2). 
Fgura 02: Participantes

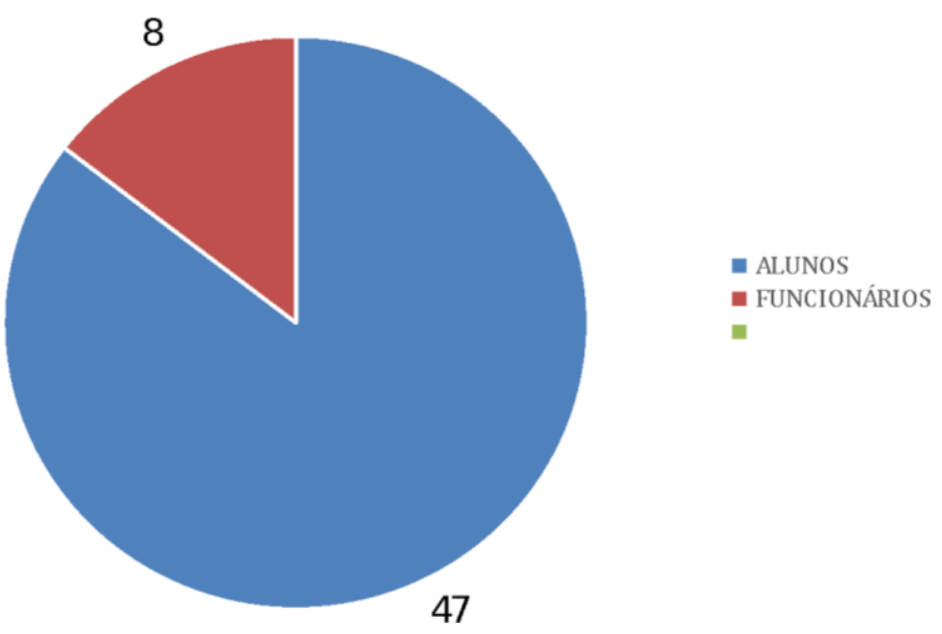

Fonte: Própria (2020);

O questionamento sobre o autodiagnóstico que os participantes fizeram, a respeito do seu conhecimento de Hardware, teve como resultado notas medianas, concluindo que a maioria acha que seus saberes em informática estão na média (observe no gráfico 2).

Figura 03 - Autodiagnóstico

1) Sobre o seu conhecimento sobre informátî̃ca, você o consídera:

55 respostas

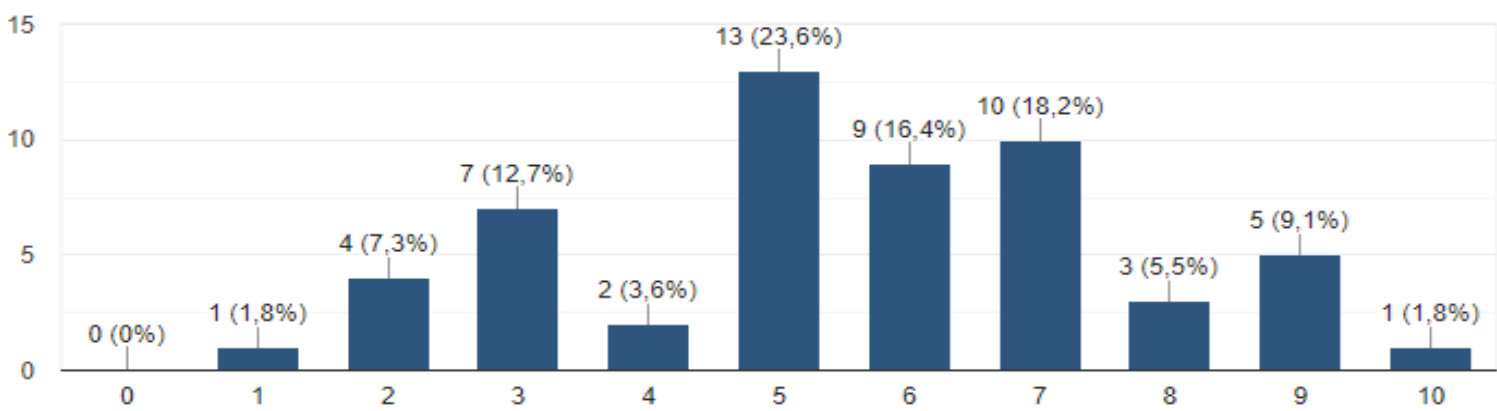

Fonte: Própria (2020);

Foi possível perceber realmente que, a partir das questões de conhecimento básico, há uma certa falta de conhecimento sobre informática de uma parte significativa dos participantes (Observe os gráficos 4 e 5 abaixo). 
Figura 04 - Respostas dos funcionários

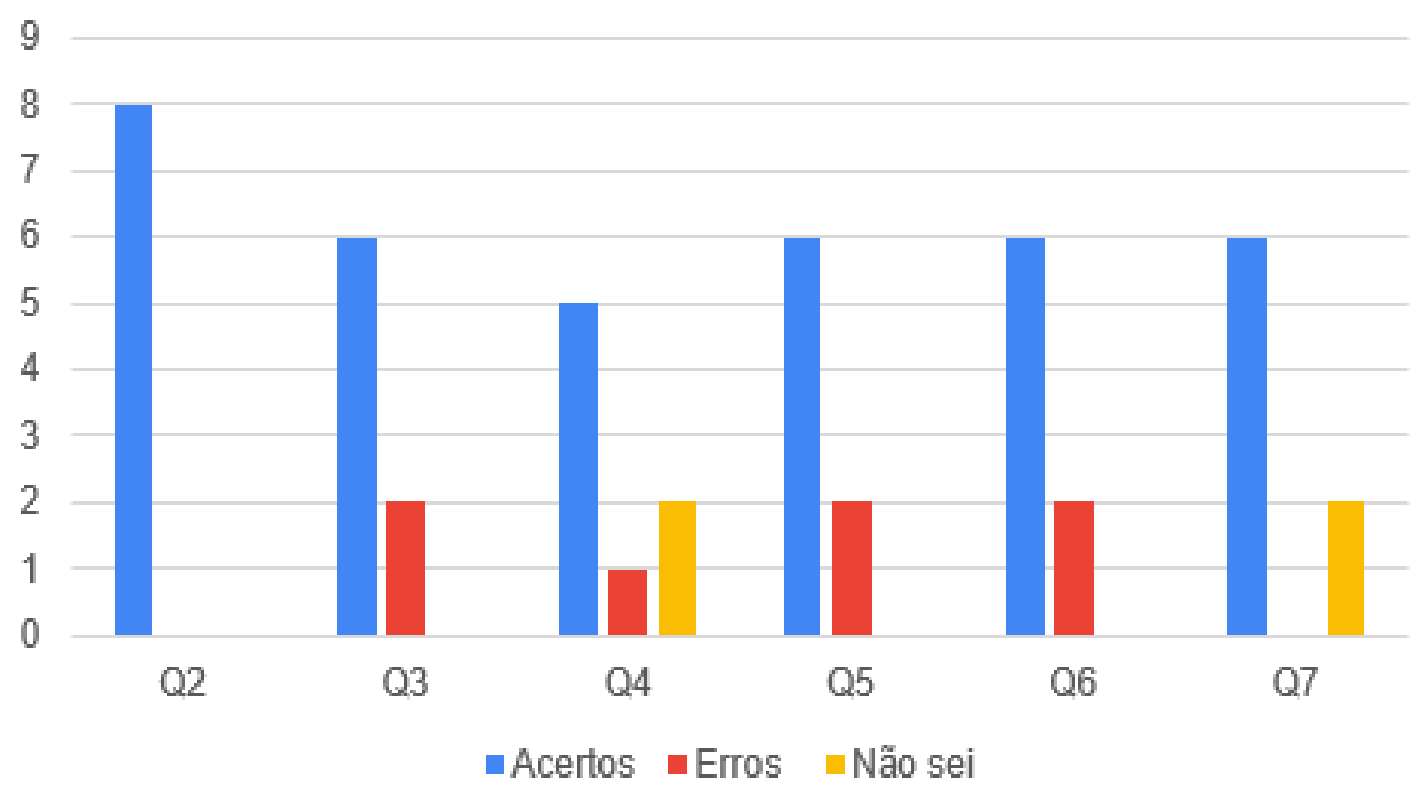

Fonte: Própria (2020);

Figura 05 - Respostas dos funcionários

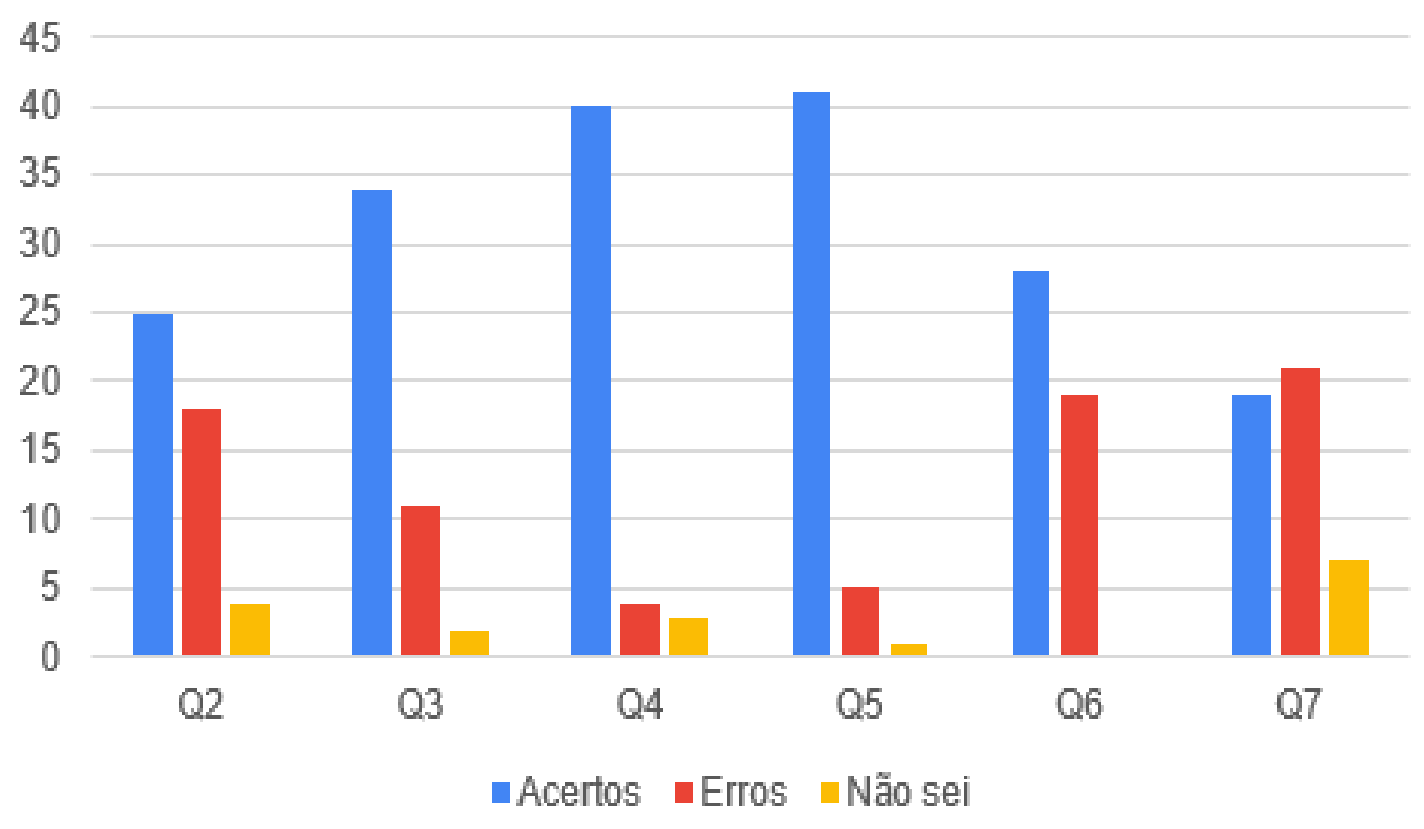

Fonte: Própria (2020)

Pode ser observado, ao analisar os gráficos, que boa parte dos participantes tem algum conhecimento de informática devido a quantidade de acertos, entretanto, levando em consideração que a maioria dos alunos que respondeu a pesquisa é concluinte na área técnica em informática, a quantidade de erros apresentados tornam-se preocupantes, já que as questões são de assuntos básicos do curso (observe a Tabela 1). 
Tabela 01- Quantidade de participantes do formulário

\begin{tabular}{|c|c|c|c|}
\hline Alunos da 1 $1^{\mathbf{a}}$ série & Alunos da 2 $\mathbf{2}^{\mathbf{a}}$ série & Alunos da 3 $\mathbf{3}^{\mathbf{a}}$ série & Funcionários \\
\hline 6 Participantes & 13 Participantes & 28 Participantes & 8 Participantes \\
\hline
\end{tabular}

Fonte: Própria (2020);

É necessário levar em consideração também o fato da escola ter iniciado suas atividades em 2017 e ainda não dispor de uma infraestrutura que comporte adequadamente todos os alunos em relação às diversas áreas da informática. Se for comparada com as Instituições Federais, o CEEP Professora Lourdinha Guerra possui dificuldades em relação à estrutura tecnológica, visto que existe apenas um laboratório de informática e um de manutenção de computadores, ocasionando em uma indisponibilidade no uso do recurso tecnológico, sendo insuficiente para atender os 509 estudantes matriculados em 2020 e, consequentemente, reduzindo a quantidade de aulas práticas na área de informática.

Em relação aos funcionários, há um pequeno índice de erros, contudo, como são os profissionais que auxiliam os estudantes e são assuntos básicos, essa quantidade também é preocupante. Por esse motivo, foi disponibilizado o Techno Podcast, para auxiliar no aprendizado de questões voltadas para manutenção e suporte em informática, tentando descrever os conteúdos de forma mais sucinta e possibilitando o acesso

Na segunda seção, os participantes avaliaram como o Podcast os ajudou a entender os assuntos das questões anteriores e os resultados foram bastante positivos (observe as Figuras 6 e 7 abaixo).

Figura 06 - Análise do Podcast

Marque um valor da escala de acordo com o seu grau de compreensã̃o sobre o assunto tratado no Podcast?

55 responses

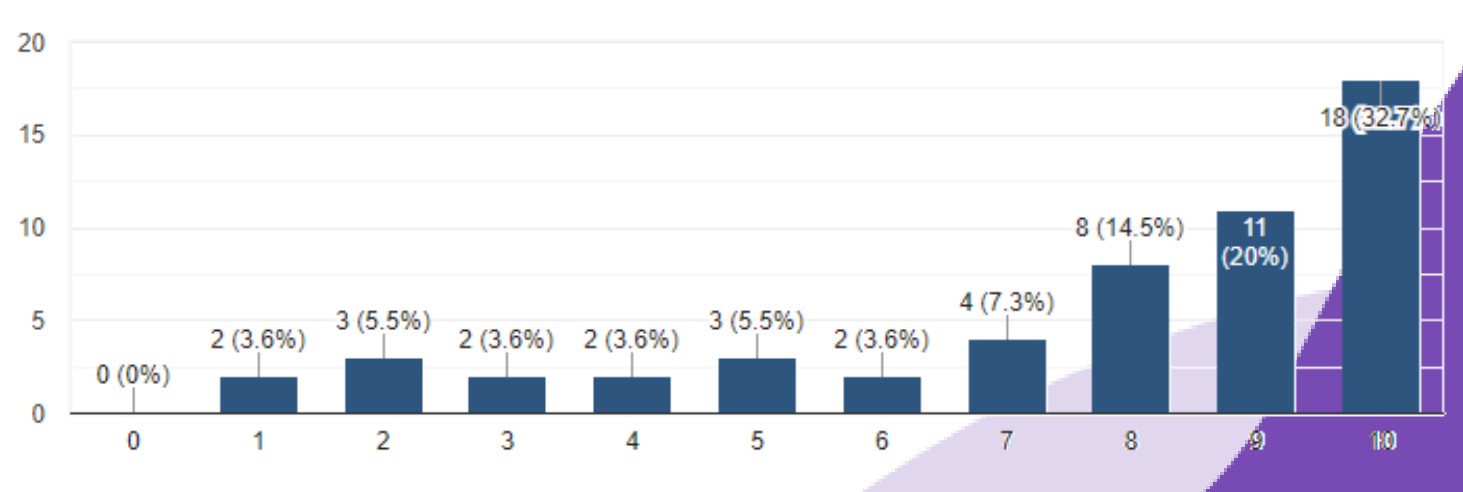

Fonte: Própria (2020); 
Figura 07 - o Podcast serve como ferramenta pedagógica

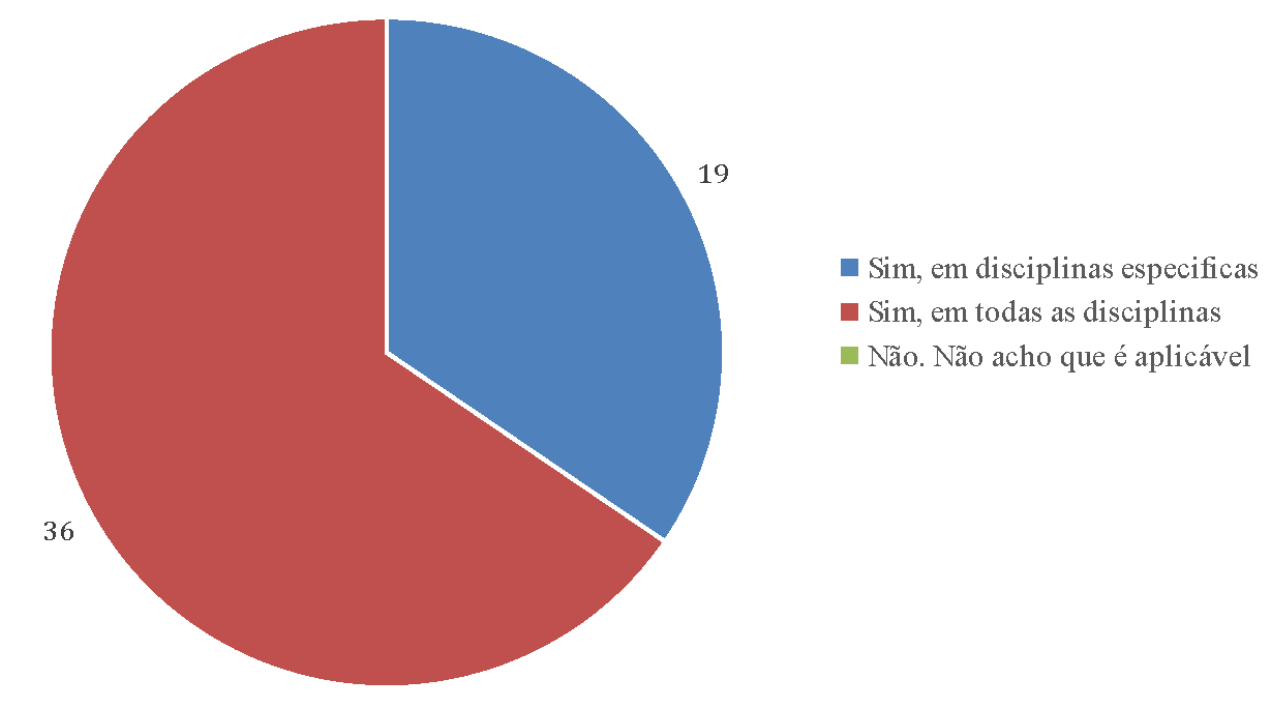

Fonte: Própria (2020);

Por fim, considerando os resultados exibidos, conclui-se que o podcast pode ser utilizado como uma ferramenta pedagógica, visto que a maioria dos participantes votaram positivamente na avaliação.

\section{CONCLUSÕES}

Como analisado na pesquisa e avaliação do Podcast, pôde-se observar que o ensino, por meio de ilustrações, torna-se mais intuitivo na hora do aprendizado do que apenas conceituar as partes de um computador, visto que houve uma quantidade considerável de erros em relação às questões sobre o funcionamento dos componentes. Ademais, foi observado na pesquisa que alunos e funcionários possuem dificuldade em relação a hardwares e softwares de computadores e, uma provável justificativa para esse fato pode ser em relação à infraestrutura e disponibilidades de recursos tecnológicos na escola.

Diante disso, em relação a criação do podcast, a avaliação apontou que ele seria uma ferramenta de aprendizagem viável pois, nenhuma das pessoas qualificaram-no de forma negativa ao responder o formulário. Nesse aspecto, conclui-se que essa ferramenta pode ser utilizada para auxiliar os professores como um material didático já que é um instrumento extremamente viável, de fácil acesso e que já é utilizado em diversas universidades mundialmente conhecidas.

Por conseguinte, é necessário incentivar os alunos a se interessarem pelo assunto, para isso, uma das alternativas é indicar sites onde eles possam aprender de forma didática, como 
cada peça de um dispositivo eletrônico funciona e qual é a sua função. Do mesmo modo, inserir mais aulas práticas com a apresentação dos hardwares, resolução de problemas básicos, tais como, problemas no cabo de um projetor, mau funcionamento de uma peça de um computador, entre outros, ou seja, mostrar na prática o seu funcionamento para tentar despertar o interesse nos alunos e funcionários sobre um assunto em específico. Logo, a educação deve estar conectada com os meios digitais para que haja uma formação integral.

\section{REFERÊNCIAS}

BOLZAN, Regina de Fátima Fructuoso de Andrade. O conhecimento tecnológico e o paradigma educacional. $1998 . \quad$ Disponível em: <https://repositorio.ufsc.br/xmlui/handle/123456789/158192>. Acesso em: 06 aug, 2020.

BOTTENTUIT JUNIOR, João Batista; COUTINHO, Clara Pereira. Podcast em Educação: um contributo para o estado da arte. 2007. Disponível em: <https://repositorium.sdum.uminho.pt/handle/1822/7094>. Acesso em: 09 set. 2020.

CORADINI, Neirimar Humberto Kochhan; BORGES, Aurélio Ferreira; DUTRA, Charles Emerick Medeiros. TECNOLOGIA EDUCACIONAL PODCAST NA EDUCAÇÃO PROFISSIONAL E TECNOLÓGICA. Revista Eletrônica Científica Ensino Interdisciplinar, v. 6, n. 16, p. 216-230, 2020.

FRANCOM, Jeff; RYAN, Thomas G.; KARIUKI, Mumbi. The Effects of Podcasting on College Student Achievement and Attitude. On-line Submission, 2011. Disponível em: <https://eric.ed.gov/?id=ED518764>. Acesso em: 09 set. 2020.

FRÓES, Jorge RM. Educação e Informática: A relação homem/máquina e a questão da cognição. Trend Tecnologia Educacional (Mimeo). Rio de Janeiro-RJ, 1998.

INSTITUTO NACIONAL DE ESTUDOS E PESQUISAS EDUCACIONAIS ANÍSIO TEIXEIRA (INEP). Censo Escolar. Disponível em: $<$ http://download.inep.gov.br/educacao_basica/censo_escolar/notas_estatisticas/2018/notas_es tatisticas_censo_escolar_2018.pdf>. Acesso em: 05 nov. 2020.

KAY, Robin H. Exploring the use of video podcasts in education: A comprehensive review of the literature. Computers. Human Behavior, v. 28, n. 3, p. 820-831, 2012.

LOPES, José Junio et al. A introdução da informática no ambiente escolar. Clube do professor, $\quad$ v. 23, 2002. Disponível <http://clubedoprofessor.com.br/artigos/artigojunio.pdf>. . Acesso em: 05 nov. 2020.

INSTITUTO BRASILEIRO DE GEOGRAFIA E ESTATÍSTICA (IBGE). PNADCONTÍNUA. Disponível <https://ftp.ibge.gov.br/Trabalho_e_Rendimento/Pesquisa_Nacional_por_Amostra de_Domic ilios_continua/Anual/Acesso_Internet_Televisao_e_Posse_Telefone_Movel_2018/Analise_do S_resultados_TIC_2018.pdf $>$. Acesso em: 05 nov. 2020, 2018. 
MOURA, Adelina; CARVALHO, Ana Amélia Amorim. Podcast: uma ferramenta para usar dentro e fora da sala de aula. Conference on Mobile and Ubiquitous Systems (CSMU), p. 155-158. Universidade do Minho: Braga, 2006. 


\title{
CAPÍTULO 05: GESTÃO INFORMATIZADA DE UM SETOR DE ASSISTÊNCIA ESTUDANTIL: UM ESTUDO DE CASO NO IFMG - CAMPUS BAMBUÍ
}

\author{
CAPÍTULO 05: GESTIÓN INFORMÁTICA DE UN SECTOR DE ASISTENCIA AL \\ ESTUDIANTE: UN ESTUDIO DE CASO EN IFMG - CAMPUS BAMBUÍ
}

\section{CHAPTER 05: COMPUTERIZED MANAGEMENT OF A STUDENT ASSISTANCE SECTOR: A CASE STUDY AT IFMG - CAMPUS BAMBUÍ}

\author{
Eduardo Cardoso Melo ${ }^{1}$; Gabriel da Silva ${ }^{2}$; Mateus Araújo Cruz ${ }^{3}$
}

DOI: https://doi.org/10.31692/978-65-88970-06-5.62-81

\section{RESUMO}

O emprego de recursos tecnológicos computacionais pode ser considerado como um dos principais meios propulsores para diversas transformações ocorridas na sociedade. Em se tratando de gestão organizacional, é quase impensável que empresas busquem atuação diversificada sem o apoio de ferramentas computacionais. Neste sentido, é consenso que a correta utilização de Sistemas de Informação tende a contribuir positivamente para o gerenciamento de processos de negócios. Este artigo objetiva apresentar como foi o processo de construção de um software cuja premissa inicial seria contribuir para a informatização de processos internos e com a gestão de um setor de Assistência Estudantil, no caso do IFMG - Campus Bambuí. Os aspectos teóricos relacionados com esta pesquisa estão baseados nos conceitos de Sistemas de Informação e inovação tecnológica na gestão pública. O gerenciamento das informações deste setor pesquisado era feito apenas com o uso de documentos de texto e planilhas eletrônicas, dificultando sobremaneira a integração de dados. A pesquisa foi desenvolvida entre o segundo semestre de 2018 até o final de 2019. As etapas para a produção do software tiveram como base a adaptação de propostas da metodologia ágil Scrum, com vistas a gerar e disponibilizar um produto final com funcionalidades aderentes às necessidades do público em questão. Após a implantação do software foi possível notar que os processos de tomada de decisão dos gestores passaram a contar com o importante auxílio de informações geradas pelo sistema. O compartilhamento de informações entre os servidores públicos também foi facilitado. Por fim, a informatização do processo de registro de frequência dos estudantes residentes na Moradia Estudantil do campus otimizou o trabalho dos servidores públicos do setor, especialmente no que se refere à manutenção dos dados que, até então, era feita exclusivamente em papel.

Palavras-Chave: Sistemas de Informação, Informatização de processos, Desenvolvimento Ágil, Institutos Federais, Auxílio na tomada de decisão.

\section{RESUMEN}

El uso de recursos tecnológicos computacionales puede considerarse como uno de los principales medios propulsores de varias transformaciones en la sociedad. En lo que respecta a la gestión organizacional, es casi impensable que las empresas busquen un desempeño diversificado sin el apoyo de herramientas computacionales. En este sentido, es un consenso que el uso correcto de los Sistemas de Información tiende a contribuir positivamente a la gestión de los procesos de negocio. Este artículo tiene como objetivo presentar cómo fue el proceso de construcción del software, cuya premisa inícial sería contribuir a la informatización de los procesos internos y a la gestión de un sector de Atención al Estudiante, en el caso de IFMG - Campus Bambuí. Los aspectos teóricos relacionados con esta investigación se basan en los conceptos de Sistemas de Información e innovación tecnológica en la gestión pública. La gestión de la información en este sector investigado se realizó únicamente con el uso de documentos de texto y hojas de cálculo, lo que dificulta enormemente la integración de datos. La investigación se llevó a cabo entre el segundo semestre de 2018 y finales de 2019. Los pasos para

${ }^{1}$ Professor Mestre, IFMG, eduardo.melo@ifmg.edu.br

2 Professor Mestre, IFMG, gabriel.silva@ifmg.edu.br

${ }^{3}$ Engenharia da Computação, IFMG, mateuscruz22@gmail.com 
la producción del software se basaron en la adecuación de propuestas de la metodología ágil Scrum, con el fin de generar y poner a disposición un producto final con funcionalidades que se adhieran a las necesidades del público en cuestión. Luego de la implementación del software, se pudo notar que los procesos de toma de decisiones de los gerentes comenzaron a depender de la importante ayuda de la información generada por el sistema. También se facilitó el intercambio de información entre servidores públicos. Por último, la informatización del proceso de registro de asistencia de los estudiantes residentes en la Vivienda de Estudiantes del campus optimizó el trabajo de los servidores públicos del sector, especialmente en lo que respecta al mantenimiento de datos que, hasta entonces, se realizaba exclusivamente en papel.

Palabras Clave: Sistemas de Información, Informatización de Procesos, Desarrollo Ágil, Institutos Federales, Asistencia en la Toma de Decisiones.

\section{ABSTRACT}

The use of computer technology resources can be considered as one of the main drivers for several transformations that have taken place in society. In organizational management context, it is almost unthinkable for companies to seek diversified performance without the support of computational tools. In this sense, it is a consensus that the correct use of Information Systems tends to contribute positively to the management of business processes. This article aims to present how the software construction process was, whose initial premise would be to contribute to the computerization of internal processes and to the management of a Student Assistance sector, in the case of IFMG Campus Bambuí. The theoretical aspects related to this research are based on the concepts of Information Systems and technological innovation in public management. The management of information in this sector was done only with the use of text documents and spreadsheets, making data integration extremely difficult. The research was conducted between the second half of 2018 and the end of 2019. The steps for the production of the software were based on the adaptation of proposals from the agile methodology called Scrum, with a view to generating and making available a final product with functionalities according to the needs of the target public. After the implantation of the software, it was possible to aid the decision-making processes of managers now have the important support information generated by the system. Information sharing between public employees was also facilitated. Finally, the computerization of the attendance registration process of students residing in the Student Housing on the campus optimized the work of the public servers, especially with regard to the maintenance of data that, until then, was done exclusively on paper.

Keywords: Information Systems, Computerization Processes, Agile Development, Federal Institutes, Aid in Decision Making.

\section{INTRODUÇÃO}

A Tecnologia da Informação (TI) tem participado diretamente das principais transformações ocorridas no mundo, em especial a partir do final do século XX, sendo facilitadora de diversas mudanças que impactaram os indivíduos tanto em aspectos profissionais quanto pessoais. Quando tais transformações envolvem o ambiente organizacional é possível destacar ainda mais o papel da TI, haja visto que por meio de seus recursos as empresas passam a ter condições de otimizar seus processos internos, incrementar a produtividade de seus colaboradores e obter resultados mais satisfatórios (VILELA et al., 2016; SILVA et al., 2016). As empresas modernas de variadas áreas de atuação dependem dos recursos da TI, como os Sistemas de Informação (SI), para a realização de seus negócios.

O nível de dependência das empresas para com sistemas informatizados é alto e em contínuo 
crescimento, especialmente se for considerada a evolução frequente dos recursos tecnológicos (MARCHIORI e MAINARDES, 2015. ROZA, 2017).

Quando é analisada a utilização de recursos de TI no gerenciamento de unidades educacionais no Brasil, em especial aquelas públicas, torna-se importante ressaltar que mesmo que avanços tenham sido notados recentemente, o contexto geral ainda indica um considerável conjunto de possíveis melhorias (FREITAS, CRESMASCO JÚNIOR e SOUZA, 2015). A ampliação do uso de recursos tecnológicos na administração pública precisa ser incentivada para que as pessoas, sejam elas os próprios servidores públicos ou qualquer indivíduo que necessite de um serviço, possam obter benefícios advindos do suporte prestado pela tecnologia (ARAÚJO, PINHEIRO JÚNIOR e ABREU, 2015; ASSIS, 2016; SZIMANSKI et al., 2015; ZORZAL, 2015).

Atualmente diversas ferramentas tecnológicas são utilizadas no ambiente organizacional do Campus Bambuí do Instituto Federal de Minas Gerais (IFMG), em especial softwares para auxiliar na gestão de seus setores e no acesso à informação por parte da comunidade acadêmica (CGTI, 2020). Ressalta-se, dentre essas ferramentas, a utilização frequente dos softwares denominados $\mathrm{GLPI}^{6}, \mathrm{SEI}^{7}$ e $\mathrm{Meu} \mathrm{IFMG}^{8}$. O primeiro oferece um sistema para controle automatizado de chamados internos do campus, em especial aqueles relacionados com manutenções diversas (laboratórios, infraestrutura, etc). O segundo é uma solução tecnológica para tramitação eletrônica de processos administrativos de toda a Instituição. O último software citado é, na verdade, o módulo de um Enterprise Resource Planning (ERP) contratado pelo IFMG junto à empresa Totvs para gerenciamento de informações acadêmicas, tais como frequência de alunos, notas e registros da Secretaria.

Em sua estrutura organizacional, o Campus Bambuí do IFMG dispõe de um setor específico para atendimento de demandas dos alunos, denominado Coordenadoria de Assistência Estudantil (CAE). Sua principal atuação consiste na oferta de diversificados serviços para a comunidade acadêmica, tais como alimentação no Restaurante Universitário, atendimentos especializados nas áreas de Odontologia, Medicina, Nutrição, Psicologia e Assistência Social, atividades de esporte e lazer e residência na Moradia Estudantil. Atualmente são disponibilizadas 250 vagas para que os alunos possam residir no campus, sendo 80 delas reservadas para estudantes do sexo feminino. Todos os residentes têm gratuidade em quatro refeições diárias e no serviço de lavanderia da Instituição (CAE, 2020).

\footnotetext{
${ }^{6}$ https://sistemas.bambui.ifmg.edu.br/glpi/

${ }^{7}$ http://sei.ifmg.edu.br/

${ }^{8}$ https://meu.ifmg.edu.br/
} 
Apesar de oferecer estes e outros serviços para uma comunidade de cerca de 2.500 alunos e estender o atendimento do Restaurante Universitário a aproximadamente 410 servidores e trabalhadores terceirizados, a CAE não contava, até o ano de 2019, com um software integrado capaz de auxiliar os servidores que lá atuam na condução e registro de suas atividades, bem como na automatização e otimização de rotinas internas. Toda a gestão documental do setor era feita em formulários de papel, documentos de texto e planilhas eletrônicas, praticamente impossibilitando qualquer demanda de integração de dados e, em especial, a produção de informações relevantes capazes de auxiliar os gestores nos processos de tomadas de decisão. Outra situação frequente era a falta de controle de acesso aos dados do setor, pois os documentos elaborados pelos servidores ficavam disponíveis em uma pasta compartilhada na rede interna sem qualquer análise de perfil sobre o usuário que a acessava. Agrega-se a este contexto um incêndio ocorrido no Data Center do campus que ocasionou a perda do equipamento onde os documentos da CAE eram salvos remotamente; quase todo o histórico de dados do setor foi perdido nesta ocasião. Por fim, a Moradia Estudantil possui uma série de rotinas internas que, até então, eram realizadas manualmente, como a chamada diária dos alunos residentes e o controle de saídas dos mesmos.

A proposta desta pesquisa foi compreender as reais necessidades gerenciais do setor de Assistência Estudantil do IFMG - Campus Bambuí para, com base neste entendimento, planejar, desenvolver e implantar um software integrado e personalizado que disponibilizasse funcionalidades capazes de auxiliar os servidores nas suas tarefas cotidianas, melhorando o atendimento ao público e possibilitando uma gestão íntegra e confiável das informações.

\section{FUNDAMENTAÇÃO TEÓRICA}

Esta seção visa apresentar os conceitos fundamentais diretamente relacionados com o tema abordado no presente trabalho, o qual envolve estudos sobre Sistemas de Informação e sua contribuição para a melhoria de processos administrativos na gestão pública.

\section{Sistemas de Informação}

Mattos (2017) descreve o conceito de Sistemas de Informação como sendo sistemas com especialização em processar e comunicar dados por meio de módulos interligados entre si em uma rede comum. De Sordi e Meireles (2018) também enfatizam o caráter abrangente dos Sistemas de Informação a partir do momento que eles envolvem e integram em sua utilização vários atores e componentes, porém nada disso seria possível sem o devido 
tratamento aos dados brutos que são inseridos nos sistemas. Na visão desses autores, os Sistemas de Informação tratam, prioritariamente, de dados que podem apresentar alguma importância para a organização quando processados e integrados, gerando informações que permitam uma tomada de decisão com maior embasamento.

Uma das definições mais aceitas sobre os Sistemas de Informação é apresentada por Laudon e Laudon (2015), ao afirmarem que eles podem ser visualizados como um conjunto de módulos que atuam relacionados (normalmente de forma direta) com o intuito principal de auxiliar o gerenciamento organizacional e os processos de tomada de decisão a partir do trabalho intenso com informações.

Batista (2017) apresenta uma válida classificação dos diversos tipos de sistemas que podem ser utilizados por organizações como auxílio à gestão. Neste contexto, os sistemas poderiam ser classificados com base na sua forma de utilização, no formato de retorno proporcionado para a tomada de decisão e, por fim, de acordo com a quantidade de pessoas relacionadas com ele. Quanto às nomenclaturas utilizadas para caracterizar os diversos tipos de sistemas, o autor divide-as em sistemas empresariais básicos, sistemas de automação de escritório, sistemas de informação gerencial, sistemas de suporte à decisão, sistemas de suporte executivo e sistemas especialistas.

Gomes Filho (2018) ressaltam o atual momento da tecnologia e sua ampla utilização nas mais variadas áreas da sociedade, indicando que o emprego de Sistemas de Informação é viável na maioria das situações que requerem melhorias organizacionais. Entretanto, é fundamental que sejam conduzidos estudos contínuos para averiguar se o Sistema de Informação se mantém alinhado com os objetivos da organização e de seus usuários ao longo do tempo de sua utilização.

\section{Tecnologias da Informação (TI) na Gestão Pública}

Uma das áreas de estudo que abordam a aplicação de inovadoras tecnologias informação no contexto da Gestão Pública é conhecida como "Governo Eletrônico government)". Seu foco é compreender como as novas ferramentas tecnológicas podem auxiliar os membros da administração pública na melhoria de vários aspectos da gestão, notadamente aquele que trata sobre o relacionamento do governo com os cidadãos, empresas e unidades de sua própria estrutura (DIAS, SANO e MEIRELES, 2019).

No entendimento de Rabelo et al. (2019), o governo eletrônico precisa ser analisado com uma visão ampla que permita compreende-lo como um novo modo do governo cumprir o papel do Estado na sociedade de maneira efetiva, ao invés de somente ser considerado como a 
aplicação de tecnologias para automatizar processos.

Brognoli e Ferenhof (2020) apresentam um amplo estudo sobre como vem sendo conduzida a transformação digital no governo brasileiro desde o ano 2000. Dentre diversos indicadores favoráveis à utilização de recursos tecnológicos na administração pública, os autores destacam a grande diferença entre o custo do atendimento presencial e do virtual, indicando a importância de o governo buscar constantemente a implementação de ações que gerem efetiva economia de recursos financeiros e de pessoal.

\section{METODOLOGIA}

Considerando a obra de Wazlawick (2014), este trabalho pode ser caracterizado de acordo com o estilo "Apresentação de um Produto", cujo foco está mais relacionado com o tipo de pesquisa exploratória e busca compartilhar informações sobre um produto recémdesenvolvido e disponibilizado para uso. Trata-se de um trabalho com abordagem predominantemente qualitativa e de natureza aplicada. De acordo com Freitas e Prodanov (2013, p. 70), “a pesquisa qualitativa não requer uso de métodos e técnicas estatísticas, sendo o ambiente natural a fonte direta para coleta de dados e o pesquisador o instrumento-chave". Silveira e Córdova (2009) caracterizam a pesquisa aplicada como sendo aquela cujo foco é a solução de problemas específicos, objetivando construir novos conhecimentos práticos a respeito do que é estudado. No que se refere aos procedimentos, esta pesquisa pode ser categorizada como experimental e estudo de caso. Para Wazlawick (2014, p. 43), na pesquisa experimental o pesquisador "provocará alterações no ambiente a ser pesquisado de forma a observar se cada intervenção produz os resultados esperados”. Já o estudo de caso é entendido por Gil (2019) como sendo o estudo abrangente de determinado objeto, fazendo com que seja possível conhecê-lo em detalhes.

Em relação ao gerenciamento do projeto de desenvolvimento do software, algumas propostas da metodologia ágil Scrum foram adaptadas e utilizadas, tais como a definição dos backlogs (produto, versões e sprints) e cerimônias para acompanhamento e discussões sobre o projeto. As atividades desta pesquisa foram realizadas, em sua maioria, no Laboratório de Sistemas Computacionais (LSC) do Grupo de Pesquisa em Sistemas Computacionais (GPSisCom) do IFMG - Campus Bambuí. Neste ambiente, os participantes tiveram acesso a todos os recursos necessários para o desenvolvimento das atividades planejadas, desde computadores, internet e servidor próprio para aplicações web, até salas para reuniões diversas e testes no software desenvolvido. 


\section{Primeira etapa: levantamento e documentação dos requisitos}

A primeira etapa da pesquisa foi iniciada no segundo semestre de 2018 e baseou-se no estudo de como era o funcionamento da CAE naquele momento. Diversas reuniões presenciais com entrevistas não estruturadas foram realizadas com os gestores e servidores deste setor, sendo feita a devida documentação de todos os assuntos tratados para eventuais consultas futuras. Outra atividade conduzida foi a análise de documentos e formulários internos do setor utilizados nas tarefas cotidianas, promovendo assim uma ampla visão de quais informações eram importantes para os gestores e para o sistema como um todo. Naquele momento a equipe da pesquisa identificou a necessidade que o software funcionasse como uma aplicação web, permitindo o acesso remoto dos usuários e sendo escalável em termos de infraestrutura de armazenamento e processamento.

A partir do conhecimento obtido na primeira etapa dos trabalhos, as atividades para levantamento dos requisitos para o software foram iniciadas. Para o refinamento e entendimento complementar dos requisitos foram conduzidas novas reuniões e entrevistas não estruturadas junto aos servidores da CAE. A versão final dos requisitos foi documentada no formato de História de Usuário. A Figura 1 apresenta a História de Usuário que ilustra as características do login no sistema.

Figura 1: História de Usuário do login do sistema

\begin{tabular}{|c|c|c|c|}
\hline \multirow{2}{*}{$\begin{array}{l}\text { Número: } 01 \\
\text { Data: } 10 / 08 / 2018\end{array}$} & \multicolumn{3}{|c|}{ Tipo de História: (x) Nova ( ) Melhoria } \\
\hline & Prioridade: 1 & Risco: Baixo & Estimativa: 12 horas \\
\hline \multicolumn{4}{|c|}{$\begin{array}{l}\text { Descrição: } \\
\text { Como usuário do sistema, eu desejaria fazer login utilizando meu CPF e minha senha, bem como ter a } \\
\text { possibilidade de recuperar meus dados de acesso a qualquer momento. }\end{array}$} \\
\hline \multicolumn{4}{|c|}{$\begin{array}{l}\text { Testes de Aceitação: } \\
\text { TA01-01: O CPF informado é inválido ou indica usuário bloqueado. } \\
\text { TA01-02: A senha utilizada está sendo criptografada. } \\
\text { TA01-03: O sistema limita as tentativas incorretas de acesso. } \\
\text { TA01-04: O sistema grava um histórico dos acessos do usuário. } \\
\text { TA01-05: A recuperação dos dados de acesso é feita apenas com a va }\end{array}$} \\
\hline
\end{tabular}

Fonte: Própria (2020)

Com o intuito de proporcionar uma visão gráfica das principais funcionalidades disponíveis no sistema para seus usuários, um Diagrama de Caso de Uso geral foi elaborado e apresentado aos envolvidos com o projeto para validação do escopo que viria a ser 
desenvolvido. Tal recurso pode ser observado na Figura 2.

Figura 2: Diagrama de Caso de Uso geral do sistema

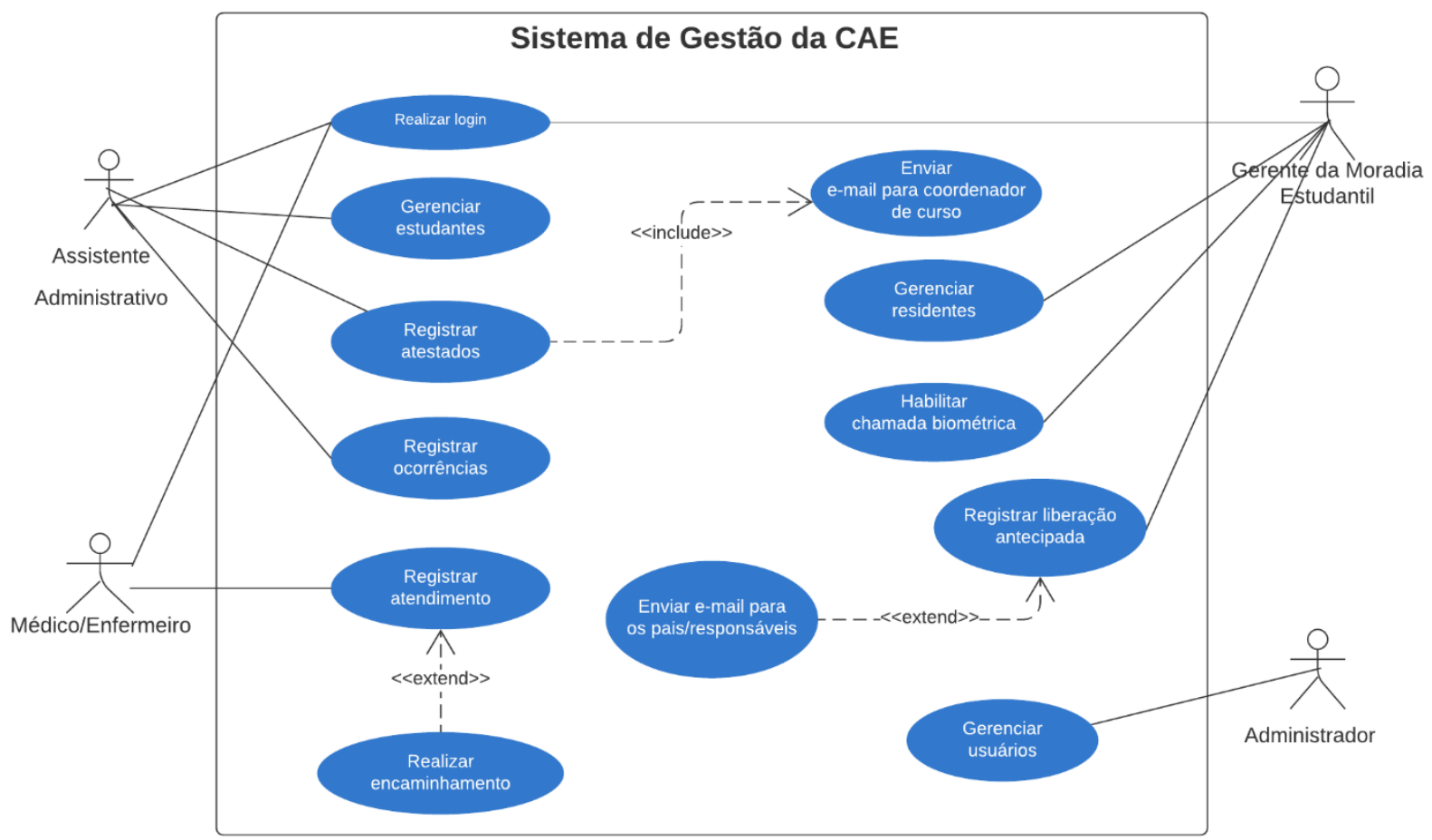

Fonte: Própria (2020)

A partir da definição inicial das funcionalidades do sistema e do entendimento dos requisitos para o seu desenvolvimento, foi elaborado o modelo dos dados na ferramenta MySQL Workbench versão 6.3, o qual proporcionou uma visão mais abrangente sobre a estrutura para armazenamento das informações gerenciadas pelo sistema. Considerando os conhecimentos prévios da equipe da pesquisa, simplicidade de configuração/manutenção e gratuidade para utilização, optou-se pela implementação do banco de dados no Sistema Gerenciador de Banco de Dados (SGBD) MySQL Community Server Edition versão 5.7. A Figura 3 apresenta o modelo de dados construído para o sistema da CAE. 
Figura 3: Modelo de dados do sistema

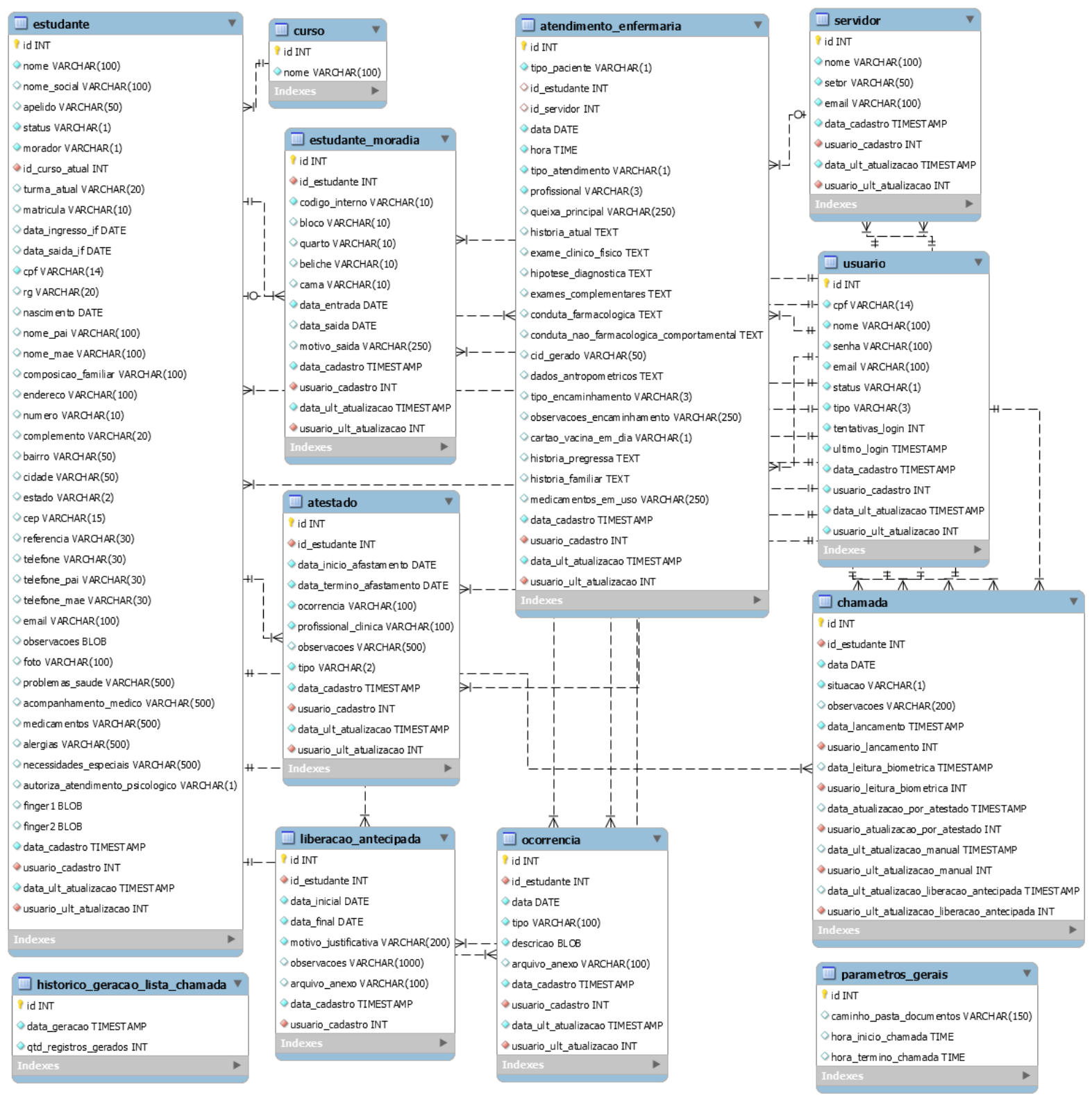

Fonte: Própria (2020)

Em relação às tecnologias para desenvolvimento do sistema, a definição das mesmas baseou-se nos conhecimentos prévios da equipe e no fato de serem de uso livre. A produção do front-end da aplicação web foi executada com o apoio das tecnologias HyperText Markup Language (HTML 5), Cascading Style Sheets (CSS 3), JavaScript, Bootstrap 4, jQuery 3 e Asynchronous Javascript and XML (AJAX), enquanto a produção do back-end foi baseada em PHP 7, framework CodeIgniter 3 e servidor Apache 2.5. 


\section{Segunda etapa: desenvolvimento da primeira versão do software}

Os recursos relacionados com o acesso ao sistema fizeram parte da versão inicial desenvolvida (Sprint 1), sendo o login a primeira funcionalidade implementada pela equipe. Os usuários podem realizar o acesso ao sistema informando seu CPF e uma senha previamente cadastrada pelo Administrador do ambiente. Para aumentar a segurança em relação ao acesso ao sistema, todas as senhas são armazenadas criptografadas no banco de dados e é feita uma limitação das tentativas de acesso não autorizadas para cada usuário. Sendo o acesso feito com sucesso, é criada uma sessão que permanece ativa durante 4 horas, ocorrendo a renovação automática no caso de interações do usuário com funcionalidades do sistema. Dentro do escopo de acesso ao sistema, foi desenvolvido também o recurso de gestão dos usuários, cujo objetivo principal é permitir ao Administrador gerenciar as informações de todas aquelas pessoas que utilizam o sistema.

Considerando a priorização das funcionalidades definidas no momento da criação do backlog do projeto, a segunda funcionalidade implementada foi o recurso de gestão dos estudantes que utilizam os serviços da CAE. Nesta rotina o usuário precisa cadastrar desde dados simples, como nome e números de documentos, até dados mais específicos que serão utilizados pelos gestores da CAE como, por exemplo, questões de saúde do estudante. O cadastro dos estudantes que residem na Moradia Estudantil do campus possui um número maior de campos para preenchimento, pois são informações que podem, eventualmente, ser utilizadas pelos servidores em momentos específicos, como na liberação dos alunos em finais de semanas ou no momento das chamadas diárias. Por fim, foi implementada uma rotina para inclusão da foto do estudante, de maneira a facilitar a identificação de cada indivíduo se assim for necessário (por exemplo, quando do lançamento de uma ocorrência disciplinar).

Ainda dentro do escopo do desenvolvimento da primeira versão do sistema, foi implementada a funcionalidade para gestão dos atestados médicos entregues pelos estudantes e validados pela CAE. Os usuários podem inserir dados específicos do atestado como a sua duração e o médico emissor e, caso seja necessário, anexá-lo para futuras consultas. Uma yez que se trata de dados sensíveis e particulares, apenas o Administrador pode ter acesso aos documentos que porventura tenham sido anexados. Neste momento é importante salientar que o sistema armazena um histórico completo de todas as inclusões, alterações, exclusões e acessos a registros, sendo factível, portanto, identificar o responsável por qualquer uma dessas ações para cada registro arquivado na base de dados. Outra funcionalidade desenvolvida nesta ocasião foi a de registro de ocorrências (disciplinares ou não) de estudantes, situação rotineira no cotidiano da CAE. As ocorrências podem ser classificadas em públicas ou particulares, 
sendo essas últimas acessíveis apenas pelo usuário que as cadastrou e pelo Administrador do sistema.

A última funcionalidade entregue na versão inicial do sistema foi o gerenciamento de atendimentos feitos pela Enfermaria do campus, local onde estudantes e também servidores são recebidos para prestação de primeiros socorros e consultas diversas. Ressalta-se que nesta versão inicial os dados demandados pelo Médico do campus não foram incluídos no cadastro, apenas aqueles relacionados ao atendimento prestado pelo Enfermeiro. A complementação da gestão dos atendimentos médicos foi inserida na segunda versão do sistema, quando as demandas do Médico em relação aos dados necessários para sua atuação foram melhor compreendidas e documentadas.

O próprio ambiente de desenvolvimento foi utilizado para a realização dos testes iniciais na primeira versão elaborada, sendo tais tarefas cumpridas pela equipe da pesquisa. Ao mesmo tempo, optou-se por disponibilizar uma cópia local do sistema para alguns servidores da CAE testarem as funcionalidades desenvolvidas. Foi realizado um treinamento prévio para todos os usuários que fizeram parte deste momento de testes iniciais. Pequenos ajustes foram solicitados pelos servidores da CAE, os quais foram prontamente realizados pela equipe da pesquisa a fim de que a primeira versão fosse considerada como pronta para uso em produção. Neste momento, o setor de Tecnologia da Informação do campus disponibilizou um ambiente próprio para hospedagem do sistema, cuja configuração foi concluída e permitiu que o sistema passasse a ser utilizado oficialmente pela CAE no início de 2019.

\section{Terceira etapa: desenvolvimento da segunda versão do software}

O desenvolvimento da segunda versão do sistema (Sprint 2) foi iniciada tão logo a primeira entrou em produção, focando a implementação de funcionalidades específicas para auxiliar o gerenciamento dos processos internos da Moradia Estudantil. Enquanto os usuários (servidores) faziam a alimentação dos dados de cadastros básicos no ambiente de produção, a funcionalidade denominada Mapa de Quartos foi desenvolvida. Nesta rotina o servidor da CAE pode visualizar a distribuição dos estudantes residentes na Moradia por unidade (de acordo com o sexo), quarto e beliche ocupados. Esta informação é importante para auxiliar o gestor da Moradia Estudantil na definição da mais adequada alocação dos estudantes dentre as vagas e locais disponíveis.

A Moradia Estudantil possuía alguns processos internos relacionados com o controle de presença dos residentes, até então dependentes da ação de seus servidores, cujos dados 
eram preenchidos em formulários de papel. O primeiro deles a ser projetado no sistema foi a liberação antecipada, rotina onde o servidor preenche os dados de determinado estudante, que ficará dispensado de se apresentar na Moradia durante um período específico e mediante devidas justificativas, como viagem em feriados prolongados para a cidade dos pais ou participação em eventos externos ao campus. Assim que a liberação de um estudante é cadastrada, o sistema armazena esta informação em um local específico para tratar a chamada do período liberado, uma vez que neste caso o estudante está resguardado e não pode constar como ausente.

O segundo processo interno da Moradia Estudantil implementado no sistema foi o controle de frequência dos estudantes residentes, o qual demandou o desenvolvimento de algumas funcionalidades com escopo bem delimitado. Inicialmente foi criado um serviço no SGBD MySQL para que, assim que um novo dia é iniciado no servidor, um registro de frequência é gerado para todos os residentes com a situação "Falta". A proposta é que os estudantes fiquem com falta até que comprovem a presença na Moradia, o que é feito durante um período de tempo parametrizado pelo gestor do local, ocorrendo normalmente durante o início da noite. Foi implementada também uma rotina para que os usuários Administradores possam consultar a geração de listas de chamadas, possibilitando analisar diariamente se os registros de frequência foram gerados corretamente pelo SGBD.

Ainda dentro do escopo do controle de frequência, a equipe da pesquisa implementou a funcionalidade de chamada dos residentes. Como a identificação dos estudantes deveria ser feita com base na leitura da impressão digital, inicialmente o cadastro de dados dos moradores foi alterado para permitir o armazenamento de duas impressões digitais para cada estudante. O gestor da CAE optou pela padronização de utilizar o dedo indicador de cada mão. Esta modificação permitiu que a rotina de chamada fosse construída tendo como foco a simplicidade. O estudante deve apenas informar seu CPF e, em seguida, posicionar no leitor biométrico a digital de um de seus dedos previamente cadastrados para que o sistema realize as devidas validações (se o estudante é residente da Moradia, se está suspenso por algum motivo, se já havia indicado a presença anteriormente) e altere a situação da chamada para "Presente". O leitor biométrico adquirido pelo campus e utilizado no sistema foi o Nitgen Fingkey Hamster III HFDU06S 9 .

Para que os servidores da CAE possam gerenciar os dados armazenados de chamadas realizadas, foi implementada uma rotina denominada "Espelho da Chamada", onde os 
registros podem ser alterados em situações específicas. Nesta página o usuário pode, por exemplo, alterar a situação da chamada (informando a devida justificativa para tal), gerar um relatório mensal da situação de frequência de cada estudante (ou de um grupo deles) e outro relatório com informações consolidadas sobre o controle de frequência dos residentes da Moradia Estudantil. Por fim, a rotina de gerenciamento de atestados foi alterada, de maneira que quando um estudante apresenta a justificativa para a ausência em determinado período o sistema automaticamente muda a situação dos registros de frequências para "Ausência justificada".

Encerrado o desenvolvimento das funcionalidades da segunda versão, a mesma foi validada em um ambiente de testes similar ao de produção. Enquanto os cadastros gerais foram testados por alguns membros da equipe da CAE, a rotina de controle de frequência foi avaliada durante dois meses envolvendo quatro quartos da Moradia Estudantil. O registro da frequência foi realizado, diariamente, na entrada do prédio principal da Moradia, sendo disponibilizados dois leitores, um para os estudantes do sexo masculino e outro para as estudantes do sexo feminino. Em seguida, a versão em produção foi atualizada com as novas funcionalidades e disponibilizada para todos os usuários do sistema.

\section{RESULTADOS E DISCUSSÃO}

Desde a implantação da primeira versão do sistema em produção, ocorrida no início de 2019, os servidores da CAE interromperam o uso de formulários em papel ou eletrônicos (por meio de documentos de texto ou planilhas eletrônicas) daquelas funcionalidades já implementadas e testadas. Optou-se pela utilização plena do sistema para que a rotina antiga de trabalho não impactasse na familiarização dos usuários com a nova ferramenta. Para que isto fosse possível, treinamentos foram realizados com os servidores e houve um acompanhamento frequente dos gestores da CAE desde o início do projeto.

Em relação aos aspectos técnicos do sistema produzido, a equipe de pesquisa preferiu desenvolver um projeto visual padronizado e simplificado, de maneira que os usuários não tivessem dificuldades para encontrar as funcionalidades disponíveis nem enfrentassem problemas na utilização das rotinas. Neste sentido, todas as interfaces gráficas do sistema apresentam o mesmo padrão de formato gráfico, considerando-se desde aspectos de cores e tipografia até os elementos inseridos nos formulários. Na Figura 4 é possível visualizar a página para manutenção dos dados dos estudantes cadastrados no sistema e constatar a simplicidade dos elementos gráficos selecionados. É válido ressaltar que são fictícios os dados 
apresentados; eles foram inseridos no processo de validação das funcionalidades desenvolvidas.

Figura 4: Página para manutenção dos dados dos estudantes

\begin{tabular}{|c|c|c|c|c|c|c|}
\hline \multicolumn{5}{|c|}{ Estudantes } & \multicolumn{2}{|c|}{\begin{tabular}{l|l} 
Pesquisar & Novo Estudante
\end{tabular}} \\
\hline ID & Nome & CPF & Curso atual & Última atualização & & Açōes \\
\hline 4 & Abel Carvalho Fernandes & $160.118 .345-05$ & $\begin{array}{l}\text { Bacharelado em Engenharia da } \\
\text { Computação }\end{array}$ & 29/10/2019 23:33:07 & 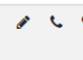 & $\Leftrightarrow 0$ 口 回 \\
\hline 2 & Clara Guimarães Melo & 222.222.222-22 & Bacharelado em Administração & 12/09/2018 19:54:29 & -6 & $\because 0$ 国 \\
\hline 5 & Fernanda Cristina Carvalho Guimarães & $444.555 .666-77$ & Bacharelado em Medicina Veterinária & 29/10/2019 23:38:25 & $\angle 6$ & 00 国 \\
\hline 7 & Joseffrido Cardoso & $122.122 .122-12$ & Bacharelado em Engenharia de Alimentos & 29/10/2018 10:48:57 & \& 6 & $\because 00$ 四 \\
\hline 1 & Lucca Guimarães Melo & $123.456 .789-10$ & $\begin{array}{l}\text { Técnico em Manutenção Automotiva } \\
\text { Subsequente }\end{array}$ & 05/11/2019 00:39:00 & c 6 & $\because 0$ 四 \\
\hline
\end{tabular}

Fonte: Própria (2020)

Para melhorar a experiência dos usuários, foi implementada no sistema a proposta de utilização de janelas modais para manipulação dos dados. Quando uma página é carregada, a listagem de registros relacionados é exibida; caso o usuário acione opções como alteração ou inclusão de registros, a janela com o formulário de dados é exibida de maneira sobreposta à listagem, ficando esta bloqueada até que a janela modal seja fechada. A Figura 5 ilustra esse comportamento do sistema ao apresentar a janela modal para alteração dos dados de um estudante fictício.

Figura 5: Alteração dos dados de um estudante por meio de uma janela modal

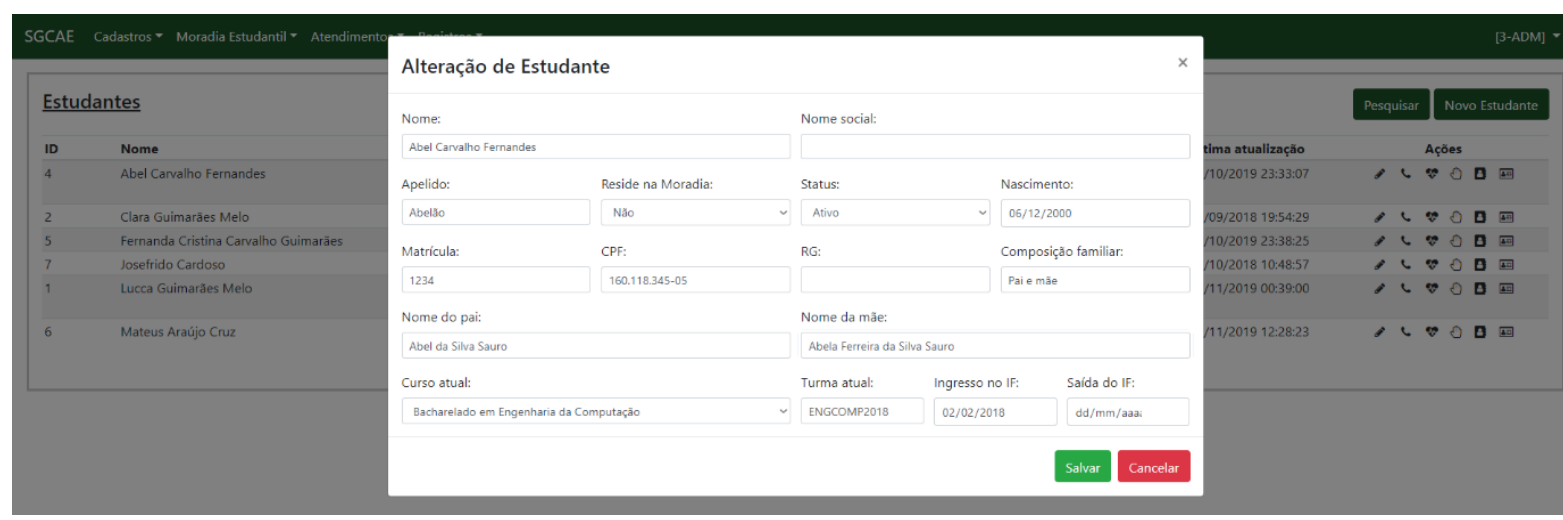

Fonte: Própria (2020)

Para efeitos de padronização das páginas e janelas do sistema, as listagens de dados incluem botões de ação vinculados a cada registro apresentado, bem como um botão específico para inserção de novos dados e outro para que o usuário possa refinar sua pesquisa com o auxílio de filtros em campos específicos. Esta opção de filtragem dos dados foi enfatizada pelos gestores da CAE quando das reuniões de levantamento de requisitos para o sistema como tendo fundamental importância para os usuários, principalmente se for levado 
em consideração o volume de dados que esperava-se, naquele momento, que seria gerado a partir da constante utilização da ferramenta. Ressalta-se que os campos disponíveis para filtragem de registros variam entre as páginas do sistema. A Figura 6 apresenta a janela modal com as opções de pesquisa relacionadas com os dados dos atestados.

Figura 6: Opções de pesquisa para filtragem de dados

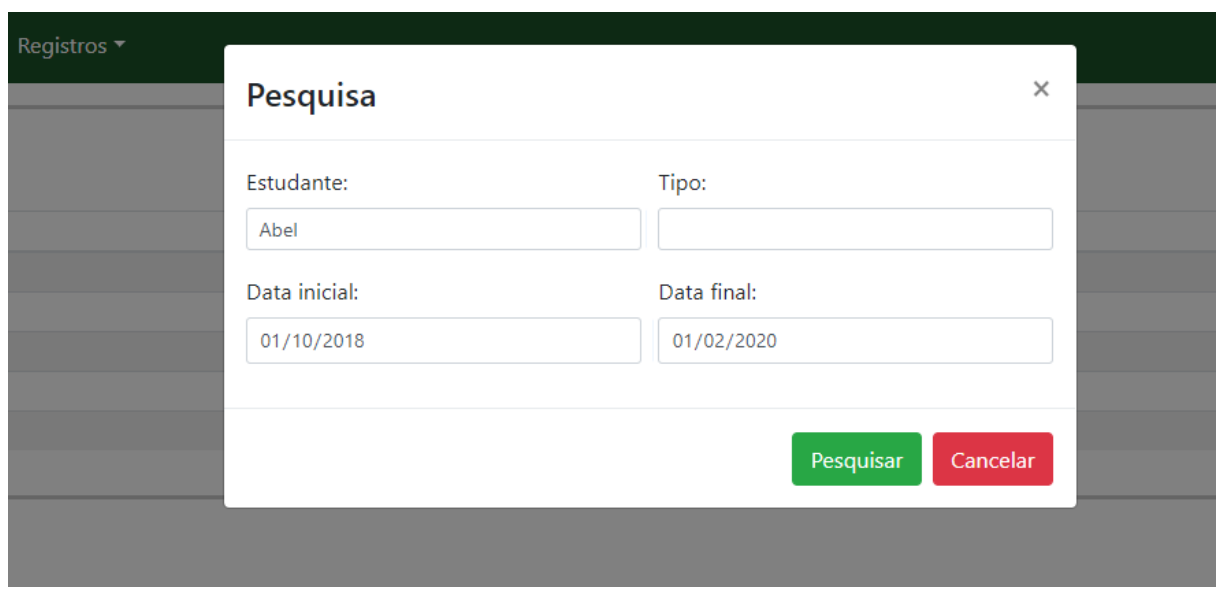

Fonte: Os Autores (2020)

A funcionalidade do Mapa de Quartos possui uma interface mais específica, pois seus dados necessitam ser agrupados em dois níveis: blocos e quartos. Assim como se pode observar a partir da análise da Figura 7, o gestor tem uma visão mais abrangente da ocupação dos espaços da Moradia Estudantil por esta página. Até a utilização do sistema, a divisão dos estudantes por quartos era uma tarefa extremamente trabalhosa, de acordo com os gestores da CAE, pois as informações de blocos e quartos ficavam espalhadas em diferentes arquivos, alguns no formato de documento de texto e outros como planilhas eletrônicas.

Figura 7: Funcionalidade de Mapa de Quartos

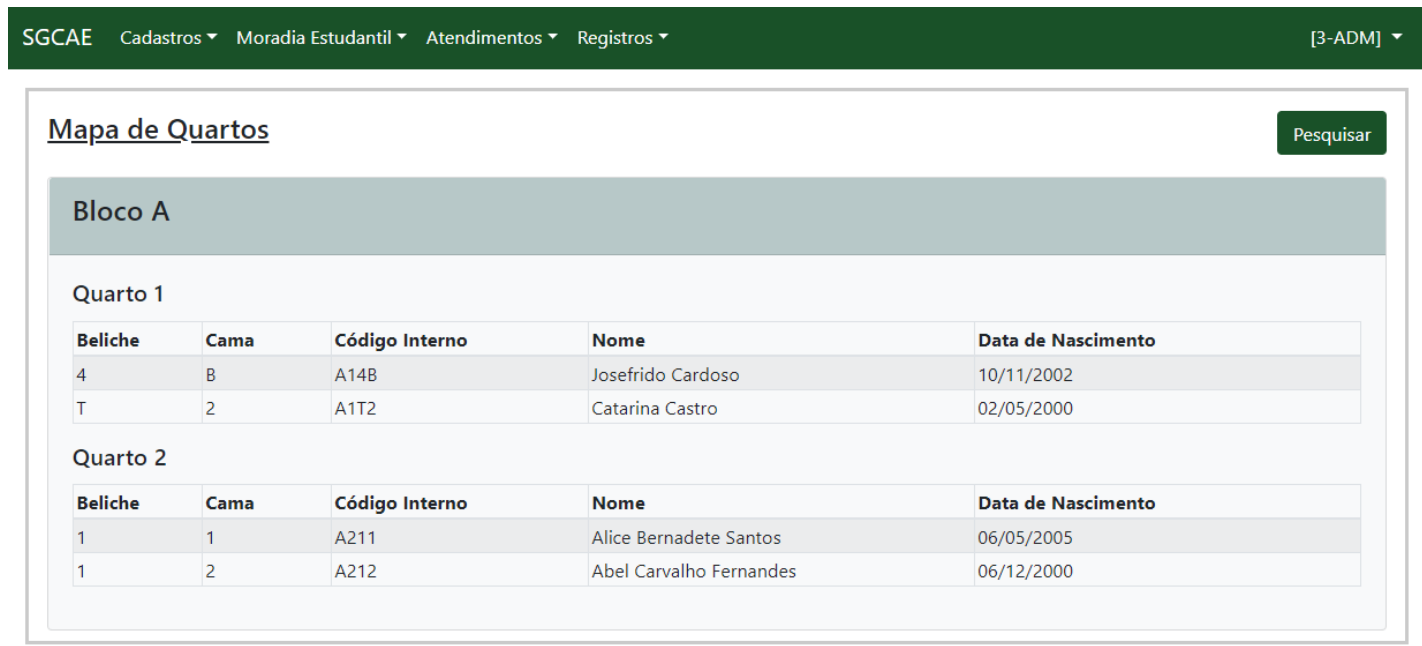

Fonte: Própria (2020)

Conforme exposto anteriormente, o processo de registro de frequência foi idealizado 
para ser de fácil manuseio, em especial por parte dos estudantes. A Figura 8 apresenta a página para realização das chamadas diárias; nela é possível visualizar o campo para preenchimento pelo estudante de seu CPF e um botão para iniciar o processo de leitura da impressão digital. O tempo gasto por um estudante desde o início da rotina até a sua finalização tem sido, em média, de 10 (dez) segundos. O período da chamada pode ser parametrizado pelo Administrador do sistema, fazendo com que até o momento não tenham sido geradas filas para registro da frequência por parte dos estudantes.

Figura 8: Página para registro de frequência com auxílio de leitor de impressão digital

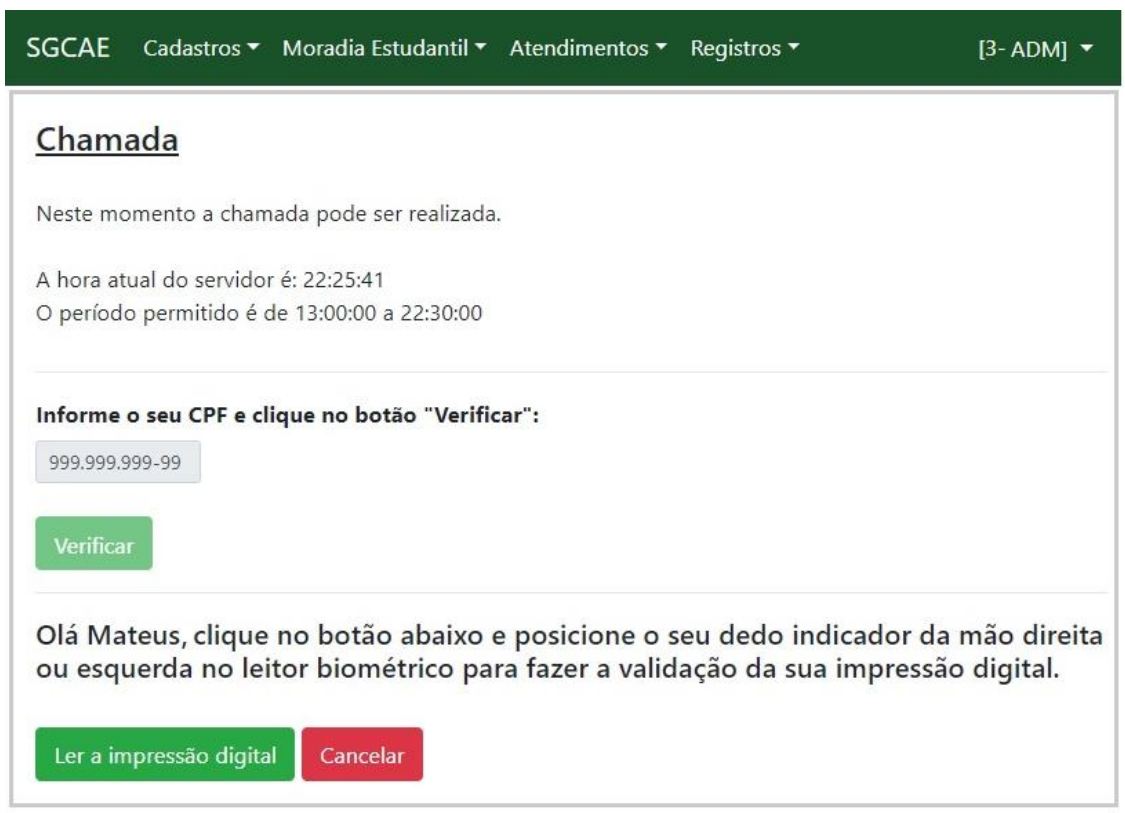

Fonte: Própria (2020)

Uma das grandes possibilidades do sistema está relacionada à geração e obtenção de informações sobre os registros inseridos no banco de dados, o que até então não era possível ou, no melhor dos casos era muito complexo, em função da utilização de documentos de texto e planilhas eletrônicas dispersas entre os usuários do setor. Durante o primeiro ano de utilização do sistema (2019), foram registrados eletronicamente 1.125 atestados médicos, 797 ocorrências, 551 atendimentos no setor de enfermaria e 985 liberações antecipadas de estudantes que residem na Moradia Estudantil. Tais números não podem ser comparados com dados de anos anteriores em função da baixa confiabilidade dos indicadores disponíveis na CAE, até então. Em relação à Moradia, o processo de controle de frequência (e suas rotinas auxiliares) já passou a fazer parte do cotidiano de estudantes e servidores vinculados à CAE. Houve otimização do trabalho de dois servidores que atuam na Moradia, pois antes da implantação do sistema eles percorriam cada um dos quartos para fazer a chamada 
manualmente em papel e, assim que finalizada, os dados eram preenchidos em uma planilha eletrônica. Neste sentido, o sistema desenvolvido trouxe importantes ganhos de produtividade, haja vista que o processo de chamada foi automatizado e a emissão de relatórios gerenciais é feita a qualquer momento, não necessitando de nenhum tipo de preenchimento manual por parte dos servidores.

Finalmente, um dos grandes propósitos da pesquisa foi alcançado, pois a partir da implantação e utilização frequente e correta do sistema pelos servidores da CAE, tornou-se possível a emissão de um relatório consolidando todas as informações sobre determinado estudante. Em suma, esta rotina exibe todo o histórico de um estudante selecionado, apresentando suas informações de cadastro, atestados entregues, ocorrências nas quais teve envolvimento, atendimentos no setor de enfermaria e controle da frequência na Moradia Estudantil (caso seja residente). A expectativa é que tal documento passe a ser utilizado (com o devido sigilo) também pelos gestores dos cursos e pela Diretoria de Ensino no intuito de conhecer melhor o perfil dos estudantes do campus, identificando suas demandas, dificuldades e características.

\section{CONCLUSÕES}

Os resultados obtidos a partir da execução desta pesquisa evidenciam que a gestão pode ser beneficiada pela utilização de recursos tecnológicos, tais como softwares, desde que os mesmos apresentem a devida adequação e aderência ao ambiente em questão e que, tanto gestores quanto outros tipos de usuários estejam dispostos a apoiar uma forma de trabalho mais moderna e dinâmica.

Percebeu-se, entre outras referências positivas, que os problemas de gerenciamento das informações da Assistência Estudantil do IFMG - Campus Bambuí são agora melhor tratados com o apoio do sistema construído, pois todas as funcionalidades desenvolvidas estavam estritamente de acordo com as demandas dos servidores que lá atuam. Ademais, foi possível notar que os processos de trabalho foram facilitados, mesmo ao considerar-se naturais dificuldades advindas do uso de uma nova ferramenta e de novos métodos de trabalho. O compartilhamento de informações passou a ser possível, independentemente do servidor que as detém, pois mesmo com os perfis definidos pelo sistema os dados básicos podem ser acessados por aquelas pessoas que realmente necessitam deles para a tomada de alguma decisão.

Outros benefícios obtidos pela utilização do sistema foram a redução na quantidade de 
papel utilizado no cotidiano do setor e o acesso mais rápido às informações, seja de um estudante específico ou daquelas consolidadas de determinados indicadores. A integração dos dados também foi facilitada pelo sistema, pois ao utilizar uma base de dados centralizada e padronizada, a geração de informações fica mais simples de ser processada, neste caso em formato de relatórios gerenciais cujo modelo foi definido previamente pelos servidores da CAE. A rotina de backup desta base de dados em nuvem permite também que, caso ocorra algum novo incidente com a infraestrutura de TI do campus, os dados não se percam.

Uma dificuldade enfrentada durante a execução das atividades da pesquisa que merece menção refere-se às repetidas mudanças do coordenador da Assistência Estudantil do IFMG Campus Bambuí, evento ocorrido por três vezes até o presente momento. Tal fato criou situações que atrasaram o desenvolvimento de algumas funcionalidades do sistema, pois até que os novos gestores tomassem conhecimento do mesmo e indicassem sugestões de ajustes, as tarefas de implementação ficaram pendentes para evitar possíveis retrabalhos.

Quando um software é disponibilizado em ambiente de produção para seus usuários entende-se que ele, na verdade, está apenas começando a ter sua vida dentro da organização. É comum que correções, ajustes e melhorias sejam demandados pelos usuários para que, efetivamente, o sistema possa contribuir de acordo com o que era esperado. Neste sentido, esta pesquisa pode ser melhorada a partir de uma integração com o sistema acadêmico utilizado pelo campus para gestão das informações dos estudantes. Tal ação não foi possível pelo fato de o sistema atualmente utilizado ser de propriedade particular de uma empresa e não disponibilizar uma interface para comunicação externa direta com outras aplicações. Outra melhoria sugerida é a integração com o sistema utilizado pelo Restaurante Universitário, fazendo com que novas informações sejam agregadas ao histórico de cada estudante cadastrado no sistema da CAE. Por fim, é necessário que outras áreas de atuação da CAE, como Psicologia e Nutrição, tenham seus processos internos mapeados e implementados no sistema para que os servidores que nelas atuam também possam usufruir da ferramenta tecnológica ao planejar e executar suas ações.

\section{REFERÊNCIAS}

ARAÚJO, B. D. L.; PINHEIRO JÚNIOR, F. M. L.; ABREU, F. P. Gerenciamento de aquisições de soluções de tecnologia da informação em uma universidade pública do Ceará. Revista Gestão em Análise, v. 4, n. 1, p. 43-53, 2015.

ASSIS, W. C. Governança de TI na administração Pública Federal: aprimorando a 
governança de TI no setor público brasileiro. 2016. Disponível em: http://repositorio.uniceub.br/jspui/handle/235/8064. Acesso em: 17 jul. 2020.

BATISTA, E. O. Sistemas de Informação. São Paulo: Saraiva, 2017.

BROGNOLI, T. S.; FERENHOF, H. A. Transformação Digital no governo brasileiro: desafios, ações e perspectivas. Navus - Revista de Gestão e Tecnologia, [S.1.], v. 10, p. 01-11, jan/dez. 2020. ISSN 2237-4558. Disponível em: <http://navus.sc.senac.br/index.php/navus/article/view/989/pdf>. Acesso em: 24 ago. 2020.

CAE. Coordenadoria de Assistência Estudantil (CAE) do IFMG - Campus Bambuí. Disponível em: <http://bambui.ifmg.edu.br/portal/cae>. Acesso em: 18 jul. 2020.

CGTI. Sistemas de Informação da Coordenadoria de Gestão de Tecnologia da Informação do IFMG - Campus Bambuí. Disponível em: http://www.bambui.ifmg.edu.br/portal/cgti/sistemas-de-informacao. Acesso em: 18 jul. 2020.

DIAS, T. F.; SANO, H.; MEDEIROS, M. F. M. Inovação e tecnologias da comunicação e informação na administração pública. Brasília: ENAP, 2019.

FREITAS, A. L. S.; CREMASCO JÚNIOR, D.; SOUZA, M. P. Transição da gestão de tecnologia da informação para a governança eletrônica na Universidade Federal de Rondônia. 2015. Disponível em: https://repositorio.ufsc.br/handle/123456789/136120. Acesso em: 15 ago. 2020.

FREITAS, E. C. de; PRODANOV, C. C. Metodologia do Trabalho Científico: Métodos e Técnicas da Pesquisa e do Trabalho Acadêmico. 2. ed. Novo Hamburgo: Feevale, 2013.

GIL, A. C. Métodos e Técnicas de Pesquisa Social. 7. ed. São Paulo: Atlas, 2019.

GOMES FILHO, A. C. Gestão de Tecnologia da Informação: Abordagem para o Setor Público. 2018. Disponível em: http://repositorio.unicentro.br:8080/jspui/bitstream/123456789/1314/1/GOMES_Gestao_de\% 20TI_abordagem_para_setor_publico.pdf. Acesso em: 23 ago. 2020.

LAUDON, K.; LAUDON, J. Sistemas de Informações Gerenciais. São Paulo: Pearson, 2015.

MARCHIORI, D. M.; MAINARDES, E. W. A Relação Entre os Fatores Criadores do Technostress e a Qualidade Percebida de Serviços de Tecnologia da Informação. ENCONTRO SEMINÁRIOS EM ADMINISTRAÇÃO (SEMEAD), v. 18, 2015.

MATTOS, A. C. M. Sistemas de Informação: uma visão executiva. 2. ed. São Paulo: Saraiva, 2017.

RABELO, C. L. A. et al. A participação da sociedade no governo eletrônico sob a perspectiva da democracia digital. Revista Argumentum-Argumentum Journal of Law, v. 13, p. 225-255, $2019 . \quad$ Disponível http://ojs.unimar.br/index.php/revistaargumentum/article/view/1093/687. Acesso em: 15 ago. 2020. 
ROZA, R. H. Revolução informacional e os avanços tecnológicos da informática e das telecomunicações. Ciência da Informação em Revista, v. 4, n. 3, p. 3-11, 2017.

SILVA, R. T. et al. Gestão por Processos em Tecnologia da Informação: um estudo em uma empresa de médio porte. Revista de Administração do UNIFATEA, v. 12, n. 12, 2016.

SILVEIRA, D. T.; CÓRDOVA, F. P. A pesquisa científica. Porto Alegre: UFRGS, 2009.

SORDI, J. O.; MEIRELES, M. Administração de Sistemas de Informação. 2. ed. São Paulo: Saraiva, 2018.

SZIMANSKI, F. et al. Reestruturando a Área de Tecnologia da Informação: um relato de experiência na administração pública. In: Anais do XI Simpósio Brasileiro de Sistemas de Informação. SBC, 2015. p. 475-482.

VILELA, B. D. et al. Coordenação em cadeias de suprimentos: o papel da tecnologia da informação e da gestão orientada por processos. Exacta, v. 14, n. 4, p. 645-660, 2016.

WAZLAWICK, R. S. Metodologia de pesquisa para ciência da computação. 2 . ed. Rio de Janeiro: Elsevier, 2014.

ZORZAL, L. Transparência das informações das universidades federais: estudo dos relatórios de gestão à luz dos princípios de boa governança na Administração Pública Federal. 2015. Disponível em: http://repositorio.unb.br/handle/10482/19202. Acesso em: 15 abr. 2020. 


\title{
CAPÍTULO 06: SISTEMA EMBARCADO PARA O CONTROLE DE POSIÇÃO DE UM ROBÔ PARALELO TIPO DELTA LINEAR DE BAIXO CUSTO
}

\section{CAPÍTULO 06: SISTEMA EMPOTRADO PARA EL CONTROL DE POSICIÓN DE UN ROBOT LINEAL DELTA LINEAL DE BAJO COSTE}

\section{CHAPTER 06: EMBEDDED SYSTEM FOR THE POSITION CONTROL OF A LOW- COST LINEAR DELTA LINEAR ROBOT}

\author{
José Lucas Moreira Cavalcanti de Abreu ${ }^{1}$; Asafe dos Santos Silva ${ }^{2}$; João Manoel Freitas Souza ${ }^{3}$ Alexander \\ Patrick Chaves de Sena ${ }^{4}$
}

DOI: https://doi.org/10.31692/978-65-88970-06-5.82-98

\begin{abstract}
RESUMO
O presente trabalho apresenta um sistema embarcado para o controle de posição de um robô paralelo com aplicação para acabamentos mecânicos. Anteriormente a máquina operava através do suporte computacional utilizando um dispositivo de alto custo. Dessa forma, com a substituição do aparato de processamento, sem a perda qualitativa, é possível estimar uma maior acessibilidade ao sistema concebido. Foi selecionada para a realização do trabalho a plataforma de software livre Arduino Due. O dispositivo controlado possui três bases manipuladas, com $300 \mathrm{~mm}$ de curso útil. Cada base é acionada por um motor de corrente contínua (CC) e um encoder, com resolução de 400 pulsos por volta. É utilizada a técnica de controle PID, com base no método Ziegler-Nichols de definição paramétrica. Para a melhor visualização, de forma gráfica, e definição dos dados empregados no sistema, desenvolveu-se um programa supervisório por meio da linguagem Java, que permite ao usuário definir os ganhos proporcionais, derivativos e integradores, bem como visualizar em tempo real a resposta sistemática perante aos parâmetros aplicados. Ao término do trabalho, pode se verificar um erro atuante máximo nos carros de aproximadamente $2,86 \%$, obtendo por fim um dispositivo mais barato, com eficiência compatível com a original.
\end{abstract}

Palavras-Chave: controlador PID; controle de posição; robô paralelo; sistema embarcado.

\section{RESUMEN}

El presente trabajo presenta un sistema embebido para el control de posición de un robot paralelo con aplicación para acabados mecánicos. Anteriormente, la máquina operaba mediante soporte computacional utilizando un dispositivo de alto costo. Así, con la sustitución del aparato de procesamiento, sin pérdida cualitativa, es posible estimar una mayor accesibilidad al sistema diseñado. La plataforma de software libre Arduino Due fue seleccionada para realizar el trabajo. El dispositivo controlado tiene tres bases manipuladas, con $300 \mathrm{~mm}$ de recorrido útil. Cada base es accionada por un motor de corriente continua (CC) y un codificador, con una resolución de 400 pulsos por revolución. Se utiliza la técnica de control PID, basada en el método de definición paramétrica de Ziegler-Nichols. Para la mejor visualización, gráfica y definición de los datos utilizados en el sistema, se desarrolló un programa supervisor en lenguaje Java, que permite al usuario definir las ganancias proporcionales, derivadas e integradores, así como visualizar la respuesta en tiempo real. sistemático ante los parámetros aplicados. Al final del trabajo se puede comprobar un error máximo activo en los coches de aproximadamente $2,86 \%$, obteniendo finalmente un dispositivo más económico, con eficiencia compatible con el original.

Palabras Clave: Controlador PID, control de posición, robot paralelo, sistema empotrado.

\section{ABSTRACT}

\footnotetext{
${ }^{1}$ Técnico em Mecatrônica, Instituto Federal de Pernambuco Campus Caruaru, josedeabreu

${ }^{2}$ Engenharia Mecânica, Instituto Federal de Pernambuco Campus Caruaru, asafesilv

3 Técnico em Mecatrônica, Instituto Federal de Pernambuco Campus Caruaru, joss

${ }^{4}$ Doutor, Instituto Federal de Pernambuco Campus Caruaru, alexander.sena@ caruaru.ifpe.edu.br
}

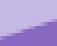


The present work presents an embedded system for the position control of a parallel robot with application for mechanical finishes. Previously, the machine operated through computational support using a high-cost device. Thus, with the replacement of the processing apparatus, without qualitative loss, it is possible to estimate greater accessibility to the designed system. The free software platform Arduino Due was selected to carry out the work. The controlled device has three manipulated bases, with $300 \mathrm{~mm}$ of useful stroke. Each base is driven by a direct current motor (DC) and an encoder, with a resolution of 400 pulses per revolution. The PID control technique is used, based on the ZieglerNichols method of parametric definition. For the best visualization, in graphic format, and definition of the data used in the system, a supervisory program was developed through the Java language, which allows the user to define proportional, derivative and integrating gains, as well as to visualize in real time, the systematic response to the applied parameters. At the end of the work, a maximum active error in the cars of approximately $2,86 \%$ can be verified, finally obtaining a cheaper device, with efficiency compatible with the original.

Keywords: PID controller; position control; parallel robot; embedded system.

\section{INTRODUÇÃO}

Considerando o atual crescimento na demanda por produtos, as indústrias estão passando por um período de grandes invetimentos nas linhas de produção, geralmente atuando na aplicação de robôs manipuladores (CORREIA, 2018). Estas máquinas podem realizar uma série de tarefas com maior velocidade, precisão e qualidade que o homem, além de aumentarem de uma maneira significativa a produção. Inicialmente os robôs foram desenvolvidos para a execução de tarefas humanas, e neste sentido, deviam ter uma boa manobrabilidade e bom espaço de trabalho, mas a relação da capacidade de carga com o seu peso era baixa (ALMEIDA JUNIOR, 2018a). Em termos mecânicos, os manipuladores seriais são constituídos por atuadores nas suas partes móveis, implicando em massas e momentos de inércia relativamente altos. Na sua maioria um atuador é fixo à base, sendo que os demais são embarcados, ocasionando no aumento de inércia das partes móveis. Além disso, cada junta suporta a massa das demais e dos segmentos subsequentes. Nessas condições a rigidez do sistema é comprometida, acarretando em uma menor precisão e capacidade de posicionamento (SILVA et. al., 2020). Por isso, para garantir um mínimo de rigidez ao sistema, os elementos devem ser volumosos e pesados, comprometendo o comportamento dinâmico da estrutura serial. Um conceito importante é a complacência de um robô. Em geral o efetuador de um robô serial quando submetido a forças e torques externos sofre pequenas modificações em sua posição devido a uma folga dos atuadores, vibração de seus componentes ou deformação em seus links, entre outros. Essas grandezas não podem ser quantificadas por sensores internos do robô e por isso não podem ser corrigidas pela malha de controle, dai o nome complacência passiva (SILVA, et al., 2019).. Em diversas aplicações na indústria como, por exemplo, em máquinas ferramentas, essa complacência é uma característica indesejada. Erros nas juntas até o órgão terminal, somados à flexibilidade da 
estrutura, comprometem à precisão do conjunto robótico (SILVA, et al., 2019).

Robôs paralelos são mecanismos com cadeias fechadas que apresenta vantagens frente aos robôs seriais quanto à rigidez, precisão/velocidade de posicionamento e razão peso/carga (SENA, SILVA e SILVA, 2017). Nos manipuladores paralelos, todos os atuadores são montados próximos à base, possibilitando assim uma possível redução da massa nas suas partes móveis, implicando que os manipuladores paralelos apresentam características dinâmicas melhores em relação aos seriais (SILVA et. al., 2020). Suas principais desvantagens, no entanto, referem-se ao espaço de trabalho limitado e à maior complexidade de seus componentes mecânicos (SENA, SILVA e SILVA, 2017). O interesse pelos robôs paralelos ocorreu como uma alternativa para os problemas de pouca capacidade de carga e rigidez que tinham os robôs de configuração serial (SENA, SILVA e SILVA, 2017). Para controlar esse sistema de forma que o mesmo seja capaz de imitar movimentos específicos, é essencial conhecer quais são suas características cinemáticas e dinâmicas, suas limitações espaciais e finalmente de que forma podem ser controlados os diferentes atuadores para realizar as diferentes trajetórias planejadas. Cadeias cinemáticas fechadas possuem, em geral, rigidez mais elevada que as estruturas com cadeias abertas, e a deformação proveniente da complacência passiva é facilmente medida no efetuador (SILVA et. al., 2020). Dentre as diferentes aplicações de sistemas de posicionamento modernos utilizando dispositivos robóticos paralelos podemos destacar: simuladores de voo, máquinas ferramentas, manipuladores cirúrgicos, sistemas de locomoção bípedes, entre outros. O presente documento visa propor a concepção de um sistema embarcado para o controle de um robô paralelo tipo delta de baixo custo, que pode ser visualizado na Fig.(01).

Recentemente algumas pesquisas foram publicadas descrevendo o uso da arquitetura paralela para concepção de robôs específicos, tais como: Sena, Silva e Silva (2017), Almeida Júnior et al. (2018a), Almeida Júnior et al. (2018b) e Silva et. al. (2020).

A técnica de controle PID (Proporcional-Integral-Derivativo) consiste em calcular um valor de atuação sobre o processo a partir das informações de um valor desejado de posição, por exemplo, e do valor real da variável obtido por um sistema de medição. A possibilidade dos robôs paralelos operarem com altas acelerações e alta exatidão gerou a necessidade do desenvolvimento de sistemas de controle de alto desempenho (SILVA et. al., 2020). Os controladores de alto desempenho podem ser implementados computadorizados ou embarcados. Os denominados "sistemas embarcados" ou "embutidos" são sistemas microprocessados de funcionalidades específicas (QUEIROZ, 2015), o que os distinguem dos computadores convencionais, os quais são utilizados para propósito geral. 
Figura 01: Robô paralelo delta linear de baixo custo.

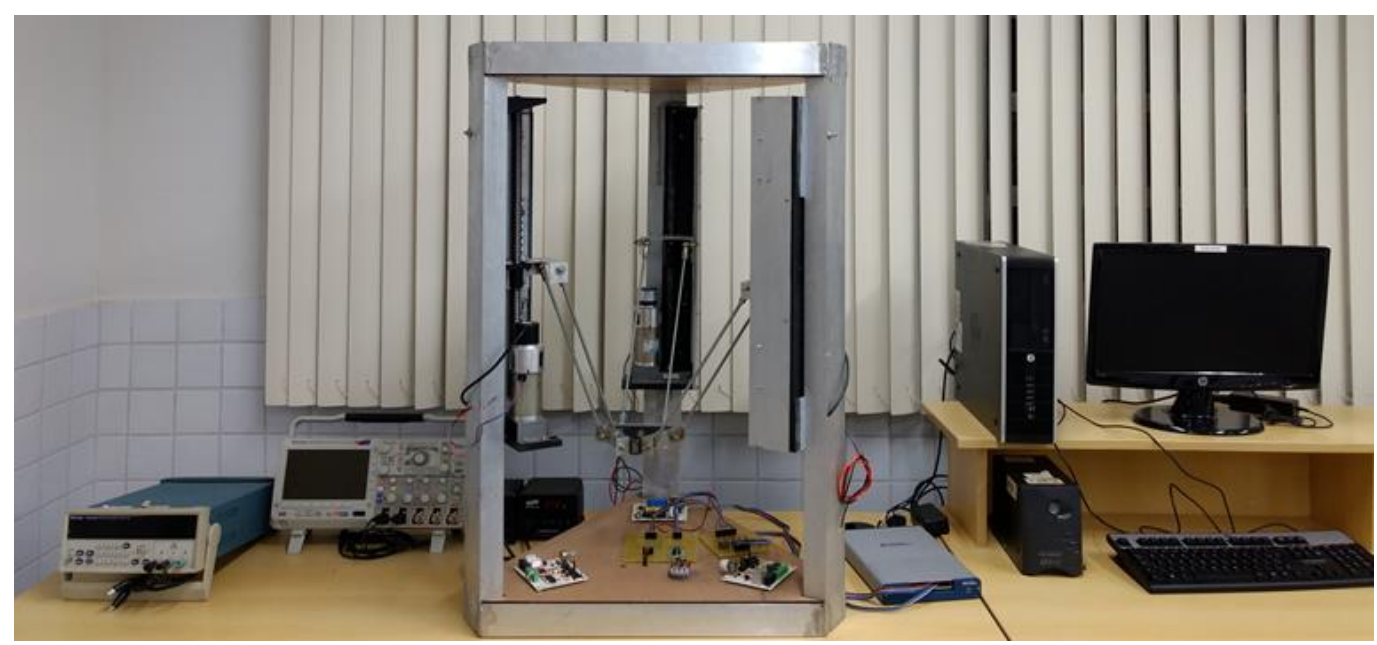

Fonte: Própria (2020).

Em Almeida Júnior et al. (2018b), a mesma máquina foi controlada por meio de sistema computadorizado (alto custo) composto pelo módulo multifuncional de aquisição NI USB-6353 da National instruments ${ }^{\circledR}$, desktop e supervisório em Labview ${ }^{\circledR}$, entretanto, para caracterizar um baixo custo para o produto final, visa-se através do presente trabalho embarcar a solução por meio de microcontrolador, tornando assim o sistema mais acessível. O dispositivo tem sido utilizado para realização do acabamento de puído em jeans. O puído é um processo abrasivo de desgaste das fibras e do tecido, sendo muito usado para imitar o efeito de desgaste natural que a roupa passa a apresentar com o tempo de uso. Usualmente o efeito desfiado ou rasgado nos jeans é obtido utilizando uma retífica manual, ocasionando uma falta de padronização dos produtos. Neste sentido, o trabalho se enquadra no processo de obtenção de uma solução para a diminuição das não conformidades nos acabamentos mecânicos da indústria confeccionista. Os resultados obtidos com o sistema computadorizado permitiu um erro de posicionamento de 2,50\%, considerado aceitável para a aplicação de acabamentos. Com a substituição do sistema de controle, objetiva-se um erro de posicionamento menor que $5 \%$.

\section{FUNDAMENTAÇÃO TEÓRICA}

O objetivo básico de um sistema de controle consiste em aplicar sinais adequados na entrada do processo de modo a que o sinal de saída satisfaça certas especificações e/ou apresente um comportamento particular. O sistema a ser controlado geralmente chamado de processo ou planta é o dispositivo ou fenômeno que se deseja atuar com alguma finalidade, 
sendo este representado por uma variável de entrada, uma variável de saída e uma relação (função de transferência) entre as duas variáveis. A entrada do processo é chamada de variável de controle ou variável manipulada, e a saída do processo é chamada de variável controlada ou variável de processo. Um distúrbio ou perturbação é caracterizado por um sinal que tende a afetar de modo adverso o valor da variável de saída de um sistema.

Neste contexto, um Sistema de Controle em Malha Aberta (SCMA) consiste em aplicar um sinal de controle pré-determinado, esperando-se que ao final de um determinado tempo a variável controlada atinja um determinado valor ou apresente um determinado comportamento, sendo que neste tipo de sistema não são utilizadas informações sobre evolução do processo para determinar o sinal de controle a ser aplicado em um determinado instante. Por outro lado, no controle em malha fechada, informações sobre como a saída de controle está evoluindo a partir de uma realimentação, são utilizadas para determinar o sinal de controle que deve ser aplicado ao processo em um instante específico. O sinal de saída é comparado com um sinal de referência e o desvio (erro) entre estes dois sinais é utilizado para determinar o sinal de controle que deve efetivamente ser aplicado ao processo. Assim, o sinal de controle é determinado de forma a corrigir este desvio entre a saída e o sinal de referência. O dispositivo que utiliza o sinal de erro para determinar ou calcular o sinal de controle a ser aplicado à planta é chamado de controlador ou compensador (DORF, 2018).

Uma vantagem dos sistemas de controle a malha fechada é o fato de que o uso da retroação torna a resposta do sistema relativamente insensível a perturbações externas e a variações internas de parâmetros do sistema, sendo possível à utilização de componentes baratos e sem muita exatidão para obter o controle preciso de um determinado processo, o que não é possível com o controle à malha aberta. Entretanto, do ponto de vista da estabilidade, é mais fácil construir sistemas a malha aberta porque a estabilidade destes sistemas é menos problemática. Por outro lado, a estabilidade em sistemas de controle a malha fechada é sempre um grande problema pela tendência em corrigir erros além do necessário, o que pode ocasionar oscilações de amplitude constante ou crescente com o tempo. Deve-se enfatizar que, para sistemas onde as entradas são conhecidas antecipadamente no tempo e não há distúrbios é aconselhável o uso de controle a malha aberta.

Inserido na malha de controle fechada, o controlador determina um sinal de erro comparando o valor de saída da planta com uma referencia de entrada. A partir desse erro, determina um sinal de controle para reduzir o erro à zero ou a um valor aceitável, do ponto de vista da utilização do sistema controlado. 
As malhas convencionais de controle têm sido utilizadas na maioria dos processos automatizados no meio industrial nos últimos 50 anos. Entre os motivos pode-se mencionar: estrutura simples, robustez, reduzido número de parâmetros configurados, conhecimento intuitivo sobre o desempenho destas técnicas de controle, e requerimento mínimo de conhecimento matemático e técnico. Entretanto, na teoria de controle convencional, os objetivos de projeto dos controladores são fixos e definidos pelo projetista. Consequentemente, a abordagem convencional de controle é limitada para muitas situações complexas, devido ao fato que estas requerem algumas formas de autonomia e as estratégias convencionais de controle oferecem um número reduzido de graus de liberdade. Estas complexidades caracterizam processos com modelos matemáticos "pobres", elevados níveis de ruído, rigorosos índices de desempenho, presença de não-linearidades, sensores distribuídos e a necessidade da tomada de decisões.

Para obtenção de modelo matemático da planta, com o objetivo de se projetar o controlador, inicialmente é realizado o processo de identificação da planta, podendo ser usados métodos como caixa preta, branca e cinza. Desse modo, o projeto do controlador é realizado a partir das especificações desejadas para um bom desempenho do sistema. Apesar da realimentação manter estabilidade para futuras variações e incertezas do sistema, algumas variações são tão amplas e com efeitos significativos sobre o comportamento dinâmico que um ganho de realimentação linear e com coeficientes constantes é incapaz de fornecer a flexibilidade necessária para atender às especificações de desempenho. Sendo assim, passa a ser necessário medir continuamente estas variações e então ajustar devidamente os parâmetros de controle ("ganhos não-lineares"). A Fig. (02) apresenta o diagrama de blocos típico de uma estrutura de controle clássico.

Figura 02: Filosofia de controle clássico.

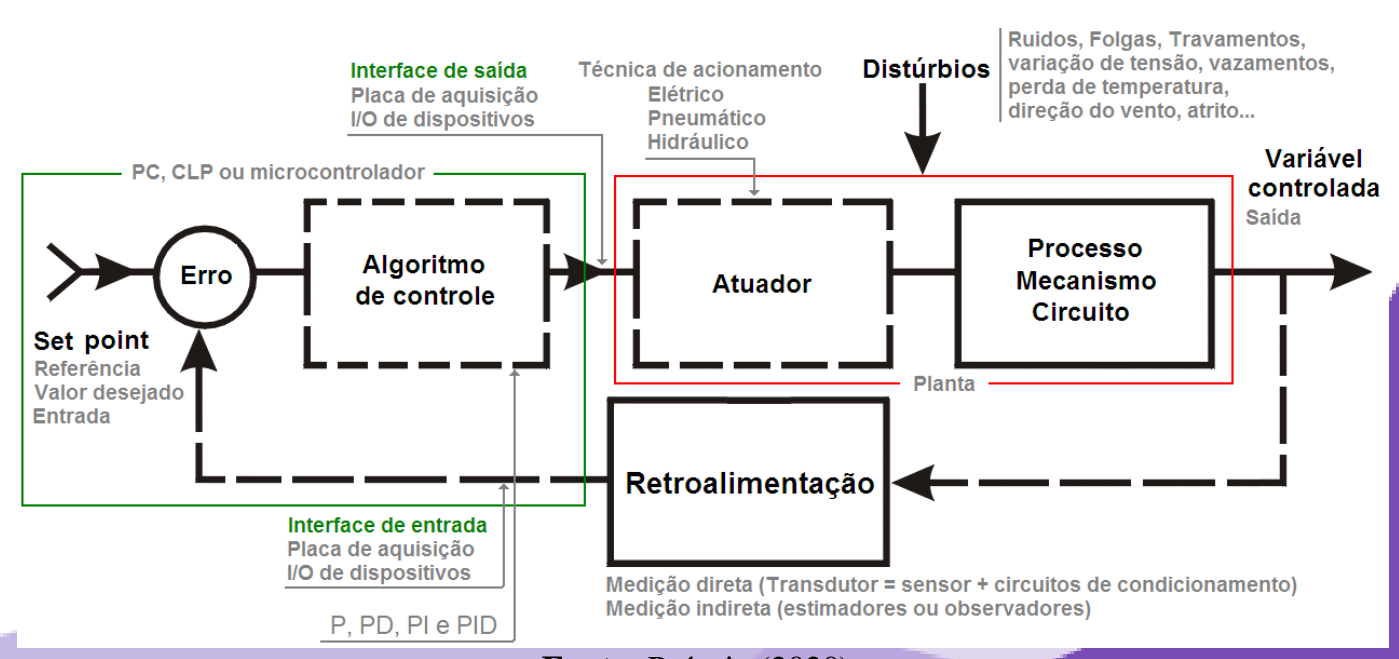

Fonte: Própria (2020). 
Segundo Ogata (2015) o controlador PID, como o próprio nome sugere, é uma técnica que combina as três ações de controle, proporcional, integral e derivativo. A combinação dessas ações fornece as vantagens individuais de cada uma das três técnicas, juntando todas em um único controlador. O funcionamento deste controlador discretizado é regido pela Eq.(01).

$$
u(t)=K_{p} e(t)+u i(k T)+K_{i} e(t) T+K_{d}(t) \frac{e(t)-e(k t)}{T}
$$

Onde $K_{p}$ é o ganho proporcional do sistema; $K_{i}$ é o ganho integral do sistema; $K_{d}$ é o ganho derivativo do sistema; $T$ é o período de amostragem; $e(t)$ é o erro atual do sistema; $e(k T)$ é o erro no instante anterior ao atual; $u i(k T)$ é o valor integral no instante anterior ao atual e $u(t)$ é a saída PID propriamente dita do sistema.

Este controlador é bastante popular em função de sua simplicidade e aplicabilidade em diversos sistemas. Outra vantagem destes controladores, é que regras empíricas podem ser aplicadas, tais como Ziegler-Nichols, permitindo o ajuste dos parâmetros do controlador sem a necessidade do conhecimento do modelo matemático do sistema. Uma das dificuldades na implementação do controle PID, é a sintonização experimental dos valores dos ganhos proporcional, integral e derivativo. Apesar da maioria dos processos serem intrinsecamente não-lineares, o uso deste tipo de controlador se baseia na consideração de que, em torno do ponto típico de operação, o sistema se comporta de maneira aproximadamente linear. Esta premissa funciona bem em grande parte dos processos, para uma determinada janela de tempo e operação, a partir da qual normalmente se faz necessária uma ressintonia do controlador.

\section{METODOLOGIA}

A metodologia para este trabalho foi estruturada em algumas etapas, conforme apresentado na Fig.(03). 
Figura 03: Metodologia para o projeto do controle do robô Delta.

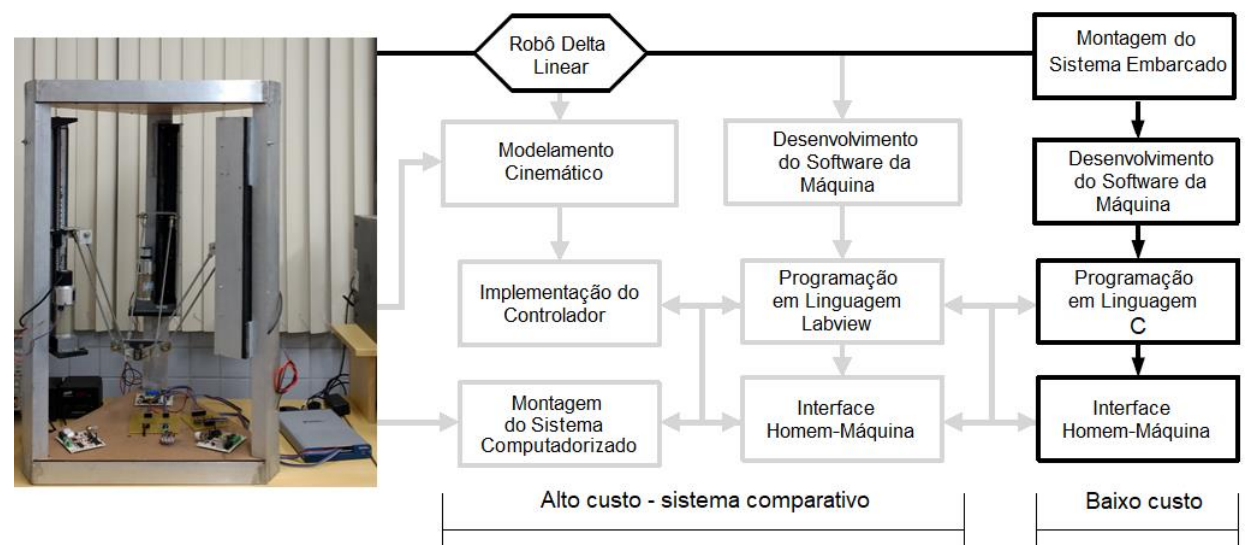

Fonte: Própria (2020).

A fim de substituir o sistema computadorizado para uma alternativa barata e eficiente, decidiu-se embarcar o controle PID através de um microcontrolador, selecionado a partir de testes de aquisição dos dados dos sensores, averiguando-se a velocidade na qual os dados eram processados e os valores de posição, em comparação com o sistema computadorizado. A plataforma open source Arduino Due, foi utilizada como novo componente computacional operante para o controle dos parâmetros PID, dispositivo esse que possui: processador ATMEL SAM3X8E (32 bits), 54 entradas e saídas digitais, 12 entradas analógicas, $84 \mathrm{MHz}$ de frequência de clock, 512 KB de memória Flash, 96 KB de memória SRAM, 54 portas com interrupção, 12 saídas PWM. Outras plataformas foram testadas, como Arduino Mega, não obtendo êxito nas leituras. O microcontrolador é o hardware responsável pelas entradas e saídas de sinais nos processos de medição e controle por meio de sistemas embarcados.

Os elementos funcionais de um sistema de aquisição embarcado são comumente os sensores e transdutores, os cabos de ligação, o condicionamento de sinal (quando necessário), o conversor A/D e o algoritmo de aquisição. A Fig.(04) apresenta o diagrama esquemático da aquisição de sinais de um fenômeno físico para controle por meio de um sistema embarcado.

Figura 04: Diagrama funcional de um sistema de aquisição por sistema embarcado.

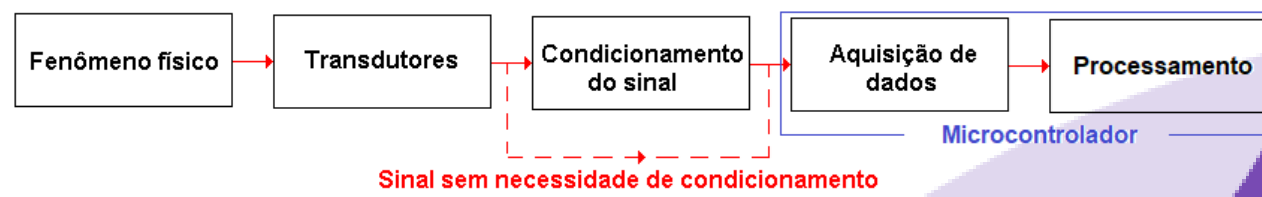

Fonte: Própria (2020).

Nos encoders incrementais com código Gray, a frequência dos pulsos determina a 
velocidade do eixo, e a quantidade de pulsos, a partir de um referencial, determina o deslocamento angular, fornecendo a distância linear percorrida. O processo de conversão de um código Gray para binário é realizado repetindo o bit mais significativo, e o valor do bit menos significativo é o resultado da operação lógica "ou exclusivo", entre os dois bits Gray. O processo de conversão de um número binário em decimal é realizado multiplicando-se cada bit binário pela base do sistema (base dois), elevado à posição que ocupa da direita para esquerda, iniciando-se do índice zero. A contagem decimal primária se limita a representação dos quatro estados possíveis nos encoders. Para varrer todo o conjunto de valores decimais inteiros, foi implementado um algoritmo de incremento ou decremento unitário. Os encoders incrementais adquiridos (A38S6-400-2-2-24) permitem uma resolução de 400 Pulsos/volta, gerando na combinação dos dois canais, um código Gray de 1600 estados/volta. Com base no passo dos fusos (5mm) é possível relacionar cada estado gerado nos encoders, ao deslocamento dos sistemas lineares (calculado em 0,003125 mm/pulso).

A Fig.(05) apresenta o hardware do sistema de aquisição montado para todo o conjunto robótico.

Figura 05: Detalhamento do hardware de aquisição montado.

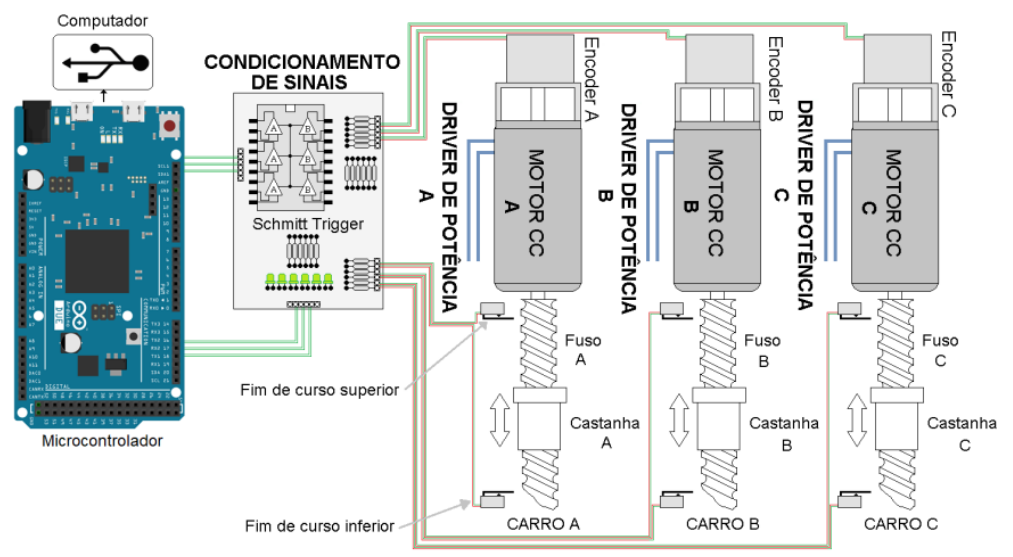

Fonte: Própria (2020).

O sistema de acionamento permite o comando e ajuste da rotação dos motores Corrente Continua (motores de CC) por meio de circuitos drivers (circuitos de potência). Os circuitos drivers recebem sinais PWM dos controladores PID implementados em linguagem C. A Fig.(06) apresenta o diagrama de blocos do sistema de acionamento.

Figura 06: Diagrama funcional do sistema de acionamento de acionamento.

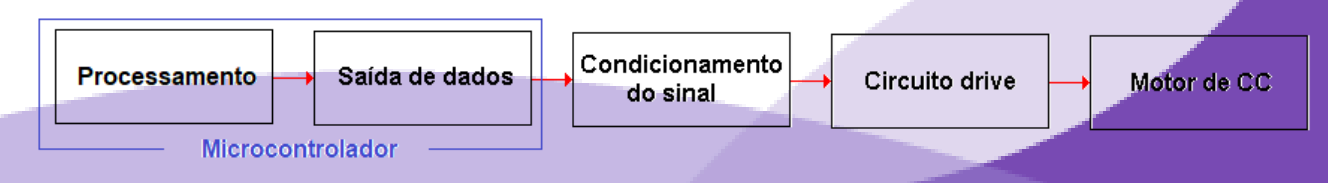

\section{Fonte: Própria (2020).}


O sinal de saída do microcontrolador (sinal de controle) tem valor que varia de 0 e 3,3Vcc, que são amplificados para 5Vcc (Tensão de entrada dos drivers). Portas digitais enviam sinais com a informação do sentido de giro para os drivers. Para realizar o controle do motor, utilizou-se uma placa de potência controlada (driver) por PWM, onde o circuito é composto a partir do sistema de Ponte-H tipo BTS7960 da NovalithIC ${ }^{\mathrm{TM}}$. Esta placa tem as seguintes características: alimentação máxima de $24 \mathrm{VCC}$, corrente de saída máxima de $43 \mathrm{~A}$ (contínuo), ajuste de potência por PWM de 0 a $100 \%$ com frequência até $25 \mathrm{kHz}$, inversão de polaridade digital, freio elétrico, supressão da corrente de pico do motor, entradas de sinal de direção e velocidade externas. A Fig.(07) apresenta o hardware de acionamento montado para todo o conjunto robótico.

Figura 07: Detalhamento do hardware de acionamento montado.

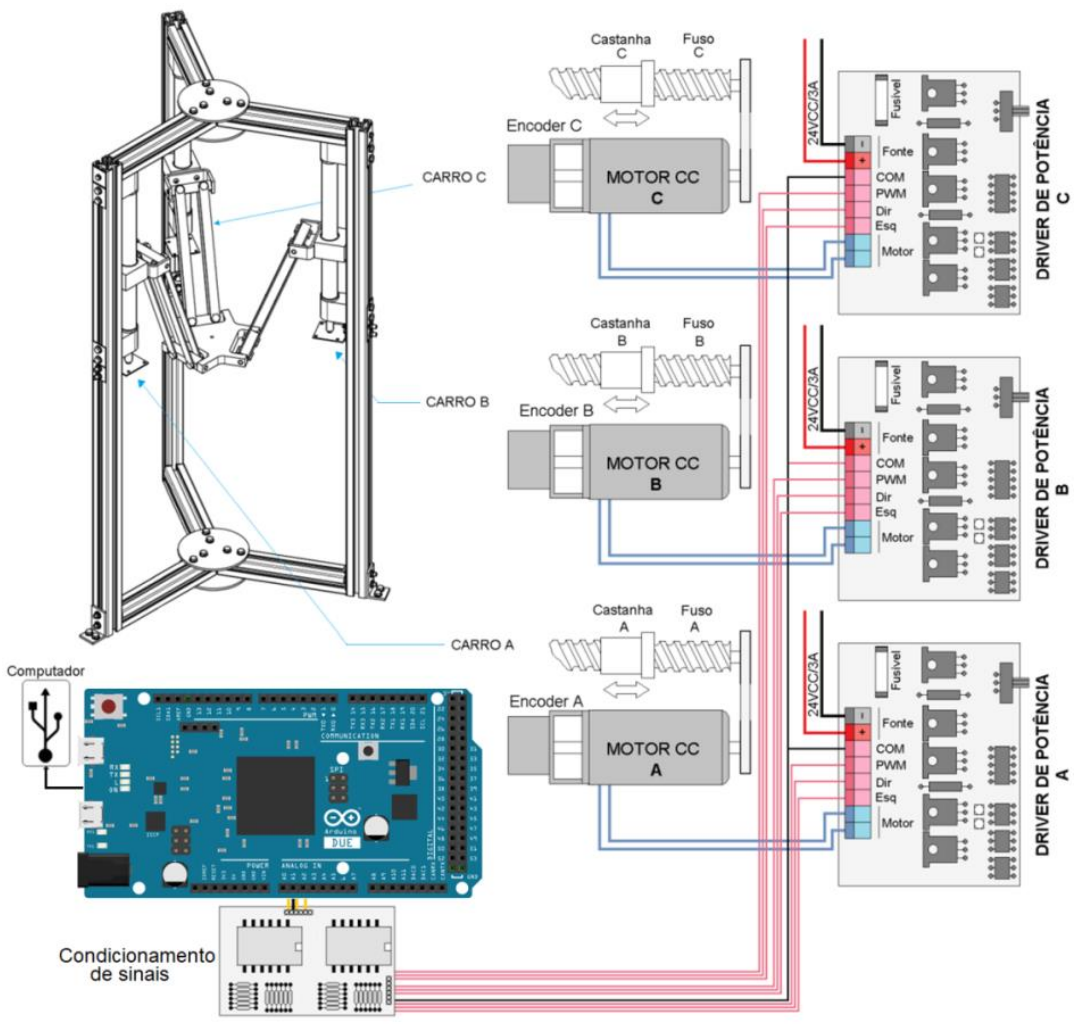

Fonte: Própria (2020).

A técnica de sintonização elaborada por Ziegler e Nichols propõe o ajuste para as constantes de compensação PID baseadas em experimentos de resposta ao degrau ou em alterações de ganho de um compensador puramente proporcional, que leve um sistema à instabilidade marginal. Essa técnica se mostra eficaz ao se trabalhar com uma operação que é permitida uma pequena faixa de erro. A princípio, os parâmetros de controle são definidos na interface gráfica, programada em linguagem Java, e repassada ao controlador por meio da 
comunicação serial. Na tela do dispositivo é possível orientar os componentes proporcional, derivativo e integrador, bem como visualizar as informações de atuação sistemática, realimentação e saída, através da exibição gráfica. A Interface Homem-Máquina pode ser visualizada na Fig.(08).

Figura 08: Interface Homem-Máquina.

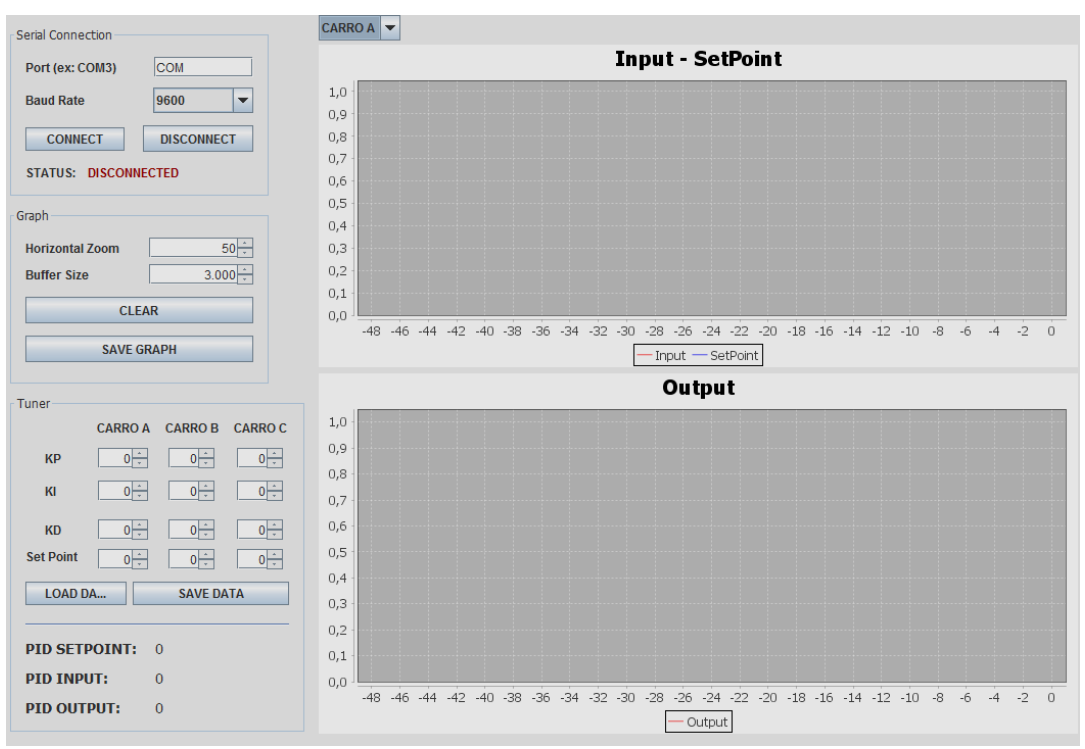

Fonte: Própria (2020).

A Fig.(09) apresenta o diagrama de blocos previsto para a implementação de algoritmos controladores.

Figura 09: Diagrama de controle do mecanismo paralelo.

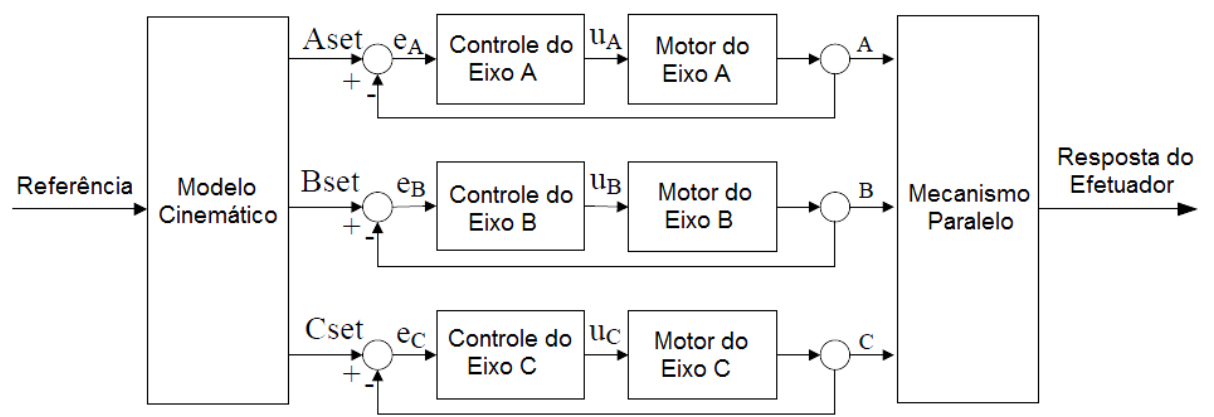

Fonte: Adaptado de Chiang e Lin (2011).

\section{RESULTADOS E DISCUSSÃO}

\section{Aquisição dos Dados de Retroalimentação}

Buscando testar a capacidade do microcontrolador, o sistema foi acionado manualmente, através de botões de pressão, em um dos carros na sua velocidade máxima. A medição do deslocamento serviu de parâmetro comparador, onde as leituras foram realizadas 
de forma simultânea pelo sistema computadorizado, previamente responsável pelo controle da máquina, e pelo sistema embarcado. Os ensaios experimentais realizados até o momento testaram o desempenho do sistema de aquisição de dados dos encoders para o posicionamento dos transportadores A, B e C. As amostras foram obtidas sequencialmente a partir da leitura dos encoders. A Tab.(01) exibe cada medição, respectivamente numerada de acordo com sua ordem e os valores computados pelos sistemas. Para uma confirmação visual do posicionamento de cada carro, foi acoplada uma régua de resolução milimétrica, conforme Fig.(10).

Tabela 01: Comparativo da aquisição entre sistemas.

\begin{tabular}{|c|c|c|}
\hline Amostras & Embarcado & Computadorizado \\
\hline $1^{\circ}$ & $0 \mathrm{~mm}$ & $0 \mathrm{~mm}$ \\
\hline $2^{\circ}$ & $188,790 \mathrm{~mm}$ & $188,803 \mathrm{~mm}$ \\
\hline $3^{\circ}$ & $79,650 \mathrm{~mm}$ & $79,680 \mathrm{~mm}$ \\
\hline $4^{\circ}$ & $77,600 \mathrm{~mm}$ & $77,610 \mathrm{~mm}$ \\
\hline $5^{\circ}$ & $55,350 \mathrm{~mm}$ & $55,350 \mathrm{~mm}$ \\
\hline $6^{\circ}$ & $280,310 \mathrm{~mm}$ & $280,309 \mathrm{~mm}$ \\
\hline
\end{tabular}

Fonte: Própria (2020).

Figura 10: Posição Final para os deslocamentos de: (a) 40 mm (b) 150 mm (c) 60 mm (d) 120 mm.

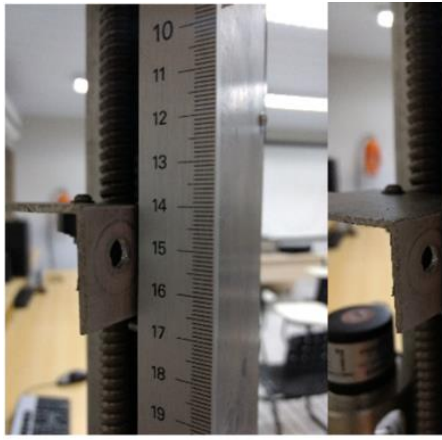

(a) (b)

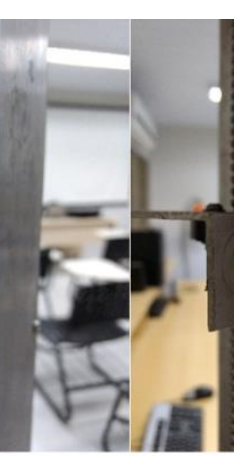

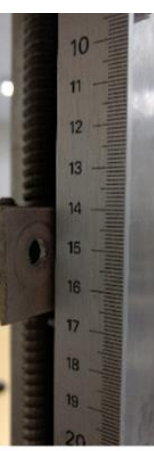

(c)

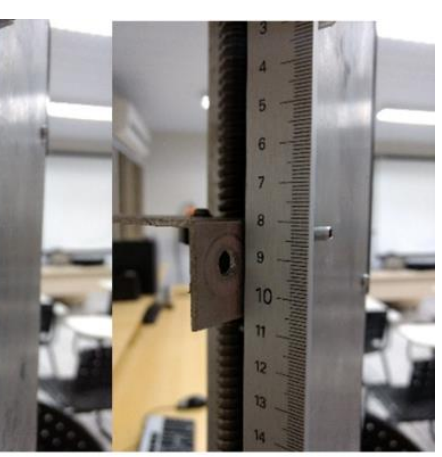

(d)

Fonte: Própria (2020).

\section{Resposta ao Controle de Posição}

Os melhores resultados do controle foram obtidos por meio do Método Ziegler-

Nichols com os ganhos apresentados na Tab.(02). 
Tabela 02: Ganhos PID.

\begin{tabular}{|c|c|c|c|}
\hline Ganhos & Carro A & Carro B & Carro C \\
\hline $\mathrm{K}_{\mathrm{p}}$ & 40,00 & 40,00 & 32,00 \\
\hline $\mathrm{K}_{\mathrm{i}}$ & 0,00 & 0,00 & 0,00 \\
\hline $\mathrm{K}_{\mathrm{d}}$ & 0,00 & 0,00 & 0,016 \\
\hline
\end{tabular}

Fonte: Própria (2020).

A fim de testar a ação do controlador de posição, as bases A, B e C foram submetidas a distintos sinais de referência. De início, os carros foram acomodados em $0 \mathrm{~mm}$ de suas respectivas orientações e em seguida foi aplicado um valor de referência (setpoint) positivo de $100 \mathrm{~mm}$. Os comportamentos dos carros quanto à movimentação com sentido a favor da gravidade podem ser observados na Fig.(11).

Figura 11: Resposta do controle dos carros A, B e C para entrada de $100 \mathrm{~mm}$, e respectivos sinais atuantes.
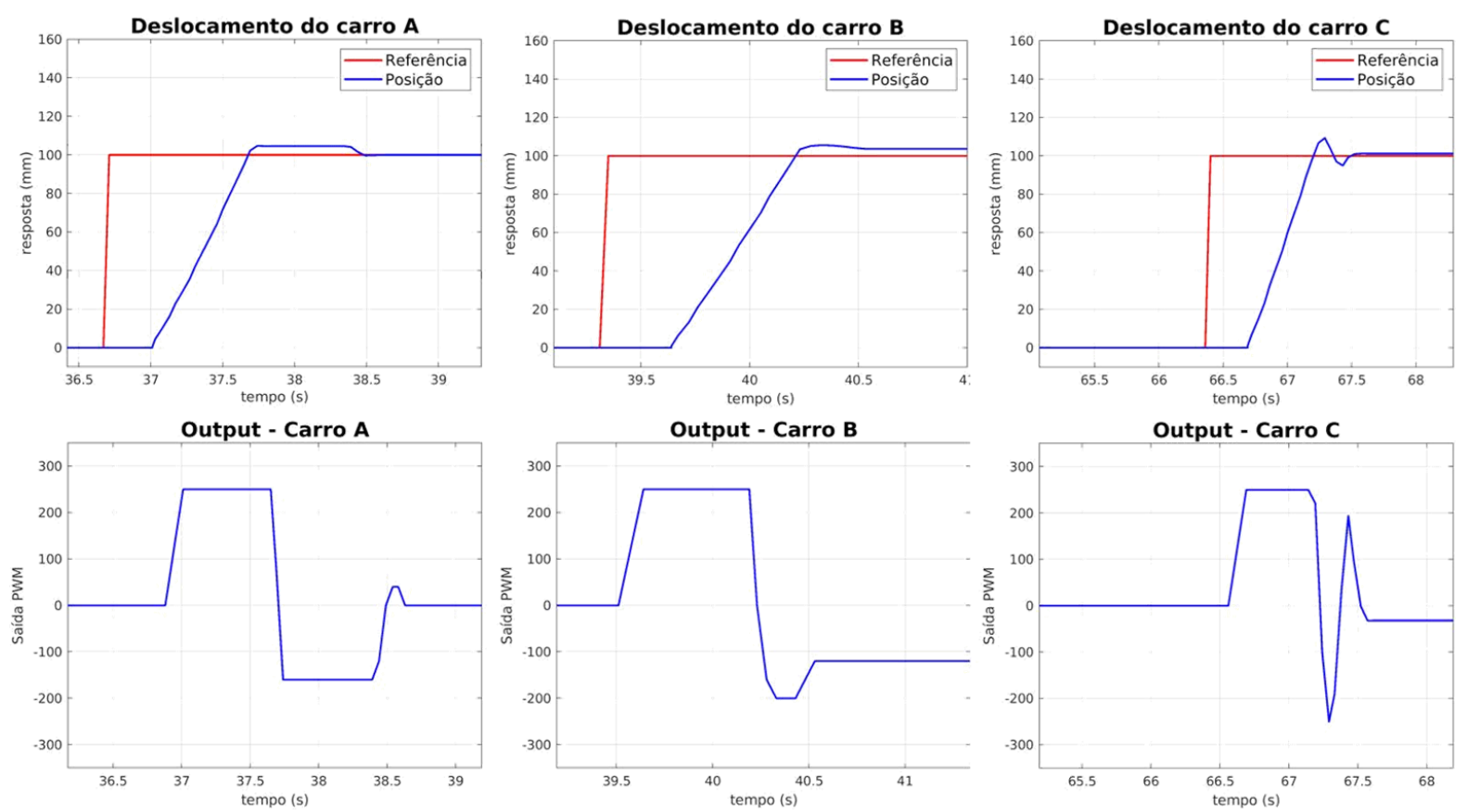

Fonte: Própria (2020).

Como continuidade, os carros manipulados foram posicionados novamente nas suas respectivas posições $0 \mathrm{~mm}$ e foi aplicado um valor de referência negativo de $100 \mathrm{~mm}$. Os comportamentos dos carros quanto à movimentação com sentido contrário a força gravitacional podem ser observados na Fig.(12). 
Figura 12: Resposta do controle dos carros A, B e C para entrada de - $100 \mathrm{~mm}$, e respectivos sinais atuantes.

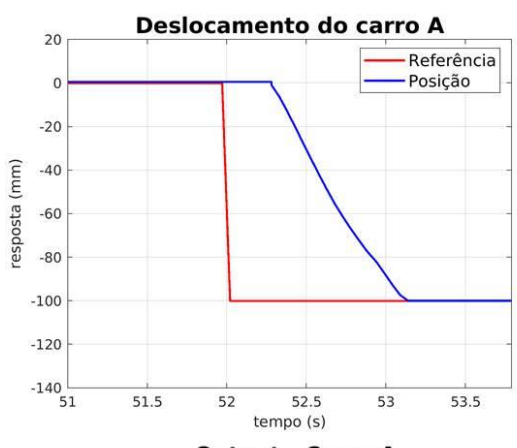

Output - Carro A

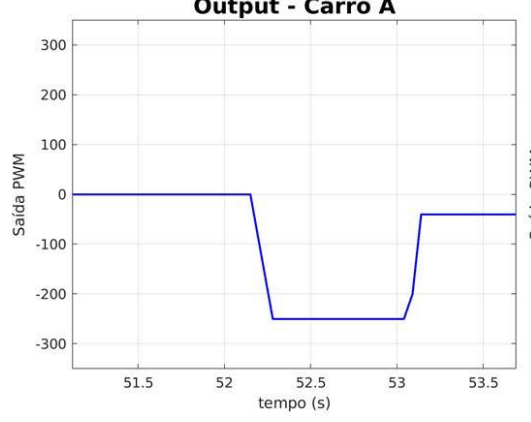

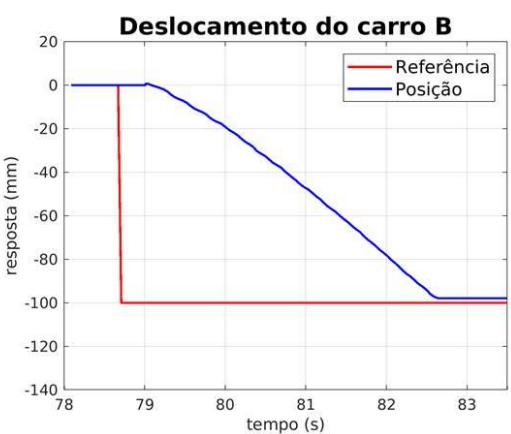

Output - Carro B

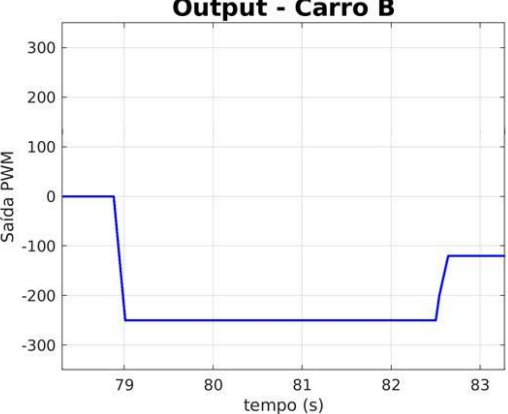

Fonte: Própria (2020).

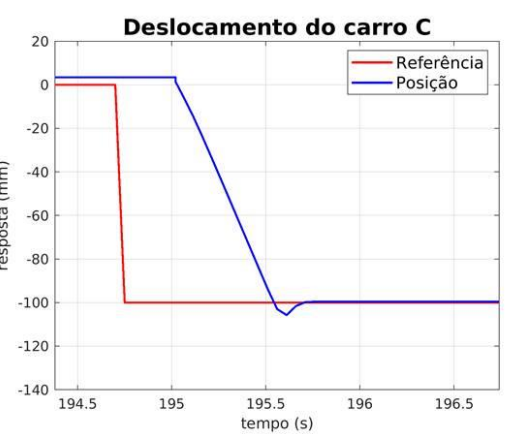

Output - Carro C

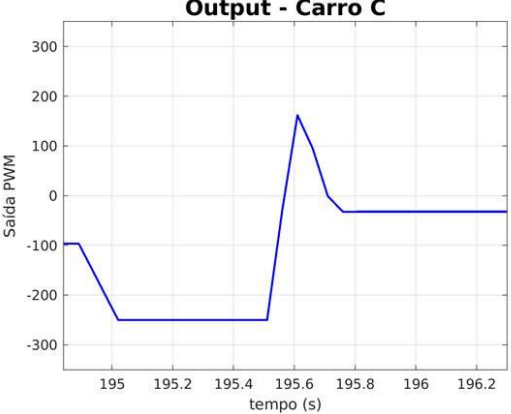

Através destas curvas, foi possível obter alguns parâmetros das respostas nos regimes transitórios e permanentes, que são importantes para a análise do desempenho do controlador.

Nas Tab.(03), Tab.(04) e Tab.(05) são apresentados, para os carros A, B e C, respectivamente, o tempo de subida $\mathrm{T}_{\mathrm{r}}$ (tempo necessário para a resposta passar de $10 \% \mathrm{a}$ 90\% do valor de referência), o tempo de atraso $\mathrm{T}_{\mathrm{d}}$ (tempo necessário para a resposta atingir pela primeira vez a metade do valor de referência), o tempo de acomodação $\mathrm{T}_{\mathrm{s}}$ (tempo necessário para o sistema alcançar e permanecer dentro de um limite aceitável), o sobressinal $\mathrm{M}_{\mathrm{p}}$ (valor percentual máximo da resposta em relação ao sinal de referência) e erro de regime permanente ess (erro que o sistema apresenta após o tempo de acomodação).

Tabela 03: Índices de desempenho do controlador respectivo ao carro A.

\begin{tabular}{|c|c|c|}
\hline \multirow{2}{*}{ Parâmetro analisado } & \multicolumn{2}{|c|}{ Controlador Carro A } \\
\cline { 2 - 3 } & $0-100 \mathrm{~mm}$ & $100-0 \mathrm{~mm}$ \\
\hline $\mathrm{T}_{\mathrm{r}}(\mathrm{s})$ & $0,52 \mathrm{~s}$ & $0,66 \mathrm{~s}$ \\
\hline $\mathrm{T}_{\mathrm{d}}(\mathrm{s})$ & $0,65 \mathrm{~s}$ & $0,61 \mathrm{~s}$ \\
\hline $\mathrm{T}_{\mathrm{s}}(\mathrm{s})$ & $1,78 \mathrm{~s}$ & $1,20 \mathrm{~s}$ \\
\hline $\mathrm{M}_{\mathrm{p}}(\%)$ & $4,72 \%$ & $0,02 \%$ \\
\hline $\mathrm{e}_{\mathrm{ss}}(\mathrm{mm})$ & $0,032 \mathrm{~mm}$ & $0,02 \mathrm{~mm}$ \\
\hline
\end{tabular}

Fonte: Própria (2020). 
Tabela 04: Índices de desempenho do controlador respectivo ao carro B.

\begin{tabular}{|c|c|c|}
\hline \multirow{2}{*}{ Parâmetro analisado } & \multicolumn{2}{|c|}{ Controlador Carro B } \\
\cline { 2 - 3 } & $0-100 \mathrm{~mm}$ & $100-0 \mathrm{~mm}$ \\
\hline $\mathrm{T}_{\mathrm{r}}(\mathrm{s})$ & $0,42 \mathrm{~s}$ & $2,74 \mathrm{~s}$ \\
\hline $\mathrm{T}_{\mathrm{d}}(\mathrm{s})$ & $0,60 \mathrm{~s}$ & $2,37 \mathrm{~s}$ \\
\hline $\mathrm{T}_{\mathrm{s}}(\mathrm{s})$ & $1,90 \mathrm{~s}$ & $4,57 \mathrm{~s}$ \\
\hline $\mathrm{M}_{\mathrm{p}}(\%)$ & $5,60 \%$ & $2,13 \%$ \\
\hline $\mathrm{e}_{\mathrm{ss}}(\mathrm{mm})$ & $2,86 \mathrm{~mm}$ & $2,13 \mathrm{~mm}$ \\
\hline
\end{tabular}

Fonte: Própria (2020).

Tabela 05: Índices de desempenho do controlador respectivo ao carro C.

\begin{tabular}{|c|c|c|}
\hline \multirow{2}{*}{ Parâmetro analisado } & \multicolumn{2}{|c|}{ Controlador Carro C } \\
\cline { 2 - 3 } & $0-100 \mathrm{~mm}$ & $100-0 \mathrm{~mm}$ \\
\hline $\mathrm{T}_{\mathrm{r}}(\mathrm{s})$ & $0.42 \mathrm{~s}$ & $0.40 \mathrm{~s}$ \\
\hline $\mathrm{T}_{\mathrm{d}}(\mathrm{s})$ & $0.56 \mathrm{~s}$ & $0.56 \mathrm{~s}$ \\
\hline $\mathrm{T}_{\mathrm{s}}(\mathrm{s})$ & $2.27 \mathrm{~s}$ & $0.96 \mathrm{~s}$ \\
\hline $\mathrm{M}_{\mathrm{p}}(\%)$ & $9.32 \%$ & $5.68 \%$ \\
\hline $\mathrm{e}_{\mathrm{ss}}(\mathrm{mm})$ & $1.16 \mathrm{~mm}$ & $0.48 \mathrm{~mm}$ \\
\hline
\end{tabular}

Fonte: Própria (2020).

No intuito de observar o resultado do sistema frente à inserção de entradas de curta distância, foram aplicados valores de referência próximos à posição do elemento manipulado. Foram empregadas dez entradas, nos dois sentidos direcionais, com um distanciamento de 10 mm da posição vigente dos carros, gerando, de forma gráfica, um perfil semelhante ao de uma escada. Os resultados podem ser observados na Fig.(13).

Figura 13: Resposta do controle dos carros A, B e C para entradas do tipo degrau sequenciadas.

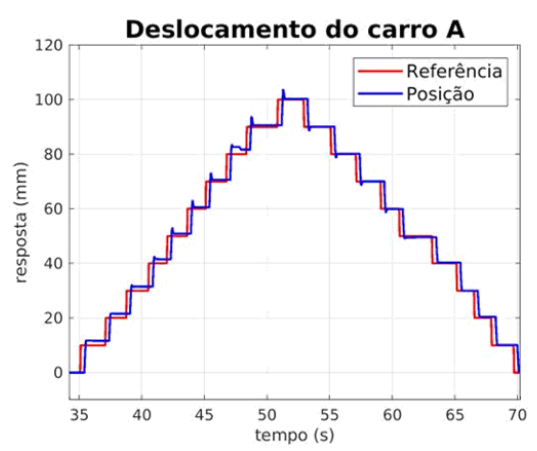

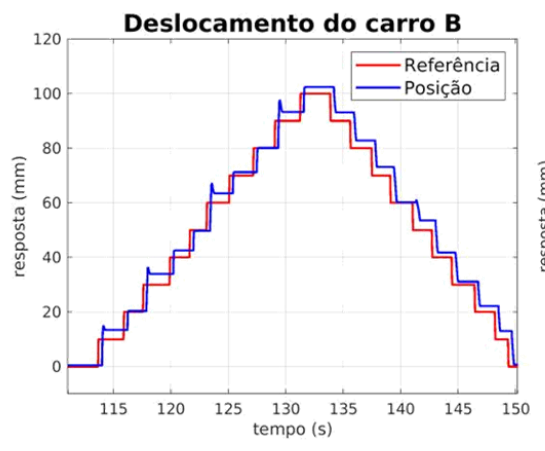

Fonte: Própria (2020).

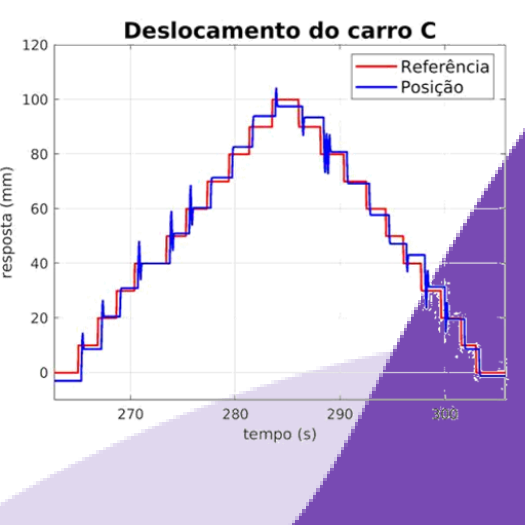




\section{CONCLUSÕES}

O presente trabalho apresentou a implementação de um sistema embarcado na concepção do controle de um robô paralelo linear. A base do trabalho se estrutura na substituição de um dispositivo de alto custo financeiro (aproximadamente $\mathrm{R} \$ 15.400,00$ ) por outro de maior viabilidade financeira. Foi escolhido para computar os dados atuantes no conjunto eletromecânico em questão, o microprocessador de código aberto Arduino Due (aproximadamente R $\$ 220,00)$. Um controlador PID foi testado e validado para cada carro transportador com erro máximo de posicionamento de 2,86\%. Este erro ficou um pouco acima do obtido através do módulo de aquisição, que foi de 2,50\%, conforme apresentado em Almeida Júnior et al. (2018b). No entanto, para a aplicação de acabamentos, este erro continua aceitável, bem como a resposta temporal. O método de sintonização de ZieglerNichols foi utilizado para a obtenção dos parâmetros inseridos no controlador. Assim, realizando-se uma análise acerca da atuação da máquina, concluir-se que os objetivos deste trabalho foram atingidos de forma satisfatória, obtendo por fim um dispositivo mais barato, e tão preciso quanto o sistema computacional.

\section{REFERÊNCIAS}

ALMEIDA JUNIOR, A.G. et al. Desenvolvimento e Controle de Robô Delta para Manipulação Industrial. [Anais]. II Congresso Internacional de Gestão e Tecnologias, João Pessoa. 2018a.

ALMEIDA JÚNIOR, A.G. et al. Projeto Eletromecânico e Controle de Robô Paralelo Tipo Linapod. [Anais]. II Congresso Internacional de Gestão e Tecnologias, João Pessoa. Anais do II COINTER PDVGT. 2018b.

CORREIA, V.C.A. Um Estudo Sobre o Impacto da Robótica Colaborativa na Produtividade em Tarefas Manuais. Monografia (Graduação em Engenharia Elétrica com ênfase em Sistemas de Energia e Automação). Escola de Engenharia de São Carlos da Universidade de São Paulo, São Carlos, USP, 2018.

DORF, R.C. Sistemas de Controle Moderno. 13ª ed., São Paulo, SP. Brasil. LTC, 2018.

OGATA, K. Engenharia de Controle Moderno. $5^{\text {a }}$ ed. São Paulo: Pearson, 2015.

QUEIROZ, P.G.G. Uma Abordagem de Desenvolvimento de Linha de Produtos Orientada a Modelos para a Construção de Famílias de Sistemas Embarcados Críticos. Tese de doutorado, ICMC/USP, 2015.

SENA, A.P.C.; SILVA, A.V.S. ; SILVA, A.S. Construction and Control Pid of Delta Parallel 
Robot. [Anais]. 24th ABCM International Congress of Mechanical Engineering, Curitiba. 2017. v. 1.

SILVA, A.S. et al. Evaluation of Pid Controllers in Robotic Prototype With Parallel Cinematic Applied to Industrial Manipulation. [Anais]. III Congresso Internacional do PDVGT, Recife, 2019.

SILVA, A.S. et. al. Construção e Controle de Posição para um Robô Paralelo com Aplicação na Indústria Confeccionista. A Produção do Conhecimento na Engenharia Elétrica 2. $1^{\text {a }}$ ed. Ponta Grossa: Atena Editora, 2020, v. 2, p. 82-94. 


\title{
CAPÍTULO 07: ANÁLISE DE DEFEITOS NO ROLAMENTO EM UM MOTOR DE INDUÇÃO TRIFÁSICO UTILIZANDO A EMISSÃO ACÚSTICA
}

\section{CAPÍTULO 07: ANÁLISIS DE LOS DEFECTOS DE LOS RODAMIENTOS EN UN MOTOR DE INDUCCIÓN TRIFÁSICO CON EMISIÓN ACÚSTICA}

\author{
CHAPTER 07: ANALYSIS OF BEARING DEFECTS IN A THREE-PHASE \\ INDUCTION MOTOR USING ACOUSTIC EMISSION
}

\author{
Gustavo Pereira Bruno; André Fellipe Cavalcante Silva²; José Anselmo de Lucena Júnior ${ }^{3}$; Silvana Luciene do \\ Nascimento Cunha Costa ${ }^{4}$
}

DOI: https://doi.org/10.31692/978-65-88970-06-5.99-115

\begin{abstract}
RESUMO
Os motores de indução trifásicos (MIT) são responsáveis por $90 \%$ da fonte primária de energia mecânica que é utilizada nas indústrias. Para garantir o desempenho desejado destes equipamentos, sem que haja interrupções na linha de produção, faz-se necessária a elaboração e a implementação de um plano de manutenção. Dentre as práticas de manutenção, ressalta-se a manutenção preditiva, que é de suma importância para otimizar os processos industriais e poupar custos operacionais. Para viabilizar este tipo de manutenção em motores de indução trifásico (MIT), é necessária a utilização de um sensor para aferir uma grandeza física e realizar a predição. Neste trabalho foi proposto a utilização de um sensor alternativo (microfone) para detectar falhas na pista interna e na pista externa de um rolamento. Com esta técnica alternativa é possível realizar o diagnostico sem qualquer tipo de contato físico com o motor, tornando viável a utilização de um único dispositivo para diversos motores. A execução do processamento do áudio é realizada de forma sequencial e automática. Com isto, para diagnosticar o rolamento, o usuário tem a função única de iniciar o sistema e aguardar o resultado. Para identificar o tipo do defeito, dentre os estudados, foi utilizada uma Rede Neural Convolucional (RNC), que ao final do treinamento, obteve uma acurácia de 93,02\%.
\end{abstract}

Palavras-Chave: Emissão Acústica; MIT; RNC.

\section{RESUMEN}

Los motores de inducción trifásica (MIT) representan el $90 \%$ de la fuente primaria de energía mecánica que es utilizada en las industrias. Para garantizar el desempeño deseado de estos equipos, sin que haya interrupciones en la línea de producción, se hace necesaria la elaboración e implementación de un plan de mantenimiento. Dentro de las prácticas de mantenimiento, se destaca el mantenimiento predictivo, que es de suma importancia para optimizar los procesos industriales y disminuir los costos operacionales. Para hacer posible este tipo de mantenimiento en motores de inducción trifásica (MIT), es necesaria la utilización de un sensor para medir una cantidad física y realizar una predicción. En este trabajo se propuso la utilización de un sensor alternativo (micrófono) para detectar fallas en la pista interna y en la pista externa de un rodamiento. Con esta técnica alternativa es posible realizar un diagnóstico sin ningún tipo de contacto físico con el motor, haciendo posible la utilización de un único dispositivo para diversos motores. El procesamiento del audio se realiza de forma secuencial y automática. Con esto, para diagnosticar un rodamiento, el usuario tiene la única función de iniciar el sistema y aguardar el resultado. Para identificar el tipo de defecto, entre los estudiados, se utilizó una Red Neural Convolucional (RNC), que al final del entrenamiento, obtuvo una precisión del 93,02

Palabras clave: emisión acústica; MIT; RNC.

ABSTRACT

Three-phase induction motors (TIM) are responsible for $90 \%$ of the primary source of mechanical

${ }^{1}$ Mestrado em Engenharia Elétrica, IFPB, gustavo.bruno@academico.ifpb.edu.br

${ }^{2}$ Doutor, IFPB, andrefellipecs@gmail.com

${ }^{3}$ Mestrado em Engenharia Mecânica, UFPB

${ }^{4}$ Doutor, IFPB, silvana@ifpb.edu.br 
energy that is used in industries. To guarantee the desired performance of this equipment, without interruptions in the production line, it is necessary to develop and implement a maintenance plan. Among maintenance practices, predictive maintenance stands out, which is of paramount importance to optimize industrial processes and save operating costs. To make this type of maintenance feasible in three-phase induction motors (TIM), it is necessary to use a sensor to measure a physical quantity and make the prediction. In this work it was proposed to use an alternative sensor (microphone) to detect failures in the inner and outer race of a bearing. With this alternative technique it is possible to carry out the diagnosis without any kind of physical contact with the engine, making it feasible to use a single device for several engines. The audio processing is performed sequentially and automatically. With this, to diagnose the bearing, the user has the unique function of starting the system and waiting for the result. To identify the type of defect, among those studied, a Convolutional Neural Network (CNN) was used, which at the end of the training, obtained an accuracy of 93.02\%.

Keywords: TIM; Acoustic Emission; CNN.

\section{INTRODUÇÃO}

Motores de indução trifásicos (MIT) consomem cerca de $40 \%$ a $50 \%$ de toda energia elétrica no setor industrial, sendo responsáveis por mais de $90 \%$ de todo acionamento das principais nações industrializadas. Apesar da natureza simplista e robusta desta máquina, é necessário que haja um plano de manutenção para garantir sua integridade física e boa performance (AHAMED et al., 2010). Dentre os tipos de manutenção existentes, conforme a NBR 5462, se destaca a manutenção preditiva, onde o elemento em questão é monitorado constantemente, permitindo assim, um uso otimizado de sua vida útil e baixa probabilidade de uma parada não planejada.

Conforme Silva (2018), existem sinais acústicos quando há alguma variação na pressão do ar, em relação à pressão média do ambiente, ao longo de um determinado tempo. O diagnóstico por emissão acústica (EA) está ganhando espaço no cenário atual por meio de inovações tecnológicas e pesquisas dirigidas. Esta técnica alternativa permite um diagnóstico para detecção de falhas em motores na fase inicial (PODDAR e TANDON, 2019), além de admitir uma ampla faixa de velocidade, uma vez que o método convencional (análise por vibrações) exige que o motor esteja funcionando na velocidade nominal, para que o sinal de vibração tenha energia suficiente para ser analisada de forma satisfatória (AKBEN, 2019).

A técnica de análise por emissão acústica para detectar defeitos em rolamentos é amplamente estudada por diferentes pesquisadores, que em geral, realizam a análise no domínio da frequência.

Este trabalho se propõe a utilizar o processamento digital de imagens (PDI) para tratar o espectrograma do sinal de áudio emitido pelo motor em funcionamento. A partir da análise do espectrograma será feito um diagnóstico do estado do motor, indicando se há falha nos rolamentos de pista interna e externa. 


\section{FUNDAMENTAÇÃO TEÓRICA}

O MIT é um elemento conversor de energia elétrica em energia motriz mais utilizado, sendo indispensável aos processos produtivos industriais, porque, além do baixo custo, apresentam adaptabilidade às diferentes exigências de cargas mecânicas e resistência para operação em ambientes (SANTOS et al., 2014). Ainda que o MIT disponha de extrema robustez e confiabilidade, com o decorrer do tempo ocorrerá naturalmente o desgaste de seus elementos construtivos. Dentre estes elementos, o que se destaca são os rolamentos devido à ação do atrito. Segundo estudos, cerca de 50\% dos defeitos relatados em MITs ocorrem no rolamento (SALAZAR-VILLANUEVA e IBARRA-MANZANO, 2013).

Defeitos incipientes (falhas potenciais) podem ser detectados, antes de se tornaram falhas significativas (falhas funcionais). Quando um defeito não é detectado, o processo natural de evolução da falha levará à instalação de uma falha potencial, a qual acarretará, necessariamente, em prejuízos ao processo industrial.

Um rolamento perde sua funcionalidade quando instalado ou mantido inadequadamente. Nesta situação, o rolamento apresentará uma falha prematura, totalmente diferente de uma falha por fadiga do aço (escamamento). Entretanto, todo tipo de falha que ocorra no rolamento terá um ruído acústico característico (NSK, 2008).

De forma elementar, um rolamento é constituído por três partes: elemento rolante, pista interna e pista externa. Considerando uma velocidade fixa e conhecida, é possível calcular a frequência com que o elemento rolante passa sobre um determinado ponto. Desta forma, um defeito genérico (um furo, por exemplo) gera componentes em uma frequência determinável. Estas frequências podem ser calculadas pelas Equações 1 e 2 [7]. A Equação 1 representa a Frequência de falha na pista interna e a Equação 2 a frequência de falha na pista externa).

$$
\begin{aligned}
& F p i=\frac{n F_{r}}{2}\left[1-\frac{d}{D} \cos (\phi)\right], \\
& F p o=\frac{n F_{r}}{2}\left[1+\frac{d}{D} \cos (\phi)\right],
\end{aligned}
$$

onde $d$ é o diâmetro do elemento rolante, $\mathrm{D}$ a distância entre centros das esferas (Pitch), $n$ o número de elementos rolantes e $\phi$ o contato angular da esfera.

Estas variáveis são parâmetros inerentes à construção do rolamento e podem ser observados na Figura 1. 
Figura 01: Geometria de um rolamento.

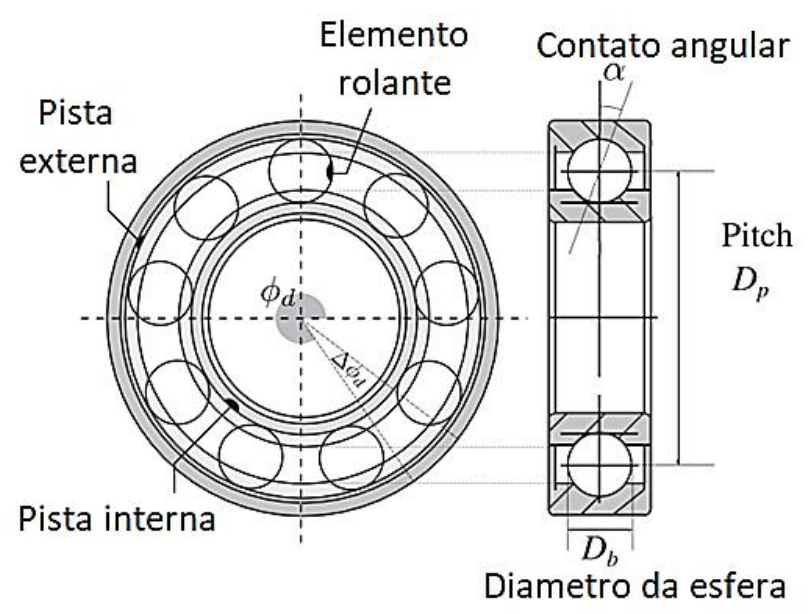

Fonte: Dolenc et al. (2015) [adaptado].

\section{METODOLOGIA}

Esta pesquisa é de caráter experimental quantitativo. O fluxograma da Figura 2 apresenta o método empregado nesta pesquisa para realizar a aquisição e o processamento do sinal.

Inicialmente, o sinal acústico do MIT é capturado pelo microfone, que é processado pela interface de áudio. Neste ponto o áudio é digitalizado e enviado para a Raspberry Pi, que direciona o áudio para um servidor online, onde é mantido um banco de dados com os áudios originais e para uma workstation, onde de fato é realizado o todo o processamento. $\mathrm{O}$ resultado deste processamento é retornado para a Raspberry $\mathrm{Pi}$, para ser exibido ao operador em um display e encaminhado também para o servidor, para ser armazenado.

Figura 02: Fluxograma do sistema proposto.

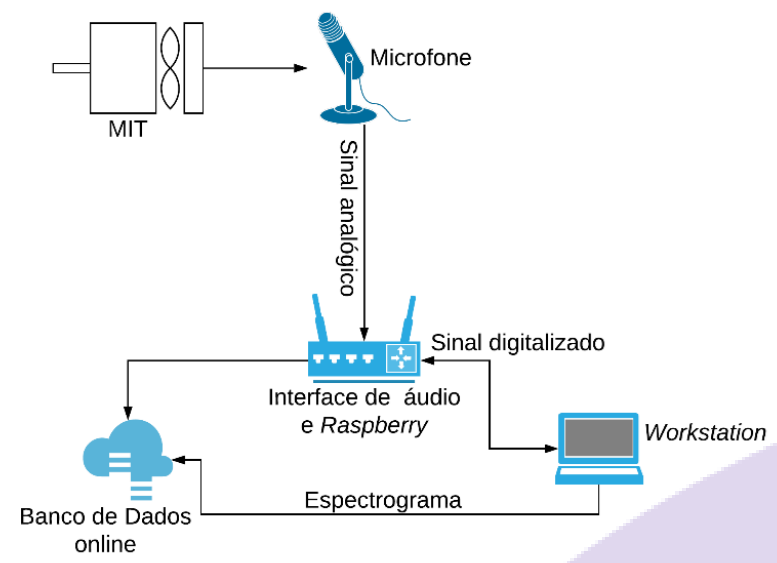

Fonte: Própria (2020). 
O microfone utilizado para aquisição do sinal gerado pelo MIT está ligado à placa de áudio (conversor $\mathrm{AD}+$ amplificador) por cabo (padrão XLR blindado). A placa de áudio está isolada eletricamente de outros dispositivos (exceto o microfone) e da rede elétrica, evitando assim ruído externo de origem eletromagnética. Além disto, esta configuração facilita o manuseio do equipamento, uma vez que o mesmo pode ser acionado remotamente, através de uma conexão sem fio (Wi-Fi).

Foi desenvolvido um sistema offline, para análise dos sinais coletados, o qual permite o armazenamento dos dados originais coletados, tanto em dispositivos físicos como cartões de memória, quanto em meios virtuais, como os serviços de armazenamento em nuvens.

Para a realização da pesquisa, foi utilizada a bancada de testes, projetada e construída pelo Grupo de Instrumentação, Controle e Estudo em Energia e Meio Ambiente (GPICEEMA), da Universidade Federal da Paraíba (UFPB), Campus João Pessoa. Nesta bancada é possível substituir o rolamento do motor e submeter os mesmos a diferentes situações de funcionamento do MIT, como por exemplo, a alteração de cargas e de velocidade sobre o eixo do motor. A bancada possui um sistema de monitoramento embarcado, que inclui um tacômetro e uma célula de carga (torquímetro). A referida bancada será descrita, detalhadamente, no item 2 .

\section{Componentes para aquisição do sinal de Emissão Acústica}

Neste tópico serão detalhados os dispositivos necessários para realização desta pesquisa.

\subsection{Microfone}

Em uma pesquisa deste tipo, que se propõe a utilizar o método da Emissão Acústica (EA), para detecção de defeitos, o dispositivo responsável pela aquisição das ondas sonoras assume um papel fundamental. O microfone exercerá a função do transdutor responsável por transformar o sinal mecânico, modulado nas ondas sonoras, em sinal elétrico a fim de que, posteriormente, seja digitalizado e analisado. A escolha de um dispositivo adequado tem influência direta sobre os procedimentos de tratamento de dados, podendo impactar e até mesmo delimitar a eficácia do sistema.

Conforme Silva (2018), existem diferentes tipos de microfones. Os que captam sons provenientes de todas as direções são chamados de omnidirecionais. Os que captam sons provenientes de uma única direção são chamados de direcionais. Os que captam sons vindos de direções opostas são chamados de bidirecionais. Existem ainda os que captam, com precisão, os sons que vêm da frente para onde aponta o transdutor. Estes microfones 
especializados, que captam apenas os sons frontais, são chamados de cardioides ou hipercardioides.

Visando a adequada captura da EA, proveniente dos componentes do rolamento do MIT, buscou-se utilizar um transdutor, cujo espectro de sensibilidade abrangesse as faixas de frequência de EA, dos itens analisados. Com base nestes parâmetros, verificou-se que o melhor transdutor indicado, para esta situação, seria um microfone do tipo condensador, que apresentasse um diafragma largo, proporcionando boa sensibilidade, com a característica de captar, com precisão, os sons provenientes da fonte emissora, para o qual o transdutor fosse apontado. Optou-se, então, por se utilizar o microfone condensador Samson Co1, com diafragma de $19 \mathrm{~mm}$, sensibilidade de $-33 \mathrm{~dB} / \mathrm{Pa}$, o qual é capaz de atuar em ampla faixa de frequências $(20 \mathrm{~Hz}$ a $18 \mathrm{kHz})$ e de operar em uma zona de captação unidirecional (polar cardioide). Estas configurações, imprescindíveis para o desenvolvimento desta pesquisa, são apresentadas na Figura 3, assim como o microfone utilizado.

Figura 03: Dispositivo de captura do sinal acústico.

A- Resposta em frequencia

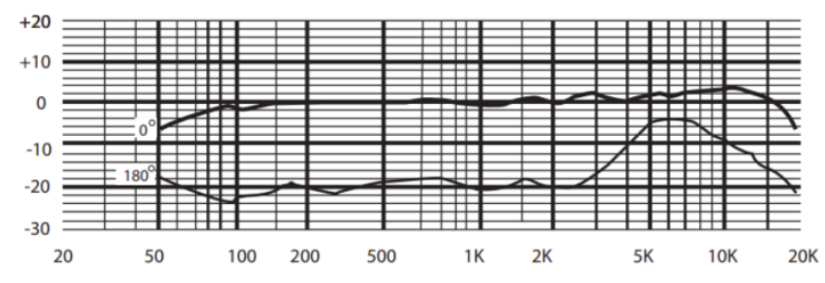

C- Microfone Samson C01
B- ângulo de operação

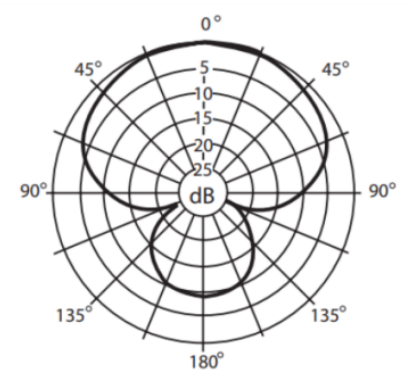

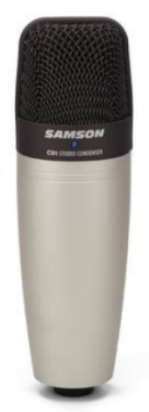

Fonte: Própria (2020).

\subsection{Interface de Áudio}

A onda sonora, captada pelo transdutor (microfone), foi transformada, por este, em um sinal elétrico analógico. A Interface de Áudio foi utilizada para realizar a conversão do sinal analógico proveniente da saída do microfone, para sinal digital. Ou seja, exerceu a 
funcionalidade de um conversor analógico digital (A/D), visando viabilizar o posterior processamento, classificação e armazenamento do sinal.

Na presente pesquisa, utilizou-se uma interface Behringer U-PHORIA UMC22, a qual possui uma taxa de amostragem máxima de $48 \mathrm{kHz}$, com resolução de 16 bits. Este dispositivo, por meio de portas $I / O$ do tipo $U S B$ permitiu a gravação do áudio diretamente em um banco de dados na Raspberry de comunicação, de onde é automaticamente enviado, via Wi-Fi, para o computador (workstation).

Neste trabalho, o áudio foi gravado a uma taxa de amostragem de 44.100 amostras por segundo, o que permitiu a digitalização de sinais de até $22 \mathrm{kHz}$, com fidelidade. Este dispositivo está ilustrado na Figura 4.

Figura 04: Interface de áudio.

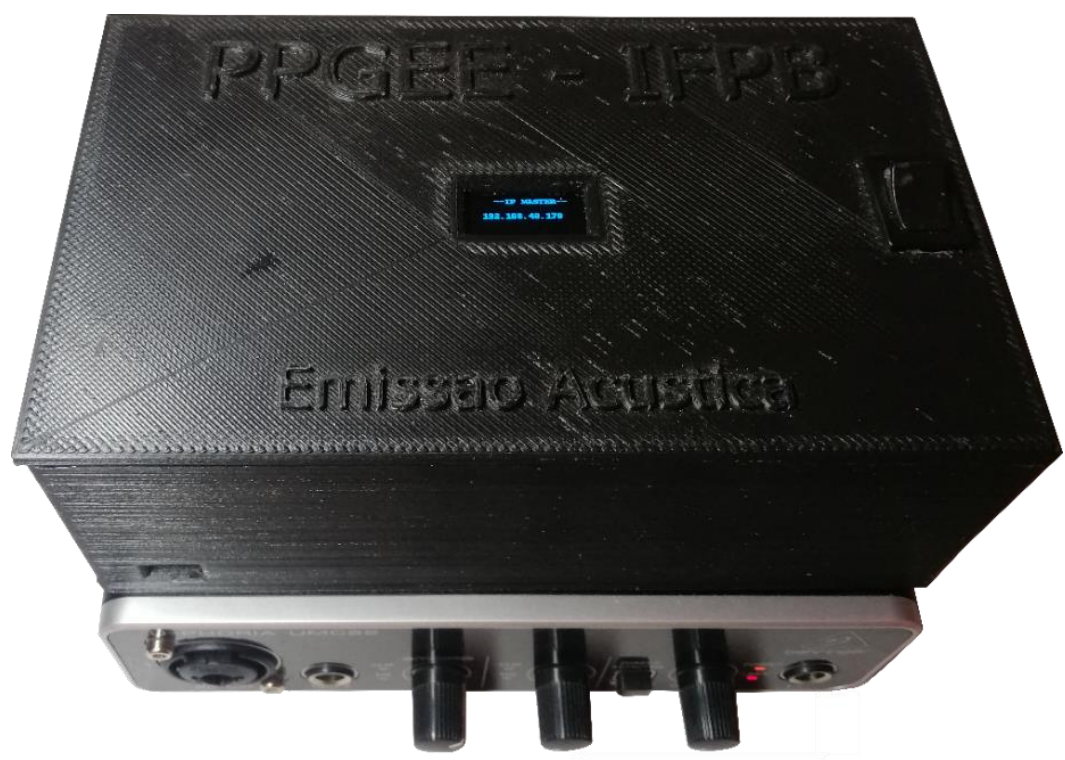

Fonte: Própria (2020).

\section{Bancada de ensaios}

A bancada utilizada nesta pesquisa foi projetada e montada pelo Grupo de Instrumentação e Controle em Estudo e Energia e Meio Ambiente (GPICEEMA) para ensaiar diferentes tipos de falhas/defeitos em motores de indução trifásicos. A bancada pode ser yista na Figura 5. É composta por: motor de indução trifásico (1), mancal para apoio con dois rolamentos (2), torquímetro digital (3), motor Corrente Contínua (CC) para aplicar carga (4) e transdutor de velocidade (5). 
Figura 05: Bancada de ensaios.

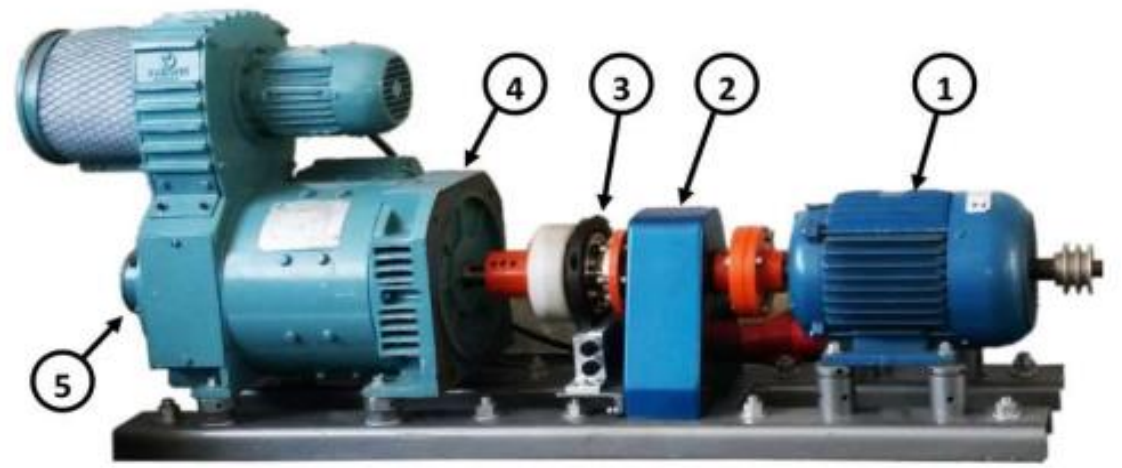

Fonte: Sobrinho (2020).

\section{Método para aquisição do sinal}

Foram utilizados quatro rolamentos do mesmo modelo/fabricante para esta pesquisa. Dentre estes quatro, três com defeitos e um saudável (controle). Os defeitos foram fabricados no laboratório da UFPB, pelo processo de eletro erosão (furo radial com $1 \mathrm{~mm}$ de diâmetro).

Para simular diferentes situações, a qual um rolamento é exposto, foi realizada a coleta dos dados em três situações diferentes para cada rolamento: com carga no eixo nula $(0 \mathrm{Nm})$, carga nominal $(12 \mathrm{Nm})$ e carga máxima $(24 \mathrm{Nm})$. Todos os ensaios foram gravados com uma duração de 60 segundos nas configurações citadas no tópico 1.2. O microfone foi posicionado a uma distância de aproximadamente $150 \mathrm{~mm}$, direcionado para a fonte emissora.

\section{Análise do defeito (pista interna e externa)}

A análise do espectrograma permite avaliar a amplitude da frequência em função do tempo. Para esta pesquisa, este tipo de análise permite acompanhar a frequência de defeito e suas harmônicas (Equações 1 e 2) em toda extensão do sinal, asseverando assim uma maior confiabilidade na análise, visto que ruídos de curta duração no tempo podem ser isolados para não interferir no diagnóstico. Além disto, por meio desta análise, é possível obter resultados confiáveis mesmo em velocidades baixas (menor que $200 \mathrm{rpm}$ ), diferente das técnicas convencionais que são ineficazes para análise em baixas velocidades (HASAN, ISLAM e KIM, 2019).

\subsection{Processamento digital da imagem}

Para realizar o diagnóstico do rolamento, o sinal acústico foi processado utilizando uma cadeia de técnicas, que são ilustradas na Figura 06 e particularizadas nos tópicos seguintes. 
Figura 06: Fluxograma do processamento digital da imagem.

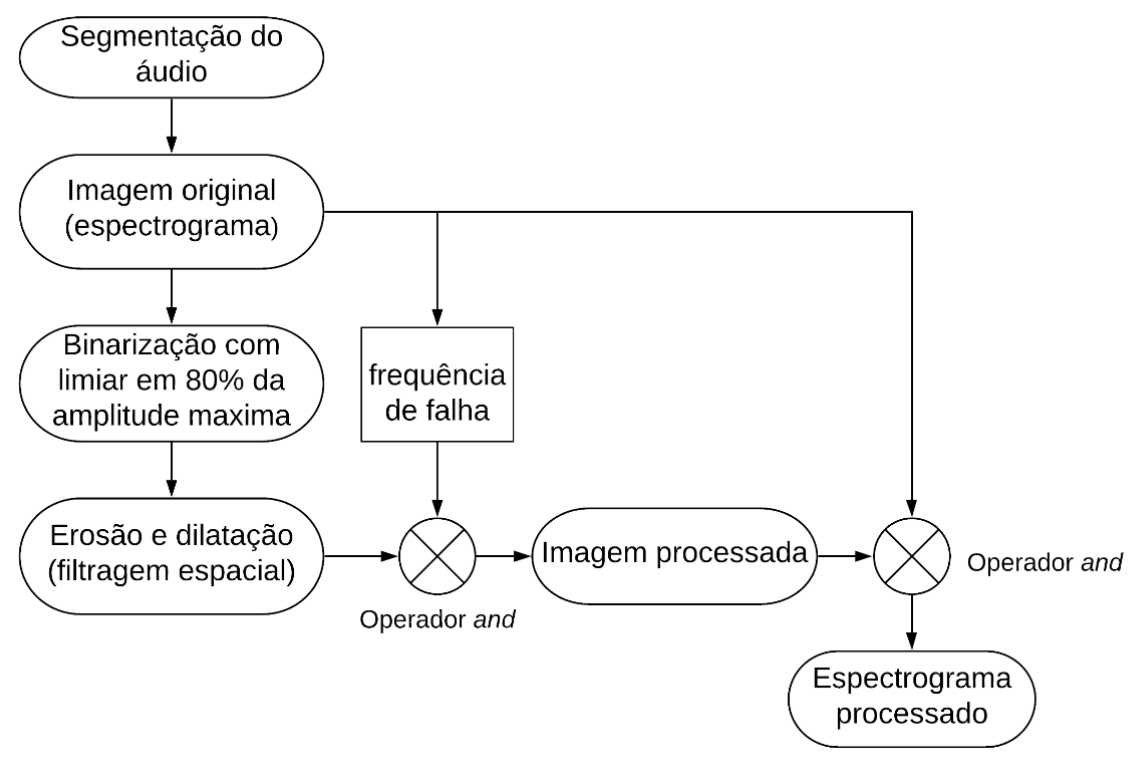

Fonte: Própria (2020).

\subsubsection{Segmentação do áudio}

Inicialmente o áudio é segmentado com overlap de 50\%, transformando assim um áudio de 60 s em cinco áudios com 20s de duração. Este procedimento foi importante para aumentar a quantidade de amostras no treinamento da rede neural convolucional. Além disto, esta técnica permite que um único áudio seja processado cinco vezes de forma independente. Com isso, caso haja algum tipo de ruído externo de curta duração no tempo, que comprometa totalmente o diagnóstico, o segmento correspondente a este ruído será descartado.

\subsubsection{Cálculo do espectrograma}

Nesta etapa é calculada a transformada rápida de Fourier (FFT) e o espectrograma do sinal. Para isto, foi utilizada a janela de Hammig com 4096 amostras. A imagem resultante é salva em formato PNG sem compactação em duas cópias: uma colorida para melhorar a experiência visual do usuário; e outra em tons de cinza para otimizar o processamento. Já espectro do sinal é utilizado para calcular as frequências de defeito, conforme as Equações 1 e 2. Estas frequências são armazenadas para serem utilizadas nas etapas posteriores

\subsubsection{Binarização da imagem}

Esta é uma técnica convencionalmente utilizada no processamento digital de imagens para realizar a segmentação de uma imagem. Nesta pesquisa, esta técnica foi utilizada para extrair da imagem original as frequências de alta magnitude. Na imagem, estas frequências 
são proporcionais ao valor do pixel onde ocorrem, ou seja, quanto mais perto do branco (255) maior a magnitude da frequência. De forma experimental, foi estipulado um limiar de 210 para realizar a Binarização, conforme a Equação 3.

$$
g(x, y)=\left\{\begin{array}{c}
0 \text { se } f(x, y) \leq 210 \\
255 \text { se } f(x, y)>210
\end{array}\right.
$$

\subsubsection{Filtragem (Erosão e Dilatação)}

O resultado da operação anterior é submetido a mais duas técnicas em conjunto, para atenuar os ruídos que possam existir e realçar as componentes de alta magnitude que ocorrem no decorrer do tempo. Pra isto, primeiro é realizado o processo de erosão com três interações, seguido do processo de dilatação com cinco interações. Foi utilizado um elemento estruturante (Kernel) em forma de linha horizontal nos dois procedimentos. Este foi um diferencial importante para esta pesquisa, pois permitiu realçar as componentes de alta magnitude que se estendem no tempo (componentes de frequências importantes para esta pesquisa) e atenuar componentes de alta magnitude com curta duração do tempo (característico de ruídos externos). Matematicamente, estas duas operações são translações de um dado conjunto numérico sobre outro e são representados conforme as Equações 4 e 5, respectivamente.

$$
\begin{aligned}
& A \ominus B=\left\{x \mid(B)_{x} \subseteq A\right\} \\
& A \ominus B=\left\{x \mid(B)_{x} \subseteq A\right\}
\end{aligned}
$$

\subsubsection{Identificação da frequência de defeito}

Esta etapa utiliza as frequências de defeito, que foram calculadas na segunda etapa, para ressaltar as frequências de alta magnitude que ocorrem na frequência de defeito e em suas harmônicas. Para isto, é criada uma máscara com linhas em branco no local correspondente às frequências que estas representam. Por sua vez, esta máscara é multiplicada com a imagem filtrada na etapa anterior. Devido a esta pesquisa estudar dois tipos de defeitos, neste procedimento são criadas duas imagens, sendo a primeira o resultado da multiplicação da imagem filtrada com a máscara contendo as frequências de defeito da pista interna e a segunda utiliza a mesma imagem filtrada multiplicada com a máscara com as frequências de defeito da pista externa. Além das frequências de defeito, ambas as máscaras contêm um retângulo preto no inferior, no local correspondente as frequências de zero a $500 \mathrm{~Hz}$. Este artifício é utilizado para realizar uma filtragem no domínio da frequência, uma vez que esta faixa de frequência não contém informações relevantes para o diagnóstico do rolamento com 
esta técnica.

Ainda nesta etapa do processamento é calculada a porcentagem de ocorrência de cada defeito. Este cálculo é o somatório dos pixels das duas imagens processadas, dividido pela somatória dos pixels da imagem filtrada. Logo tem-se dois índices: porcentagem de ocorrência na pista interna e a porcentagem de ocorrência na pista externa. Esses dois índices são utilizados para identificar se um dado rolamento possui defeito ou não. Para realizar este primeiro diagnostico, foi estabelecido experimentalmente um limar de $10 \%$. Portanto, se a somatória dos dois índices for superior a $10 \%$ indica que o rolamento está com algum tipo de defeito.

Se for detectado defeito no rolamento, as duas imagens processadas são combinadas em uma única imagem com dois canais para serem apresentadas à rede neural convolucional. Esta etapa será detalhada no tópico seguinte

\subsection{Rede Neural Convolucional}

A RNC (Rede Neural Convolucional) é uma variação das redes neurais de múltiplas camadas adaptada para ser utilizada em imagens. Este tipo de rede neural é amplamente utilizado para reconhecimento em imagens por ser capaz de aplicar diferentes filtros mantendo a disposição dos pixels, ou seja, além do valor que o pixel assume é considerado também o espaço que este se encontra, de acordo com sua vizinhança. Diferente da rede neural perceptron, na rede utilizada nesta pesquisa apenas um conjunto de entradas é conectada a cada neurônio para realizar a análise de campos receptivos locais.

Para o desenvolvimento desta pesquisa, foi utilizado o framework Keras para criar a rede neural convolucional. Esta aplicação utiliza o TensorFlow como backend engine para realizar o treinamento da rede. Com estas ferramentas, a arquitetura da rede foi elaborada de forma experimental, com duas camadas de convolução seguida de quatro camadas densas. Foi utilizada a função de ativação Relu (Equação 6) para otimizar o processamento (Krizhevsky et al. 2012). Já na camada de saída, foi utilizada a função de ativação sigmoide (funçã́o logística, Equação 7).

$$
\begin{gathered}
\operatorname{ReLU}(x)=\max \{0, x\} \quad \operatorname{ReLU}^{\prime}(x)=\left\{\begin{array}{c}
1, \text { se } x \geq 0 \\
0, \text { c.c. }
\end{array}\right. \\
\sigma(x)=\frac{1}{1+e^{x}} \quad \sigma^{\prime}(x)=\sigma(x)(1-\sigma(x))
\end{gathered}
$$

Esta arquitetura de rede foi treinada com supervisionamento utilizando um conjunto de 180 imagens, sendo estas organizadas em três classes: rolamento saudável, rolamento com 
defeito na pista interna e rolamento com defeito na pista externa.

\section{RESULTADOS E DISCUSSÃO}

Neste tópico são apresentados os resultados obtidos ao utilizar o classificador aqui desenvolvido para diagnosticar 10 áudios, sendo estes de rolamentos com defeito ou não. Ao realizar a aquisição do sinal, o motor estava funcionando na velocidade da rede $(60 \mathrm{~Hz})$, com três situações de carga mecânica imposta ao eixo: 0 Nm, 12 Nm e 24 Nm.

Já no tópico 1 serão apresentados os resultados pertinentes ao processamento digital de imagem, ao passo que no tópico 2 serão expostos os resultados da RNC.

Para simular o defeito de forma genérica no rolamento foi retirada uma pequena quantidade de material utilizando uma descarga elétrica. Com este método, foi possível fabricar o defeito de forma pontual com $1 \mathrm{~mm}$ de diâmetro, como apresentado pela Figura 7.

Figura 07: Defeito na pista interna.
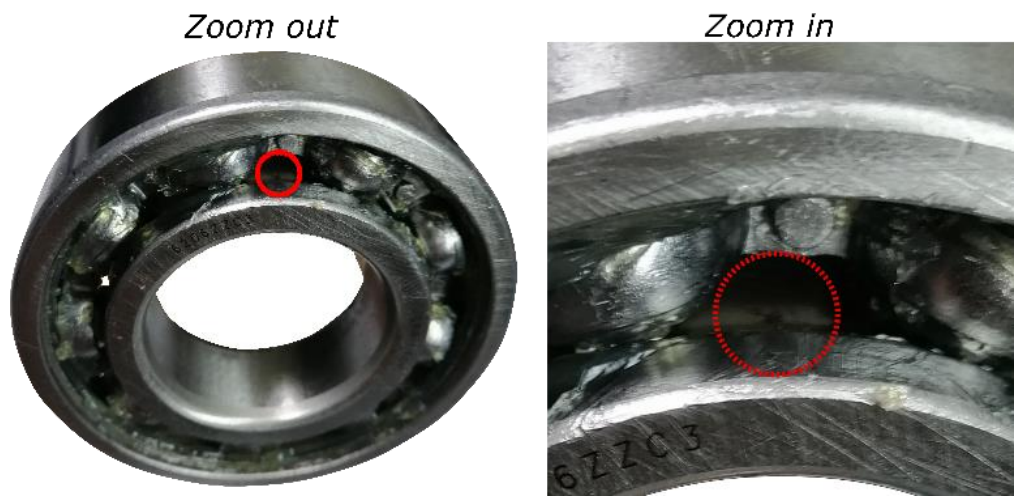

Fonte: Própria (2020).

Este método foi utilizado tanto para fabricar defeito na pista interna como na pista externa. Contudo, para cada rolamento foi fabricado só um tipo de defeito. Para assegurar que o rolamento só possuía o defeito que havia sido fabricado, foram utilizados rolamentos novos lubrificados conforme as especificações do fornecedor.

Para validar o software desenvolvido, foi utilizado um banco de dados contendo 36 áudios de rolamentos em funcionamento. A aquisição dos sinais deste banco de dados se deu conforme o tópico 1.2. Contudo, estes áudios não foram utilizados em nenhuma etapa do treinamento da rede. Os resultados desta etapa de validação serão apresentados de forma resumida pelas Figuras 8 a 10 . 
Figura 08: Diagnóstico de um rolamento saudável.

A-Audio 1

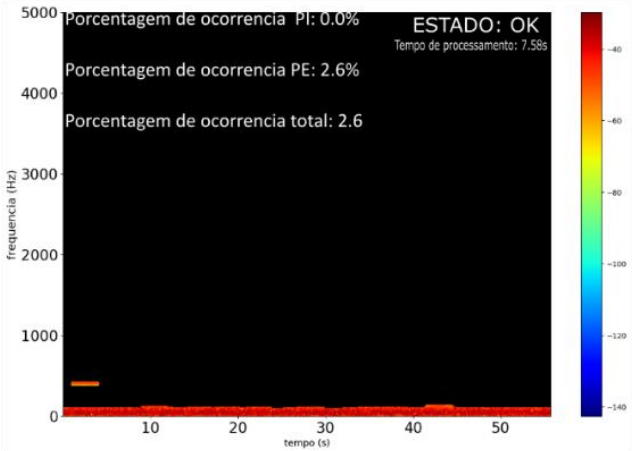

C- Audio 3

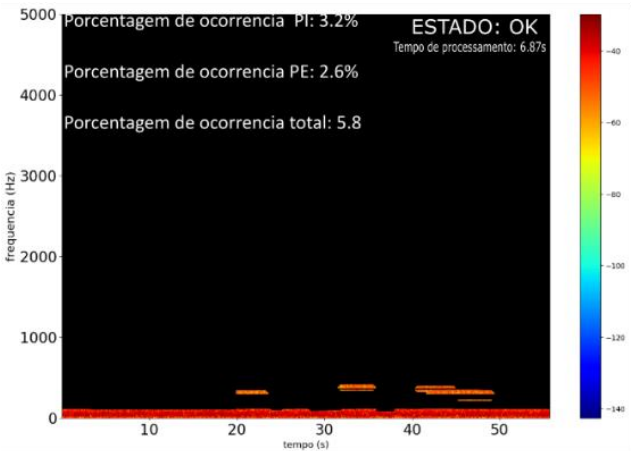

E- Audio 5

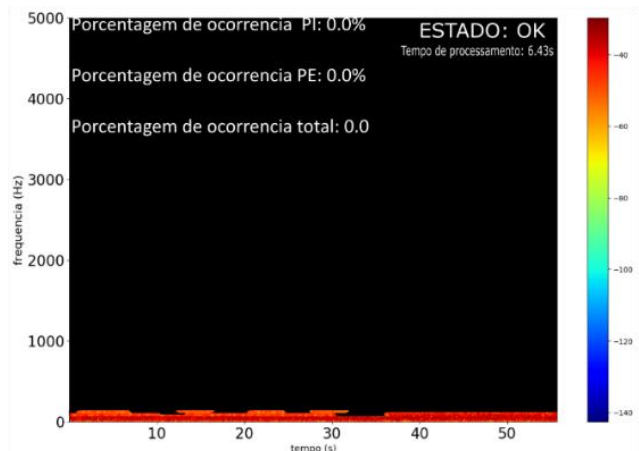

B- Audio 2

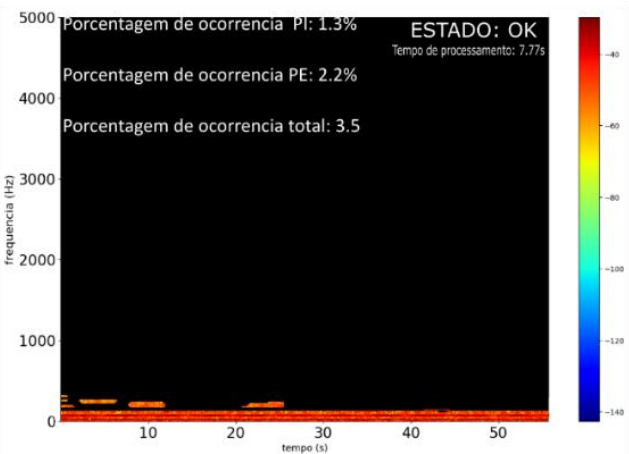

D- Audio 4

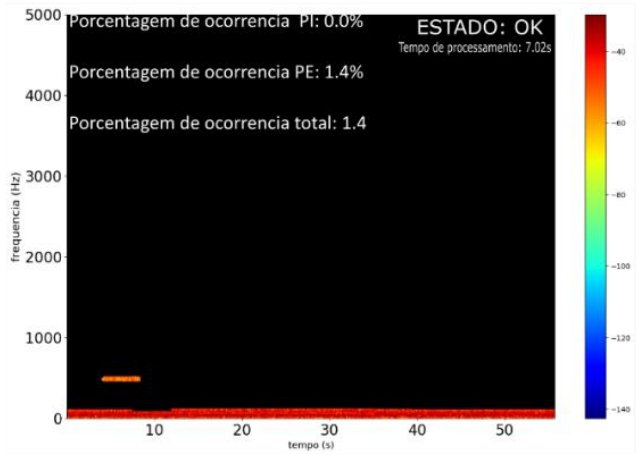

F- Audio 6

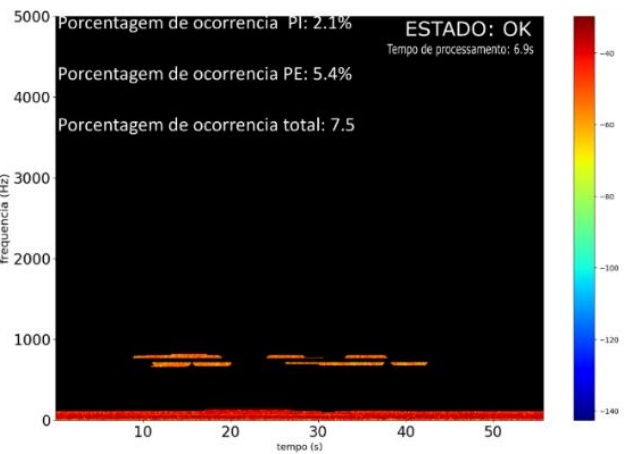

Fonte: Própria (2020).

Todos os diagnósticos apresentados na Figura 8 são referentes a rolamentos novos sem defeito. O tempo para gerar estes resultados é inferior (mais de 50\%) quando comparado ao tempo para gerar os resultados de um rolamento defeituoso, uma vez que não se utiliza a RNC para este diagnóstico. No momento da aquisição do sinal, foram impostas três situações de funcionamento do motor variando a carga mecânica sobre o eixo. Ainda assim, nas diversas situações imposta ao motor, $100 \%$ dos diagnósticos realizados foram corretos.

De forma semelhante, a Figura 9 demonstra o funcionamento do software para o diagnóstico de rolamentos com defeito na pista interna. 
Figura 09: Diagnóstico de um rolamento com defeito na pista interna.
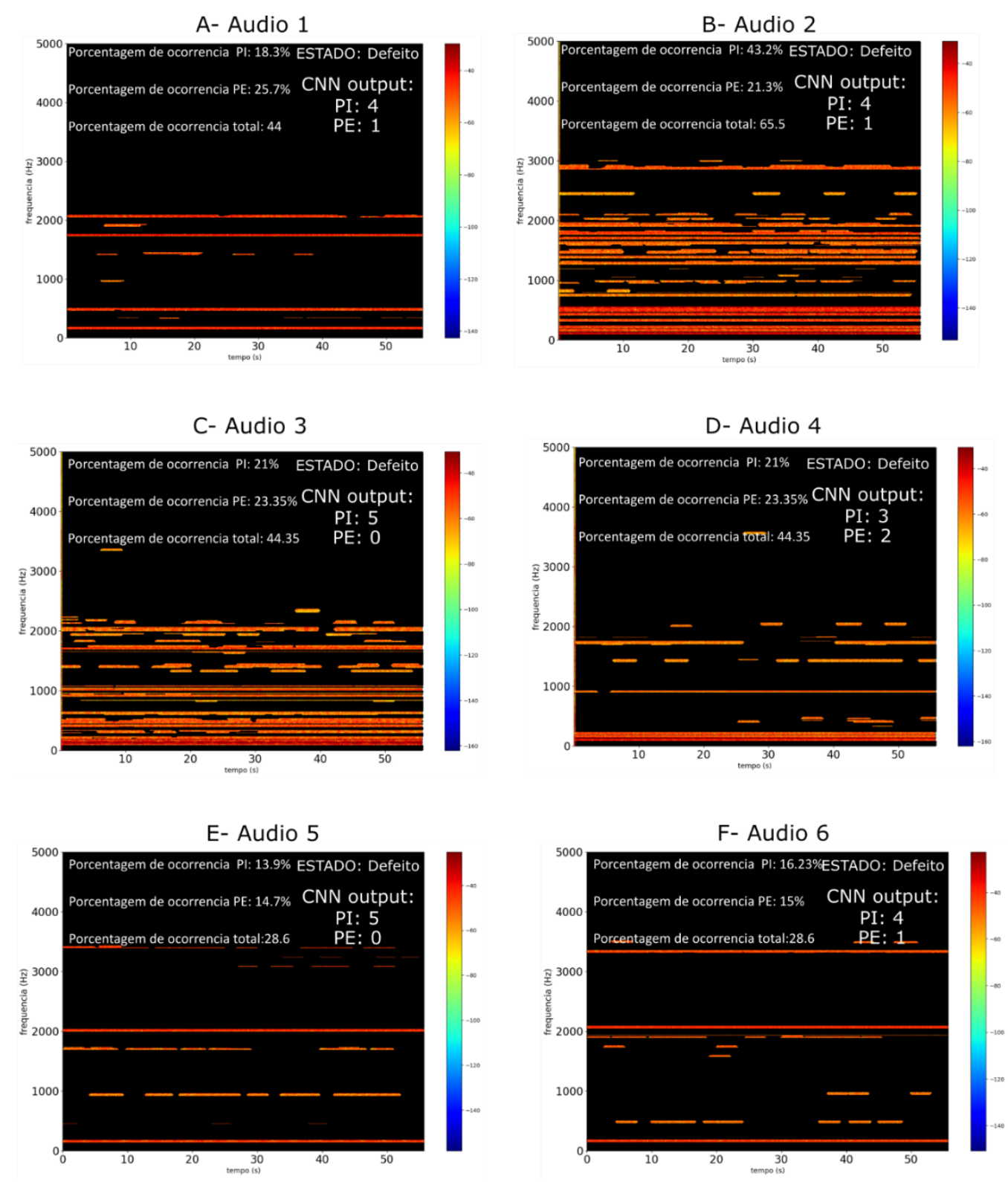

Fonte: Própria (2020).

O software implementado também obteve um desempenho satisfatório classificação de rolamentos com defeito na pista interna. Apesar de algumas imagens apresentarem um grau de certeza menor (menos segmentos classificados de forma certa) para todos os áudios correspondentes ao rolamento com defeito na pista interna, a classificação do mesmo foi realizada de forma correta.

Por fim, a Figura 10 apresenta os resultados que o software gerou ao inserir áudios de um rolamento com defeito na pista externa. 
Figura 10: Diagnóstico de um rolamento com defeito na pista externa.
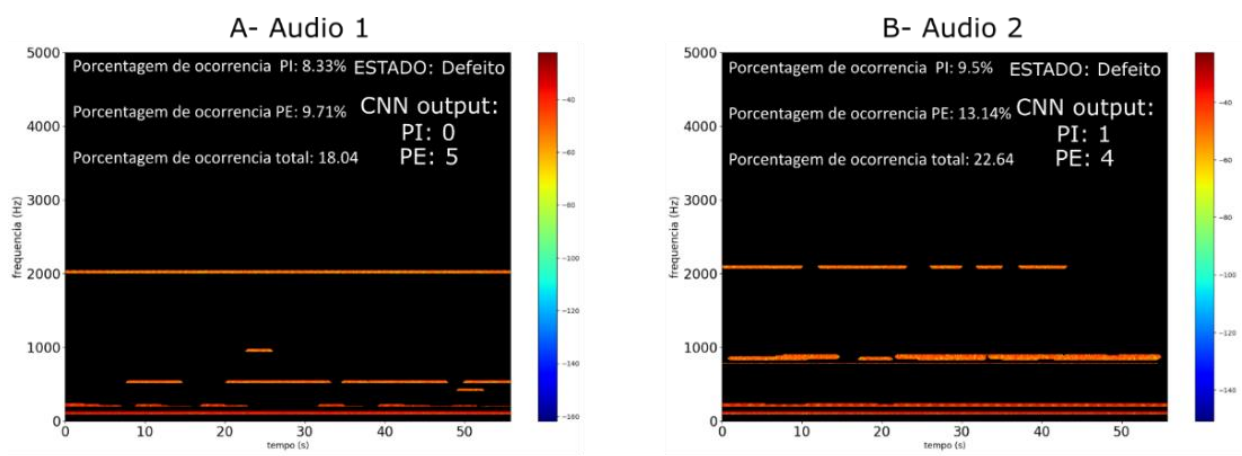

C- Audio 3
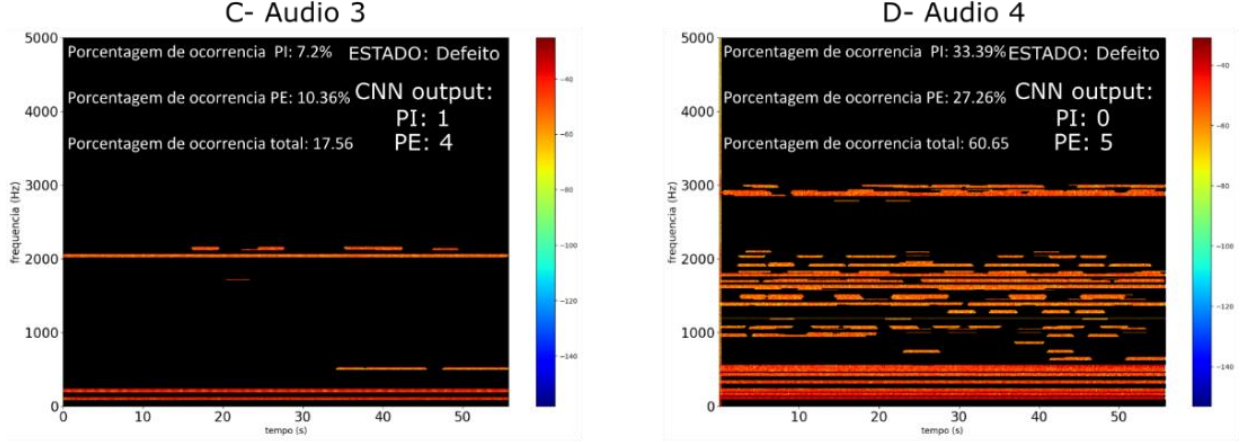

E- Audio 5

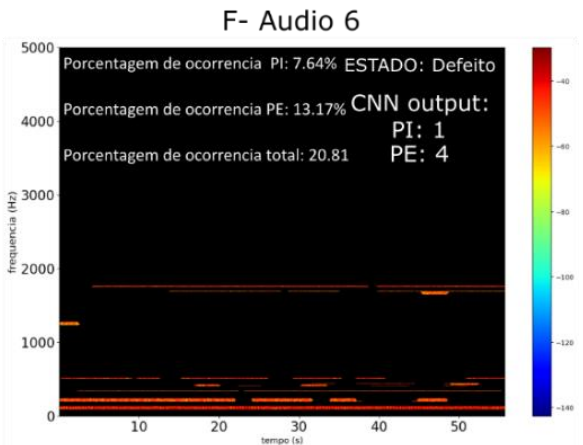

Fonte: Própria (2020).

De forma semelhante, o software implementado classificou todos os áudios desta classe de forma correta, com um tempo de processamento aproximado de 14s.

\section{CONCLUSÕES}

No estudo aqui apresentado foi desenvolvida uma ferramenta de suma importância para auxiliar o profissional responsável a diagnosticar de forma correta e rápida um rolamento em pleno funcionamento, independente da velocidade de funcionamento. Diferente das pesquisas realizadas tradicionalmente nesta área, o trabalho aqui desenvolvido utilizou um conjunto de técnicas para proporcionar um resultado objetivo, sem que haja necessidade de o operador deduzir informações. Com isto, além de facilitar a utilização da ferramenta, esta ferramenta confere maior confiabilidade no diagnóstico do rolamento. 
Inevitavelmente, o método de aquisição de sinal aqui utilizado está predisposto a ruídos externos, principalmente no âmbito industrial, onde há diferentes sistemas eletromecânicos em funcionamento continuo. Com isto, faz-se necessário para pesquisas futuras o desenvolvimento de um sistema de cancelamento de ruído, viabilizando assim a utilização desta ferramenta na esfera industrial.

Por fim, pode-se concluir que esta pesquisa possuiu uma relevância substancial, uma vez que foi capaz de diagnosticar os rolamentos de forma eficaz, mesmo utilizando componentes de baixo custo, quando comparado aos equipamentos convencionalmente utilizados para a mesma função.

\section{REFERÊNCIAS}

AHAMED, S. K.; KARMAKAR, S.; MITRA, M.; SENGUPTA, S. Novel Diagnosis Technique of Mass Unbalance in Rotor of Induction Motor by the Analysis of Motor Starting Current at No Load Through Wavelet Transform. 6th International Conference on Electrical and Computer Engineering, pp. 474 - 477, 2010.

AKBEN. "Acoustic spectral imaging and transfer learning for reliable bearing fault diagnosis under variable speed conditions", p. 1-19, 2019

GONZALEZ, Rafael C.; WOODS, Richard E. Processamento de imagens digitais. Editora Blucher, 2000.

HASAN, Md Junayed; ISLAM, MM Manjurul; KIM, Jong-Myon. Acoustic spectral imaging and transfer learning for reliable bearing fault diagnosis under variable speed conditions. Measurement, v. 138, 2019. p. 620-631.

Krizhevsky, A., Sutskever, I., and Hinton, G. E. Imagenet classification with deepconvolutional neural networks. Advances in neural information processing systems, 2012. p. 1097-1105.

NSK (org.). NSK Bearing Doctor: Diagnóstico Rápido de Ocorrências em Rolamentos, 2001. 36 p. Disponível em:

< http://www.nsk.com.br/upload/file/B08.pdf> Acesso em 05 nov. 2020.

PODDAR, S.; TANDON, N. Detection of particle contamination in journal bearing using acoustic emission and vibration monitoring techniques. Tribology International, v. 134, p. 154-164, 2019.

SALAZAR-VILLANUEVA, F.; IBARRA-MANZANO, O. G. Spectral analysis for identifying faults in induction motors by means of sound. In: CONIELECOMP 2013, 23rd International Conference on Electronics, Communications and Computing. IEEE, 2013. p. 149-153.

SANTOS, T. H.; GOEDDTEL, A.; SILVA, S. A. O.; SUETAKE, M. Scalar control of an 
induction motor using a neural sensorless technique. Electric Power Systems Research, 2014. Vol. 108.

SILVA, J. C. Sistema totalmente não-invasivo para determinação da velocidade de rotação do eixo, torque e rendimento em motores de indução em operação. 2018. $111 \mathrm{f}$. Dissertação (Mestrado) - Curso de Engenharia Mecânica, Centro de Tecnologia (ct) Programa de Pós-graduação em Engenharia Mecânica, Universidade Federal da Paraíba, João Pessoa, 2018. 


\title{
CAPÍTULO 08: DESAFIOS ENFRENTADOS COM O USO DE NOVAS TECNOLOGIAS: ENSINO E APRENDIZAGEM EM PERÍODO DE PANDEMIA COVID-19
}

\author{
CAPÍTULO 08: DESAFÍOS ENFRENTADOS CON EL USO DE NUEVAS \\ TECNOLOGÍAS: ENSEÑANZA Y APRENDIZAJE EN PERÍODO DE PANDEMIA \\ COVID-19
}

\section{CHALLENGES FACED WITH THE USAGE OF NEW TECHNOLOGIES: TEACHING AND LEARNING IN COVID-19 PANDEMIC PERIOD}

\author{
Guilherme de Siqueira Freitas Pontes ${ }^{1}$; Dayane Camile Bezerra de Lima ${ }^{2}$; Simone de Paula Silva ${ }^{3}$. Derek Luiz \\ Alves dos Santos ${ }^{4}$; Erick Viana da Silva ${ }^{5}$
}

DOI: https://doi.org/10.31692/978-65-88970-06-5.116-132

\begin{abstract}
RESUMO
Este artigo acadêmico foi idealizado a partir de reflexões sobre a necessidade em gerar discussão e conhecimento mais aprofundado sobre temáticas como o contexto histórico da pandemia gerada pelo Novo Coronavírus, também conhecido por Covid-19. Tal epidemia global apresenta grande potencial de proliferação em ambientes com aglomeração de pessoas, como as escolas e universidades. Além disso será possível compreender quais foram as implicações causadas na educação, uma vez que foram abordados temas quanto às alternativas encontradas para instituições educativas seguirem com as práticas de aulas, o que se refere ao ensino remoto emergencial, adotado em escolas mundo afora, bem como diversos cursos de extensão promovidos por institutos de ensino da rede pública e privada. Ademais de tais temáticas inovadoras para os modelos de ensino, estudou-se uma perspectiva relacionada aos problemas apresentados no ensino remoto, entre os quais pode-se destacar falta de infraestrutura adequada para vários estudantes de áreas rurais ou periféricas no Brasil, bem como a fadiga e a dificuldade em se manter conectado por longos períodos, por parte de alunos e docentes, no tocante às atividades remotas. Quanto à metodologia, este trabalho científico teve como base uma pesquisa de natureza qualitativa, com estudo da arte de temas voltados ao ensino, tecnologia e também sobre o período pandêmico. Enquanto resultados obtidos, pode-se perceber o estudo da problemática das transformações em sala de aula, como distanciamento social e diferenças entre a comunicação gerada por telas de computadores e celulares e o diálogo direto e pessoal. Desta forma, é necessário tratar de forma científica assuntos presentes, a fim de auxiliar no entendimento de como o processo educativo está sendo tratado, desde seus efeitos remotos até as diferentes particularidades do período de quarentena.
\end{abstract}

Palavras-Chave: Ensino Remoto, Aprendizagem à Distância, Educação Tecnológica.

\section{RESUMEN}

Este artículo académico fue idealizado desde reflexiones sobre la necesidad en generar discusiones y conocimiento más profundado sobre temáticas como el contexto histórico de la pandemia generada por el Nuevo Coronavirus, también conocido por Covid-19. Tal epidemia global presenta gran potencial de proliferación en ambientes con aglomeración de personas, como las escuelas y universidades. Además, será posible comprehender cuales fueron las implicaciones causadas para la educación, ya que fueron abordados temas sobre las alternativas encontradas para instituciones educativas siguieren con las prácticas de clases, lo que se refiere a la enseñanza remota de emergencia, adoptada en

\footnotetext{
${ }^{1}$ Tecnólogo em Gestão de Turismo, Instituto Federal de Pernambuco, guilhermesfpontes@gmail

${ }^{2}$ Técnico em Edificações, Instituto Federal de Pernambuco, dayanecamilelima@gmail.com

${ }_{3}^{3}$ Mestra em Gestão Ambiental, Instituto Federal de Pernambuco, simonedypaula@ gmail.col

4 Mestre em Gestão do Desenvolvimento Local Sustentável, Instituto Federal
}

derek.alves@ recife.ifpe.edu.br

${ }^{5}$ Mestre em Administração, Instituto Federal de Pernambuco, erick.viana@ recife.ifpe.edu.br

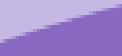


escuelas mundo afuera, bien como los diversos cursos de extensión promovidos por institutos de enseñanza de la rede pública y privada. Además de estas temáticas innovadoras para los modelos de enseñanza, fue estudiada una perspectiva relacionada a los problemas presentados en la enseñanza remota, entre los cuales se puede destacar la poca infraestructura adecuada para muchos estudiantes de áreas rurales o periféricas en Brasil, bien como la fatiga y la dificultad en mantenerse conectado por largos períodos, por parte de discentes y docentes, en relación a las actividades remotas. Cuanto a la metodología, este trabajo científico tiene como base una pesquisa de naturaleza cualitativa, con estudio del arte de temas vueltos a la enseñanza, tecnología y también sobre el periodo pandémico. Sobre los resultados obtenidos, se puede percibir el estudio de la problemática de los cambios en clase, como el distanciamiento social y diferencias entre la comunicación generada por pantallas de computadoras y móviles y el dialogo directo y persona. De este modo, es necesario comprender la forma científica de los asuntos presentes, a fin de auxiliar en entendimiento de cómo el proceso educativo está siendo tratado, desde los efectos remotos hasta las distintas particularidades del período de cuarentena.

Palabras Clave: Enseñanza Remota, Aprendizaje a Distancia, Enseñanza Tecnológica.

\begin{abstract}
This academic article was idealized after reflect about the needing to generate discussion and specified knowledge about themes like historical context of pandemic caused by New Coronavirus, also known as Covid-19. This global epidemic presented with great proliferation potential in places with people agglomerated, case of schools and Universities. Moreover, it will be possible to comprehend which were the problems caused in the education, once that themes related to the alternative found by the educative institutions to keep with classroom practice, referred to the emergently remote learning, adopted in schools around the world, as well diverse extension courses promoted by learning institutes, public or private. Moreover, these innovative themes for learning models, it was studied a perspective related to the problems presented in remote learning, whom questions can be explicated by the bad infrastructure for many students in rural and periphery areas in Brazil. As well tiring and difficulty to keep connected for long periods, independent if the person is student or professor, in case of remote activities. About the methodology, this scientific work had basis on a qualitative research, with art study in themes related to learning, technology and also pandemic period. About the results, it is possible to perceive the study of the changes in classroom, as social distancing and differences between communication generated by computer or cellphone screens and the direct and personal. This way, it is necessary to treat scientifically present topics, looking for how the educative process is being understood, since these remote effects until the different particularities from the quarantine period.
\end{abstract}

Keywords: Remote Learning, Distancing Learning, Technological Education.

\title{
INTRODUÇÃO
}

No final do ano de 2019, começou-se a divulgar informações por meio de portais de mídia sobre uma doença viral com alto potencial de contágio. A enfermidade, oriunda da província de Wuhan, na China, causada pelo Novo Coronavírus ou Covid-19, acarretou problemas mundiais, uma vez que o vírus se espalhou rapidamente em todo planeta. Em março de 2020, a Organização Mundial da Saúde denominou o surto como pandemia (UOL, 2020). Vale ressaltar, porém, que esta não foi a primeira ocasião de um vírus com proporções continentais, uma vez que ocorreram, previamente, a Peste Negra, do século XIV, e a Gripe Espanhola, iniciada após o final da Primeira Guerra Mundial, em 1918 (PASTERNAK, 2018; GALILEU, 2020).

Em decorrência da rápida transmissão do vírus, autoridades sanitárias de diversos 
países indicaram medidas como isolamento social, utilização de álcool gel (para higienização das mãos) e máscaras, com intuito de frear a proliferação, conter a pandemia e evitar a contaminação entre pessoas. Sendo assim, alguns estabelecimentos com grande potencial de ajuntamneto de indivíduos foram aconselhados a deixarem de atender presencialmente. As escolas e universidades, por serem ambientes nos quais geram grandes probabilidades de aglomerações, foram consideradas locais a se evitar presencialmente (SARAIVA, TRAVERSINI, LOCKMANN, 2020).

Sendo assim, as instituições de ensino, em diversos locais, optaram por realizar o ensino remoto, como forma de minimizar a perda das atividades acadêmicas e continuação das relações escolares. Embora não seja recente a prática de aulas não presenciais, não havia demanda significativa e nem todas as realidades tinham habilidades e conhecimento para utilizar tal sistema distanciado. Isto tudo ocasionou mudanças significativas nas relações sociais entre educadores e educandos, os quais se viram obrigados a não mais se encontrarem e precisaram utilizar novas metodologias educacionais, algo que aumentou a produtividade, gerando novas oportunidades (SARAIVA, TRAVERSINI, LOCKMANN, 2020).

Desta forma, este artigo acadêmico terá como objetivo compreender e analisar os desafios, bem como a crescente de novas possibilidades relacionadas ao ensino. Permitiu-se, pois, a comunidade acadêmica empoderar-se de plataformas virtuais, por conta das dificuldades em decorrência da pandemia. Os dados estudados a seguir foram extraídos, majoritariamente de revisão bibliográfica.

É importante salientar, que o intuito deste artigo é expor algumas das experiências e conclusões raciocinadas, mediante as pesquisas concretizadas, neste momento de distanciamento social. O estudo visa ajudar futuras análises desta fase de pandemia global e fortalecer novas descobertas sobre a área do ensino remoto que está sendo cada vez mais desbravada e que continuará na vida acadêmica das próximas gerações.

\section{FUNDAMENTAÇÃO TEÓRICA}

A fundamentação teórica do artigo será composta por duas etapas. Na primeira será realizada uma descrição histórica e problematização da questão de acesso à tecnologia por camadas socialmente excluídas na sociedade. Já a segunda etapa, descreve algumas das inovações a serem possibilitadas a partir do uso da tecnologia em períodos de ensino remoto e home office. 


\section{EDUCAÇÃO E TECNOLOGIA}

A tecnologia vem sendo uma ferramenta muito importante para a formação das sociedades contemporâneas. Dessa maneira, os avanços tecnológicos também geraram diversas contribuições para a educação moderna. Uma das primeiras demonstrações para desenvolver a educação à distância (EAD) foi iniciada a partir do século XIX, nos Estados Unidos, com matérias por correspondência em jornais. No Brasil, a difusão deste modelo aconteceu através de cursos por rádio (OLIVEIRA, 2019).

Como se percebe, já é possível verificar a disruptividade na educação como algo presente na sociedade, ao se utilizar a tecnologia como forma a aprimorar o aprendizado (ARAÚJO et al, 2017). Além disso, pode-se identificar a presença de uma nova forma de ensinar e aprender inovando e empreendendo em novos meios de interação entre discentes e docentes buscando atender às novas demandas da sociedade, como em atividades lúdicas nas próprias disciplinas tradicionais (COSTA, 2019).

Pensando nisso, é possível também recordar o conceito de educação empreendedora, isto é, "aquela que procura despertar nos alunos a vontade de inovar" (LIMA, 2017, p.15). O empreendedorismo, enquanto ação que visa suprir a dor de uma sociedade, na área da educação se possibilita à realização de novas soluções para desafios nas escolas (BAGGIO, BAGGIO, 2014).

Sendo assim, este artigo acadêmico visa trazer uma reflexão sobre a possibilidade de se reinventar em períodos distintos do habitual, isto é, uma análise sobre o que seria a aprendizagem em um novo normal, num período durante e após a pandemia. A partir disso, Amaral e Polydoro (2020) expõem que, no caso da universidade estudada pelas escritoras Universidade Estadual de Campinas, foi realizado um avanço nos sistemas digitalizados, com apoio à elaboração de vídeos, podcasts e conteúdos online, no sentido de auxiliar não somente os docentes, mas também os discentes a continuarem produzindo.

No entanto, Crawford et al (2020) entendem que não é simples o processo readaptação. Algumas das dificuldades relatadas por estes autores dizem respeito à total ou mesmo parcial falta de infraestrutura residencial adequada para o trabalho e estudo home office, ou seja, trabalho remoto. Já Huang et al (2020) recordam a dificuldade de certos grupos em utilizarem as redes de internet de maneira confiável. Além dessas problemáticas externas (2020, p.57) citam, algumas questões internas aos alunos, dentre o que podemos destacar: "os estudantes relataram dificuldade em gerenciar os estudos e necessidade de investir maior tempo para a realização das atividades e para apreensão do conteúdo". 
Ainda ressaltando os percalços trazidos pela dificuldade em se concentrar ou realizar atividades remotamente, junta-se ao fator que Oliveira (2020) aponta a distinção entre estudantes de escolas da rede pública se comparadas à rede privada. Esta autora cita que parcela significativa dos alunos oriundos de escolas estatais não possuem quaisquer dispositivos habilitados com acesso à internet para utilizarna educação.

O Centro Regional de Estudos para Desenvolvimento da Sociedade da Informação CETIC.BR (2020), entidade civil de direito privado, que faz parte do Núcleo de Informação e Coordenação do Ponto BR - NIC.BR, realizada anualmente pesquisa que possui o intuito de avaliar e compreender a quantidade e evolução de estudantes por todo o Brasil por meio do levantamento com mais de 11.361 estudantes das redes privada e pública, em todas as regiões geográficas brasileiras, urbana ou rural, além da participação de profissionais do ensino.

Sendo assim, esta pesquisa traz a problemática de que muitos dos estudantes do ensino público urbano não possuem tablet, computador de mesa ou portátil, uma vez que em torno de $40 \%$ não demonstra possuir nenhum desses aparelhos. Este dado traz a reflexão que, apesar de não ser maioria, parte significativa de estudantes foram prejudicados durante a pandemia, pois ficaram sem acesso a aulas remotas. Já na rede particular de ensino, ocorre uma situação distinta: aproximadamente $9 \%$ dos estudantes entrevistados não possuem acesso a computador ou tablet em suas residências. Quando o objeto de estudo passa a ser as escolas rurais, a dificuldade em acessar a rede é acentuada. Entre as instituições dessas regiões, $60 \%$ não possui acesso à internet, enquanto que $76 \%$ não apresentam meios para o acesso comunitário na grande rede. Já neste ponto, identifica-se que a falta de acesso à internet prejudica o desenvolvimento e isola ainda mais alunos da sala de aula.

Essa situação exposta sobre as diferenças relacionadas às escolas públicas e privadas nas áreas urbanas, bem como a disparidade percebida no tocante às escolas rurais, trazem reflexões sobre futuros sistemas educacionais. Além da necessidade de abordar a inclusão e democratização tecnológica é válido trazer a discussão de quais formas pode-se auxiliar no acesso dos estudantes a aparelhos que facilitem pesquisas, como é o caso dos tablets e computadores de mesa ou portáteis.

2. DESAFIOS E SOLUÇÕES DO ENSINO REMOTO PARA EDUCADORES E EDUCANDOS

Sene (2020), explica que neste contexto das dificuldades originadas pela pandemia, existe uma disparidade existente nas instituições de ensino em todo Brasil. A autora relata 
principalmente o quão difícultoso se tornou o período ao explicitar que no ensino público diversos alunos não possuem acesso adequado às atividades realizadas de forma remotamente.

Segundo, Sene (2020) na Universidade Federal de Pernambuco existe um total de $80 \%$ entre os profissionais técnicos ou docentes estão dispostos a realizar cursos visando o ensino remoto, isto é, aquele modelo de ensino no qual não há contato físico, discentes e docentes se encontram separados geograficamente a fim de terem a prática de classe (BEHAR, 2020).

$O$ intuito seria auxiliar na formação pessoal e desenvolvimento próprio e da comunidade acadêmica, bem como aumentar a capacitação pessoal visando uma maior qualidade acadêmica (PECHARKI, 2020). Uma outra solução apresentada para contornar a crise educacional gerada é a abertura de licitações e editais para os estudantes carentes possuírem acesso à compra ou empréstimo de materiais tecnológicos a fim de acompanharem as aulas.

Além disso, outras iniciativas inovadoras surgiram, como é o caso de maratonas no estilo hackathon, (GUIZARDI et al, 2018), a exemplo do Hacking Help Covid, primeira edição da maratona na condição virtual (ANPROTEC, 2020), ocorridas no mês de maio de 2020 contribuíram na busca por soluções inovadoras, a partir de situações reais propostas, visando melhor lidar com a problemática durante e após a pandemia.

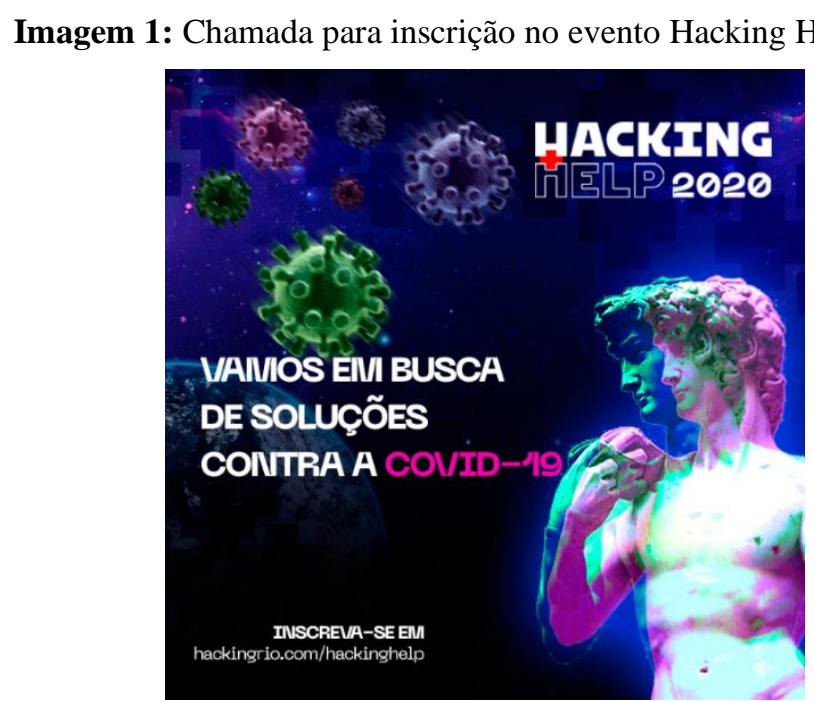

Fonte: Twitter UERJ (2020)

A tecnologia, cada vez mais, torna-se uma ferramenta importante em nossa sociedade globalizada (INOVAPARQ, 2016) possibilitando conferir avanços em todas as áreas do conhecimento. Porém, mesmo com a presença marcante de tecnologias em diversas camadas da sociedade, nem todos possuem acesso a ela.

Vale ressaltar, que um estudo proposto pelo Comitê Gestor da Internet, com dados 
levantados pela TIC Domicílios, o qual também faz parte do grupo CETIC.BR apontam que $30 \%$ dos brasileiros não possuíam acesso à internet em 2019. Esta situação, segundo Mattas e Chagas (2008), é histórica no Brasil, não apenas sobre a temática da tecnologia, mas também relacionado à distribuição desigual de renda e riquezas no país.

Tais dados comprovam, inclusive, que a renda dos cidadãos está ligada ao seu acesso à tecnologia. Para justificar tal informação, é possível analisar, entre outras adversidades, que a infraestrutura que permite o acesso às linhas telefonicas e o aumento do número de computadores por habitantes (assim como a quantidade deles conectados à internet) mostra-se ainda bastante insuficiente (MATTAS; CHAGAS, 2008, p. 80).

Assim, com a situação mundial apresentada pela pandemia, foi demonstrada a importância do estudo de políticas educacionais em relação a acessibilidade e democratização da tecnologia entre estudantes (SAE DIGITAL, 2020).

Desse modo, diversos estudos começaram a ser promovidos, buscando soluções para situações advindas dessa nova problemática e também apontando os benefícios das mesmas a serem utilizadas como ferramenta de ensino na nossa sociedade.

Tais pesquisas foram de grande importância para o momento pandêmico, mas também irão ajudar as futuras possibilidades de ensino e a sociedade no geral. Com a pandemia, o uso de tecnologias na vida do cidadão brasileiro, de acordo com o registro da empresa Akamai, teve um aumento de 112\%, no Brasil (BIELASKI, 2020). Essa necessidade de avanço nos meios educacionais e tecnológicos foram analisadas e geraram diversos questionamentos e respostas.

Assim, as adaptações de diversas atividades cotidianas foram sendo feitas por todos. Essas soluções encontradas no uso das redes sociais, videoconferências e modalidade de Educação a Distância (EAD), ficaram cada vez mais comuns. Isso demonstrou a solicitação, por parte do povo brasileiro, em relação a mudanças e avanços da tecnologia na educação. Sendo essas modificações não só urgentes para o presente momento, mas também, como possíveis modelos permanentes no futuro como a democratização ao acesso a internet.

Vale lembrar, que o uso das Tecnologias Digitais da Informação e Comunicação (TDIC) nos ambientes educacionais facilita o processo de ensino e aprendizagem e amplia a possibilidade da inclusão social. Mas, para haver um resultado favorável no processo de ensino, este deverá ser realizado através de estratégias arrojadas e eficientes que venham ao encontro com as premências das disciplinas e discentes, respeitando as exigências estabelecidas pelas instituições de ensino (OLIVEIRA; SILVA, 2015).

Os resultados favoráveis, citados anteriormente, estão interligados com as formas de $[122]$ 
relação entre professor, aluno e família. A presença da família no auxílio aos estudos dos alunos tende a resultar um significativo benefício para o desenvolvimento dos discentes, nesse novo modelo educacional. Além disso, outros métodos de revisão e monitoramento de aprendizagem do estudante tiveram de ser desenvolvidos e adotados, de forma conjunta, tentando adequar a relação entre responsáveis, crianças e escola (HEDLUND; AMARAL, 2020).

Com o avanço das tecnologias de ensino, nesse período, educadores tiveram maior conexão entre discentes. A utilização de jogos, aplicativos e outra plataformas mais interativas se tornou comum, trazendo experiências mais modernas para a sala de aula virtual. Ademais, professores e alunos puderam ter maior contato com as famílias.

Apesar disso, foram apontados problemas como a não inovação na forma de educar, com professores utilizando os mesmos métodos tradicionais, nas circunstâncias atuais (CORDEIRO, 2020): “A maioria dos professores imigrantes digitais que se inseriram no mundo da tecnologia, têm uma forma de ensinar que nem sempre está em sintonia com o modo como os nativos aprendem melhor, ou, pelo menos, que lhes desperta maior interesse". (BACICH, 2015, p.31)

Visto isso, depreende-se que as dificuldades estariam presentes, por ser uma situação atípica para todos. Contudo o crescimento e avanço tecnológico na educação deve ser reconhecido e estudado ainda mais. Assim, a comunicação, forma de avaliação e diversos outros tópicos devem ser debatidos para a melhoria desse ensino por meio da tecnologia e no avanço da educação tradicional (BARBOSA et al; HEDLUND; CORDEIRO, 2020).

\section{METODOLOGIA}

Este artigo teve, de forma predominante, os procedimentos metodológicos com exercício de revisão de literatura e estado da arte. Desta forma, a principal característica do trabalho é ser uma pesquisa de natureza qualitativa, isto é, o pesquisador procura ir a campo para estudar determinado assunto, sem pré julgamentos e analisando mais de um posicionamento (GODOY, 1994).

De acordo com Lara e Molina (2011), este tipo de pesquisa já é praticada há algumas décadas no Brasil, sendo que é necessário interpretar os dados e conceitos para se esclarecer de forma fundamentada o que está sendo exposto no texto corrido (OLIVEIRA, 2009). Ainda nessa linha de pensamento, Richardson (1999) compreende a coleta de informações no processo exploratório como parte da ciência. 
Após este entendimento da tipologia da pesquisa realizada, é importante também descrever o processo pelo qual foi desempenhada a busca de informações. Ao considerar que a Pandemia do Novo Coronavírus atingiu maiores proporções no ano de 2020, é dificultoso encontrar amplo referencial teórico que embase detalhadamente os efeitos, motivos e possíveis consequências sobre o que o distanciamento social causa, bem como o efeito de se trabalhar por tempo longo em estilo home office. O caso do ensino remoto, que utiliza diversas plataformas e desgasta os envolvidos, é uma das situações que ainda não há muito estudo a respeito.

Além disso, ao se realizar apanhados históricos e conceitos que comprovam a disruptividade do ensino remoto, embora emergencial, também pode-se denominar a característica de interpretação de dados da realidade, conferindo à pesquisa científica o seu caráter qualitativo.

\section{RESULTADOS E DISCUSSÕES}

É geralmente posto de forma consensual que a educação exerce forte influência nas transformações da sociedade, sendo a responsável pelo desenvolvimento da capacidade cognitiva e crítica do indivíduo. Além disso, a educação atesta o grau de desenvolvimento da sociedade, através de certos índices (PINTO, 2019). Diante disso é importante destacar que o rompimento de processos ou mudanças bruscas nos mesmos, acabam por trazer consequências nada satisfatórias ao crescimento social do país. (DIAS; PINTO 2019)

De acordo com Freire (1979), quando o homem compreende a sua realidade, pode levantar hipóteses sobre o desafio desse meio e procurar soluções. Assim, pode transformá-la e o seu trabalho pode criar um mundo próprio: seu eu e as suas circunstâncias. Desse modo, a partir da busca por soluções e percebendo-se que o período pandêmico acarretou transformações no fazer e ensinar da educação brasileira, diversos estudos estão sendo feitos.

Objetiva-se, pois, encontrar possíveis respostas para os problemas decorrentes dificuldades impostas pela contraindicação ao ensino presencial, necessitantdo-se adequação a metodologias mais adequadas para prosseguir com a prática do ensino para crianças, jovens e adultos. Para tanto, a utilização em ampla escala do ensino remoto tornou-se um novo horizonte na sociedade brasileira. É necessário, por isso, compreender como vem ocorrendo a adaptação de docentes e discentes no ensino remoto, bem como verificar quais estratégias adotadas por meio das plataformas utilizadas nas aulas.

Dessa forma, percebe-se que as mudanças de metodologias educacionais são visíveis, 
trazendo reflexões sobre o futuro do ensino tradicional e remoto e qual novo modelo se adequar. Pode-se pensar, desta forma, no ensino híbrido ou metodologias intituladas como sala de aula invertida (SANTOS, SANTOS; 2020). Lembra-se, pois, que tais inovações geram aprendizados valiosos à sociedade, por aliar novas possibilidades tecnológicas às salas de aula. observamos que as adversidades estarão presentes, quando considera-se mudar as metodologias educacionais de forma mais imediata e, possivelmente, permanente quando inicia-se debates sobre o futuro do ensino tradicional e remoto. Apesar disso, é importante lembrar das inovações e aprendizados trazidos para nós como sociedade, por meio desse atípico período que estamos vivenciando.

Com todas mudanças, essas discussões realizadas sobre a metodologia de ensino remoto, que apesar de não ser nova, nunca teve tanta influência e importância em nossa sociedade até os dias de hoje. Assim, análises comportamentais e técnicas puderam ser estudadas para a melhoria no entendimento e na prática da nova atividade. Como vimos, percebeu-se as habituais situações de cansaço e estresse diante das aulas síncronas ou assíncronas, videoconferências e outros (POLLO, 2020). Esse processo tem sido intitulado de Zoom Fatigue, traduzido literalmente por fadiga de Zoom, uma plataforma comumente utilizada para videoconferências (FOLHAPRESS, 2020).

Tais sensações foram explicadas por diversos estudiosos, a psicóloga Maluh Duprat, pesquisadora do Janus (Laboratório de Estudos de Psicologia e Tecnologias da Informação e Comunicação) da PUC-SP, cita a causa de algumas, como a dificuldade da leitura da linguagem corporal é uma delas.

As dificuldades vão além da comunicação, mas também estão relacionadas com a falta de preparo para o uso de tecnologias por parte dos professores. Como mostra uma pesquisa do Instituto Península, realizada com 7734 professores em todo o Brasil, apontou que $88 \%$ dos professores nunca tinha dado aula à distância de forma remota e 83,4\% não se sentiam preparados. Essa situação resulta em casos de falhas na apresentação das aulas, problemas com áudio e som dos aparelhos, dificuldades na correção de atividades, entre outros (OLIVEIRA, 2020).

Algumas situações ligadas ao emocional de cada docente e discente, também afetaram a eficiência das atividades. O suporte emocional não foi uma medida presente na vida de todos educadores e estudantes. Levando em consideração a atual pandemia, problemas relacionados com a ansiedade e outros problemas psicológicos ou até mesmo a perda de entes queridos, foram constantes, fazendo com que esse apoio mental adquirisse grande importância na vida de todos (SALAS, 2020). 
Ainda que existam os problemas decorrentes da pandemia, é necessário pensar novas possibilidades de voltar à interação física, uma vez que os seres humanos, como diria Aristóteles, é um animal social (REDAÇÃO PSICANÁLISE CLÍNICA, 2020). Assim sendo, uma das possibilidades de se retornar ao convívio em sala de aula é por meio de cadeiras com distanciamento social. Tal medida visa a diminuição de contato e auxilia a não proliferação do Novo Coronavírus.

Ademais da necessidade de reinserção no ambiente escolar, é possível pensar em uma intensificação do já proposto ensino híbrido, isto é, uma fusão entre as práticas presenciais com aquelas remotas, ao se utilizar os métodos tecnológicos para a educação. Isto ajuda a evoluir e cada vez mais tornar o ensino inovador e digital, por meio da tecnopedagogia, ou seja, a aplicação conjunta de ferramentas tecnológicas à educação. Resultando, assim, em aulas que auxiliem e tornem indispensável a evolução do ensino cotidiano (ZEDNIK et al, 2014).

Imagem 2: Sala de aula com distanciamento social

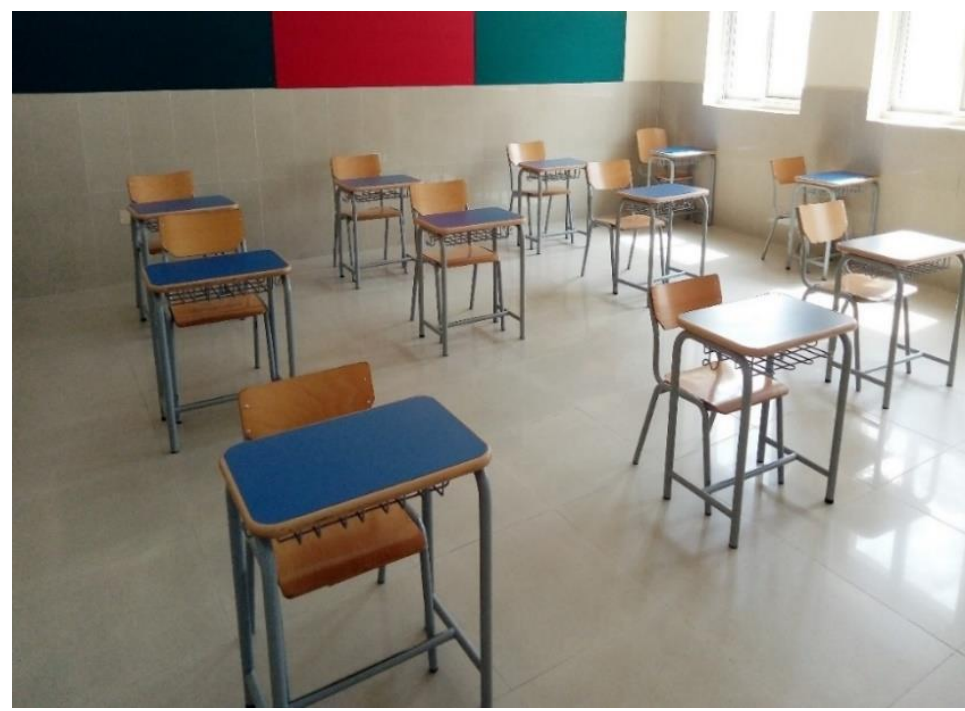

Fonte: Google Imagens - Pixa Bay

Ademais, ao analisar as muitas conexões feitas entre alunos e professores por meio de uma educação mais dinâmica e interativa, com o uso de plataformas virtuais diversas. Além também, o engajamento das famílias na educação daqueles do qual eram responsáveis teve, de acordo com o Conselho Nacional de Educação (CNE, 2020), um papel ainda mais importante na elaboração de um vínculo forte entre escola e aluno, para que esse não obtivesse retrocessos no seu desenvolvimento educacional (AMARAL, 2020).

Portanto, as situações inusitadas foram presentes durante esse período atípico da sociedade moderna. Apesar das dificuldades, essas trouxeram também desenvolvimento e 
inovação. Aprender a ensinar exige que os professores reflitam e compreendam a aprendizagem de maneiras bem diferentes daquilo que aprenderam com a própria experiência como estudantes (HAMMERNESS et al., 2019).

\section{CONCLUSÃO}

Entende-se, portanto, a importância e influência que a tecnologia vem apresentando na sociedade moderna. Desse modo, torna-se importante perceber que durante esse período de pandemia mundial, sua evolução foi significativa, entretanto essa conclusão ainda não possui dados concretos, já que no momento atual deste artigo, está ainda não foi cessada. Apesar disso, diante das informações discutidas e explicitadas, vemos que esta adquiriu um impacto de valor para os modelos de educação atuais e futuros.

Ao entender as aulas remotas enquanto saída plausível para estudantes e professores estarem em contato no compartilhamento do saber, também foi analisada uma série de deficiências e novas possibilidades que o período trouxe. Um exemplo de deficiência seria a fadiga por elevados tempos em conexão online, enquanto uma questão mais positiva volta-se para o uso da tecnologia como forma de avançar a educação, por meio da disruptividade empreendedora de cursos e maratonas de extensão.

Por fim, a discussão trazida tem potencial para exploração cada vez maior, desde soluções e até análises de lições tiradas pelo isolamento social forçado. Traz-se à tona questões voltadas à desigualdade de renda presente no Brasil e em diversos países, que o distanciamento acentuou economicamente e dificultou o aprendizado de populações menos favorecidas por condições mínimas de avanço no aprendizado. Mesmo assim, é válido lembrar que essas adversidades não devem ser desprezadas, mas, sim, levadas a busca de soluções para o avanço educacional, tecnológico e social.

\section{REFERÊNCIAS}

AMARAL, E.; POLYDORO, S. Os desafios da mudança para o ensino remoto emergencial na graduação na UNICAMP- Brasil. Linha Mestra. n. 41 a, p.52-62, 2020.

AMARAL, H. U. do. Relação Das Escolas Com as Famílias Durante a Pandemia. Disponível em:camadaseducacionais.com.br/blog/relacao-das-escolas-com-as-familiasdurante-a-pandemia. Acesso em: 2 Nov. 2020.

ARAÚJO, S. P. de. Tecnologia na educação: contexto histórico, papel e diversidade. IV 
Jornada de Didática III Seminário de Pesquisa do CEMAD, 2017.

ANPROTEC. Anprotec apoia o Hacking Help 2020 em busca de soluções que minimizem os efeitos da Covid-19. Disponível em: https://anprotec.org.br/site/2020/05/anprotec-apoia-ohacking-help-2020-em-busca-de-solucoes-que-minimizem-os-efeitos-da-covid-19/ Acesso em: 01 de novembro de 2020.

BAGGiO, A. F.; BAGGIO, D. K. Empreendedorismo: Conceitos e Definições. Rev. de Empreendedorismo, Inovação e Tecnologia, v. 1, n. 1, p. 25- 38, 2014.

BARBOSA, J. F. M. et al. Experiências no processo de ensino - aprendizagem -avaliação durante a pandemia. In: Anais do 39 Seminário de Atualizações de Práticas Docentes. 2020.

CETIC BR. Escolas estão mais presents nas redes sociais, mas plataformas de aprendizagem a distância são pouco adotadas. Disponível em: https://cetic.br/pt/noticia/escolas-estao-mais-presentes-nas-redes-sociais-mas-plataformas-deaprendizagem-a-distancia-sao-pouco-adotadas/ Acesso em: 05 de novembro de 2020.

COSTA, T. T. Empreendedorismo No Ensino Básico e Superior Já é Uma Realidade. Disponível em: www.correiobraziliense.com.br/app/noticia/comunidadeei/2019/07/23/noticias-comunidadeei,773153/empreendedorismo-no-ensino-basico-esuperior-ja-e-uma-realidade.shtml. Acesso em: 31 Out. 2020.

CRAWFORD, J. et al. Covid-19: 20 countries' higher education intra-period digital pedagogy responses. Journal of Applied Learning and Teaching, v. 3, n. 1, 2020.

DESENVOLVIDO POR IPOOMWEB - IPOOMWEB.COM.BR. Uso Da Internet Cresce 112\% No Brasil Durante Pandemia | ClicCamaquã. Disponível em:www.cliccamaqua.com.br/noticia/54862/uso-da-internet-cresce-112-no-brasil-durantepandemia.html. Acesso em: 31 Out. 2020.

DIÁRIO DO COMÉRCIO. 8,8 Milhões de Brasileiros Estão Em Home Office - Diário Do Comércio." Disponível em: diariodocomercio.com.br/economia/88-milhoes-de-brasileirosestao-em-home-office/. Acesso em: 1 Nov. 2020.

DUTRA, F. Artigo: O Ensino Remoto Emergencial e a Educação a Distância Coronavírus. Disponível em: www.ufrgs.br/coronavirus/base/artigo-o-ensino-remotoemergencial-e-a-educacao-a-distancia/. Acesso em: 2 Nov. 2020.

FREIRE, P. Educação e mudança. 12 ed. Paz e Terra, 1979.

FUNDAÇÃO TELEFÔNICA VIVO. Pesquisa TIC Educação 2019 Mostra o Impacto Da Tecnologia No Aprendizado. Disponível em: fundacaotelefonicavivo.org.br/educacao-doseculo-xxi/pesquisa-tic-educacao-2019-mostra-o-impacto-da-tecnologia-no-aprendizado/.

Acesso em: 31 Out. 2020.

G1 RIO. Hacking.Rio promove hackaton online para desenvolver soluções de combate à Covid-19. Disponível em: https://g1.globo.com/rj/rio-dejaneiro/noticia/2020/05/18/hackingrio-promove-hackathon-online-para-desenvolver-solucoesde-combate-a-covid-19.ghtml Acesso em: 31 de outubro de 2020. 
GALILEU. Peste Bubônica: 5 Pontos Para Entender o Que é a Doença. Disponível em: revistagalileu.globo.com/Ciencia/Saude/noticia/2020/07/peste-bubonica-5-pontos-paraentender-o-que-e-doenca.html. Acesso em: 1 Nov. 2020.

GODOY, A. S.. Pesquisa Qualitativa: tipos fundamentais. RAE. Revista de Administração de Empresas JCR, São Paulo, v. 35, n.3, p. 20-29, 1995.

GUIZARDI, F.L; SANTOS, K.G; LEMOS, A.S.P; SEVERO, F.M.D . Maratonas hackers no Brasil com desafios no campo da Saúde. São Paulo: Interface (Botucatu), 2018.

Cordeiro, K. M. D. A. (2020). O Impacto da Pandemia na Educação: A Utilização da Tecnologia como Ferramenta de Ensino.Disponível em: http://idaam.siteworks.com.br/jspui/bitstream/prefix/1157/1/O\%20IMPACTO\%20DA\%20PA NDEMIA\%20NA\%20EDUCA\%c3\%87\%c3\%830\%20A\%20UTILIZA\%c3\%87\%c3\%830\% 20DA\%20TECNOLOGIA\%20COMO\%20FERRAMENTA\%20DE\%20ENSINO.pdf Acesso em: 04 de novembro de 2020

HEDlund, A. O Papel Da Família e Sua Relação Com a Escola No Ensino Remoto | Edify Education - Programa Bilíngue. Disponível em: www.edifyeducation.com.br/blog/opapel-da-familia-e-sua-relacao-com-a-escola-no-ensino-remoto/. Acessoem: 1 Nov. 2020.

HUANG, R. H. et al. Handbook on facilitating flexible learning during educational disruption: The Chinese experience in maintaining undisrupted learning in COVID-19. Outbreak Beijing: Smart Learning Institute of Beijing Normal University, 2020.

INOVAPARQ. O Impacto Das Novas Tecnologias Na Sociedade. Disponível em: inovaparq.com.br/o-impacto-das-novas-

tecnologias/\#: :text=A\%20tecnologia\%20vem\%20influenciando\%20a,uma\%20maior\%20bus ca\%20por\%20informa\%C3\%A7\%C3\%B5es. Accessed 31 Out. 2020.

LARA, A. M. B. ; MOLINA, Adão Aparecido . Pesquisa Qualitativa: apontamentos, conceitos e tipologias. In: Cèzar de Alencar Arnaut de Toledo; Maria Teresa Claro Gonzaga. (Org.). Metodologia e Técnicas de Pesquisa nas Áreas de Ciências Humanas. Maringá: EEduem, 2011, v. 01, p. 121-172.

LIMA, J. de A. Educação Empreendedora e Educação Escolar: Uma Aplicação no Ensino Médio. 2017. 40 p. Trabalho de Conclusão de Curso, (Especialização), Especialização em Educação Empreendedora, Pontifícia Universidade Católica do Rio de Janeiro, Rio de Janeiro, 2017.

MATTOS, F. A. M. de.; CHAGAS, G. J. do N. Desafios para a inclusão digital no Brasil. Perspectivas em Ciência da Informação. v. 13, n. 1, p. 67-94, jan/abr. 2008.

MOVIMENTO DE INOVAÇÃO NA EDUCAÇÃO. O Que o Uso Das Tecnologias Digitais No Ensino Remoto Evidência Sobre o Futuro Da Escola - Movimento de Inovação Na Educação. Disponível em: movinovacaonaeducacao.org.br/noticias/o-que-o-uso-dastecnologias-digitais-no-ensino-remoto-evidencia-sobre-o-futuro-da-escola/. Nov. 2020. 
OLIVEIRA, A. Uninter oferece 12 cursos de extensão gratuitos durante pandemia de coronavírus. Disponível em: https://www.uninter.com/noticias/uninter-oferece-12-cursos-deextensao-gratuitos-durante-a-pandemia-de-coronavirus Acesso em: 02 de novembro de 2020.

OLIVEIRA, B. Como Surgiram Os Cursos de Ensino a Distância? | Blog CathoEdu. Disponível em: www.catho.com.br/educacao/blog/como-surgiram-os-cursos-de-ensino-adistancia-no-brasil-e-no-

mundo/\#: :text=J\%C3\%A1\%20outros\%20acreditam\%20que $\% 20 \mathrm{o}$,conhecimento $\% 20$ por $\% 20$ meio\%20do\%20r\%C3\%A1dio. Acesso em: 1 Nov. 2020.

OLIVEIRA, C. L. Um apanhado teórico-conceitual sobre a pesquisa qualitativa: tipos, técnicas e características. In: Travessias, 2008, Cascavel-PR. Anais: UNIOESTE, 2009.

OLIVEIRA, E. Quase 40\% Dos Alunos de Escolas Públicas Não Têm Computador Ou Tablet Em Casa, Aponta Estudo. Disponível em: g1.globo.com/educacao/noticia/2020/06/09/quase-40percent-dos-alunos-de-escolas-publicasnao-tem-computador-ou-tablet-em-casa-aponta-estudo.ghtml. Acesso em: 31 Out. 2020.

OLIVEIRA, M. V. Professores Pedem Apoio Técnico e Psicológico Durante a Quarentena - PORVIR. Disponível em: porvir.org/professores-pedem-apoio-tecnico-epsicologico-durante-a-quarentena/. Acesso em: 1 Nov. 2020.

PASTERnAK, N. Gripe Espanhola: 100 Anos Da Mãe Das Pandemias. Disponível em: saude.abril.com.br/blog/cientistas-explicam/gripe-espanhola-100-anos-da-mae-daspandemias/. Acesso em: 2 Nov. 2020.

PECHARKI, J. Cursos Online: 9 Sites Para Melhorar o Currículo Durante a Pandemia. Disponível em: www.gazetadopovo.com.br/gazz-conecta/plataformas-de-cursos-online-paramelhorar-o-curriculo/. Acesso em: 2 Nov. 2020.

PINTO, D. de O. Pisa - Ranking de Educação Mundial: Entenda Os Dados Do Brasil. Disponível em: blog.lyceum.com.br/ranking-de-educacao-mundial-posicao-do-brasil/. Acesso em: 2 Nov. 2020.

POLLO, L. Efeito no cérebro: por que todo mundo está exausto de conversar po vídeo. Disponível em: https://tab.uol.com.br/noticias/redacao/2020/05/08/por-que-todo-mundo-estaexausto-de-conversar-por-video.htm?cmpid=copiaecolaAcesso em: 03 de novembro de 2020.

PORTAL IFPE. Campus oferece extensão online em diversas áreas durante quarentena. Disponível em: https://portal.ifpe.edu.br/campus/recife/noticias/campus-ofereceextensao-online-em-diversas-areas-durante-a-quarentena Acesso em: 01 de novembro de 2020.

RABELlO, M. E. Lições Do Coronavírus: Ensino Remoto Emergencial Não é EAD. Disponível em: desafiosdaeducacao.grupoa.com.br/coronavirus-ensino-remoto/. Acesso em: 1 Nov. 2020.

REDAÇÃO PSICANÁLISE CLÍNICA. O Homem é Um Ser Social: 3 Teorias Científicas. Disponível em: www.psicanaliseclinica.com/o-homem-e-um-ser-social/. Acesso em: 30 Out. 2020. 
REDAÇÃO RBA. Brasil Da Pandemia: Quase 9 Milhões Em 'home Office' e 15 Milhões Afastados - Rede Brasil Atual. Disponível em: www.redebrasilatual.com.br/economia/2020/06/brasil-pandemia-home-office/. Acesso em: 31 Out. 2020.

RICHARDSON, R. J. Pesquisa social: métodos e técnicas. 3. ed. São Paulo: Atlas, 1999.

SAE DIGITAL. Educação e Coronavírus - Quais São Os Impactos Da Pandemia? - SAE Digital. Disponível em: sae.digital/educacao-e-coronavirus/. Acesso em: 2 Nov. 2020.

SALAS, P. Ansiedade, Medo e Exaustão: Como a Quarentena Está Abalando a Saúde Mental Dos Educadores. Disponível em: novaescola.org.br/conteudo/19401/ansiedademedo-e-exaustao-como-a-quarentena-esta-abalando-a-saude-mental-dos-educadores. Acesso em: 31 Out. 2020.

SANTIAGO, E. G. Vertentes teóricas sobre empreendedorismo em Schumpeter, Weber e Mcclelland: novas referências para a sociologia do trabalho. Revista de Ciências Sociais, v. 40. n. 2, p. 87 - 103, 2009.

SANTOS, V. B. O. dos; SANTOS, S. M. P. Ensino remoto pelo edmodo em tempos de pandemia. Revista Carioca de Ciência, Tecnologia e Educação. Rio de Janeiro: v. 5, n. especial, 2020.

SARAIVA, K.; TRAVERSINI, C. LOCKMAN, K. A educação em tempos de Covid-19: ensino remoto e exaustão docente. Práxis Educativa. v. 15, 2020.

SENE, A. Ensino remoto: desafios para o ensino público brasileiro durante a pandemia da Covid-19. Disponível em: http://www.adufepe.org.br/ensino-remoto-desafios-para-oensino-publico-brasileiro-durante-a-pandemia-da-covid-19/ Acesso em: 05 de novembro de 2020.

Tic Educação $2019 . \quad$ Disponível em: https://cetic.br/media/analises/tic_educacao_2019_coletiva_imprensa.pdf Acesso em: 04 de novembro de 2020

UOL. Coronavírus: Cuidados Que Você Deve Ter Para Se Prevenir Da Covid-19. Disponível em: www.uol.com.br/vivabem/faq/coronavirus-cuidados-que-voce-deve-ter-parase-prevenir-da-covid-19.htm. Acesso em: 2 Nov. 2020.

---. Coronavírus Na China: Perguntas e Respostas Sobre a Doença. Disponível em: www.uol.com.br/vivabem/noticias/bbc/2020/01/22/coronavirus-na-china-perguntas-erespostas-sobre-a-doenca-que-matou-6.htm. Acesso em: 1 Nov. 2020.

---. Efeitos No Cérebro: Por Que Todo Mundo Está Exausto de Conversar Por Vídeo. Disponível em: tab.uol.com.br/noticias/redacao/2020/05/08/por-que-todo-mundo-estaexausto-de-conversar-por-video.htm. Acesso em: 2 Nov. 2020.

---. Efeitos No Cérebro: Por Que Todo Mundo Está Exausto de Conversar Por Vídeo. Disponível em: tab.uol.com.br/noticias/redacao/2020/05/08/por-que-todo-mundo-esta- 
exausto-de-conversar-por-video.htm. Acesso em: 31 Out. 2020.

---. Proliferação de Vírus Acelera e Gera $20 \%$ de Casos Severos e Críticos. Disponível em: noticias.uol.com.br/colunas/jamil-chade/2020/03/20/coronavirus-pode-gerar-20-de-casosseveros-ou-criticos-diz-oms.htm. Acesso em: 1 Nov. 2020.

ZEDNIK, H. et al. Tecnologias Digitais na Educação: proposta taxonômica para apoio à integração da tecnologia em sala de aula. In: Anais do Workshop de Informática na Escola. 2014, p. 507-516. 


\title{
CAPÍTULO 09: O USO DAS REDES SOCIAIS EM ÉPOCA DE PANDEMIA - UM ESTUDO DE CASO APLICADO EM QUATRO ESCOLAS TÉCNICAS ESTADUAIS DE PERNAMBUCO
}

\section{CAPÍTULO 09: EL USO DE LAS REDES SOCIALES EN TIEMPOS DE PANDEMIA - UN ESTUDIO DE CASO APLICADO A CUATRO ESCUELAS TÉCNICAS DEL ESTADO DE PERNAMBUCO}

\section{CHAPTER 09: THE USE OF SOCIAL NETWORKS IN PANDEMIC TIMES - A CASE STUDY APPLIED TO FOUR TECHNICAL SCHOOLS IN THE STATE OF PERNAMBUCO}

\begin{abstract}
Ana Elisabeth de Brito Alves ${ }^{1}$; Guilherme da Silva Andrade ${ }^{2}$; José Alisson de Oliveira ${ }^{3}$; Juliana de Brito Alves ${ }^{4}$;
\end{abstract} Nadiene de Paiva Brandão ${ }^{5}$

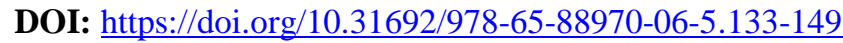

\begin{abstract}
RESUMO
O tema desenvolvido nessa pesquisa vem trazer um debate sobre o uso das redes no período do "pico" da pandemia da COVID-19. A partir de toda percepção sobre o comportamento anterior à pandemia desses jovens e fazendo um paralelo ao momento atual, vislumbrou-se uma necessidade de conhecer mais perto como os jovens pesquisados estão interagindo e usando as redes sociais, visto que agora eles estão cada vez mais conectados. Analisar se as redes sociais, nesse momento de pandemia representam para eles uma necessidade íntima, lazer ou dependência. Essa pesquisa tem a natureza qualitativa / quantitativa do tipo study of case, cujo campo (universo) são quatro escolas técnicas da rede estadual de ensino em Pernambuco (PE), os sujeitos envolvidos na pesquisa técnico são estudantes de 14 a 18 anos, que fazem o ensino de nível médio na modalidade integral nos cursos de Administração e Desenvolvimento de sistemas, os instrumentos utilizados foram um questionário elaborado pelo Google forms, contendo 21 perguntas elaboradas com o modelo de escala de Likert (mostrando a ordem de importância), dados quantificados foram considerados tratados no programa EpiInfo como modo de frequência. Após a análise dos questionários utilizou-se "rodas de conversa", debates por vídeo chamada pelo aplicativo Google meet. Assim, toda pesquisa, dados colhidos e debates, mostram que o virtual não deve ser visto como melhor nem pior, nem como substituto nem como efetivo, e sim uma ferramenta de transformação atual e que as redes sociais vieram para ficar, independente de formato, fama ou usabilidade.
\end{abstract}

Palavras-Chave: Redes sociais, Pandemia Covid-19, Estudantes da Rede Pública Estadual de PE, Dependência tecnológica.

\section{RESUMEN}

El tema desarrollado en esta investigación trae un debate sobre el uso de las redes durante el período "pico" de la pandemia OVID-19. De toda la percepción sobre el comportamiento prepandémico de estos jóvenes y haciendo un paralelo con el momento actual, se vislumbró la necesidad de conocer más de cerca cómo están interactuando y utilizando las redes sociales los jóvenes investigados, ya que ahora están cada vez más conectados. Analizar si las redes sociales, en este momento de la pandemia, representan para ellos una necesidad íntima, de ocio o de dependencia. Esta investigación tiene el carácter cualitativo / cuantitativo del estudio de tipo de caso, cuyo campo (universo) son cuatro escuelas técnicas de la red estatal de educación en Pernambuco (PE), los sujetos involucrados en la investigación técnica son estudiantes de 14 a 18 años, que hacen la educación secundaria en la

\footnotetext{
${ }^{1}$ Esp. Gerenciamento de Projetos, Pontifícia Universidade Católica de MG, anabritoalves@gm

${ }^{2}$ Grad. Administração, Faculdade de Ciências de Timbaúba-FACET, guilhermeandradempp

${ }^{3}$ Grad. Administração, Faculdade de Ciências de Timbaúba-FACET, alisson_oliveira0@

${ }^{4}$ Esp. Mídias da Educação, Universidade Federal de Pernambuco-UFPE, julianadeb

${ }^{5}$ Mestre, Instituto Superior de Leiria-ISLA, Portugal, nadienebrandao@ gmail.com
} 
modalidad integral en los cursos de Administración y Desarrollo de Sistemas, los instrumentos utilizados fueron un cuestionario preparado por formularios de Google, que contiene 21 preguntas preparadas con el modelo de escala de Likert (mostrando el orden de importancia), los datos cuantificados se consideraron en el programa EpiInfo como el modo de asistencia. Después del análisis de los cuestionarios, se utilizaron "ruedas de conversación", discusiones de video llamadas por la aplicación Google meet. Así pues, todas las investigaciones, los datos recopilados y los debates muestran que lo virtual no debe considerarse ni mejor ni peor, ni como un sustituto ni como eficaz, sino más bien como una herramienta de transformación actual y que las redes sociales han llegado para quedarse, independientemente del formato, la fama o la facilidad de uso.

Palabras Clave: Redes sociales, Pandemia Covid-19, Estudiantes de Red Pública Estatal de PE, Dependencia tecnológica.

\begin{abstract}
The theme developed in this research brings a debate about the use of networks during the "peak" period of the OVID-19 pandemic. From all the perception about the pre-pandemic behavior of these young people and making a parallel to the current moment, a need to know more closely how the researched young people are interacting and using the social networks was glimpsed, since now they are more and more connected. To analyze if the social networks, at this moment of the pandemic, represent for them an intimate need, leisure or dependence. This research has the qualitative / quantitative nature of the study of case type, whose field (universe) are four technical schools of the state education network in Pernambuco (PE), the subjects involved in the technical research are students from 14 to 18 years, who do the high school education in the full mode in the courses of Administration and Development Systems, the instruments used were a questionnaire prepared by Google forms, containing 21 questions prepared with the Likert scale model (showing the order of importance), quantified data were considered in the EpiInfo program as mode of attendance. After the analysis of the questionnaires, "conversation wheels" were used, video discussions called by the Google meet application. Thus, all research, data collected and debates, show that the virtual should not be seen as better or worse, neither as a substitute nor as effective, but rather as a tool for current transformation and that social networks are here to stay, regardless of format, fame or usability.
\end{abstract}

Keywords: Social networks, Covid-19 Pandemic, PE State Public Network Students, Technological Dependence.

\title{
INTRODUÇÃO
}

O tema desenvolvido nessa pesquisa trouxe um debate sobre o uso das redes sociais por jovens estudantes dos 14 aos 18 anos de quatro escolas técnicas estaduais do Estado de Pernambuco, no período do "pico" da pandemia da COVID-19. A vivência cotidiana mostra que as redes sociais ao longo do tempo, fez surgir nos indivíduos muitas necessidades, maioria delas são necessidades psicológicas, principalmente entre esses jovens, onde as mesmas redes se traduzem como um "casulo acolhedor", onde eles possuem com muito mais afinco as mudanças, as tendências, a curiosidade, embora que superficial, mas que vão aos poucos dirigindo suas demandas, e estas fazem todo sentido para uma vida "reclusa" e "virtual".

Os requisitos estabelecidos pela OMS (Organização Mundial de Saúde) e todo o protocolo guiado para a manutenção do distanciamento social, fizeram com que sociedade se isolasse em casa e ficasse muito mais tempo conectada à internet e utilizando uma infinidade 
de aplicativos, redes sociais e ferramentas tecnológicas para a nova experiência que se iniciava em meados de março de 2020. Criaram-se novos hábitos, costumes e mudança de cultura doméstica, aula remota, trabalhos em home Office, diminuição da prática de exercícios físicos e desregramentos alimentares, proporcionando uma "nova vida" que trouxe dessa forma novas perspectivas, umas positivas e outras nem tanto.

Mesmo em época de aulas presenciais, os jovens envolvidos na pesquisa, têm uma necessidade de estarem conectados, utilizando redes sociais com mais afinco e muitas vezes atrapalhando a aula, interrompendo os professores, prejudicando os colegas e em casa se ausentando da vida em família, esse contexto é vivenciado nas escolas públicas estaduais pesquisadas onde as mesmas não tem autonomia para proibir o uso errado (fora de hora) desses equipamentos eletrônicos.

A partir de toda percepção acerca do comportamento anterior à pandemia desses jovens e fazendo um paralelo ao momento atual, vislumbrou-se uma necessidade de se conhecer mais de perto como os jovens pesquisados estão interagindo e executando o uso das redes sociais, visto que agora eles estão cada vez mais conectados. Será que a realidade virtual mais do que nunca está se "impondo" à realidade presencial, ou se é apenas um mecanismo momentâneo de comunicação como tantos outros? O uso mais que o normal dessas redes sociais fará com que os estudantes substituam de vez o contato físico, já que são da geração que mais utiliza esses meios de comunicação? O uso exacerbado do virtual, para esses jovens, vem nessa época como uma necessidade, lazer ou dependência?

O objetivo geral dessa pesquisa é entender esse novo cenário na vida desses jovens e como eles estão se sentindo frente à nova realidade virtual. Como objetivos específicos, se buscou compreender: Conhecer as necessidades desses jovens permanecerem conectados às redes sociais; entender os sentimentos desses jovens ao buscarem tanto a permanência frente às redes sociais; analisar se as redes sociais, nesse momento de pandemia representam para esses jovens uma necessidade íntima, lazer ou dependência.

A decisão de pesquisar o tema com esse público é por trabalhar com o mesmo, mais perto e conhecer um pouco sua rotina e vislumbrar o que mudou radicalmente nos de março a setembro de 2020 (época dessa pesquisa). Visto que, o contato virtual passou a ter uma superioridade ao contato presencial, onde a conversa através de telas digitais ganhou amplo aspecto, e isso é um sinal de uma nova percepção de mundo. O público pesquisado é uma geração que "quase" só viveu a experiência virtual e para a mesma, não existe uma diferença gritante entre contato e intermediação, mas mesmo assim, sofreram um impacto emocional muito forte, o que os levou a mergulhar ainda mais no mundo digital, por motivos 
que serão apresentados na pesquisa de campo. Muitos desses jovens, mesmo antes da pandemia da Covid-19 preferiam ficar em casa a sair para um passeio urbano ou se encontrar com os amigos, mas ao mesmo tempo buscam afetividade, e isso nessa época de pandemia se intensificou; a permanência em casa se prolongou e também a dependência virtual, a carência emocional, a ausência de outros fatores importantes, etc. Por assim ser, nas redes sociais, os jovens expressam e deixam "sua marca", "vendem" suas opiniões e adquirem "amigos" e "seguidores".

Essa pesquisa tem a natureza qualitativa/quantitativa do tipo estudo de caso, cujo campo (universo) é quatro escolas técnicas da rede estadual de ensino em PE, os sujeitos envolvidos na pesquisa são estudantes de 14 a 18 anos, que fazem o ensino técnico de nível médio na modalidade integral nos cursos de Administração e Desenvolvimento de sistemas, os instrumentos utilizados foram debates por vídeo chamadas pelo Google Meet e após a roda de conversa foi aplicado um questionário elaborado pelo Google Forms, contendo vinte e uma (21) perguntas elaboradas com o modelo de escala de Likert (mostrando ordem de importância), cujos dados quantitativos foram tratados no programa EpiInfo como modo de frequência e serão demonstrados mais adiante nos resultados.

A contribuição desse artigo acerca do tema abordado é positiva e pertinente, possibilitando conhecer mais de perto o que ocorre com esses estudantes nesse momento de pandemia, como eles se comportaram frente ao cenário virtual e como eles se sentem, visto que o uso das redes sociais por esses estudantes possibilita a manutenção das atividades de estudos, ter acesso e informação acerca da pandemia e suas formas de proteção, e várias outras ações cotidianas, onde os estudantes conseguem manter certa rotina muito embora com algumas mudanças de hábitos e criação de outros vícios que podem ser ou não prejudiciais e serão apresentados mais adiante. A relevância do presente trabalho registra-se não apenas pelo seu objetivo geral, mas identifica-se, também, com o fornecimento de subsídios que permitam entender a dinâmica oculta dos relacionamentos e as conexões entre indivíduos que, voluntariamente, tornam-se propulsores de informação e grandes colaboradores organizações. É esse o intuito do trabalho apresentado.

\section{FUNDAMENTAÇÃO TEÓRICA}

\section{A educação técnica profissional de nível médio na rede estadual em Pernambuco}

A educação profissional vive um momento decisivo, mas não conclusivo. A procura por esse tipo de ensino atingiu patamares inéditos no Brasil e em Pernambuco, em que escolas 
técnicas estaduais vêm formando jovens e adultos, nas modalidades integral e subsequente e também à distância.

A iniciativa de implantar cursos técnicos em escolas estaduais vem suprir a carência da mão de obra técnica qualificada no estado de Pernambuco, onde cursos de diversas áreas são oferecidos a estudantes que cursam o ensino médio e técnico concomitantes em período integral durante três anos, e também estudantes que já concluíram o ensino médio, realizando apenas o ensino técnico profissional de nível médio no período de um ano e meio.

Em meio a pontos forte e fracos, o ensino profissional precisa ser melhor articulado, para não entrar em colapso e se perder do foco. Apesar de cada vez mais jovens estarem buscando aprender uma profissão, pode-se dizer que ainda falta um maior interesse do público-alvo. Segundo um agente responsável da consultoria Ceplan, em uma entrevista ao Diário de Pernambuco (2012) afirmou:

\begin{abstract}
"A dura verdade é que o desejo pelo diploma universitário, uma cultura secular no Brasil, mascara um preconceito enraizado na sociedade: de que ensino profissional é coisa de pobre. Em 2011, Pernambuco contava com 31.411 alunos matriculados em cursos técnicos, públicos e privados. Mas análise da consultoria Ceplan mostra que somente as demandas até 2014 de dois segmentos econômicos, a construção civil e a indústria metal mecânica, são de 32.500 novos trabalhadores por ano. O equilíbrio está distante. São 9 milhões de estudantes de Ensino Médio no Brasil."
\end{abstract}

Segundo dados do site da Secretaria de Educação do Estado, Pernambuco dispõe hoje (2020) de uma ampla rede de instituições que oferecem educação profissional gratuita em diversas habilitações. As novas cadeias produtivas aportadas neste Estado, nos últimos anos, vêm gerando uma demanda crescente por mão de obra especializada, trazendo dinamismo econômico e principalmente novas oportunidades para a educação técnica. Assim, o Governo do Estado de Pernambuco definiu como uma das suas prioridades a valorização, ampliação e estruturação da Rede Estadual de Educação Profissional e Tecnológica. Como resultado do esforço realizado na área, temos, atualmente, 28 Escolas Técnicas Estaduais em funcionamento, cerca de 27.480 estudantes matriculados nestas unidades e a oferta de 35 cursos em 23 municípios distribuídos em 12 Regiões de Desenvolvimento que compõem/o Estado. Os cursos são organizados por eixos tecnológicos: Ambiente e Saúde; Informação e Comunicação; Gestão e Negócios; Infraestrutura; e Controle de processos industriais.

De acordo com o site da SEDUC (Secretaria de Educação de Pernambuco), para assegurar e consolidar os avanços da educação técnica no Estado, desde 2009, a própria SEDUC, através da Secretaria Executiva de Educação Profissional, é responsável por formular, programar, acompanhar e avaliar as políticas estaduais de educação profissional em nível técnico. 
As opções de ensino técnico de nível médio permitem que todos os estudantes da rede estadual pelo Estado tenham a oportunidade de se qualificarem sem sair das suas regiões de desenvolvimento, garantindo formação específica e direcionada ao mercado de trabalho.

A história explica a barreira cultural quando o assunto é ensino profissional no Brasil. Logo, todas as iniciativas são válidas do ponto de vista governamental e social, mas ainda é sentida a falta de interesse dos próprios estudantes em formarem-se técnicos e também por parte de algumas empresas que escasseiam a oportunidade empregatícia.

\section{Formas de Oferta}

De acordo com as informações abaixo, retiradas do site da SEDUC, temos as formas de oferta do ensino profissional em escolas técnicas estaduais em Pernambuco.

- Integrada ao Ensino Médio em jornada integral: oferecida a quem já tenha concluído o ensino fundamental, sendo o curso planejado de modo a conduzir o aluno à habilitação profissional técnica de nível médio, vivenciando matriz curricular única com formação geral e profissional na mesma instituição de ensino;

- Subsequente ao Ensino Médio: oferecida somente a quem já tenha concluído o ensino médio;

- Concomitante ao Ensino Médio: ofertada nos cursos à distância.

\section{Modalidades de ensino profissional}

- Presencial: atende em sala de aula convencional estudantes egressos do ensino fundamental, preferencialmente da faixa etária de 14 a 18 anos, no ensino médio integrado em horário integral e estudantes ou trabalhadores, egressos do ensino médio, maiores de 18 anos, na forma de oferta subsequente;

- À Distância: atende estudantes, jovens e adultos na modalidade concomitante e subsequente, por intermédio do uso de tecnologias ma sala de aula, onde professores e alunos tem o contato mediado por interfaces.

\section{As redes sociais}

De acordo com Lemos (2019),

"As redes sociais são estruturas básicas de uma sociedade, são formadas pelas pessoas e seus relacionamentos; nossa rede social é formada pelos nossos relacionamentos diretos, como parentes, amigos e colegas de trabalho, e pelos relacionamentos que estes possuem com outras pessoas, de forma que todos os integrantes de um mesmo grupo social provavelmente estão direta ou indiretamente conectados." 
As redes sociais, segundo Marteleto (2001) representam "[...] um conjunto de participantes autônomos, unindo ideias e recursos em torno de valores e interesses compartilhados". As relações podem ser direcionais ou não direcionais. Ainda sob a ótica de Marteleto (2001),

\footnotetext{
"As redes nas ciências sociais designam normalmente - mas não exclusivamente os movimentos fracamente institucionalizados, reunindo indivíduos e grupos em uma associação cujos termos são variáveis e sujeitos a uma reinterpretação em função dos limites que pesam sobre suas ações."
}

Uma rede social refere-se a um conjunto de pessoas (organizações ou entidades) conectadas por relacionamentos sociais, motivadas pela amizade relação de trabalho ou troca de informação - uma representação formal de atores e suas relações. O fenômeno da conectividade é que constitui a dinâmica das redes e existe apenas na medida em que as conexões forem estabelecidas (MARTELETO, 2001). Portanto, segundo a mesma autora, a origem das redes sociais situa-se nas relações informais entre atores, capazes de organizar ações propositivas em uma esfera política. Estas ações, por sua vez, delineiam-se em função da dinâmica circunscrita pelo próprio movimento da rede.

O estabelecimento de vínculos entre os indivíduos é o que marca o surgimento de uma Rede Social Informal (RSI) numa organização, que Marteleto (2001) descreve como estruturas formadas de elos. Sob a ótica de Marteleto (2001), nas redes sociais, existe a valorização dos elos informais e das relações em detrimento da estrutura hierárquica.

Assim, a origem das redes sociais confunde-se com a origem da sociedade humana. " $\mathrm{O}$ que se convencionou chamar de redes hoje em dia são apenas ferramentas, que podem ajudar ou não na formação delas" (FRANCO, 2012).

Ainda para FRANCO (2012), "[...] entender a sociedade em rede é entender as redes, e entender as redes é entender a fenomenologia da interação. [...] Elas acontecem independentemente de nossas intenções de disciplinar o fluxo, guardá-lo ou congelá-lo".

\section{O uso das redes sociais e o acesso à internet}

A nova forma de comunicação tem afetado o dia a dia dos internautas. A quantidade de redes sociais é tão grande que os internautas gastam horas por dia para gerenciá-las. O usuário brasileiro passa em média 279 horas por mês na internet, boa parte desse tempo em sites de relacionamento, como Facebook e Instagram, segundo De Luca (2018) no relatório global da We are social publicado.

Hoje, as pessoas podem realizar várias atividades de sua casa, todas realizadas através da internet e suas redes sociais, vistas como ferramentas vitais nestes tempos, uma vez que, 
para o ser humano é fundamental se comunicar e manter o contato com o mundo.

Para muitos, as redes sociais se tornaram aliadas fiéis durante o confinamento, inclusive até para se "desconectar" do que está acontecendo, no entanto para outros, pode ser uma fonte de ansiedade (pela grande carga de informações dessa crise sanitária e até pela saturação de tantas atividades oferecidas), de frustração (por não possuir o que outros aparentemente têm), podendo até ser um sério problema de dependência.

Certamente, existem usuários mais ousados e usam as redes sociais para expressarem o que pensam, sentem e vivem, transformando essas ferramentas numa espécie de diário virtual. Esse tipo de usuário é o que passa mais tempo na internet: são pessoas que expõem as suas vidas, chegando na maioria das vezes a publicarem vídeos e fotos pessoais. Segundo Aros e Gomes:

[...] a informação é valiosa no sentido de que é a partir dela que um sujeito é capaz de se posicionar perante a sociedade. Quando esta é verdadeira e ancorada à realidade, manifesta-se a possibilidade, por parte de quem lê, de persuadir o outro, ver o corpo social de uma maneira mais crítica e construir um pensamento capaz de influir o mundo que o rodeia. Estar bem informado requer um exercício constante, ininterrupto e diário. (2017, p. 510).

Pelo exposto acima, a pesquisadora e professora do Programa de Pós-graduação em Saúde da Criança e da Mulher (PGSCM) do Instituto Nacional de Saúde da Mulher, da Criança e do Adolescente Fernandes Figueira (IFF/Fiocruz), Suely Deslandes fala em sua entrevista na revista 'Ciência e Saúde Coletiva' 2020, sobre o papel das redes sociais durante a pandemia:

\begin{abstract}
"Como indicam várias cartilhas e orientações de instituições de saúde, a internet nesse momento de isolamento social possibilita manter as interações com amigos, familiares e vizinhos. Mesmo aqueles que não estão podendo fazer o isolamento social, com a suspensão das aulas e de muitas frentes de trabalho, também estão mais tempo em casa e acessando mais a internet. $\mathrm{O}$ acesso à internet possibilita que muitos continuem a ter aulas, a manter atividades de trabalho, a participar de atividades culturais e artísticas e acessar suas redes de apoio. É através das redes digitais que se tem acesso a informações sobre a pandemia e as formas de proteção. A internet tem o papel fundamental de manter uma certa rotina e parâmetros de "normalidade" nesse momento de suspensão das atividades presenciais. Como cito em artigo de minha autoria com o professor Tiago Coutinho ("O uso intensivo da internet por crianças e adolescentes no contexto da Covid-19 e os riscos para violências autoinflingidas"), também publicado recentemente na Ciência e Saúde Coletiva, vemos que pela primeira vez o contato com o mundo "real" só é possível via conexão digital".
\end{abstract}

Fazendo um paralelo ao que diz Lipovstky (2010) "A vida cotidiana, em aspecto amplo, é caracterizado pelo aumento do tempo doméstico", e não só informações sobre a pandemia, mas, a internet e as redes sociais são os lugares de império do entertainement para os jovens, que vem procurando um "escape" nas telas, onde muitos desses jovens se isolam 
nesses espaços virtuais e são por excelência uma busca de prazer recluso, ou seja: Todo tempo livre em casa é atualmente ocupado pela "navegação nas redes sociais"

Suely Deslandes ainda completa:

\begin{abstract}
"Em primeiro lugar, o uso intensivo da internet pode gerar uma adição, um uso compulsivo, definindo uma dependência e centralidade do uso da internet em relação a qualquer outra ação cotidiana. A participação intensiva nas redes sociais também pode gerar um "excesso" de informação ou, em muitos casos, desinformação sobre a pandemia. O excesso de informação pode gerar ansiedade e a difusão da noção de um "medo global", com ênfase no número de mortes e previsões das curvas de contágio. Alguns autores sugerem que se busque definir um tempo determinado dentro da rotina para buscar informações, evitando assim estar "conectado o tempo todo". A lógica é de qualidade e não quantidade de informação. Assim, é melhor ter acesso a sites confiáveis (sites de órgãos oficiais de saúde) ao invés de ficar navegando em muitos sites que se contradizem e espalham notícias sem qualquer respaldo científico".
\end{abstract}

A priore, uma "rotina saudável" não é possível de ser definida, pois cada faixa etária/geração tem uma relação diferente e faz usos diversos das redes sociais. Para os jovens, por exemplo, a sociabilidade digital é essencial. Suely Deslandes argumenta:

\begin{abstract}
"Assim, a navegação on-line percorrerá caminhos diferentes entre games, busca de informação, interações com familiares/amigos/conhecidos, compra e contratação de serviços/mercadorias, entretenimento, aprendizagem escolar ou diversa, hobbies, etc. O que "faz bem" ou é "saudável" pode variar de acordo com a cultura, com os parâmetros de saúde mental e com a idade desse usuário. Os manuais da Organização Mundial da Saúde e do Unicef sugerem que os pais pactuem com seus filhos um tempo de uso da internet por dia, evitando que deixem de realizar outras atividades."
\end{abstract}

A sociabilidade digital é essencial à era contemporânea, ou seja, veio "para ficar" ainda que continue a sofrer constantes mudanças, de acordo com a incorporação de novas tecnologias. Porém, quando a quarentena se encerrar continuará a ser essencial. Contudo, a sociabilidade presencial, que permite a vinculação das corporalidades, a força dos sentidos, do toque, do abraço continuará a essencial da vida em comum, à vida humana.

\title{
METODOLOGIA
}

Essa pesquisa tem a natureza qualitativa/quantitativa do tipo estudo de caso, base em pesquisa bibliográfica; o campo (universo) de pesquisa, foram quatro escolas técnicas da rede estadual de ensino em $\mathrm{PE}$, os sujeitos envolvidos na pesquisa são estudantes de 14 a 18 anos, totalizando 343 estudantes, que fazem o ensino técnico de nível médio na modalidade integral nos cursos de Administração e Desenvolvimento de Sistemas; os instrumentos utilizados foram debates por vídeo chamadas pelo aplicativo Google Meet, que foi realizado após a aplicação de um questionário elaborado pelo Google Forms, contendo 20 
perguntas elaboradas com o modelo de escala de Likert (mostrando ordem de importância do menos importante ou "nunca" para o mais importante ou "sempre"), cujos dados quantitativos foram tratados no software EpiInfo como modo de frequência e serão demonstrados mais adiante nos resultados através de análise gráfica estatística.

\section{RESULTADOS E DISCUSSÃO}

É sabido que as tecnologias de informação e comunicação (TIC) contribuíram fortemente para democratização do acesso à informação, possibilitando a transposição de muitas barreiras, bem como o encurtamento de distâncias. Os resultados obtidos com a presente pesquisa tiveram dados surpreendentes, dentre as vinte perguntas que foram feitas aos estudantes, nove delas apresentam peso fundamental para o desdobramento da problemática e dos objetivos, correlacionando-se assim com a proposta justificada.

Na Tabela 01 - Sinto uma grande necessidade de permanecer conectado às redes sociais; Os dados percentuais mostram que 33,63\% sentem essa necessidade de forma razoável (3), ou seja, apresentou o maior número de respondentes (115 estudantes);

Tabela 01: Sinto uma grande necessidade de permanecer conectado às redes sociais If SINTO UMA GRANDE NZCISSSIDADE DE PERMLANECER CONECTADO AS REDES Frequency Percent Cum. Percent

\begin{tabular}{l|r|r|r|r}
\hline $\mathbf{2}$ & 15 & $4,39 \%$ & $4,39 \%$ & \\
\hline $\mathbf{2}$ & 40 & $11,70 \%$ & $16,08 \%$ & \\
\hline $\mathbf{4}$ & 115 & $33,63 \%$ & $49,71 \%$ & \\
\hline $\mathbf{5}$ & 94 & $27,49 \%$ & $77,19 \%$ & \\
\hline Iotal & 78 & $22,81 \%$ & $100,00 \%$ & \\
\hline
\end{tabular}

Fonte: Própria (2020).

$\mathrm{Na}$ Tabela 02 - Preciso de cada vez mais tempo para lidar com meus assuntos relacionados às redes sociais; os dados trazem um resultado de $31,49 \%$ sentem essa necessidade de forma também razoável (3), ou seja, contando com o maior número respondentes (108 estudantes);

Tabela 02: Preciso de cada vez mais tempo para lidar com meus assuntos relacionados às redes sociais IF SINTO UAIA GRANDE NzCISSIDADE DE PERMLANECER CONECTADO AS REDES Frequency Percent Cum. Percent

\begin{tabular}{|l|r|r|r|r|}
\hline 1 & 15 & $4,39 \%$ & $4,39 \%$ & \\
\hline 2 & 40 & $11,70 \%$ & $16,08 \%$ & \\
\hline 3 & 115 & $33,63 \%$ & $49,71 \%$ & \\
\hline 4 & 94 & $27,49 \%$ & $77,19 \%$ & \\
\hline 5 & 78 & $22,81 \%$ & $100,00 \%$ & \\
\hline Iotal & 342 & $100,00 \%$ & $100,00 \%$ & \\
\hline
\end{tabular}

Fonte: Própria (2020). 
Na Tabela 03 - $\underline{\mathrm{O} \text { tempo que antes eu destinava para estar conectado às redes sociais }}$ não me satisfaz mais. Preciso de mais tempo; Contou com 98 respondentes $(28,82 \%)$ a maioria na escala (1) que representa "nunca" ou "menos importante", significando que eles não precisam de mais tempo, cujo tempo que já ficam nas redes é o suficiente para suprir as suas necessidades.

Tabela 03: $\mathrm{O}$ tempo que antes eu destinava para estar conectado às redes sociais não me satisfaz mais. Preciso de mais tempo

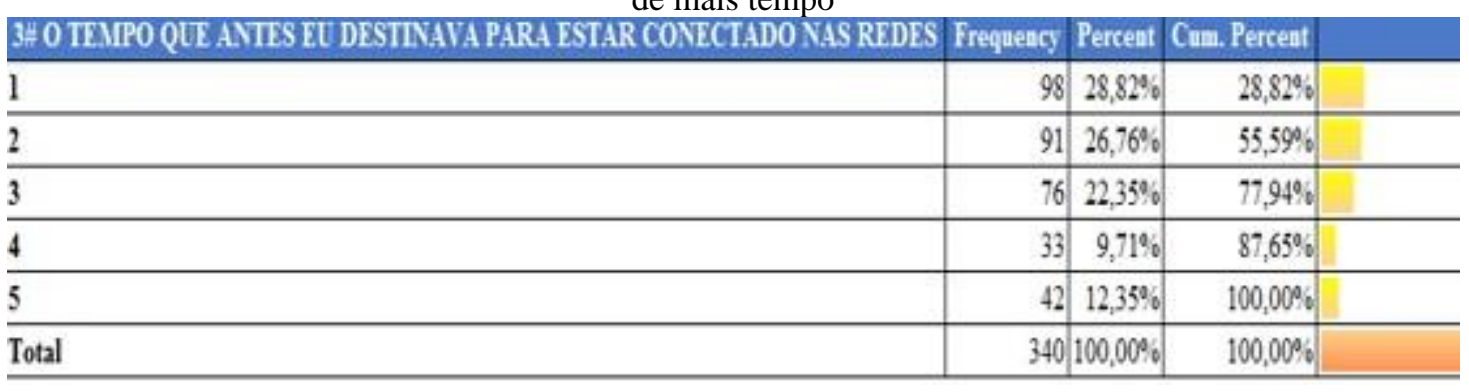

Fonte: Própria (2020).

Na Tabela 04 - Fico irritado se não consigo entrar nas redes sociais; Apresenta 28,45\% (a maioria 97 respondentes), afirmaram que "nunca" ficam irritados se não conseguirem entrar nas redes sociais, um indicativo positivo de que ficam tranquilos e que as redes sociais não é uma necessidade ou um vício. Já a minoria, 12,32\% (42 respondentes) afirmam que sente uma necessidade alta de estarem conectados às redes sociais e que ficam sim irritados e chateados se não conseguem o acesso.

Tabela 04: Fico irritado se não consigo entrar nas redes sociais

\begin{tabular}{|l|r|r|r|r}
\hline 6\# FICO IRRITADO SE NÄ0 CONSIGO ENTRAR NAS REDES SOCLAIS\# & Frequency & Percent & Cum. Percent & \\
\hline $\mathbf{1}$ & 97 & $28,45 \%$ & $28,45 \%$ & \\
\hline $\mathbf{2}$ & 74 & $21,70 \%$ & $50,15 \%$ & \\
\hline $\mathbf{3}$ & 79 & $23,17 \%$ & $73,31 \%$ & \\
\hline $\mathbf{4}$ & 42 & $12,32 \%$ & $85,63 \%$ & \\
\hline $\mathbf{5}$ & 49 & $14,37 \%$ & $100,00 \%$ & \\
\hline Total & 341 & $100,00 \%$ & $100,00 \%$ & \\
\hline
\end{tabular}

Fonte: Própria (2020).

Na Tabela 05 - Quando entro nas redes sociais perco a noção de tempo; A maioria estudantes pesquisados, $121(35,38 \%)$ na escala (5) afirmam que perdem totalmente a noção do tempo, significando que basta entrar nas redes para permanecerem mais tempo do que esperavam ficar, uma distância significativa em comparação com o menor índice de frequência que foi de 10,23\% que "nunca" perdem a noção de tempo quando entram nas redes sociais.

Tabela 05: Quando entro nas redes sociais perco a noção de tempo 


\begin{tabular}{|c|c|c|c|}
\hline 9: QUANDO ENIRO NAS RIDES SOCIAIS PERCO A NOCGO DE TEMIPO & Frequency & Percent & Cum. Percent \\
\hline 1 & 35 & $10,23 \%$ & $10,23 \%$ \\
\hline 2 & 39 & $11,40 \%$ & $21,64 \%$ \\
\hline 3 & 73 & $21,35 \%$ & $42,98 \%$ \\
\hline 4 & 74 & $21,64 \%$ & $64,62 \%$ \\
\hline 5 & 121 & $35,38 \%$ & $100,00 \%$ \\
\hline Total & 342 & $100,00 \%$ & $100,00 \%$ \\
\hline
\end{tabular}

Fonte: Própria (2020).

Na Tabela 06 - Não consigo me desconectar das redes sociais por vários dias; temos um percentual de muita atenção para o valor mínimo e máximo, onde o mínimo (ordem de importância 01 , ou "nunca") 25\% (85 respondentes) relataram uma negação à pergunta, não se sentindo viciados em redes sociais; Já uma diferença de apenas dez respondentes (75 estudantes, 22\%) afirmam que "sempre" não conseguem se desconectar por vários dias, se mostrando viciados realmente na interatividade.

Tabela 06: Não consigo me desconectar das redes sociais por vários dias

\begin{tabular}{|l|r|r|r|r|}
\hline 12 NAO CONSIGO MIE DESCONECTAR DAS REDES SOCLAIS POR VARIOS DLAS & Frequency & Percent & Cum. Percent & \\
\hline $\mathbf{1}$ & 85 & $25,00 \%$ & $25,00 \%$ & \\
\hline $\mathbf{2}$ & 69 & $20,29 \%$ & $45,29 \%$ & \\
\hline $\mathbf{3}$ & 60 & $17,65 \%$ & $62,94 \%$ & \\
\hline $\mathbf{4}$ & 51 & $15,00 \%$ & $77,94 \%$ & \\
\hline $\mathbf{5}$ & 75 & $22,06 \%$ & $100,00 \%$ & \\
\hline Total & 340 & $100,00 \%$ & $100,00 \%$ & \\
\hline
\end{tabular}

Fonte: Própria (2020).

Na Tabela 07 - Descuido de minhas amizades e/ou familiares por estar conectado às redes sociais; $189(55,43 \%)$ estudantes, afirmam que "nunca" fazem isso, ou seja, nunca descuidam das amizades e familiares, são presentes na vida de seus amigos e da família, e ficando distante do percentual dos que estão descuidando "sempre" do seu universo familiar e de amizades por conta da permanência e vício às redes sociais, representando a escala (5) de um total de 10 respondentes $(2,93 \%)$.

Tabela 07: Descuido de minhas amizades e/ou familiares por estar conectado às redes sociais

\begin{tabular}{|l|r|r|r|r|r|}
\hline 15: DESCUIDO DAS MIINHAS AMIZADES OU FAMIIIIARES POR ESTAR CONECTA & Frequency & Percent & Cuni. Percent & \\
\hline $\mathbf{1}$ & 189 & $55,43 \%$ & $55,43 \%$ & \\
\hline $\mathbf{2}$ & 73 & $21,41 \%$ & $76,83 \%$ & \\
\hline $\mathbf{3}$ & 45 & $13,20 \%$ & $90,03 \%$ & \\
\hline $\mathbf{4}$ & 24 & $7,04 \%$ & $97,07 \%$ & \\
\hline $\mathbf{5}$ & 10 & $2,93 \%$ & $100,00 \%$ & \\
\hline Total & 341 & $100,00 \%$ & $100,00 \%$ & \\
\hline
\end{tabular}

Fonte: Própria (2020).

Na Tabela 08 - Creio que seja um problema a intensidade e a frequência com que entro e uso as redes sociais; não acham que seja um problema a frequência com que entram nas redes sociais, representando $25,66 \%$ (87 respondentes), já 49 estudantes (14,45\%) afirmam 
que está sendo um problema a intensidade com que entram e navegam nas redes sociais, fazendo ao mesmo tempo justificar a pergunta da figura 07. Esses têm a consciência de que a permanência navegando nas redes sociais já está lhes trazendo problemas diversos, e mesmo assim não conseguem dimunuir o ritmo. Um dado importante nesse resultado é que a distância entre a escala é mínima e que o nível intermediário (3) também apresentou um número considerável de estudantes, em que julgam "razoável” e que acham já um problema a intensidade em que frequentam as redes sociais.

Tabela 08: Creio que seja um problema a intensidade e a frequência com que entro e uso as redes sociais

\begin{tabular}{|c|c|c|c|}
\hline 20" CREIO QLE SEJA UM PROBLEMA A INTIENSIDADE E A FREQUENCCIA COM & Frequency & Percent & Can. Percent \\
\hline 1 & 87 & $25,66 \%$ & $25,66 \%$ \\
\hline 2 & 86 & $25,37 \%$ & $51,03 \%$ \\
\hline 3 & 81 & $23,89 \%$ & $74,93 \%$ \\
\hline 4 & 36 & $10,62 \%$ & $85,55 \%$ \\
\hline 5 & 49 & $14,45 \%$ & $100,00 \%$ \\
\hline Total & 339 & $100,00 \%$ & $100,00 \%$ \\
\hline
\end{tabular}

Fonte: Própria (2020).

Na Tabela 09 - A maioria dos estudantes respondentes foram do gênero feminino, totalizando 204, do gênero masculino 133 e outros 2. Das 204 alunas respondentes, 73 $(35,78 \%)$ afirmam que possuem muitas atividades para fazerem fora das redes sociais, e que negam a afirmativa da pergunta "Não sei o que fazer quando estou desconectado das reses sociais", sendo assim NÃO dependentes da conectividade. Já 28 dessas estudantes $(13,73 \%)$ afirmam que não sabem mesmo o que fazer quando estão desconectadas das redes sociais, se sentem sozinhas e não pertencentes ao núcleo familiar e alegam que estão distantes das amizades, dos parentes e se relacionam apenas virtualmente e que essa virtualidade aumentou muito nesse período de pandemia, muito embora antes desse período já estavam muito conectadas. Um dado significativo na roda da conversa, após a aplicação do questionário, essas alunas que se mostram dependentes ao extremos das redes sociais acham normal, que não se sentem prejudicadas com a regularidade em que estão conectadas às redes sociais, e afirmam ser até melhor o convívio virtual do que o presencial, tendo uma visão positiva e um olhar tranquilo disso tudo.

Tabela 09: Não sei o que fazer quando estou desconectado das redes sociais e gênero 


\begin{tabular}{|c|c|c|c|c|c|c|}
\hline \multirow[b]{2}{*}{$21 \#$ QUAL SEU GENERO } & \multicolumn{5}{|c|}{ 5\# Näo sei o que fazer quando estou desconectado das redes socia } & \multirow[b]{2}{*}{ Total } \\
\hline & 1 & 2 & 3 & 4 & 5 & \\
\hline Feminino & 73 & 38 & 39 & 26 & 28 & 204 \\
\hline Row $\%$ & $35,78 \%$ & $18,63 \%$ & $19,12 \%$ & $12,75 \%$ & $13,73 \%$ & $100,00 \%$ \\
\hline Col\% & $54,89 \%$ & $59,38 \%$ & $67,24 \%$ & $70,27 \%$ & $59,57 \%$ & $60,18 \%$ \\
\hline Masculino & 58 & 26 & 19 & 11 & 19 & 133 \\
\hline Row\% & $43,61 \%$ & $19,55 \%$ & $14,29 \%$ & $8,27 \%$ & $14,29 \%$ & $100,00 \%$ \\
\hline $\mathrm{Col} \%$ & $43,61 \%$ & $40,63 \%$ & $32,76 \%$ & $29,73 \%$ & $40,43 \%$ & $39,23 \%$ \\
\hline Outros & 2 & 0 & 0 & 0 & 0 & 2 \\
\hline Row $\%$ & $100,00 \%$ & $0,00 \%$ & $0,00 \%$ & $0,00 \%$ & $0,00 \%$ & $100,00 \%$ \\
\hline $\mathrm{Col} \%$ & $1,50 \%$ & $0,00 \%$ & $0,00 \%$ & $0,00 \%$ & $0,00 \%$ & $0,59 \%$ \\
\hline IOTAL & 133 & 64 & 58 & 37 & 47 & 339 \\
\hline Row $\%$ & $39,23 \%$ & $18,88 \%$ & $17,11 \%$ & $10,91 \%$ & $13,86 \%$ & $100,00 \%$ \\
\hline Col $\%$ & $100,00 \%$ & $100,00 \%$ & $100,00 \%$ & $100,00 \%$ & $100,00 \%$ & $100,00 \%$ \\
\hline
\end{tabular}

Fonte: Própria (2020).

Dos 133 alunos (gênero masculino) respondentes, 58 (43,61\%) também possuem muitas atividades para fazer fora das redes sociais, e que negam a afirmativa da pergunta "Não sei o que fazer quando estou desconectado das reses sociais", sendo assim NÃO dependentes da conectividade, nem dependentes delas para interagir. Já 19 (14,29\%) desses alunos se afirmam muito dependentes das redes sociais, que realmente não sabem o que fazer quando estão sem conecção. O interessante é que diferente das alunas, eles apresentam uma certa preocupação com essa dependência às redes, e que ficam nas redes sociais e navegando por mais de 12 horas diárias e que gostariam de dimunuir a assiduidade; outros relataram que se sentem doentes e gostariam de se tratar desse "vício". Os outros dois estudantes (gênero outros) não se sentem dependentes da permanência nas redes sociais, e interagem muit bem sem elas. Se mostram firmes quanto a normalidade do uso e também não viciados nessas redes.

Partindo para as questões propostas de investigação que deram vida a essa pesquisa, temos os questionamentos seguintes e iremos desmembrá-los em três partes:

1. Será que a realidade virtual mais do que nunca está se "impondo" à realidade presencial, ou se é apenas um mecanismo momentâneo de comunicação como tantos outros? A partir dos dados da pesquisa, se verificou que ao mesmo tempo em que se excluem de uma convivência mais social e coletiva presencial, esses estudantes mostram o que são e o que não são, ou desejariam ser, na vida virtual, buscando uma "felicidade fictícia", muitas vezes acompanhada de uma solidão coletiva; muitos deles buscam por uma identidade de grupo seja esta facilitada ou não pelo universo virtual, afinal, só seguirão ou serão seguidos por pares afins. A realidade virtual é um fato existente e chegou para ficar, é sim um mecanismo de comunicação não mais 
momentâneo e sim perene, não que seja "imposto" ao momento atual, mas que veio envolver a sociedade como um todo com suas ferramentas; devido à sua necessidade real não deve ser visto como uma imposição e sim como uma necessidade facilitadora para que a comunicação flua o mais rápido e que possa envolver o maior número de usuários possíveis, onde foram mostrados nos dados da pesquisa que não se precisa de mais tempo para lidar com meus assuntos relacionados às redes sociais, pois o tempo que já desprendem é o suficiente (Tabela 2); que não sentem uma grande necessidade de permanecer conectado às redes sociais (Tabela 1), mostrando que existe vida além das redes; A pesquisa mostra a mínima adesão à necessidade de se ter mais tempo disponível para estar conectado às redes sociais, (Tabela 3) ou seja, não precisam de mais tempo. Sendo assim para os estudantes a resposta ao questionamento 1 é que: Não, a realidade virtual não vai se impor à vida presencial.

2. O uso mais que o normal dessas redes sociais, faz com que os estudantes substituam de vez o contato físico, já que são da geração que mais utiliza esses meios de comunicação? De fato é a geração que mais utiliza na história esses meios de comunicação virtual, mas como mostra a imagem 4, não ficam irritados se não estão em conexão com as redes sociais, mostra uma não dependência, sendo impossível uma substituição do contato físico, onde a grande maioria (Tabela 5) não perdem a noção de tempo quando entram nas redes sociais, mostrando que sabem administrar bem o uso do tempo para coisa úteis e necessárias, e que não apresentam a necessidade de ficar conectado por vários dias (Tabela 6), mostrando mais uma vez que a vida além das redes é a vida real.

3. O uso exacerbado do virtual, para esses jovens, vem nessa época como uma necessidade, lazer ou dependência? A Tabela 7 mostra um dado importante, em que os jovens não se descuidaram das amizades e da família nesse período de pandemia e isolamento social, onde a sua conexão às redes não os impedem da convivência e do cuidado com os que amam, não configurando uma "dependência" das redes sociais, e eu não é um problema a intensidade e a frequência com que entro e uso as redes sociais, indicando mais um lazer do que uma dependência, muito embora outros percentuais se autodeclarem dependentes, mas é a minoria dos estudantes pesquisados.

A intenção dos jovens pesquisados com relação às redes sociais heterogêneas demais para se traçar uma linha tênue entre os principais motivos, o que a pesquisa busca mostrar é a "prole" em pesquisa, por ser filha da revolução digital, se 
dessocializa gradativamente e abandonam cada vez mais as atividades vistas como tradicionais. A maioria dos jovens que participaram da pesquisa possui o gosto pelo "livre" o desejo de sair, de ver pessoas, de participarem de shows e festas de rua, mas, que todo esse desejo foi "trocado" pelo passeio virtual e quem já era "viciado" nessa conectividade ficou ainda mais preso a ela. A virtualidade em época de pandemia diminui os gastos desses jovens com entretenimento, alimentação e outros supérfluos, e fazendo uma ligação comparativa ao que fala Lipovstky (2010), "vive-se a era da cultura digital que cedeu lugar ao império do entertainement virtual".

\section{CONCLUSÕES}

As redes sociais são "consumidas" por esses jovens abruptamente, e em muitos casos esse consumo funciona como lazer, como fuga da realidade e também como um meio de buscar afetividade.

Continuaremos nos desdobrando entre as fronteiras cada vez mais borradas entre os mundos online e off-line. O que nos parece ainda um desafio imediato é o investimento numa educação digital, para que o uso do internet e consequentemente das redes sociais seja ético, para que as informações ali veiculadas sejam absorvidas de forma crítica e reflexiva e assim possamos usufruir das muitas possibilidades de comunicação, produção e disseminação de conhecimento, afeto, de lutas por direitos e mesmo de serviços e negócios, e não uma prisão, e não um adoecimento mesmo que inconsciente. As redes sociais são "consumidas" por esses jovens estudantes de maneira extremamente abrupta, e muitos deles não sabem o mal que podem causar a si próprios pelo seu uso exagerado; Alguns estudantes buscam "lazer" nessa permanência nas redes sociais, outros buscam interagir, mesmo que essa convivência seja ociosa, por divertimento ou por prazer, assim, toda pesquisa, dados colhidos e debates, mostram que o virtual não deve ser visto como melhor nem pior, nem como substituto nem como efetivo, e sim uma ferramenta de transformação atual e que as redes sociais vieram para ficar, independente de formato, fama ou usabilidade.

Todos os envolvidos na pesquisa aprenderam muito sobre ferramentas tecnológicas e outros usos para as redes sociais, como lives com professores dando aula, por exemplo; aprenderam que o IGVT serve como plataforma para postar vídeos sobre algum assunto mais extenso e o professor não teve outro meio para postar; aprenderam que o youtube é uma fonte riquíssima não só de entretenimento, mas, sobretudo de pesquisa acadêmica, e que essa transformação gera necessidades e uma delas é mostra-se presente no mundo, é interagir e se 
comunicar, é trocar experiências e expandir conhecimentos.

E encerramos com um ponto de vista de Harari (2011) no livro Sapiens, "há 70.000 anos, a chamada revolução cognitiva mudou a espécie humana para sempre", ou seja, a complexidade da linguagem, as redes de relações, transformou o cérebro humano e fizeram do Homo Sapiens um vitorioso, sobre toda a natureza.

\section{REFERÊNCIAS}

HARARI, Yuval Noah. Sapiens: Uma breve história da humanidade. 29a edição. Editora Harper, 2011.

LIPOVETSKY, Gilles. A Felicidade Paradoxal: Ensaio Sobre a Sociedade do Hiperconsumo. Lisboa: Edições 70, 2010.

MARTELETO, Regina Maria. Análise de redes sociais: aplicação nos estudos de transferência da informação. Ciência da Informação. Brasília, v.30, n.1, p. 71-81, Instituto Brasileiro de Informação em Ciência e Tecnologia, 2001.

RECUERO, Raquel: Redes sociais na Internet. Porto Alegre: Sulina, 2009.

Sites e outros autores pesquisados:

AROS; GOMES. A influência das redes sociais na comunicação humana. http://cortezze.com.br/a-influencia-das-redes-sociais-na-comunicacao-humana/>, Acesso em novembro de 2020.

DE LUCA. Cristina. Relatório global da We are social. https://porta23.blogosfera.uol.com.br/2018/02/05/brasileiro-passa-mais-de-3-horas-e-meiapor-dia-em-redes-sociais/>, Acesso em novembro de 2020.

FERREIRA, Suely. COUTINHO, Tiago. O uso intensivo da internet por crianças e adolescentes no contexto da COVID-19 e os riscos para violências autoinflingidas. http://www.cienciaesaudecoletiva.com.br/artigos/o-uso-intensivo-da-internet-por-criancas-eadolescentes-no-contexto-da-covid19-e-os-riscos-para-violencias-autoinflingidas/>, Acesso em 20 de setembro de 2020.

FRANCO, Augusto. A origem das redes sociais é a sociedade humana. Disponível em http://gazetaonline.globo.com/ >, Acesso em 22 de agosto de 2020.

LEMOS, R. Silvio; COSTA, A. Ricardo; JUCÁ, M. Paulyne; SILVA, M. Edeilson. Redes sociais. Disponível em https://sistemascolaborativos.uniriotec.br/wpcontent/uploads/sites/18/2019/06/SC-cap4-redessociais.pdf>, Acesso em novembro de 2020. 


\title{
CAPÍTULO 10: QUARENTENA DAS “LIVES": APRENDENDO COM QUARENTEMAS DURANTE A PANDEMIA
}

\section{CAPÍTULO 10: CUARENTENA DE LOS "LIVES": APRENDIENDO CON “QUARENTEMAS" DURANTE LA PANDEMIA}

\section{CHAPTER 10: LIVES OF QUARANTINE: LEARNING WITH “QUARENTEMAS" DURING THE PANDEMIC}

\begin{abstract}
Vitor Carvalho Silva ${ }^{1}$; Anderson Dias Viana ${ }^{2}$; Viviane da Silva Medeiros ${ }^{3}$.
\end{abstract}
DOI: $\underline{\text { https://doi.org/10.31692/978-65-88970-06-5.150-154 }}$

\section{INTRODUÇÃO}

No mês de dezembro de 2019, na cidade de Wuhan na China, foi relatado o primeiro caso de infecção causada pelo novo coronavírus (Sars-cov-2) (WANG et al, 2020). Desde então, o número de casos cresce no mundo inteiro, com milhares de pessoas contaminadas ou mortas. Para evitar que as consequências desse vírus fossem mais graves do que já estão atualmente, foi necessário, em meados de fevereiro e março de 2020, que o mundo entrasse em quarentena, tendo que realizar o isolamento físico e parar com suas atividades diárias. Assim, o mundo inteiro parou, ninguém mais poderia sair de casa; em alguns países era necessário preencher um documento para realizar as atividades necessárias a qualquer um, como ir ao supermercado, entre outras.

Para muitas pessoas não foi fácil passar por esta situação, tendo em vista que a rotina foi mudada completamente, já que havia a necessidade de ficar em casa e não ter contato com grande parte dos amigos, dos familiares, enfim, com as pessoas que participavam da convivência diária. Além desta mudança de rotina, alguns estudos indicam que o medo da contaminação por uma doença potencialmente fatal, que pouco se conhece sobre seu mecanismo de ação, leva muitas pessoas a desenvolverem casos de ansiedade (ASMUNDSON \& TAYLOR, 2020). Desta forma, muitos foram afetados psicologicamente, já que grande parte não estava acostumada a conviver com este tipo de situação. As manhãs e as tardes já não eram mais as mesmas, sem poder ter contato com as pessoas da convivência diária e a expectativa de ter contato apenas por meio das redes sociais, algo difícil para todos, mas necessário para a preservação da saúde.

Observando esta situação pela qual muitos estudantes passavam, um grupo de

\footnotetext{
${ }^{1}$ Técnico em informática, Escola Agrícola de Jundiaí/UFRN, vitinho21.2005@gmail.com

${ }^{2}$ Doutor em Química, Escola Agrícola de Jundiaí/UFRN, andersondiasviana@ gmail.com

${ }^{3}$ Doutora em Psicobiologia, Escola Agrícola de Jundiaí/UFRN, vivianemedeiros.eaj@ gmail.com
}

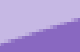


professores da Escola Agrícola de Jundiaí desenvolveram um projeto de extensão, "Quarentemas", para auxiliar a todos que estavam passando pelo isolamento social e, através desta oportunidade, poderiam estudar, discutir temas importantes e atuais, ao tempo que poderiam interagir com colegas, professores e pessoas não necessariamente vinculadas aos cursos da EAJ. O projeto acontece por meio do Instagram, com temas atuais que despertam bastante a atenção e aguçam a curiosidade de qualquer pessoa.

\section{RELATO DE EXPERIÊNCIA}

Na primeira semana do Projeto "Quarentemas", foram discutidas as famosas notícias falsas, boatos, Fake News (Figura 1).

Figura 1: Post do Instagram sobre Fake News de 26 de março de 2020.

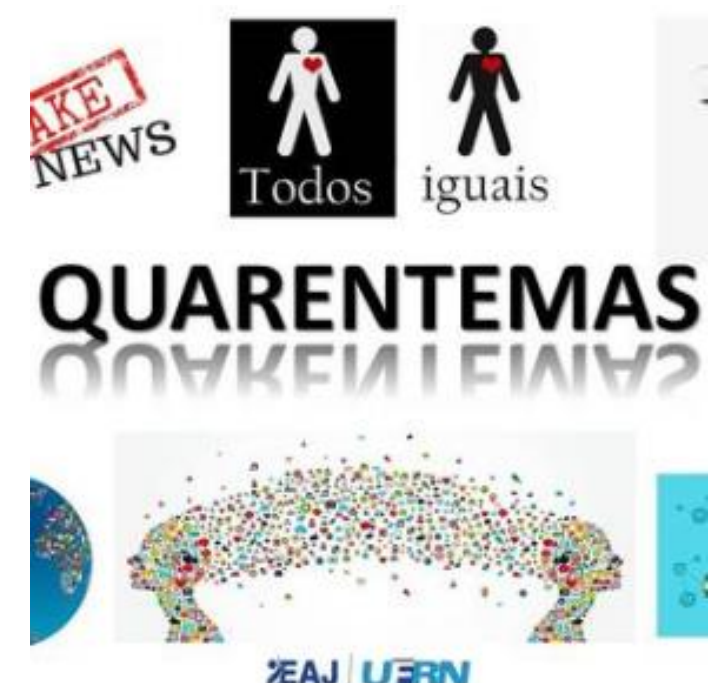

Fonte: Quarentemaseaj (2020).

Ainda que sejam notícias fabricadas e isso não seja algo novo, a divulgação de forma rápida nas redes sociais e a grande capacidade de serem compartilhadas agravam o problema, que vem se espalhando cada vez mais em nossa sociedade (DELMAZO \& VALENTE, 2018).

Muitos outros temas foram apresentados desde o início do Projeto e seguem até hoje, que vão desde a valorização da cultura nordestina à tecnologia, da linguagem à preservação do meio ambiente, dentre outros temas que fazem parte do projeto.

$\mathrm{O}$ projeto abordou diversos temas interessantes que ajudaram muitos participantes a terem um maior contato, mesmo que virtual, com a escola neste período de distanciamento. No período de março a junho de 2020, o projeto aconteceu quatro vezes por semana, de terça a sexta, às $17 \mathrm{~h}$ (Tabela 1$)$. 
Tabela 1: Alguns temas abordados no "Quarentemas" e semanas em que foram apresentados

\begin{tabular}{|c|c|}
\hline Semana & Tema \\
\hline $\begin{array}{l}31 / 03 \\
\text { (terça-feira) }\end{array}$ & $\begin{array}{l}\text { A (há) verdade nas fake news (?) - palestrante Prof. Rafael Borges (mediação } \\
\text { profa. Olga Spindola) }\end{array}$ \\
\hline $\begin{array}{c}07 / 04 \\
\text { (terça-feira) }\end{array}$ & $\begin{array}{l}\text { "Mulheres, as excluídas da história: dos silenciamentos ao direito de existir (e } \\
\text { resistir)" - palestrante profa. Maiara Gonçalves (mediação prof. Severino) }\end{array}$ \\
\hline $\begin{array}{l}15 / 04 \\
\text { (Quarta- feira) }\end{array}$ & $\begin{array}{l}\text { Palestra do prof. Ivan Max/mediação da profa. Olga Spínola - "Ei, cuidado! Não } \\
\text { é uma pessoa que está comentando a notícia ou o vídeo do Youtube." }\end{array}$ \\
\hline $\begin{array}{c}24 / 04 \\
(\text { Sexta-feira })\end{array}$ & $\begin{array}{l}\text { "Esse tal de racismo (não) velado: a construção racista da sociedade brasileira", } \\
\text { palestra profa. Maiara Juliana Gonçalves (mediação profa. Luciana Dantas) }\end{array}$ \\
\hline $\begin{array}{l}\text { 30/04 (Quinta- } \\
\text { feira ) }\end{array}$ & $\begin{array}{l}\text { "Trabalho, corpo e saúde na sociedade do cansaço", palestra do prof Moaldecir } \\
\text { Freire (mediação profa. Luciana Dantas) }\end{array}$ \\
\hline $\begin{array}{l}\text { 06/05 (Quarta- } \\
\text { feira) }\end{array}$ & $\begin{array}{l}\text { "Educação como prática para o cuidado animal", palestra da profa. Viviane } \\
\text { Medeiros (mediação prof. Anderson Viana) }\end{array}$ \\
\hline $\begin{array}{l}\text { 14/05 (Quinta- } \\
\text { feira) }\end{array}$ & $\begin{array}{l}\text { "Tudo que é sólido se desmancha no ar": Mudanças climáticas provocadas pela } \\
\text { atividade humana, palestra do prof. Anderson Viana (mediação profa. Luciana } \\
\text { Dantas) }\end{array}$ \\
\hline $\begin{array}{l}\text { 20/05 (Quarta- } \\
\text { feira) }\end{array}$ & $\begin{array}{l}\text { "Ética, violência e vulnerabilidade: Leituras em Slavoj Žižek e Judith Butler", } \\
\text { palestra do prof. Robson Souza (mediação profa. Olga Spínola) }\end{array}$ \\
\hline $\begin{array}{l}\text { 28/05 (Quinta- } \\
\text { feira ) }\end{array}$ & $\begin{array}{l}\text { "50 tons de Boole - linguagem, computação e aritmética da polarização } \\
\text { política", palestra do prof. Severino Gomes (mediação prof. Robson Souza) }\end{array}$ \\
\hline $\begin{array}{c}05 / 06 \\
(\text { Sexta-feira })\end{array}$ & $\begin{array}{l}\text { "(Não) deixem os historiadores para lá!: uma análise histórica sobre o } \\
\text { Bolsonarismo", palestra da profa. Maiara Juliana Gonçalves (mediação profa. } \\
\text { Olga Espinola) }\end{array}$ \\
\hline $\begin{array}{c}13 / 06 \\
\text { (Sábado ) }\end{array}$ & $\begin{array}{l}\text { "Xote, maracatu e baião: a música nordestina cabe num matulão?", palestra da } \\
\text { profa. Olga Espinola (mediação prof. Ivan Max) }\end{array}$ \\
\hline $\begin{array}{l}\text { 30/09 (Quarta- } \\
\text { feira) }\end{array}$ & $\begin{array}{l}\text { "Culto à estética: saúde, vaidade ou escravidão?". Professora Julianne Santos e o } \\
\text { professor Moaldecir Freire. }\end{array}$ \\
\hline $\begin{array}{l}\text { 07/10 (Quarta- } \\
\text { feira) }\end{array}$ & $\begin{array}{l}\text { "Nem que a vaca tussa: da invenção da vacina ao discurso antivacinação." Profa. } \\
\text { Olga Espínola e prof. Anderson Dias }\end{array}$ \\
\hline $\begin{array}{l}\text { 14/10 (Quarta- } \\
\text { feira) }\end{array}$ & $\begin{array}{l}\text { "Agronegócio, agroterritório, agrodiscurso, agroconflito: as várias faces de uma } \\
\text { mesma moeda." Profa. Márcia Silva de Oliveira e profa. Wiara de Assis Gomes }\end{array}$ \\
\hline $\begin{array}{l}\text { 28/10 (Quarta- } \\
\text { feira) }\end{array}$ & $\begin{array}{l}\text { "Servidor público: trabalho, visão e reforma.” Prof. Dárlio Teixeira e prof. } \\
\text { Anderson Dias. }\end{array}$ \\
\hline
\end{tabular}

Atualmente, retornou as atividades uma vez por semana, sempre às quartas-feiras no mesmo horário. Ocupando as tardes com ótimos temas que não ficam restritos apenas à transmissão de conhecimentos, mas que aproximam os alunos dos professores e da escola $[152]$ 
como um todo durante este período de isolamento físico. As lives nos provocam a um olhar crítico sobre diversos assuntos que foram ou não discutidos, nos proporcionando uma quarentena diferente. Desde o início do projeto, os dias foram passando de melhor forma, conforme eram realizadas as diversas discussões que nos eram apresentadas, contribuindo para construção de conhecimentos de uma forma lúdica, crítica, distanciando os participantes dos medos e da ansiedade pelo momento que todos viviam, tornando a quarentena mais leve.

\section{CONCLUSÕES}

Durante a experiência de participação como ouvinte das apresentações e com a possibilidade de interação através dos espaços de diálogo (chat), foi possível aprender sobre diversos temas e possibilitar momentos de interação e aprendizado com colegas, professores e pessoas que não faziam parte do público de relacionamento na EAJ. Esta possibilidade de interação nessa vivência deixou longe da ansiedade e do medo extremo da COVID-19, pois através de momentos de descontração, esperados alegremente das terças às sextas-feiras semanalmente, proporcionou uma ótima experiência que colaborou para uma quarentena mais divertida .

A interação através de redes sociais foi uma possibilidade gerada pela pandemia e que deve ser mantida em outros momentos, mesmo com aulas regulares presenciais, como uma possibilidade de interação entre os grupos internos e externos à comunidade escolar. Serviu para mostrar também como é possível garantir atividades interdisciplinares para a aprendizagem dos estudantes, seja de forma presencial ou remota, não só contribuindo para um melhor aprendizado dos alunos, mas também colaborando para a relação estudante e professor.

\section{REFERÊNCIAS}

ASMUNDSON, Gordon JG; TAYLOR, Steven. How health anxiety influences responses to viral outbreaks like COVID-19: What all decision-makers, health authorities, and health care professionals need to know. Journal of Anxiety Disorders, v. 71, p. 102211, 2020.

DELMAZO, Caroline; VALENTE, Jonas CL. Fake news nas redes sociais online: propagação e reações à desinformação em busca de cliques. Media \& Jornalismo, v. 18, n. 32, p. 155$169,2018$.

WANG, Cuiyan et al. Immediate psychological responses and associated factors during the initial stage of the 2019 coronavirus disease (COVID-19) epidemic among the general 
population in China. International journal of environmental research and public health, v. 17, n. 5, p. 1729, 2020.

O primeiro tema do nosso projeto será Fake News. Macaíba, 26 de março de 2020. Disponível em: https://www.instagram.com/p/B-Nrf1qA-31/?utm_source=ig_web_copy_link Acesso em: 03/11/2020. 